\title{
The ECONOMIC ImpaCts of COVID-19: Evidence from a New Public Database Built Using Private Sector Data*
}

\author{
Raj Chetty, John N. Friedman, Michael Stepner, \\ and the Opportunity Insights Team ${ }^{\dagger}$
}

First Version: May 2020

This Version: April 2023

\begin{abstract}
We build a publicly available database that tracks economic activity in the U.S. at a granular level in real time using anonymized data from private companies. We report weekly statistics on consumer spending, business revenues, job postings, and employment rates disaggregated by county, sector, and income group. Using the publicly available data, we show how the COVID19 pandemic affected the economy by analyzing heterogeneity in its impacts across subgroups. High-income individuals reduced spending sharply in March 2020, particularly in sectors that require in-person interaction. This reduction in spending greatly reduced the revenues of small businesses in affluent, dense areas. Those businesses laid off many of their employees, leading to widespread job losses, especially among low-wage workers in such areas. High-wage workers experienced a "V-shaped" recession that lasted a few weeks, whereas low-wage workers experienced much larger, more persistent job losses. Even though consumer spending and job postings had recovered fully by December 2021, employment rates in low-wage jobs remained lower in areas that were initially hard hit, indicating that the job losses due to the demand shock led to a persistent reduction in labor supply. Building on this diagnostic analysis, we evaluate the impacts of fiscal stimulus policies designed to stem the downward spiral in economic activity. Cash stimulus payments led to sharp increases in spending early in the pandemic, but much smaller responses later in the pandemic, especially for high-income households. Real-time estimates of marginal propensities to consume provided better forecasts of the impacts of subsequent rounds of stimulus payments than historical estimates. Overall, our findings suggest that fiscal policies can stem secondary declines in consumer spending and job losses, but cannot restore full employment when the initial shock to consumer spending arises from health concerns. More broadly, our analysis demonstrates how public statistics constructed from private sector data can support many research and real-time policy analyses, providing a new tool for empirical macroeconomics. JEL: E01, E32.
\end{abstract}

${ }^{*}$ We thank the corporate partners who provided the underlying data used to construct the public database built in this paper: Affinity Solutions (especially Atul Chadha and Arun Rajagopal), Lightcast (Anton Libsch and Bledi Taska), CoinOut (Jeff Witten), Earnin (Arun Natesan and Ram Palaniappan), Homebase (Ray Sandza and Andrew Vogeley), Intuit (Christina Foo and Krithika Swaminathan), Kronos (David Gilbertson), Paychex (Mike Nichols and Shadi Sifain), Womply (Derek Doel and Ryan Thorpe), and Zearn (Billy McRae and Shalinee Sharma). We are very grateful to Nathaniel Hendren, who collaborated with us to launch the initial version of the database and helped conduct preliminary analyses for the first draft of this paper in Spring 2020. We are also grateful to Ryan Rippel of the Gates Foundation for his support in launching this project and to Gregory Bruich for early conversations that helped spark this work. We thank David Autor, Gabriel Chodorow-Reich, Haley O'Donnell, Emmanuel Farhi, Jason Furman, Steven Hamilton, Erik Hurst, Xavier Jaravel, Lawrence Katz, Fabian Lange, Emmanuel Saez, Ludwig Straub, Danny Yagan, and numerous seminar participants for helpful comments. The work was funded by the Chan-Zuckerberg Initiative, Bill \& Melinda Gates Foundation, Overdeck Family Foundation, and Andrew and Melora Balson. The project was approved under Harvard University IRB 20-0586.

${ }^{\dagger}$ The Opportunity Insights Economic Tracker Team as of April 2023 has consisted of Hamidah Alatas, Camille Baker, Harvey Barnhard, Matt Bell, Gregory Bruich, Tina Chelidze, Lucas Chu, Westley Cineus, Sebi DevlinFoltz, Michael Droste, Dhruv Gaur, Federico Gonzalez, Rayshauna Gray, Abigail Hiller, Matthew Jacob, Tyler Jacobson, Margaret Kallus, Fiona Kastel, Laura Kincaide, Cailtin Kupsc, Sarah LaBauve, Lucía Lamas, Maddie Marino, Kai Matheson, Jared Miller, Christian Mott, Kate Musen, Danny Onorato, Sarah Oppenheimer, Trina Ott, Lynn Overmann, Max Pienkny, Jeremiah Prince, Sebastian Puerta, Daniel Reuter, Peter Ruhm, Tom Rutter, Emanuel Schertz, Shannon Felton Spence, Krista Stapleford, Kamelia Stavreva, Ceci Steyn, James Stratton, Clare Suter, Elizabeth Thach, Nicolaj Thor, Amanda Wahlers, Kristen Watkins, Alanna Williams, David Williams, Chase Williamson, Shady Yassin, Ruby Zhang, and Austin Zheng. 


\section{Introduction}

Since Kuznets (1941), macroeconomic policy decisions have been made on the basis of publicly available statistics constructed from recurring surveys of households and businesses conducted by the federal government. Although such statistics have great value for understanding total economic activity, they have two limitations. First, survey-based data typically cannot be used to assess variation across geographies or subgroups; due to relatively small sample sizes, most statistics are typically reported only at the national or state level and breakdowns for demographic subgroups or sectors are unavailable. Second, such statistics are often available only at low frequencies, often with a significant time lag. ${ }^{1}$

In this paper, we address these challenges by (1) building a public database that measures spending, employment, and other outcomes at a high-frequency, granular level using anonymized transaction data collected by companies in the private sector and (2) demonstrating how this new database can be used to obtain insights into the effects of the coronavirus pandemic (COVID-19) and policy responses in near real-time - within three weeks of the shock or policy change of interest.

We organize the paper in three parts. First, we construct statistics on consumer spending, business revenues, employment rates, job postings, and other key indicators - disaggregated by geographic area (county or ZIP code), industry, and income level - by combining data from credit card processors, payroll firms, and financial services firms. The main challenge in using transactional data collected by private companies (which we refer to as "private sector data" in what follows) to measure economic activity is a tension between research value and privacy protection. For research, it is beneficial to use raw, disaggregated data - ideally down to the individual consumer or business level - to maximize precision and flexibility of research designs. But from a privacy perspective, it is preferable to aggregate and mask data to reduce the risk of disclosure of private information. To balance these conflicting interests, one must construct statistics that are sufficiently aggregated and masked to mitigate privacy concerns yet sufficiently granular to support research. Our goal is to demonstrate how one can produce public statistics that deliver insights analogous to those obtained from the underlying confidential microdata, thereby improving the transparency, timeliness, and reproducibility of empirical macroeconomic research (Miguel et al. 2014).

We construct publicly available series suitable for research from raw transactional data in a series of steps. We first develop algorithms to clean the raw data by removing data artifacts and

\footnotetext{
${ }^{1}$ For example, data on consumer spending disaggregated by geography are only available for selected large metro areas at a bi-annual level in the Consumer Expenditure Survey (CEX).
} 
smoothing seasonal fluctuations. Raw transactional data can exhibit sharp fluctuations and noise driven by changes in clientele, platform design, or exogenous events such as holidays (Leamer 2011, McElroy, Monsell, and Hutchinson 2018). We systematically examine each series for such artifacts and develop methods to address them. Next, we take steps to limit privacy loss by reporting only changes since January 2020 (rather than raw levels), masking small cells, and pooling data from multiple companies to comply with regulations governing the disclosure of material non-public information. After establishing these protocols, we report the final statistics using an automated pipeline that ingests data from businesses and publishes processed data, typically within a week after the relevant transactions occur.

The new data series we construct are a complement to rather than a replacement for existing public statistics obtained from representative surveys. The benefits of our data are their granularity and frequency - providing daily or weekly data for sectors and subgroups down to the county level. The drawback is that there are no ex-ante guarantees that the data provide a representative picture of economic activity because any one company's clients are not necessarily a representative sample of U.S. households or firms. We discuss these tradeoffs in greater detail in Section II.C. To address these challenges, we benchmark each series to publicly available statistics from representative surveys and create series that track the survey-based measures closely, making ongoing adjustments to series that diverge from national statistics (e.g., because of changes in a data provider's clients). Ultimately, the statistics we construct from transactional data provide an additional set of (imperfect) signals on economic activity that can in principle yield better statistical inferences when combined with existing survey-based statistics. ${ }^{2}$ Whether these data yield valuable new insights in practice is an empirical question.

In the second part of the paper, we evaluate the empirical value of the new data by using them to analyze the economic impacts of COVID-19, focusing on the period from March 2020 to December 2021 - covering both the decline in economic activity and the recovery to baseline spending levels. To evaluate how far one can get solely with public statistics rather than confidential data, we deliberately conduct our empirical analysis using the aggregate statistics we release publicly. ${ }^{3}$

National accounts reveal that GDP fell in the second quarter of 2020 following the COVID-19

\footnotetext{
${ }^{2}$ Survey-based statistics themselves do not necessarily provide "ground truth" because of sampling error, recall error, and growing non-response bias (Meyer and Mittag 2021, Dutz et al. 2021). Thus, even for longer-term inferences at the national level, combining information from transactional data with information from surveys can be valuable.

${ }^{3}$ We provide a replication kit that generates all of the results in the paper from publicly available data. We use non-public data for certain robustness checks and validation analyses reported in the Appendix (as documented in the replication kit).
} 
shock primarily because of a reduction in consumer spending. We find that spending fell primarily because high-income households started spending much less, using the median household income in the ZIP code where the cardholder lives as a proxy for household income. ${ }^{4}$ As of April 2020, $41 \%$ of the reduction in total spending since January 2020 came from households who lived in ZIP codes with median income in the top quartile, while $12 \%$ came from households who lived in ZIP codes with median income in the bottom quartile. This is both because the rich account for a larger share of spending to begin with and because they cut spending more in percentage terms. Spending reductions were concentrated in services that require in-person physical interaction, such as hotels and restaurants, consistent with contemporaneous work by Alexander and Karger (2021) and Cox et al. (2020). These findings suggest that high-income households reduced spending primarily because of health concerns rather than a reduction in income or wealth.

Next, we leverage geographic variation in the demand shocks businesses face to identify the impacts of the consumer spending shock on businesses. In-person services are typically produced by small businesses (such as restaurants) that serve customers in their local area. The revenues of those small businesses in high-income, dense areas (high-rent ZIP codes) fell by $61 \%$ between January and mid-April, compared with $31 \%$ in the lowest-rent ZIP codes.

As businesses lost revenue, they passed the shock on to their employees, particularly low-wage workers. Postings for jobs with low skill requirements fell sharply in April 2020, with a much larger reduction in high-rent areas than low-rent areas. Postings for jobs with high skill requirements fell much less, and exhibit no cross-sectional gradient with respect to rent. As a result of the labor demand shock, employment rates fell by $38 \%$ for workers with wages rates in the bottom quartile of the pre-COVID wage distribution as of April 15, 2020 (the trough of the COVID recession), consistent with results first established using other confidential payroll data sources by Cajner et al. (2020). For those in the top wage quartile, employment rates fell by $14 \%$. Low-wage individuals working at small businesses in affluent areas were especially likely to lose their jobs. At small businesses located in the highest-rent ZIP codes, 30\% of workers were laid off within two weeks after the COVID crisis began; in the lowest-rent ZIP codes, $15 \%$ lost their jobs.

Employment levels for workers in the top wage quartile rebounded quickly, returning to preCOVID levels by the end of June 2020. In contrast, employment recovered much more slowly for low-wage workers. The total number of jobs in the bottom quartile of the pre-pandemic wage

\footnotetext{
${ }^{4}$ We verify the quality of our publicly available ZIP-code level proxies for income by showing that our estimates of spending by income group during the pandemic are closely aligned with those of Cox et al. (2020), who observe household income directly for JPMorgan Chase clients in confidential microdata.
} 
distribution remained 13.5\% below baseline even as of December 2021 (adjusting for wage growth). Why did employment rates for low-wage workers remain persistently lower? Unlike at the start of the pandemic, the source of lower employment rates at the end of 2021 was not a lack of labor demand: total consumer spending and low-skilled job postings were well above pre-COVID baseline levels throughout 2021. Furthermore, job postings for low-skilled workers were just as high in high-rent areas as they were in low-rent areas by December 2021. However, employment rates for low-wage workers continue to exhibit a sharp gradient with respect to rent, with employment levels (adjusted for wage growth) returning to pre-COVID baseline rates in the lowest-rent areas but remaining 26pp below pre-COVID levels in the highest-rent areas. Employment rates in December 2021 were much more strongly related to the size of the initial shock to economic activity - e.g., the change in employment rates as of April 2020 - than contemporaneous factors such as COVID case rates or unemployment benefit levels. In short, the initial labor demand shock induced by the reduction in aggregate demand in March 2020 led to a persistent reduction in labor supply among low-wage workers in the hardest-hit areas. As a result, business cycle dynamics during the COVID crisis were not symmetric: on the way down, spending and employment fell in lockstep, but on the way back, they did not rise together, echoing patterns documented in the Great Recession (Yagan 2019).

In the third part of the paper, we examine the scope for stabilization policies to break the chain of events documented above. We focus on the impacts of stimulus payments, whose goal was to mitigate reductions in economic activity by boosting aggregate spending. The federal government sent households stimulus checks at three points during the crisis: April 15, 2020, January 4, 2021, and March 17, 2021. Using an event study design, we find that the stimulus payments made in April 2020 increased spending uniformly across the household income distribution (again proxying for income based on ZIP code), with both low- and high-income households increasing spending substantially in the days after they received checks, consistent with evidence from Baker et al. (2020) and Cox et al. (2020) using individual-level administrative data.

In contrast, the January 2021 payments had highly heterogeneous impacts across the income distribution: low-income households continued to spend a substantial fraction of their stimulus checks, but high-income households (those living in the top quartile of ZIP codes by median income) spent virtually none of the money they received. The impacts of the stimulus changed sharply over the course of the recession because of the heterogeneous spending dynamics documented above: high-income households cut spending sharply but did not lose much income, and as a result had built 
up considerable savings by January 2021, sharply reducing their marginal propensity to consume. Because our spending data are available with a short lag, we were able to establish this result three weeks after the second stimulus payment. These results were cited in policy debates regarding who should receive the March 2021 stimulus payments, which ultimately concluded with policymakers lowering the income threshold for eligibility relative to initial proposals.

Finally, as predicted based on impacts of the January stimulus, we find that the March 2021 stimulus payments increased spending for low-income households, but had little impact on spending for high-income households who remained eligible. Hence, estimates of marginal propensities to consume in January 2021 provided much better forecasts of the impacts of the March 2021 stimulus payments than historical estimates from prior recessions, which suggested there would be little heterogeneity in MPCs by income level (Sahm, Shapiro, and Slemrod 2012 and Broda and Parker 2014), or even estimates from just months earlier in the same recession (April 2020). This example demonstrates how public statistics constructed from private sector data can support a "real time" approach to macroeconomic policy, where policies are adjusted based on current evidence on their impacts rather than relying solely on historical predictions from other economic environments.

The data can analogously be used to analyze the impacts of other policies beyond stimulus payments that were implemented during the COVID-19 crisis. We find that results from our publicly available data match those from studies that use confidential data sources closely. For instance, we find that state-ordered shutdowns and reopenings of economies had modest impacts on economic activity (as in Goolsbee and Syverson 2021) and that loans to small businesses as part of the Paycheck Protection Program (PPP) had small impacts on employment rates (as in Granja et al. 2022, Autor et al. 2022a, and Hubbard and Strain 2020). Additionally, several studies use the new data constructed here to evaluate the impacts of many other policies, from the impacts of unemployment benefit changes (as in Casado et al. 2020) to eviction moratoria (as in An, Gabriel, and Tzur-Ilan 2022).

We conclude by analyzing whether the combination of government policies was adequate to stem the decline in economic activity set off by the reduction in consumer spending documented above. Consumer spending fell sharply in April 2020 in the dense, affluent areas where many low-wage workers lost their jobs, portending the start of a downward spiral of secondary effects stemming from the initial aggregate demand shock. However, the relationship between consumer spending and the rate of local job loss flattened sharply by July 2020, with spending remaining at or above baseline levels even in places where many low-wage workers lost their jobs. The stability of low-income 
spending even in areas that experienced sharp losses in employment was presumably because of the substantial infusion of income to such areas in the form of fiscal stimulus, unemployment benefits, and other programs that led to an increase in disposable income at the bottom of the distribution (Blanchet, Saez, and Zucman 2022).

Overall, our findings suggest that fiscal policies can be very valuable for limiting secondary declines in consumer spending arising from a loss of income as workers lose their jobs. However, fiscal policy itself does not have the capacity to restore full employment when the initial shock to consumer spending arises from health concerns (Guerrieri et al. 2022). Furthermore, even after health concerns have abated, changes in labor supply among those who lost their jobs may lead to persistent reductions in employment. It may therefore be useful to target re-employment policies to individuals who held low-wage jobs in places that suffered the largest job losses (Austin, Glaeser, and Summers 2018). Our data provide a way to monitor the areas and sectors in which job losses persist, information that can be used to target and evaluate such programs going forward.

Beyond showing how the COVID-19 pandemic affected economic activity, the broader contribution of this study is the construction of a new public database of granular macroeconomic statistics that opens new avenues for empirical macroeconomics, from finer analysis of heterogeneous impacts across subgroups and areas to real-time policy fine tuning. Importantly, such analyses can be conducted by many researchers and policy analysts, not just those who can secure access to confidential data and devote resources to cleaning and harmonizing it. In this sense, the data assembled here provide a prototype for a new system of real-time, granular national accounts that can be refined in future work, much as Kuznets (1941) and Summers and Heston (1984, 1991) developed prototypes for national accounts that were refined in subsequent work (e.g., Feenstra, Inklaar, and Timmer 2015). Going forward, our intention is to continue to maintain and refine this database in collaboration with researchers at government statistical agencies, with the ultimate aim of creating a complement to survey-based statistics that yield further detail on economic activity.

Our work builds on two literatures: a longstanding literature on macroeconomic measurement and a recent literature on the economics of pandemics. In the macroeconomic measurement literature, our work is most closely related to studies showing that private sector data sources can be used to forecast government statistics; see Abraham et al. (2019) for an overview of this work. In the COVID-19 pandemic literature, numerous papers have used confidential private sector data to analyze consumer spending; see Vavra (2021) and Brodeur et al. (2021) for surveys. The contribution of the present study is to present a comprehensive characterization of how COVID-19 
and subsequent stabilization policies affected economic activity by disaggregating data across geographic areas and subgroups at a high frequency; we discuss specific connections with prior work in the context of presenting our results.

The rest of this paper is organized as follows. The next section describes how we construct the data series we make public. In Section III, we analyze the effects of COVID-19 on spending, revenue, and employment. Section IV analyzes the impacts of stimulus and other government policies enacted to mitigate COVID's impacts. Section V concludes. Technical details are available in an online appendix, and the data used to produce the results can be downloaded online.

\section{Construction of the Public Database}

We use anonymized data from several private companies to construct public indices of consumer spending, small business revenue, job postings, and employment rates. All of the data series described below can be freely downloaded from the Economic Tracker website.

We release each data series at the highest available frequency using an automated pipeline that ingests data from data providers, constructs the relevant statistics, conducts quality control tests, and outputs the series publicly. Appendix A details the engineering of this pipeline.

\section{II.A Methods}

We disaggregate each series by industrial sector, county, and income quartile wherever feasible. To systematize our approach and facilitate comparisons between series, we adopt the following four principles when constructing each series.

First, we remove artifacts in raw data that arise from changes in data providers' coverage or systems. For instance, firms' clients often change discretely, sometimes leading to discontinuous jumps in series, particularly in small cells. We systematically search for large jumps in series, study their root causes by consulting with the data provider, and address such discontinuities by imposing continuity using series-specific methods described below.

Second, we smooth low- and high-frequency fluctuations in the data. We address high-frequency fluctuations through aggregation, e.g. by reporting 7-day moving averages to smooth fluctuations across days of the week. Certain series - most notably consumer spending and business revenue - exhibit strong lower-frequency seasonal fluctuations that are autocorrelated across years (e.g., a surge in spending around the holiday season). We de-seasonalize such series by indexing each 
week's value in 2020 relative to corresponding values for the same week in 2019.

Third, we take a series of steps to protect the confidentiality of businesses and their clients. Instead of reporting levels of each series, we report indexed values that show percentage changes relative to mean values in January 2020. ${ }^{5}$ We suppress small cells and exclude outliers to meet privacy and data protection requirements, with thresholds that vary across datasets as described below. For data obtained from publicly traded firms - whose ability to disclose data is restricted by Securities and Exchange Commission regulations governing the disclosure of material non-public information - we combine data from multiple firms so that the statistics we report do not reveal information about any single company's activities.

Finally, we address the challenge that our data sources capture information about the customers each company serves rather than the general population. Instead of attempting to adjust for this non-representative sampling, we characterize the portion of the economy that each series represents by comparing each sample we use to national benchmarks and label the sector and population subgroup that each series represents.

We follow these four broad principles to construct every public data series that we release, while adapting the specific data processing methodology to the specific characteristics of each data source.

\section{II.B Data Series}

This section provides an overview of how we produce each data series. We summarize the data sources and give an overview of our key processing steps in Appendix Table 1, and provide summary statistics on sample sizes for each series in Appendix Table 2.

\section{II.B.1 Consumer Spending}

We measure consumer spending primarily using aggregated and anonymized data on credit and debit card spending collected by Affinity Solutions Inc, a company that aggregates consumer credit and debit card spending information to support a variety of financial service products, such as loyalty programs for banks. Affinity Solutions captures nearly $10 \%$ of debit and credit card spending in the U.S. We obtain raw data from Affinity Solutions disaggregated by county, ZIP code income quartile, industry and day starting from January 1, 2019.

\footnotetext{
${ }^{5}$ We always index to January 2020 after summing to a given cell (e.g. geographic unit, industry, etc.) rather than at the firm or individual level. This dollar-weighted approach overweights bigger firms and higher-income individuals, but leads to smoother series and is more relevant for certain macroeconomic policy questions (e.g., changes in aggregate spending).
} 
We process the raw Affinity data into an analytical series following the four steps aboveremoving artifacts and outliers, de-seasonalizing, indexing, and benchmarking - and describe each step in detail in Appendix B. As an example of our data processing methods, we detect and remove discontinuous breaks caused by entry or exit of card providers from the sample. Because these card providers have geographically concentrated customer bases, the number of active cards in a county exhibits a sharp upward or downward spike when the sample of local card providers changes (Appendix Figure 1A). We identify these sudden changes by analyzing the number of unique cards from each county with at least one transaction in each week, using a Supremum Wald test for a structural break at an unknown break point. If we identify a structural break in week $t$, we impute spending levels in weeks $\{t-1, t, t+1\}$ using the mean week-to-week percent change in spending excluding all counties with a structural break in the same state.

The Affinity series has broad coverage across industries, but over-represents categories in which credit and debit cards are used for purchases (see Appendix Figure 2 discussed in Appendix B). We therefore view the Affinity series as providing statistics that are representative of total card spending, but not total consumer spending.

\section{II.B.2 Small Business Revenue}

We obtain data on small business transactions and revenues from Womply, a company that aggregates data from several credit card processors to provide analytical insights to small businesses and other clients. Womply receives data from approximately 500,000 small businesses, which corresponds to more than 5\% of small businesses with 1-499 employees in the U.S. in 2020 (U.S. S.B.A Office of Advocacy 2020). In contrast to the Affinity series on consumer spending, which is a cardholder-based panel covering total spending, Womply is a firm-based panel covering total revenues of small businesses disaggregated by county, sector and week. Another key distinction is that location in Womply data measures the location of the business as opposed to where the cardholder lives.

We process this small business data following each of the same four broad steps as with the consumer spending data from Affinity, but we tailor the methodology to the structure of the Womply data, as detailed in Appendix C. To take one example, there are again discontinuous breaks in the number of observed small businesses due to churn in the observed sample of payment processors, analogous to the entry and exit of card providers in consumer spending data. However, unlike the repeated cross-sections of consumer spending data, we can address such sample churn more directly 
using the panel data on small businesses. In each calendar year, we follow the sample of businesses operating during the first week of the year: no new businesses enter the panel mid-year. We must still detect cases where a payment processor exits the sample, and we adopt a similar approach to detecting discontinuous breaks as we applied to consumer spending data. We look for sharp drops in businesses operating at the state and national levels (Appendix Figure 1B). ${ }^{6}$ After adjusting for these discontinuous exits, we proceed with the rest of the steps described in Appendix $\mathrm{C}$ to construct a seasonally-adjusted series for total small business revenue.

Womply revenues are broadly distributed across sectors. A larger share of the Womply revenue data come from industries that have a larger share of small businesses, such as food services, professional services, and other services, as one would expect given that the Womply data only cover small businesses (Appendix Figure 2).

\section{II.B.3 Job Postings}

We obtain data on job postings from 2007 to present from Lightcast (formerly known as Burning Glass Technologies). Lightcast aggregates nearly all jobs posted online from approximately 40,000 online job boards in the United States. Lightcast then removes duplicate postings across sites and assigns attributes including geographic locations, required job qualifications, and industry.

We receive raw data from Lightcast on job postings disaggregated by industry, week, job qualifications and county. ${ }^{7}$ We report job postings at the weekly level, expressed as changes in percentage terms relative to the first four complete weeks of 2020 .

Lightcast provides a sample that is representative of private sector job postings in the U.S. Appendix Figure 3 shows that the distribution of industries in the Lightcast data is well-aligned with the Bureau of Labor Statistics' Job Openings and Labor Market Turnover Survey (JOLTS), consistent with Carnevale, Jayasundera, and Repnikov (2014).

\section{II.B.4 Employment}

We use three data sources to obtain information on employment rates: payroll data from Paychex and Intuit and worker-level data from Earnin. We describe each of these data sources in turn and

\footnotetext{
${ }^{6}$ We use a higher level of geographic aggregation to detect breaks here than the county-level aggregation used for consumer spending because the number of small businesses is an order of magnitude smaller than the number of active credit and debit cards, and so tests for structural breaks have less power.

${ }^{7}$ Industry is defined using select NAICS supersectors, aggregated from 2-digit NAICS classification codes. Job qualifications are defined using ONET job zones, which classify jobs into five groups based on the amount of preparation they require. We also obtain analogous data broken down by educational requirements.
} 
then discuss how we construct a weekly series that is broadly representative of private non-farm employment rates in the U.S (see Appendix Tables 3 and 4).

Paychex and Intuit. Paychex provides payroll services to approximately 670,000 small- and medium-sized businesses across the United States and pays $8 \%$ of U.S. private-sector workers (Paychex 2020). To track how employment changes vary across the wage distribution, we separate employees into four groups based on their hourly wage rates. We split the sample into the four groups whose wages (if they work full time for the full year) would be above/below 100\%, $150 \%$ and $250 \%$ of the federal poverty line (FPL). For convenience, we refer to these groups as "wage quartiles" because these thresholds group workers approximately into quartiles before the pandemic. ${ }^{8}$ This approach allows us to track the total number of jobs in different parts of the wage distribution, adjusting for inflation over time. We obtain aggregated weekly data on total employment for each hourly wage group by county, industry (two-digit NAICS), firm size bin, and pay frequency.

Intuit offers payroll services to businesses as part of its Quickbooks program, covering approximately one million businesses as of January 2020. Businesses that use Quickbooks tend to be very small (fewer than 20 employees). We obtain anonymized, aggregated data on month-on-month and year-on-year changes in total employment (the number of workers paid in the prior month) based on repeated cross-sections. We construct a national series from population-weighted averages of state changes in each month.

To protect business privacy and maximize precision, we combine Paychex and Intuit data to construct our primary employment series. We clean this series for analysis following the general principles described above (see Appendix E). ${ }^{9}$ We do not seasonally adjust our employment series because we have incomplete data in 2019; fortunately, seasonal fluctuations in employment are an order of magnitude smaller than those in spending (Appendix Figure 4) and hence are unlikely to affect our results.

Earnin. Earnin is a financial management application that provides its members with access to

\footnotetext{
${ }^{8}$ In January 2020 , the thresholds were $\$ 13.10, \$ 19.65$ and $\$ 32.75$ and the four bins in ascending order by wage contained $23.4 \%, 27.4 \%, 25.7 \%$, and $23.5 \%$ of CPS respondents. The federal poverty line (FPL) is updated annually at the beginning of each year. We use the annual FPL to set the thresholds each January and smoothly adjust the thresholds within the year using CPI inflation, as described in Appendix E.

${ }^{9}$ As an example of the specific data processing challenges that we address in constructing the employment series, bunching at integer values in the wage distribution generates discontinuities in the number of workers assigned to each wage group as the thresholds for the groups are updated due to inflation (in step with the FPL). For example, when the threshold for the lowest wage group crosses $\$ 14$ /hour, a discrete mass of workers who were previously a part of the second quartile are now defined as being in the bottom quartile, causing a discontinuity in both series. To address this issue, we spread workers out from the whole number wages by adding a random number between -0.5 and 0.5 to their hourly wage, transforming the point mass at the integer wage into a uniform distribution between $[$ wage -0.5, wage + 0.5] (see Appendix E.2 for details).
} 
their income as they earn it, in advance of their paychecks. Because its users tend to have lower income levels, Earnin primarily provides information on employment for low-wage workers. We obtain anonymized data from Earnin from January 2020 onward, describing the date a paycheck is received, workplace ZIP code, firm size, industry and amount of pay. Earnin complements the firm-based payroll datasets discussed above by providing a worker-level sample with more granular ZIP-level geographic identifiers. However, because workers self-select into the sample when they enter or exit the Earnin customer base, the labor market disruptions of the pandemic generate substantial sample selection over time. We therefore use the Earnin sample only to study the first six months of the COVID pandemic, from March to September 2020, when the sample is relatively stable. We convert the Earnin data into an employment series using an approach similar to that used to construct the combined Paychex and Intuit employment series (detailed in Appendix E).

\section{II.B.5 Public Data Sources: UI Records, COVID-19 Incidence, and Google Mobility Reports}

In addition to the new private sector data sources described above, we also collect and use three sets of data from public sources to supplement our analysis: data on unemployment benefit claims obtained from the Department of Labor and state government agencies; data on COVID-19 cases and deaths obtained from the New York Times, Johns Hopkins, the CDC and the U.S. Department of Health and Human Services; and data on the amount of time people spend at home vs. other locations obtained from Google's COVID-19 Community Mobility Reports. Further details on these data sources are provided in Appendices F to H.

\section{II.C Limitations}

The rest of this paper demonstrates how the database assembled here is valuable for uncovering the economic impacts of COVID-19. However, these new data also have three important limitations that users should weigh, especially in future applications.

First, each data series we construct necessarily reflects the clientele of the data provider, and thus does not provide guarantees of population representativeness. We take several steps to verify that each data series is nationally representative: we compared the cross-sectional composition of each series against nationally representative statistics in this section, and compare trends in each series during the COVID-19 pandemic to data from publicly available benchmarks in the next section. But it is impossible to verify the representativeness of each level of disaggregation (e.g. county-

level consumer spending), precisely because no existing public datasets provide similarly granular 
and high-frequency data - hence the value of these novel data sources. Given this limitation, it is valuable to verify empirical results using multiple different data series and triangulate findings against whatever data are available from representative surveys at coarser levels of aggregation, as we do in our analysis below.

Second, the series we construct have sampling error from both idiosyncratic variation across firms and households as well as from changing client bases and business closures. The economic shocks associated with COVID-19 were especially large, making their impacts easy to detect even in the presence of such errors. In Section III.C, we show that the data series are sufficiently reliable to detect moderate-sized changes in economic activity at local levels (e.g., employment rate changes of $4 \mathrm{pp}$ at the commuting zone level for the 50 largest CZs). Smaller fluctuations - e.g., monthly innovations in employment rates during periods of normal economic growth - will not be distinguishable from sampling noise in these datasets.

Third, while our data cover certain sectors well - such as spending on items covered by credit and debit cards - they entirely exclude other sectors, such as spending on housing and durable goods such as vehicles. In the context of the COVID-19 pandemic, the data series we construct overlap with the sectors that exhibit the largest changes in economic activity (see Section III), but in other applications that may not be the case.

In light of these limitations, the data constructed here should be used as a complement to rather than substitute for representative survey-based statistics. Furthermore, the present version of the database is a prototype that can be improved over time. For example, noise in estimates of employment rates from changes in payroll firms' clientele can be mitigated by chaining together estimates of employment changes from rotating panels of firms instead of relying on repeated cross-sections. Adding additional data partners can address gaps in coverage, such as spending on housing. Such refinements could mitigate the limitations described above, though statistics from representative surveys will remain essential as benchmarks.

\section{Economic Impacts of COVID-19}

According to the Bureau of Economic Analysis (2020), GDP fell by $\$ 1.61$ trillion (an annualized rate of $29.9 \%$ ) from the first quarter of 2020 to the second quarter of 2020, shown by the first bar in Appendix Figure 5A. GDP fell primarily because of a reduction in personal consumption expenditures (consumer spending), which fell by $\$ 1.20$ trillion. Government purchases and net exports 
did not change significantly, while private investment fell by $\$ 0.53$ trillion. ${ }^{10}$ We therefore begin our analysis by studying the determinants of this sharp reduction in consumer spending. We then turn to examine downstream impacts of the reduction in consumer spending on business activity and the labor market.

\section{III.A Consumer Spending}

We analyze consumer spending using data on aggregate credit and debit card spending. National accounts data show that spending that is well captured on credit and debit cards - essentially all spending excluding housing, healthcare, and motor vehicles - fell by approximately $\$ 0.90$ trillion between the first quarter of 2020 and the second quarter of 2020 , comprising $75 \%$ of the total reduction in personal consumption expenditures. ${ }^{11}$

Benchmarking. Our card spending series is well aligned with the Advance Monthly Retail Trade Survey (MARTS), one of the main inputs used to construct the national accounts. ${ }^{12}$ Appendix Figure 5B plots the month-on-month changes in spending on retail services (excluding auto-related expenses) and food services: both series track each other before the pandemic, then food services spending drops rapidly in March and April 2020, while total retail spending fluctuates much less during the pandemic. The root-mean-squared-error of the Affinity series relative to the MARTS is 3 to $5 \mathrm{pp}$, which is small relative to the fluctuations induced by COVID, but calls for caution in evaluating smaller shocks. Appendix Figure 6A expands this analysis to other categories by plotting the change in spending from January to April 2020 in the Affinity spending series against the decline in consumer spending as measured in the MARTS. Despite the fact that the MARTS category definitions are not perfectly aligned with those in the card spending data, the relative declines are generally well aligned across sectors, with a correlation of $0.91 .^{13}$

\footnotetext{
${ }^{10}$ Most of the reduction in private investment was driven by a reduction in inventories and equipment investment in the transportation and retail sectors, both of which are plausibly a response to reductions in current and anticipated consumer spending. In the first quarter of 2020, consumer spending accounted for an even larger share of the reduction in GDP, further supporting the view that the initial shock to the economy came from a reduction in consumer spending (Bureau of Economic Analysis 2020).

${ }^{11}$ The rest of the reduction is largely accounted for by healthcare expenditures; housing and motor vehicle expenditures did not change significantly.

${ }^{12}$ The series are not perfectly comparable because the category definitions differ slightly across the datasets. For example, we observe food and accommodation services combined together in the card data but only food services in the MARTS. In addition, the MARTS includes corporate card transactions, whereas we exclude them in order to isolate consumer spending. Hence, we would not expect the series to track each other perfectly even if the card spending data provided a perfect representation of national spending patterns.

${ }^{13}$ One specific source of potential bias in our spending series is that it does not include cash transactions and thus could be biased by potential substitution from cash to credit card purchases. We evaluate this concern using receipts data from CoinOut, which allows us to measure cash spending on groceries (see Appendix B.3). In practice, trends in card and cash spending track each other closely (Appendix Figure 6B). These results - together with the fact
} 
Heterogeneity by Income. We begin by examining spending changes by household income. We do not directly observe cardholders' incomes in our data; instead, we proxy for cardholders' incomes using the median household income in the ZIP code in which they live (based on data from the 2014-18 American Community Survey). ZIP codes are strong predictors of income because of the degree of income segregation in most American cities; however, they are not a perfect proxy for income and can be prone to bias in certain applications, particularly when studying tail outcomes (Chetty et al. 2020). To evaluate the accuracy of our ZIP code imputation procedure, we compare our estimates to those in contemporaneous work by Cox et al. (2020), who observe cardholder income directly based on checking account data for clients of JPMorgan Chase. Our estimates are closely aligned with those estimates, suggesting that the ZIP code proxy is reasonably accurate in this application. ${ }^{14}$

Figure 1A plots a seven-day moving average of total daily card spending for households in the bottom vs. top quartile of ZIP codes based on median household income. Spending fell sharply on March 15, when the National Emergency was declared and the threat of COVID became widely discussed in the United States. Spending fell from $\$ 8.3$ billion per day in February to $\$ 5.5$ billion per day between March 25 and April 14 (a 34\% reduction) for high-income households; the corresponding change for low-income households was $\$ 3.5$ billion to $\$ 2.6$ billion (a $26 \%$ reduction).

Because high-income households cut spending more in percentage terms and accounted for a larger share of aggregate spending to begin with, they accounted for a much larger share of the decline in total spending in the U.S. than low-income households. In Column 2 of Appendix Table 5, Panel A, we estimate that as of mid-April, top-quartile households accounted for $41 \%$ of the aggregate spending decline after the COVID shock, while bottom-quartile households accounted for only $12 \%$ of the decline.

This gap in spending patterns by income grew even larger over time. By August 2020, spending had returned to 2019 levels among households in the bottom quartile, whereas spending among highincome households remained $8 \%$ below baseline levels. Spending then continued to rise gradually in subsequent months and began to exceed pre-COVID levels starting in 2021 for both low- and high-income groups. The degree of heterogeneity in spending changes by income is larger than that observed in previous recessions (see Figure 6 in Petev, Pistaferri, and Eksten 2011) and played a

that our card spending series closely track estimates from the MARTS - indicate that aggregate fluctuations in card spending do not appear to have been offset by opposite-signed changes in cash spending.

${ }^{14}$ Cox et al. (2020) report an eight percentage point larger decline in spending for the highest income quartile relative to the lowest income quartile in the second week of April. Our estimate of the gap is also eight percentage points at that time, although the levels of the declines in our data are slightly smaller in magnitude for both groups. 
central role in the downstream impacts of COVID on businesses and the labor market, as we show below.

Heterogeneity Across Sectors. Next, we disaggregate the change in total card spending across categories to understand why households cut spending so rapidly. In particular, we seek to distinguish two channels: reductions in spending due to loss of income vs. fears of contracting or spreading COVID.

The left bar in Figure 1B plots the share of the total decline in spending from the pre-COVID period to mid-April accounted for by various categories. $57 \%$ of the reduction in spending came from reduced spending on goods or services that require in-person contact (and thereby carry a risk of COVID infection), such as hotels, transportation, and food services. This is particularly striking given that these goods accounted for less than one-third of total spending in January, as shown by the right bar in Figure 1B. These gaps only grew larger as the pandemic progressed, as consumer spending increased above pre-pandemic levels for durable and non-durable goods by mid-August, but remained sharply depressed for in-person services (Appendix Table 5, Panel B). The fact that the spending reductions vary so sharply across goods in line with their health risks indicates that health concerns (either one's own health or altruistic concerns about others' health) rather than a lack of purchasing power drove spending reductions.

These patterns of spending reductions differ sharply from those observed in prior recessions. Figure 1C compares the change in spending across categories in national accounts data in the COVID recession and the Great Recession in 2009-10. In the Great Recession, nearly all of the reduction in consumer spending came from a reduction in spending on goods; spending on services was almost unchanged. In the COVID recession, $71 \%$ of the reduction in total spending came from a reduction in spending on services.

Heterogeneity by COVID Incidence. To further evaluate the role of health concerns, we examine the association between COVID case rates across areas and changes in spending. Figure 2 shows that spending fell more in counties with higher rates of COVID infection, in both low- and highincome areas, during the trough in consumer spending from March 25 to April 14, 2020. However, there was a substantial reduction in spending even in areas without high rates of realized COVID infection, consistent with widespread concern about the disease even in areas where outbreaks were less prevalent. To examine the mechanism driving these spending reductions, Appendix Figure 7 uses anonymized cell phone data from Google to present a binned scatter plot of the amount of time spent outside home vs. COVID case rates, again separately for low- and high-income counties. 
As in Figure 2, there is a strong negative relationship between time spent outside and COVID case rates, with a steeper slope in low-income counties. The reduction in spending on services that require physical, in-person interaction (e.g., restaurants) follows directly from this reduction in time spent outside.

In sum, disaggregated data on consumer spending reveal that spending in the initial stages of the pandemic fell primarily because of health concerns rather than a loss of current or expected income - consistent with the mechanisms emphasized by Eichenbaum, Rebelo, and Trabandt (2021). Disposable income ultimately fell relatively little because few high-income individuals lost their jobs (as we show in Section III.C below) and because the income losses of lower-income households who lost their jobs were more than offset by supplemental unemployment benefits, stimulus payments, and other transfers (Ganong, Noel, and Vavra 2020; Blanchet, Saez, and Zucman 2022). Next, we turn to the impacts of the spending reductions induced by these health concerns on businesses and the labor market.

\section{III.B Business Revenues}

Services that are consumed in person (e.g., restaurants) are typically produced by small businesses who serve customers in their local area. ${ }^{15}$ The reduced in-person spending by high-income households documented above thus has heterogeneous impacts across areas, with businesses located in more affluent areas facing larger spending shocks. We exploit this geographic heterogeneity to identify the impacts of the reduction in consumer spending on businesses and their employees, starting by examining impacts on small business revenues. ${ }^{16}$

Benchmarking. We measure small business revenues using data from Womply, which records revenues from credit card transactions for small businesses (as defined by the Small Business Administration) at the location where the sale occurs. Because there is no publicly available series on small business revenues, we compare trends in the Womply data to the Affinity consumer spending data. These series are generally well aligned, especially in sectors with a large share of small businesses, such as food and accommodation services, where the RMSE of the Womply series relative to Affinity is 2.67pp (Appendix Figure 8). For retail, where large businesses have a larger market share, the RMSE is $6.75 \mathrm{pp}$.

\footnotetext{
${ }^{15}$ For example, over $50 \%$ of workers in food and accommodation services (a major non-tradeable sector) work in establishments with fewer than 50 employees (U.S. Census Bureau 2017).

${ }^{16}$ We focus on small businesses because their customers are typically located near the business itself; larger businesses' customers (e.g., large retail chains) are more dispersed, making the geographic location of the business less relevant.
} 
National Trends. In the aggregate time series (plotted in Appendix Figure 9A), small business revenues fell by $48 \%$ when the pandemic began and then recovered to $11 \%$ below pre-COVID levels by July 2020. Small business revenues then remained at that level until late 2020, reaching preCOVID levels only in September 2021. The larger fall and slower recovery of small business revenues relative to total consumer spending is consistent with evidence that consumer spending shifted toward large online retailers during the pandemic (Alexander and Karger 2021). Unfortunately, we lack data on revenues at large businesses, so we cannot examine these impacts directly.

Heterogeneity Across Areas. To illustrate the data underlying our geographic analysis, we map the change in small business revenues from January 2020 to the period immediately after the COVID shock (March 25 to April 14, 2020) by ZIP code in New York City, Chicago and San Francisco (Appendix Figure 10). ${ }^{17}$ In all three cities, revenue losses were largest in the most affluent neighborhoods (e.g. Manhattan in New York and Lincoln Park in Chicago) and in the central business districts in each city. But even within predominantly residential areas, businesses located in more affluent neighborhoods suffered much larger revenue losses.

Figure 3 generalizes these examples by presenting a binned scatter plot of percent changes in small business revenue vs. median rents (for a two bedroom apartment) by ZIP code. ${ }^{18}$ In the richest $5 \%$ of ZIP codes, small business revenues fell by $52 \%$, as compared with around $40 \%$ in the poorest $5 \%$ of ZIP codes, consistent with the differences observed in the Affinity consumer spending data across areas. ${ }^{19}$

The business revenue loss vs. rent gradient is similar when we compare ZIP codes within the same county by regressing revenue changes on rent with county fixed effects (Table 1 Panel A, Column 2), or when comparing businesses within the same industry across ZIP codes using sector fixed effects (Appendix Figure 12A). It also remains similar when controlling for the (pre-COVID) density of high-wage workers in a ZIP code to account for differences that may arise from shifts to remote work in business districts (Table 1 Panel A, Column 3). ${ }^{20}$

\footnotetext{
${ }^{17}$ We use 2010 Census ZIP Code Tabulation Areas (ZCTAs) to perform all geographic analyses of ZIP-level data. Throughout the text, we refer to these areas simply as "ZIP codes".

${ }^{18}$ Rents are a simple measure of the affluence of an area that combine income and population density: the highest rent ZIP codes tend to be high-income, dense areas such as Manhattan. Plotting small business revenue against median incomes or population density produces analogous results (Appendix Figure 11)

${ }^{19}$ Part of the reason that revenues fell so sharply in high-rent ZIP codes is that affluent families moved elsewhere during the pandemic. To quantify the relative contribution of such "extensive margin" mechanisms vs. intensivemargin reductions in spending by high-income households who did not leave, we use aggregated mobile phone data from SafeGraph (e.g., Allcott et al. 2020) to estimate changes in local population at high frequencies. Although population fell more in high-rent areas, changes in small business revenues as of April 2020 still exhibit a sharp gradient with respect to local rents even conditional on Safegraph-based estimates of population counts (12.3\% per $\$ 1000$ rent, s.e. 0.95$)$.

${ }^{20}$ Of course, households do not restrict their spending solely to businesses in their own ZIP code. We find similar
} 
In sum, businesses located in dense, affluent areas lost the most revenue - consistent with the sharp reduction in spending on in-person goods and services by high-income households. Next, we examine how businesses reacted to this loss of revenue, focusing on the incidence of the shock on their employees.

\section{III.C Labor Market Impacts}

We begin by analyzing how the loss of revenues affected labor demand using data on job postings from Lightcast. Figure 4 presents a binned scatter plot of the change in job postings that require minimal education between January 2020 and the April 2020 trough vs. median rents by county. Job postings with minimal educational requirements fell much more sharply (by 6.9pp, or 22.8\%) in high-rent areas than for workers in lower-rent areas, consistent with the larger shocks to revenue faced by firms located in high-rent areas. By contrast, postings for jobs that require higher levels of education - which are much more likely to be in tradeable sectors that are less influenced by local conditions (e.g., finance or professional services) — exhibit no relationship with local rents (Figure 4B).

Having established that the pandemic reduced labor demand especially for lower-skilled workers working in affluent areas, we next turn to examine its impacts on employment rates using data from payroll companies.

Benchmarking. Our payroll-based employment series is broadly aligned with measures from nationally representative statistics. Appendix Figure 13A shows that month-on-month changes in employment rates for all workers estimated from combined Paychex and Intuit payroll data generally fall between estimates obtained from the Current Employment Statistics (a survey of businesses) and Current Population Survey (a survey of households). Turning to specific sectors, Appendix Figure 13B focuses on month-on-month employment changes in two sectors that experienced very different trajectories: food services, where employment fell heavily, and professional services, where it did not. In both cases, our Paychex-Intuit series closely tracks data from the CES. Appendix Figure 14A shows more generally that changes in employment rates across sectors (two-digit NAICS) are very closely aligned in our series and the CES, with a correlation of 0.96 when looking at changes from January to July 2020.

Unlike with spending and business revenues, there are publicly available sources of data on

patterns when zooming out to the county level. Counties with larger top $1 \%$ income shares experienced larger losses of small business revenue (Appendix Figure 12B). Poverty rates are not strongly associated with revenue losses at the county level (Appendix Figure 12C), indicating that it is the presence of the rich in particular (as opposed to the middle class) that is most predictive of economic impacts on local businesses. 
employment rates that can be disaggregated geographically and used to evaluate the representativeness of our data across areas. Our employment series closely matches state-level variation in employment changes during the pandemic in the CES, with a population-weighted correlation of 0.73 when looking at changes from January to July 2020 (Appendix Figure 14B). Our estimates are also well aligned with commuting-zone-level estimates from the Quarterly Census of Employment and Wages (QCEW) (Appendix Figure 14C). Similarly, disaggregating the national data by wage rate, we find that our estimates are closely aligned with estimates based on the Current Population Survey and estimates in Cajner et al. (2020) (Appendix Figure 15).

These comparisons indicate that our combined employment series provides representative estimates of changes in employment rates across wage groups and geographic areas during the COVID pandemic. A natural question going forward is how accurate our local area estimates will be in more typical periods, where the shocks of interest are likely to be far smaller than during the pandemic. To evaluate the accuracy of our data from this broader perspective, we calculate the population-weighted root-mean-squared-error (RMSE) between our estimates of CZ-level changes in quarterly employment in 2021 and corresponding statistics from the QCEW. We find an RMSE of 1.72pp for the 50 largest CZs and 3.70pp when including all CZs. Since the QCEW statistics are based on unemployment insurance records covering the entire population, the RMSE can be loosely interpreted as the average standard error of our estimate, accounting for noise arising from both sampling error and changes in non-representative sampling. The relatively small MSEs indicate that our data can identify employment shocks considerably smaller than those induced by the pandemic. For instance, the worst-hit quartile of CZs in the U.S. in the Great Recession had mean employment losses of 8.73pp from 2007 to 2010, while the least-hit quartile of CZs had mean employment gains of $2.59 \mathrm{pp}$; our data would have been sufficiently precise to reliably differentiate those CZs. As another example, Aldy (2014) estimates that the 2010 Gulf Oil spill decreased employment in non-panhandle Gulf-coast Florida counties by $2.7 \mathrm{pp}$; since the population of this region is equivalent to the 4th largest $\mathrm{CZ}$ (with population of 7 million), our payroll-based series would have been sufficiently precise to detect and monitor this effect in near-real-time as well.

The key limitation of publicly available employment data is that existing data sources can only be disaggregated either by county or wage level. Our payroll-based data sources allow us to measure changes in employment by county and wage level, which we show next proves to be valuable in understanding the impacts of the COVID shock. ${ }^{21}$

${ }^{21}$ Another benefit of our payroll-based employment series is the timeliness of its local-area estimates: it matches 
Heterogeneity by Wage Rates. Figure 5A plots employment rates by real pre-pandemic wage quartile. Each series shows the change in the total number of workers employed in jobs with hourly wage rates that fall in the relevant quartile of the pre-COVID wage distribution (with thresholds adjusted over time for inflation as described in Section II.B.4) relative to the baseline level in January 2020.

We find substantial heterogeneity in job losses by wage rate, consistent with the findings of Cajner et al. (2020) in prior work using ADP data. Employment rates fell by $38 \%$ around the trough of the recession (April 15) for workers in the bottom wage quartile (i.e., the total number of jobs paying $<\$ 13.10 /$ hour in January 2020 was $38 \%$ lower as of April 15). By contrast, employment rates fell by only $14 \%$ for those in the top wage quartile (those jobs paying more than $\$ 32.75 /$ hour in January 2020) as of April 15.

High-wage workers not only were less likely to lose their jobs to begin with, but also recovered their jobs much more quickly. By June 2020 - just three months after the recession began employment for high-wage workers had nearly returned to the pre-COVID baseline. Employment rates in low-wage jobs also recovered rapidly to $19 \%$ below baseline levels by summer 2020, but then stalled from that point onward.

Heterogeneity Across Areas. To identify the mechanisms driving these employment impacts, we again exploit geographic variation, studying whether employment fell most in the high-rent areas that faced the largest demand shocks. Figure 4C plots changes in bottom-wage-quartile employment rates from January to July 2020 vs. median rents, by county. Consistent with the larger shocks in high-rent areas to business revenue and labor demand for low-skilled workers, low-wage employment rates fell much more in more affluent counties. Low-wage employment fell by $21.7 \%$ in the highest-rent counties, compared with $16.8 \%$ in the lowest-rent counties. We find a similar pattern at the ZIP code level using employment data from Earnin (Appendix Figure 16A). Table 1, Panel B presents a set of regression estimates quantifying these impacts. Low wage employment rates fell more in higher-rent areas (Column 1), even when controlling for the density of high-wage workers (Column 2) and comparing ZIP codes within the same county (Column 3).

The concentration of employment losses in more affluent areas is a consequence of the specific pattern of demand shocks induced by COVID rather than a general feature of recessions. Appendix Figure 17 shows that in the Great Recession (from 2007-2010), counties in the bottom quartile of

the county-level granularity of the QCEW (which is released with a lag of 6 months), but with the timeliness of the monthly employment statistics in the CES that are released at the national level and for 450 MSAs. 
the household median income distribution accounted for $29 \%$ of job losses, while those in the top quartile accounted for $21 \%$ of job losses. By contrast, in the COVID recession (from January to April 2020), counties in the top quartile accounted for a larger share of job losses than counties in the bottom quartile.

In summary, the pandemic led to a short "V-shaped" recession for high-wage workers, but a prolonged reduction in employment for lower-wage workers that persisted until at least December 2021, the end of our analysis period. Geographic disaggregation reveals that the drop in low-wage employment at the start of the pandemic was driven primarily by a contraction in spending among high-income individuals - which then reduced labor demand for low-skilled workers - rather than voluntary reductions in labor supply (that might have been induced, for example, by health concerns or unemployment benefits). In the next section, we examine why employment rates remained low even as the economy began to recover.

\section{III.D Recovery}

By the middle of 2021, aggregate consumer spending (Figure 1A) and small business revenues (Appendix Figure 9A) had met and subsequently exceeded pre-COVID baseline levels. Yet employment rates in jobs that paid wages in the bottom quartile of the pre-pandemic distribution remained $21 \%$ lower even as of December 2021. What explains this "jobless recovery" at the bottom of the wage distribution?

Wage Growth. Part of the explanation is real wage growth: wage rates rose faster than the poverty line during the pandemic, leading some workers to move up out of the bottom wage bin (rather than into non-employment). To quantify the impact of wage growth, we seek to measure how much wage rates changed in a given job. Lacking panel data at the job level, we measure changes in wage rates within detailed industry, occupation, and demographic cells using data from the CPS (see Appendix E.4 for details). Using the estimated wage growth distribution, we estimate that 7.7 percentage points of the reduction in the total number of workers in the lowest wage group as of December 2021 is due to wage growth, leaving 13.5pp due to changes in employment patterns - either exits into non-employment or switches to higher-paying jobs.

We assess the contribution of switching to higher-paying jobs using two methods: assessing whether the cross-sectional composition of employment has shifted toward higher-paying jobs and measuring employment rates by pre-pandemic wage quartile in panel data. To implement the first test, we measure the wage distribution based on pre-COVID (2019) wage rates in each industry 
$\mathrm{x}$ occupation $\mathrm{x}$ race $\mathrm{x}$ gender $\mathrm{x}$ region cell of the Current Population Survey. We find that shifts in the job distribution across these cells actually led to an increase in the share of workers in the lowest wage group as of December 2021. To implement the second test, we use the CPS Outgoing Rotation Group panel, consisting of individuals who responded to CPS survey interviews spaced twelve months apart. In this panel, non-employment rates as of July 2020-February 2021 are $7.7 \mathrm{pp}$ higher for those who started out in the bottom wage quartile pre-COVID (between July 2019-February 2020) than for those who started out in the top wage quartile. ${ }^{22}$ These findings indicate that exits to non-employment explain most of the remaining reduction in bottom-quartile employment in the cross-sectional data after accounting for wage growth.

In the rest of this section, we analyze why low-wage workers remained out of work at higher rates as of December 2021, distinguishing between labor demand and supply channels.

Labor Demand. Although aggregate demand recovered, consumer demand may have shifted across sectors and technologies in ways that reduced labor demand for lower-skilled workers in the U.S. For example, consumer demand shifted persistently over the course of the pandemic toward larger companies, online vendors, and certain sectors such as retail trade (Alexander and Karger 2021, Dunn, Hood, and Driessen 2020, Carman and Nataraj 2020). Such companies might have more capital-intensive production functions or outsource more of their production, leading to a persistent downward shift in the demand for low-skilled labor in the U.S. Furthermore, firms may have sought efficiencies in their production processes and economic activity may have shifted to more efficient firms during the recession, potentially further reducing labor demand (Berger 2012, Lazear, Shaw, and Stanton 2016, Jaimovich and Siu 2020).

To evaluate this demand-side explanation, we first examine the evolution of aggregate job postings over time in Appendix Figure 9B. Postings for jobs that required minimal or no skills had returned to pre-COVID levels by mid-2020 and were well above pre-COVID levels in most of 2021 as businesses sought to restaff after reducing their payrolls earlier in the pandemic, consistent with the findings of Forsythe et al. (2022). ${ }^{23}$

Furthermore, there is no evidence of mismatch in labor demand relative to the supply of lowwage workers across sectors or places. Figure 5B plots employment for workers in the bottom wage quartile, reweighting the series to match baseline employment shares by county and industry

\footnotetext{
${ }^{22}$ We cannot use this panel approach to examine employment beyond February 2021 conditional on pre-COVID wage rates because households responding to the CPS answer the Outgoing Rotation Group panel questions exactly twice, twelve months apart.

${ }^{23}$ The high level of job postings in the second half of 2021 may also reflect a labor supply shortage, as companies had to post more jobs to fill a given set of positions.
} 
(2 digit NAICS) in the top wage quartile. This reweighting closes very little of the gap between the two series, showing that differences in industry and location do not explain the differences in employment trajectories between low- and high-wage workers. ${ }^{24}$ Similarly, we find no evidence of a spatial mismatch between job posts and workers: reweighting job postings across counties by the number of bottom-wage-quartile workers in January 2020 has little impact on the time series of job postings (Appendix Figure 9B).

We conclude that low-wage workers appear to have had considerable demand for their skills in their own counties, yet chose not to take jobs that were available.

Labor Supply. Given these findings, we next examine mechanisms that may have led to a reduction in labor supply among low-wage workers. We begin by analyzing how the labor market recovery differed in high- vs. low-rent counties, building on the analysis in the previous sections. ${ }^{25}$

Figure $6 \mathrm{~A}$ shows that job postings were approximately $20 \%$ above pre-COVID baseline levels in both high-rent and low-rent counties in December 2021. The gradient in job postings with respect to rent that emerged when the pandemic hit (Figure 4A) disappeared entirely by December 2021. Yet low-wage employment rates remained substantially lower in high-rent areas than low-rent areas (Figure 6B). In the lowest-rent counties - where the initial reduction in aggregate demand was smallest (as measured by small business revenues and job postings) - the total number of workers with jobs in the bottom wage quartile as of December 2021 was $10 \%$ lower than it was pre-COVID. This $10 \%$ reduction is roughly consistent with what we would expect based on wage growth (as discussed above), indicating that employment had roughly fully recovered in places where the pandemic had minimal effects on aggregate demand initially. In contrast, in the highestrent counties, bottom-wage-quartile employment was 26\% lower in December 2021 than it was pre-COVID.

Panels $\mathrm{C}$ and $\mathrm{D}$ of Figure 6 characterize the evolution of the job postings and employment gradients by county-level rents by month from April 2020 to December 2021. They plot slopes from regressions of job postings and low-wage employment rates on rent across counties (weighted by population) by month. The job postings gradient begins to flatten starting in January 2021 and disappears completely by the last quarter of 2021. In stark contrast, the employment gradient

\footnotetext{
${ }^{24}$ Appendix Figure 18 presents a specific example of this result by plotting trends in employment and spending in the retail trade sector. Total retail spending was $24 \%$ higher as of December 2021 relative to the pre-COVID baseline. Employment of high-wage workers was $5 \%$ above baseline levels, yet employment of low-wage workers was still down by $21 \%$ in this sector - as in the economy as a whole.

${ }^{25}$ We omit California, Massachusetts, and New York in this cross-sectional analysis because they each raised their minimum wages during our sample, leading to a discrete mechanical reduction in the number of bottom-wage-quartile workers over the course of the pandemic (see Appendix E.2).
} 
steepens over time and never recovers during the period we study. ${ }^{26}$

The results in Figure 6 suggest that the places that experienced larger demand shocks initially (namely more affluent, high-rent areas) exhibit persistent declines in employment even as of December 2021, despite the fact that labor demand had recovered fully in those areas by that point. One potential explanation for this hysteresis in employment rates is a change in preferences or commitments that workers made when the pandemic hit that induced persistent changes in labor supply. For example, low-wage workers may have moved to smaller apartments or changed their living arrangements such that they could afford to work less when the pandemic hit, and may have decided that they preferred to retain these arrangements going forward even when labor demand recovered. Another possibility is that low-wage workers' human capital decayed and made it more difficult for them to obtain available jobs.

In Table 2, we contextualize the magnitude of the cross-sectional variation in low-wage employment rates by regressing changes in bottom-wage-quartile employment rates from January 2020 to December 2021 on median rents by county and other covariates that reflect contemporaneous economic conditions. Column 1 replicates the specification in Figure 6B, showing that employment remains sharply depressed in higher-rent areas (where the initial aggregate demand shock was more severe) relative to lower-rent areas in December 2021. In Column 2, we include two variables that measure contemporaneous health and economic conditions - the average COVID case rate from October-December 2021 (a measure of the risk of COVID exposure) and the number of weeks of unemployment insurance benefits that individuals were eligible for in their state as of December 2021 - as well as a set of demographic controls. The inclusion of these variables does not affect the relationship between median rents and employment rates significantly.

These estimates imply that the ongoing risk of COVID can explain approximately 3.1 percentage points of the 13.5pp reduction in bottom-wage-quartile employment that is not due to wage growth. Similarly, multiplying the coefficient on the UI benefits variable by the mean number of the weeks of additional UI benefits for which individuals were eligible in December 2021 implies that UI benefit extensions account for less than 1pp of the reduction in bottom-wage-quartile employment. This cross-sectional estimate based on changes in UI policies across states over time is consistent with the

\footnotetext{
${ }^{26}$ The differential changes in employment rates in low-wage jobs across low vs. high-rent areas are not driven by differential changes in wage growth rates or occupational switching. Using the approaches described above at a national level (see Appendix E.4 for details), we find that wage growth rates are, if anything, lower in highrent places than low-rent states and that rates of switching to higher-paying jobs are uncorrelated with state-level rents. Furthermore, the CPS panel shows that employment for workers who started in the bottom wage quartile pre-pandemic remained lower in high-rent states in February 2021 (Appendix Figure 19).
} 
quasi-experimental elasticities of employment rates with respect to UI benefit length estimated by Coombs et al. (2022), which also finds that UI benefits appear to have small effects on employment rates during the pandemic.

Column 3 of Table 2 presents a variant of the specification in Column 2, replacing median rent with the change in bottom-wage-quartile employment rates from January to July 2020 - the immediate loss in low-wage employment after the shock - as the key independent variable. We find a positive relationship, showing that areas where employment fell more in the immediate aftermath of the pandemic exhibited persistent declines in employment nearly two years later.

Column 4 replicates Column 2, replacing the dependent variable with the change in employment rate for jobs that paid wages in the top quartile of the pre-pandemic wage distribution. We find no relationship between top-quartile employment rates and rents, consistent with the rapid recovery of labor demand and employment for high-skilled workers.

Finally, we evaluate whether changes in the total number of available workers (i.e., the total population of lower-skilled workers in high rent areas) - rather than changes in labor supply for a given worker - can explain a significant portion of the shortfall in employment rates. Although the number of immigrants to the United States fell during the pandemic, CPS data show that trends in total low-wage employment rates for immigrants and US citizens aged 16 or older were virtually identical (Appendix Figure 20A). Internal migration from high-rent to lower-rent areas within the United States also does not explain a significant share of the larger reduction in employment rates in high-rent areas (Appendix Figure 20B). Demographic trends in aging over this short period are also too small to explain the shortfall in employment: the working age population (aged 15-64) grew from 205.7 to 207.1 million between January 2020 and 2022 (Organization for Economic Cooperation and Development 2023). Finally, the share of individuals who moved to self-employment (and hence were not available to be low-wage employees) is also too small to explain the aggregate shortfall in bottom-wage-quartile employment: the self-employed share of individuals aged 16 or older rose from 6.05\% in January 2020 to 6.15\% in December 2021 (U.S. Bureau of Labor Statistics 2023a, 2023b, 2023c).

In sum, the persistent reduction in low-wage employment is not readily explained by changes in labor demand, changes in contemporaneous incentives to work such UI benefits or ongoing health risks, or changes in the total number of workers. Rather, the strongest predictor of the crosssectional variation in employment rates in December 2021 are variables that predict the size of the initial shock to aggregate demand - echoing the findings of Yagan (2019), who documents hysteresis 
in the labor markets that were hit hardest in the Great Recession.

\section{Evaluation of Policy Responses to COVID-19}

In this section, we examine the scope for stabilization policies to break the chain of events documented above: reductions in spending, especially by high-income households, were associated with losses in business revenue and employment for low-wage workers. We begin by evaluating the stimulus payments made to households during the pandemic, illustrating how the public data we construct are useful for real-time policy evaluation. We then briefly discuss other examples of policy evaluations and conclude by assessing whether the combination of policy responses was sufficient to stabilize economic activity.

\section{IV.A Stimulus Payments to Households}

The federal government sent a total of $\$ 814.4$ billion in stimulus checks to households at three points during the pandemic: April 2020, January 2021, and March 2021 (Internal Revenue Service 2022). Were these stimulus payments successful in boosting consumer spending?

We estimate the causal effect of each of the three stimulus payments on spending in the first month after receipt, focusing in particular on heterogeneity across the income distribution. We focus on a one month horizon because prior work shows that most of the impact of stimulus payments and tax refunds is concentrated within three months of receipt (e.g., Sahm, Shapiro, and Slemrod 2010, Broda and Parker 2014). Moreover, spending impacts in the first month are highly predictive of spending impacts in the first three months across subgroups (Parker and Souleles 2019, Table $3) .27$

April 2020. The Coronavirus Aid, Relief, and Economic Security (CARES) Act made direct payments to nearly 160 million people starting in mid-April 2020. Individuals earning less than $\$ 75,000$ received a stimulus payment of $\$ 1,200$; married couples earning less than $\$ 150,000$ received a payment of $\$ 2,400$; and households received an additional $\$ 500$ for each dependent they claimed. ${ }^{28}$ IRS statistics show that $69 \%$ of stimulus payments made in April were direct-deposited on exactly April 15, 2020, while some households received payments on April 14 (Bureau of the Fiscal Service 2020).

\footnotetext{
${ }^{27}$ Prior studies benefited from substantial variation in the timing of payments, permitting identification over a longer period of time. In contrast, the stimulus payments we study each largely arrived on a single day, making it challenging to estimate impacts over longer horizons without strong assumptions about counterfactual trends.

${ }^{28}$ The payments were reduced at higher levels of income and phased out entirely for households with incomes above $\$ 99,000$ (for single filers without children) or $\$ 198,000$ (for married couples without children).
} 
We evaluate the impacts of these stimulus payments on consumer spending using a highfrequency difference-in-differences research design applied to our card spending data, comparing daily spending before vs. after April 15 in 2020 vs. spending on the same calendar date in 2019. To reduce cyclical fluctuations, we residualize daily spending (indexed to average levels in January 2019) with respect to day-of-week fixed effects, which we estimate using data for 2019. We then adjust for a linear pre-trend in spending (which we assume to be common across all income quartiles) in order to capture aggregate shocks in spending during the pandemic in $2020 .{ }^{29}$ In order to capture high-frequency changes in spending, we do not smooth the daily spending using a 7-day moving average, unlike in preceding sections.

Figure 7A plots the difference in daily spending in 2020 vs. 2019 for households who live in ZIP codes with median household income in the bottom quartile of the national distribution (which we term "low-income" households for convenience). Spending increases markedly following the arrival of payments, with particularly high spending in the days when stimulus checks first arrived. To quantify the magnitude of the (short-run) impact of the stimulus on spending, in Appendix Table 6 we estimate difference-in-difference models using OLS regressions of daily spending by income quartile (residualized against a common linear pre-trend) in the 25 days before and after April 15 on an indicator for being pre vs. post-stimulus interacted with calendar year. To capture the nonlinear dynamics evident in the non-parametric event study plots, we estimate separate treatment effects for the first five days starting on April 15 and from the 6th day onwards; see Appendix K for a more detailed description of our methodology.

Using this approach, we estimate that spending increased by $21 \mathrm{pp}$ (s.e. $=3.14$ ) for bottomincome-quartile households in the first month following the stimulus payments. Accounting for the fraction of households who actually received stimulus checks in this group, this estimate translates to an increase in spending of $\$ 438$ during the first month after receiving a $\$ 1,200$ stimulus check (see Appendix $\mathrm{K}$ for more details). The estimates remain stable when varying the window used to estimate the treatment effect, with point estimates ranging from $\$ 318$ to $\$ 448$, as shown in Appendix Figure 22 .

Figure 7B repeats this analysis for high-income households - those who live in ZIP codes with

\footnotetext{
${ }^{29}$ We permit pre-trends because spending fell rapidly for all income groups in the days immediately preceding the April 15 stimulus payments, as shown in Figure 1A. We assume common trends to maximize precision, as we find no significant differences in pre-trends in spending across income quartiles in the 25 days preceding the stimulus payments; the differential changes by income quartile discussed in Section III emerged before that period, immediately after the pandemic began. We also show that not adjusting for pre-trends at all yields qualitatively similar conclusions in Appendix Figure 21.
} 
median household income in the top quartile of the distribution. Once again, we see a clear increase in spending in the month after the stimulus payments were made relative to the month before, although there is no immediate spike in spending the day the checks were received, as one might expect given that higher-income households are less likely to be liquidity constrained at high frequencies. We estimate that spending for top-income-quartile households increased by 11pp. This smaller percentage point impact is to be expected because higher income households received smaller stimulus payments both in absolute terms and as a percentage of their total expenditure. Rescaling this effect, we estimate that high-income households spent $\$ 727$ per $\$ 1,200$ of stimulus payments received in the first month.

The first bar in each set of bars plotted in Figure 8 presents estimates of the impact of the April 2020 stimulus payments on spending over a one month horizon for each of the four ZIP-income quartiles. Across the income distribution, households spent a large fraction of their April 2020 stimulus checks in the month immediately after receipt, consistent with evidence from confidential data from JPMorgan Chase account holders subsequently reported by Cox et al. (2020). ${ }^{30}$

January 2021. The COVID-Related Tax Relief Act made payments of $\$ 600$ per person to most Americans available beginning on January 4, 2021. Eligibility criteria largely followed those for the earlier round of stimulus, with single households eligible for the full stimulus amount up to $\$ 75,000$ in income (\$150,000 for married households). The stimulus amount fell at higher income levels, with childless households with incomes up to $\$ 87,000$ (or $\$ 174,000$ if married filing jointly) receiving a payment.

To evaluate whether our data could shed light on this policy's impact sufficiently rapidly to inform the design of future stimulus payments, we analyzed the effects of the stimulus payments on spending from January 4 to 19 and released results publicly on January 26, 2021 (Chetty, Friedman, and Stepner 2021). We use the same difference-in-differences design we used to study the first stimulus, except that we use December 4 to 14 as the pre-period rather than the days immediately preceding the stimulus payments because those days coincide with the Christmas holiday period, when daily spending exhibits 10 times higher variance across days (even when looking at changes across years) than during the first half of December (Appendix Figure 23). ${ }^{31}$

\footnotetext{
${ }^{30}$ Disaggregating the spending data by sector, we find that most of the additional spending from the April 2020 stimulus went to durable goods rather than in-person services. The stimulus thus increased the overall level of spending, but did not channel money back to the businesses that lost the most revenue due to the COVID shock. These findings provide evidence for the "broken Keynesian cross" mechanism established in Guerrieri et al. (2022)'s model, where funds are not recirculated back to the sectors shut down by the pandemic, potentially diminishing multiplier effects.

${ }^{31}$ Using the same 25-day pre-period window as that used for the first stimulus yields point estimates that are
} 
We also omit pre-trends here because of the gap created by omission of the holiday period.

Figure 7C replicates the series in Figure 7A and Figure 7B for the January 2021 stimulus, plotting indexed daily changes in spending in 2021 vs 2020 for bottom- and top-income-quartile households. Low-income households increase spending significantly after the arrival of the January stimulus payments. In contrast, high-income households do not change their spending levels significantly after January 42021 relative to December 2020. Using difference-in-differences models analogous to those above, we estimate that low-income households increased spending over the first month after receiving their stimulus checks by 6pp, while high-income households increased spending by $0.4 \mathrm{pp}$, an estimate that is not significantly different from zero. The middle bars shown in Figure 8 rescale these estimated impacts into dollars per $\$ 1,200$ to facilitate comparisons across stimulus rounds. While the marginal propensity to consume (MPC) out of these stimulus payments in the first month fell significantly for all income groups in January 2021 relative to April 2020, the drop in the MPC for high-income households was especially large. We estimate that low-income households spent $\$ 186$ per $\$ 1,200$ of stimulus received, $58 \%$ smaller than the $\$ 438$ estimated in April 2020. High-income households spent much less of their second stimulus checks from $\$ 727$ per $\$ 1,200$ received in April 2020 to just $\$ 40$ per $\$ 1,200$ in January 2021, a reduction of $95 \%{ }^{32}$ These heterogeneous impacts on spending across income groups are aligned with results subsequently reported in May 2021 by Greig, Deadman, and Noel (2021, Box 1, page 20) using confidential data from JPMorgan Chase.

In short, this analysis demonstrates that one can gauge the (short-term) effects of stimulus payments with just two weeks of data after the payments are made using what are now publicly available data - enabling a rapid feedback loop for subsequent policy changes. Indeed, based on these estimates, we predicted that making further stimulus payments to high-income households would have modest impacts on their spending, suggesting that targeting the next round of stimulus towards lower-income households would save substantial resources that could be used to support other programs, with minimal impact on economic activity.

March 2021. After extensive debate about whether higher-income households should continue to receive stimulus payments - including discussion of the evidence described above (Lambert and Sraders 2021) - Congress passed the American Rescue Plan on March 11, 2021. The final

statistically indistinguishable from those we present, but with much wider confidence intervals due to the greater noise in the pre-period.

${ }^{32}$ Both of these estimates are significantly lower (with $p<0.005$ ) than those from April 2020 based on a permutation test; see Appendix Figures 24 and 25 for the full distribution of placebo estimates. 
plan continued to pay the full stimulus amount of $\$ 1,400$ to households earning up to $\$ 150,000$, but phased the payments out more rapidly beyond that threshold than initially proposed, so that households with incomes above $\$ 80,000$ (for single filers without children) or $\$ 160,000$ (for married couples without children) received no stimulus. These revisions reduced the total amount of stimulus payments made to high-income households by approximately $\$ 17$ billion relative to the original proposal in January 2020 (Watson 2021).

Did the March 2021 stimulus payments in fact have lower impacts on spending of higher-income households, as predicted based on the January 2021 evidence? Figure 7D replicates the preceding figures for the 25 days before and after the March 2021 checks were sent out; here, we use exactly the same estimator as in the first stimulus, as there are no holiday-induced fluctuations in the preperiod. Bottom-income-quartile households increased spending considerably in the days following the March payments, while spending for high-income households did not change significantly. The third set of bars in Figure 8 rescale these effects into dollar impacts per $\$ 1,200$ of stimulus payment. The estimated impacts are much more similar to those observed in January 2021 than in April 2020, with positive impacts on spending for lower-income households but near-zero impacts on spending for top-quartile households.

Discussion. Why did the marginal propensity to consume out of cash windfalls fall sharply over the course of the pandemic, especially for higher-income households? Studies of stimulus payments in prior recessions find little heterogeneity in MPCs by income, but show that households with higher liquid wealth balances exhibit lower MPCs (Johnson, Parker, and Souleles 2006; Broda and Parker 2014; Jappelli and Pistaferri 2014). In normal times, most households even in the top income quartile tend to have relatively little liquid wealth (Kaplan and Violante 2014), explaining why they exhibit high MPCs out of windfalls in previous recessions. But during the pandemic, households started to accumulate substantial liquid wealth because their incomes remained relatively stable while their spending fell sharply, as discussed above in Section III. The national savings rate (measured in NIPA Table 2.6) rose from 7.6\% in 2019 to $18.5 \%$ on average in Q2-Q4 of 2020. Using confidential data from the JPMorgan Chase, Greig, Deadman, and Noel (2021) further show that cash balances in checking accounts rose substantially from January to December 2020, with the largest increases (in dollars) among high-income households. Given this rapid growth in liquid wealth, it is not surprising that high-income households started to spend less of their stimulus payments over time. ${ }^{33}$

\footnotetext{
${ }^{33}$ Summarizing the literature on impacts of stimulus payments, Sahm (2019) observes that "households with low
} 
This analysis illustrates the value of real-time estimation of policy impacts rather than predictions based on historical estimates. Despite being based on a consensus across a large set of studies, historical predictions about the lack of heterogeneity in MPCs by income proved to be inaccurate given the unusual impacts of the pandemic on spending behavior across the income distribution. ${ }^{34}$ The core challenge is that parameters such as MPCs are not invariant to the economic and policy environment. By directly estimating such parameters in real time using newly available data, one can make policy decisions that respond transparently - based on publicly available information to current economic conditions.

\section{IV.B Impacts of Other Policies}

The data we make publicly available can also be used to study a range of other policies beyond stimulus payments. For illustration, we briefly discuss four examples of policies that were implemented during the COVID-19 crisis. The first two are based on analyses we conduct ourselves (detailed in Appendices K and L) and the latter two are analyses conducted by other researchers using our data in combination with other data sources.

State-Ordered Shutdowns and Reopenings. Many states enacted stay-at-home orders and shutdowns of businesses in an effort to limit the spread of COVID infection and later reopened their economies by removing these restrictions. Using our card spending and payroll data, we evaluate the impacts of these policies using event study designs that compare trends in states that shut down and re-opened at different dates. We find that state-ordered shutdowns and reopenings had modest impacts on economic activity. Spending and employment remained well below baseline levels even after reopenings, and trended similarly in states that reopened earlier relative to comparable states that reopened later (Appendix Figures 26-27). Spending and employment also fell well before state-level shutdowns were implemented. These findings are consistent with work by Goolsbee and Syverson (2021) and Villas-Boas et al. (2020) using cell phone location data as well as Bartik et al. (2020) using timesheet data on hours of work.

Paycheck Protection Program. The Paycheck Protection Program (PPP) sought to reduce

liquid assets relative to their income tend to spend more (and more quickly) out of additional income than those households with ample liquidity." In normal times, Sahm observes that "targeting current low-income or low-wealth households may not identify the households most likely to spend the stimulus, which could include some wealthy households." The link between income and liquid wealth changed during the pandemic, making such targeting more feasible.

${ }^{34}$ With the benefit of hindsight, one may have been able to predict that MPCs would begin to fall for high-income households as their liquid savings rose, but it is difficult to gauge ex-ante which of the many potential dimensions of heterogeneity and structural change warrant attention. 
employment losses by providing forgivable loans worth more than $\$ 800$ billion in total to small businesses that maintained sufficiently high employment (relative to pre-crisis levels). Using our payroll data disaggregated by firm size, we evaluate the impacts of the PPP on employment by comparing employment trends at firms with fewer than 500 employees (which were eligible for PPP assistance) with firms in the same sector that had more than 500 employees (who were ineligible). We find that employment increased by only 2 percentage points after the PPP was enacted in April 2020 relative to larger firms that were ineligible for PPP (Appendix Figure 28). Our point estimates imply that the cost per job saved by the PPP was $\$ 377,000$ (\$119,000 at the lower bound of the $95 \%$ confidence interval); netting out potential UI payments to these potentially unemployed workers reduces this number only slightly to $\$ 359,000$ per job saved (see Appendix L.2 for details). Autor et al. (2022a) and Autor et al. (2022b) reach similar conclusions using the same research design with microdata from ADP, another large payroll processor. Granja et al. (2022) use a different design, exploiting cross-sectional variation in PPP takeup driven by bank composition, and reach similar conclusions, partly drawing upon the data we make publicly available. Together, all of these studies suggest the PPP had modest marginal impacts on employment in the short run, likely because the vast majority of PPP loans went to inframarginal firms that were not planning to lay off many workers. ${ }^{35}$

Unemployment Benefit Increases. The Federal Pandemic Unemployment Compensation (FPUC) program paid supplemental unemployment benefits of up to $\$ 600$ per week from March to September 2020. Casado et al. (2020) use county-level variation in wage replacement rates resulting from differences in industrial composition to estimate the effect of FPUC payments on aggregate spending. Using our publicly available spending data combined with UI claims data from Illinois, they estimate that a $1 \%$ increase in the replacement rate increased county-level spending by $0.167 \%$, which implies that each $\$ 1$ of UI benefits increased aggregate spending at the county level by $\$ 1.23$. For comparison, our estimates above imply that $\$ 1$ of spending in the form of stimulus checks increased household-level spending by an MPC $=0.240$ on average. In a standard Keynesian model, an MPC of 0.24 would imply an impact on aggregate spending of $0.24 /(1-0.24)=0.32$, an order of magnitude smaller than the estimated impact of UI benefits. In the pandemic, where some sectors were effectively shut down, theory suggests that the multipliers would be even smaller than the standard Keynesian benchmark (Guerrieri et al. 2022). This comparison suggests that UI benefits

\footnotetext{
${ }^{35}$ This analysis focuses solely on short-run employment effects; it remains possible that the PPP may have longterm benefits by reducing permanent business closures, as emphasized by Hubbard and Strain (2020).
} 
targeted to unemployed individuals were a more potent tool to stimulate aggregate spending than stimulus payments to all individuals, especially later in the pandemic as employed households built up a large stock of savings.

Eviction Moratoria. Many state and local governments enacted moratoria on tenant eviction during the pandemic to provide stable housing for those who might have lost their jobs. These moratoria were implemented at different times in different states and counties. An, Gabriel, and Tzur-Ilan (2022) exploit variation in the timing of such moratoria to estimate their impacts on spending. Using our publicly available data on consumer spending by category coupled with other sources, they estimate that a one-week eviction moratorium is associated with a $1 \%$ increase in spending on necessities such as food and groceries. They conclude that eviction moratoria not only reduced housing instability but also boosted spending on other goods and potentially provided an aggregate stimulus as a result.

Methodologically, these examples illustrate that data from private sector sources can be used to evaluate a wide variety of policies rapidly because many policies have heterogeneous impacts across geographic areas or other dimensions, such as firm size. Reassuringly, the findings obtained from our public statistics match those obtained from studies with access to the underlying microdata, demonstrating that public statistics constructed from private sector data sources that can support many policy analyses. Taken together, these studies suggest that policies targeted directly at households that suffered the largest income losses - such as those who became unemployed or faced eviction - had the largest impacts on spending and downstream economic activity in the pandemic.

\section{IV.C Secondary Impacts on Spending}

We conclude by stepping back from the effects of specific policies and analyzing whether the combination of government policies - those analyzed above as well as other macroeconomic responses and changes in the economy - was adequate to stem the downward spiral in economic activity set off by the initial reduction in consumer spending documented in Section III. Did the loss of jobs among low-wage workers trigger a secondary reduction in their own spending levels due to a lack of disposable income (rather than health concerns) - potentially setting off further business revenue losses and employment losses? Or was government intervention adequate to prevent such secondary responses? We investigate secondary spending responses among low-income individuals by returning to the geographic heterogeneity in the size of initial consumer demand shocks by local rent levels, as in Section III. In particular, we compare how spending evolved in low-income ZIP 
codes whose residents worked predominantly in high-rent areas vs. those whose residents worked predominantly in low-rent areas.

Figure 9A presents a binned scatter plot of changes in low-wage employment from January to April 2020 by home (residential) ZIP code vs. average workplace rent. We construct this figure by combining ZIP-code-level data on employment rates of low-wage workers from Earnin that we make publicly available with public data from the Census LEHD Origin-Destination Employment Statistics (LODES) database, which provides information on the matrix of residential ZIP by work ZIP for low-income workers in the U.S. in 2017, to compute the average workplace median rent level for each residential ZIP. Figure 9A shows that low-income individuals who were working in high-rent areas pre-COVID were much less likely to be employed after the shock hit in April consistent with our findings above. ${ }^{36}$

Next, we analyze how these differential shocks to employment affected spending patterns, taking a step toward mapping the flow of shocks in the economy (Andersen et al. 2022). Figure 9B replicates Figure 9A using spending changes on the y-axis, restricting to households living in lowincome ZIP codes. ${ }^{37}$ Low-income individuals living in areas where people tend to work in high-rent ZIP codes cut spending by $35 \%$ on average from January to April 2020, compared with $21 \%$ for those living in areas where people tend to work in low-rent ZIPs. The relationship remains similar when we compare ZIP codes within the same county and control for rents in individuals' home (residential) ZIP code (Appendix Table 7).

Figure 9B implies that low-income households who lost their jobs at the start of the pandemic reduced their own spending more at the start of the pandemic - portending the start of the downward spiral described above. However, while employment losses for low-wage workers persisted over time, the reductions in spending did not. Figure 9C shows that by October 2020, spending in low-income ZIP codes was slightly higher than it was pre-COVID on average, and there was no longer any relationship between workplace rents and spending levels among low-income households despite the persistence of employment losses in higher-rent areas (Figure 6D). Figure 9D plots the evolution of spending in bottom-income-quartile ZIP codes that rank in the top quartile of median

\footnotetext{
${ }^{36}$ These results are driven by work location rather than sectoral differences in employment across areas: in the Earnin microdata, we find similar results even when comparing workers employed at the same firm (e.g., a chain restaurant). People working in high-rent ZIP codes in January remained less likely to have a job (anywhere) in April than their co-workers working in a different establishment of the same firm in lower-rent ZIP codes.

${ }^{37}$ We restrict this figure to households living in low-income ZIPs because we cannot disaggregate the Affinity data by individual-level income. Since the employment data already represent only low-income workers, we do not restrict to low-income ZIPs in the employment analysis above; however, the patterns are very similar when restricting to low-income ZIPs in the Earnin data.
} 
workplace rent. Despite the fact that these areas faced the largest and most persistent employment losses, consumer spending recovered very rapidly after falling sharply at the onset of the pandemic, exceeding pre-COVID levels starting in July 2020.

In sum, although a sharp gradient of spending reduction with respect to employment losses emerged early in the pandemic, it vanished within a few months. Total spending in areas where many workers had lost their jobs and remained out of work remained on par with areas where workers had lost less income - indicating that the secondary spending response that could have produced a further downward spiral was effectively shut down shortly after the crisis began. Losses in earned income likely did not translate to further spending reductions because the fiscal response to the crisis (e.g., via extended unemployment benefits and fiscal stimulus payments) actually increased the total disposable income of low-income households (Blanchet, Saez, and Zucman 2022; Ganong et al. 2022). These results suggest that as a whole, macroeconomic policy responses appear to have been effective in limiting secondary declines in consumer spending as workers lost their jobs - perhaps even going beyond what was necessary - even if they could not address the losses in employment that arose from the initial shock to consumer spending driven by health concerns.

\section{Conclusion}

Transactional data held by private companies have great potential for measuring economic activity, but to date have been accessible only through contracts to work with confidential microdata. In this paper, we have constructed a public database to measure economic activity at a high-frequency, granular level using data from private companies. By systematically cleaning, aggregating, and benchmarking the underlying micro data, we construct series that can be released publicly without disclosing sensitive information.

We use this new public database to analyze the economic impacts of COVID-19, demonstrating two ways in which the data provide a new tool for empirical macroeconomics. First, the data can be used to rapidly diagnose the root factors driving an economic crisis by learning from crosssectional heterogeneity, since different places and subgroups often face different shocks. In the case of COVID-19, we find that a sharp reduction in spending by high-income individuals due to health concerns led to losses of business revenues and persistent reductions in low-wage employment in affluent areas. Second, the data permit rapid, real-time policy evaluation - as demonstrated by our analyses showing the changing impacts of fiscal stimulus payments over the course of the pandemic - opening a path to fine-tuning policy responses based on their observed impacts rather relying 
solely on historical estimates.

The benefit of constructing a public database to conduct such analyses rather than working directly with the confidential data held by private sector firms is that it permits a much broader set of analyses by centralizing the fixed costs of cleaning the data for research purposes and making them readily accessible, facilitating transparency and reproducibility. For example, the data have been used by local policymakers to inform local policy responses and forecast tax revenue impacts (e.g., Maine, Missouri, Kansas, and Texas). They have also been used by Congressional staff to design federal policies, e.g. predicting the impacts and costs of policies targeted based on business revenue losses (RESTART Act 2020). And they have been used by other researchers to analyze a broad range of issues, from constructing price indices that account for changes in consumption bundles (Cavallo 2020) to analyzing the effects of political views on economic outcomes (Makridis and Hartley 2020).

While we have focused here on the short-run impacts of COVID-19, private sector data can be useful in monitoring impacts of economic shocks on long-term outcomes as well. As an illustration, Figure 10 plots weekly student engagement on Zearn, an online math platform used by nearly one million elementary school students as part of their regular school curriculum (see Appendix I). Children in high-income areas learned less when the COVID crisis hit and schools shifted to remote instruction, but soon recovered to baseline levels. By contrast, children in lower-income areas completed $41 \%$ fewer lessons than they did pre-pandemic through the end of the school year. These findings - first established in May 2020, and confirmed by subsequent work such as Goldhaber et al. (2022) and Jack et al. (2023) - raise the concern that the pandemic may have long-lasting impacts on low-income families not just through persistent reductions in employment documented above but also through impacts on the next generation.

Over the 20th century, the Bureau of Economic Analysis built on a prototype developed by Kuznets (1941) to institute surveys of businesses and households that form the basis for today's National Income and Product Accounts. The database built here provides a prototype for a system of more granular, real time national accounts built using transactional private sector data. The fact that even this first prototype yields insights that cannot be obtained from existing data suggests that the approach of aggregating data from private companies to construct public statistics has great potential for improving our understanding of economic activity and policymaking. 


\section{References}

Abraham, Katharine G, Ron S Jarmin, Brian Moyer, and Matthew D Shapiro (ed.) 2019. Big Data for 21st Century Economic Statistics. NBER Book Series Studies in Income / Wealth.

Aldy, Joseph E. 2014. The Labor Market Impacts of the 2010 Deepwater Horizon Oil Spill and Offshore Oil Drilling Moratorium. Working Paper, Working Paper Series 20409. National Bureau of Economic Research, August. doi:10.3386/w20409.

Alexander, Diane, and Ezra Karger. 2021. "Do Stay-at-Home Orders Cause People to Stay at Home? Effects of Stay-at-Home Orders on Consumer Behavior." The Review of Economics and Statistics (September): 1-25. ISSN: 0034-6535. doi:10.1162/rest_a_01108. https: // doi.org/10.1162/rest\%5C_a\%5C_01108.

Allcott, Hunt, Levi Boxell, Jacob Conway, Matthew Gentzkow, Michael Thaler, and David Yang. 2020. "Polarization and public health: Partisan differences in social distancing during the coronavirus pandemic." Journal of Public Economics 191:104254. ISSN: 0047-2727. doi:https: / / doi . org / 10 . 1016 / j . jpubeco . 2020 . 104254. https : / / www . sciencedirect . com / science/article/pii/S0047272720301183.

An, Xudong, Stuart A Gabriel, and Nitzan Tzur-Ilan. 2022. "More Than Shelter: The Effects of Rental Eviction Moratoria on Household Well-Being." AEA Papers and Proceedings 112:308312 .

Andersen, Asger, Emil T. Hansen, Kilian Huber, Niels Johannesen, and Ludwig Straub. 2022. Disaggregated Economic Accounts. Working Paper.

Angrist, Joshua D, Guido W Imbens, and Donald B Rubin. 1996. "Identification of causal effects using instrumental variables." Journal of the American Statistical Association 91 (434): 444455 .

Austin, Benjamin A, Edward L Glaeser, and Lawrence H Summers. 2018. "Jobs for the Heartland: Place-based policies in 21st century America." NBER Working Paper No. 24548 (April). htt ps://www.nber.org/papers/w24548.

Autor, David, David Cho, Leland D. Crane, Mita Goldar, Byron Lutz, Joshua Montes, William B. Peterman, David Ratner, Daniel Villar, and Ahu Yildirmaz. 2022a. "An evaluation of the Paycheck Protection Program using administrative payroll microdata." Journal of Public Economics 211:104664. ISSN: 0047-2727. doi:https : / / doi .org/10 . 1016/j . jpubeco . 2022 . 104664. https://www.sciencedirect.com/science/article/pii/S0047272722000664.

. 2022b. "The $\$ 800$ billion paycheck protection program: where did the money go and why did it go there?" Journal of Economic Perspectives 36 (2): 55-80. 
Baker, Scott R, R. A Farrokhnia, Steffen Meyer, Michaela Pagel, and Constantine Yannelis. 2020. "Income, Liquidity, and the Consumption Response to the 2020 Economic Stimulus Payments." NBER Working Paper No. 27097.

Bartik, Alexander W., Marianne Bertrand, Feng Lin, Jesse Rothstein, and Matt Unrath. 2020. "Measuring the labor market at the onset of the COVID-19 crisis." Brookings Papers on Economic Activity (June). https://www.brookings.edu/wp-content/uploads/2020/06/ Bartik-et-al-conference-draft.pdf.

Bennet, M. 2020. "S 3814-RESTART Act." Senate - Finance Committee.

Berger, David. 2012. Countercyclical restructuring and jobless recoveries. Technical report. Working Paper.

Blanchet, Thomas, Emmanuel Saez, and Gabriel Zucman. 2022. Real-Time Inequality. Working Paper, Working Paper Series 30229. National Bureau of Economic Research, July. doi:10 . 3386/w30229. http://www.nber . org/papers/w30229.

Board of Governors of the Federal Reserve System. 2019. The 2019 Federal Reserve Payments Study.

Broda, Christian, and Jonathan A. Parker. 2014. "The Economic Stimulus Payments of 2008 and the aggregate demand for consumption." Journal of Monetary Economics 68:S20-S36. ISSN: 0304-3932. doi:https://doi.org/10.1016/j.jmoneco.2014.09.002.

Brodeur, Abel, David Gray, Anik Islam, and Suraiya Bhuiyan. 2021. "A literature review of the economics of COVID-19." Journal of Economic Surveys 35 (4): 1007-1044. doi:https://doi . org/10.1111/joes.12423. https://onlinelibrary.wiley.com/doi/abs/10.1111/joes. 12423.

Bureau of the Fiscal Service. 2020. Daily Treasury Statement: Issues: Current and Archive.

Cajner, Tomaz, Leland D. Crane, Ryan A. Decker, John Grigsby, Adrian Hamins-Puertolas, Erik Hurst, Christopher Kurz, and Ahu Yildirmaz. 2020. "The U.S. Labor Market during the Beginning of the Pandemic Recession." Working Paper (May).

Carman, Katherine Grace, and Shanthi Nataraj. 2020. 2020 American Life Panel Survey on Impacts of COVID-19: Technical Documentation. Santa Monica, CA: RAND Corporation. doi:10 . 7249/RRA308-1.

Carnevale, Anthony P, Tamara Jayasundera, and Dmitri Repnikov. 2014. "Understanding online job ads data." Georgetown University, Center on Education and the Workforce, Technical Report (April). 
Casado, Miguel Garza, Britta Glennon, Julia Lane, David McQuown, Daniel Rich, and Bruce A Weinberg. 2020. The Effect of Fiscal Stimulus: Evidence from COVID-19. Technical report. National Bureau of Economic Research.

Cavallo, Alberto. 2020. Inflation with covid consumption baskets. Technical report. National Bureau of Economic Research.

Chetty, Raj, John Friedman, and Michael Stepner. 2021. Effects of January 2021 Stimulus Payments on Consumer Spending. Technical report. Opportunity Insights Economic Tracker.

Chetty, Raj, John N Friedman, Emmanuel Saez, Nicholas Turner, and Danny Yagan. 2020. "Income segregation and intergenerational mobility across colleges in the United States." The Quarterly Journal of Economics 135 (3): 1567-1633.

Chetty, Raj, Nathaniel Hendren, Patrick Kline, and Emmanuel Saez. 2014. "Where is the Land of Opportunity? The Geography of Intergenerational Mobility in the United States." The Quarterly Journal of Economics 129 (4): 1553-1623.

Coibion, Olivier, Yuriy Gorodnichenko, and Michael Weber. 2020. Labor Markets During the COVID19 Crisis: A Preliminary View. Technical report. National Bureau of Economic Research.

Coombs, Kyle, Arindrajit Dube, Calvin Jahnke, Raymond Kluender, Suresh Naidu, and Michael Stepner. 2022. "Early Withdrawal of Pandemic Unemployment Insurance: Effects on Employment and Earnings." AEA Papers and Proceedings 112 (May): 85-90. doi:10.1257/pandp . 20221009. https://www. aeaweb.org/articles?id=10.1257/pandp. 20221009.

Cox, Natalie, Peter Ganong, Pascal Noel, Joseph Vavra, Arlene Wong, Diana Farrell, and Fiona Greig. 2020. "Initial impacts of the pandemic on consumer behavior: Evidence from linked income, spending, and savings data." Brookings Papers on Economic Activity.

Deming, David, and Lisa B. Kahn. 2018. "Skill Requirements across Firms and Labor Markets: Evidence from Job Postings for Professionals." Journal of Labor Economics 36 (S1): S337S369. doi:10.1086/694106. https://doi.org/10.1086/694106.

Dunn, Abe, Kyle Hood, and Alexander Driessen. 2020. "Measuring the Effects of the COVID-19 Pandemic on Consumer Spending Using Card Transaction Data." National Bureau of Economic Research.

Dutz, Deniz, Ingrid Huitfeldt, Santiago Lacouture, Magne Mogstad, Alexander Torgovitsky, and Winnie van Dijk. 2021. Selection in Surveys. Working Paper, Working Paper Series 29549. National Bureau of Economic Research, December. doi:10.3386/w29549. http://www.nber . org/papers/w29549.

Eichenbaum, Martin S, Sergio Rebelo, and Mathias Trabandt. 2021. "The macroeconomics of epidemics." The Review of Financial Studies 34 (11): 5149-5187. 
Feenstra, Robert C, Robert Inklaar, and Marcel P Timmer. 2015. "The next generation of the Penn World Table." American Economic Review 105 (10): 3150-82.

Forsythe, Eliza, Lisa B Kahn, Fabian Lange, and David Wiczer. 2020. "Labor demand in the time of COVID-19: Evidence from vacancy postings and UI claims." Journal of Public Economics 189:104238.

2022. "Where have all the workers gone? Recalls, retirements, and reallocation in the COVID recovery." Labour Economics 78:102251. ISSN: 0927-5371. doi:https://doi .org/10. 1016/j . labeco.2022 . 102251. https : / www . sciencedirect.com/science/article/pii/ S0927537122001415.

Ganong, Peter, Fiona E Greig, Pascal J Noel, Daniel M Sullivan, and Joseph S Vavra. 2022. Spending and Job-Finding Impacts of Expanded Unemployment Benefits: Evidence from Administrative Micro Data. Working Paper, Working Paper Series 30315. National Bureau of Economic Research, August. doi:10.3386/w30315. http://www.nber.org/papers/w30315.

Ganong, Peter, Pascal Noel, and Joseph Vavra. 2020. "US unemployment insurance replacement rates during the pandemic." Journal of Public Economics 191:104273.

Goldhaber, Dan, Thomas J. Kane, Andrew McEachin, Emily Morton, Tyler Patterson, and Douglas O. Staiger. 2022. The Consequences of Remote and Hybrid Instruction During the Pandemic. Working Paper, Working Paper Series 30010. National Bureau of Economic Research, May. doi:10.3386/w30010. http://www.nber .org/papers/w30010.

Goolsbee, Austan, and Chad Syverson. 2021. "Fear, lockdown, and diversion: Comparing drivers of pandemic economic decline 2020." Journal of Public Economics 193:104311.

Gould, Elise, and Jori Kandra. 2022. "State of Working America 2021: Measuring wages in the pandemic labor market." Economic Policy Institute (April). https://www.epi.org/publica tion/swa-wages-2021/.

Granja, João, Christos Makridis, Constantine Yannelis, and Eric Zwick. 2022. "Did the paycheck protection program hit the target?" Journal of financial economics 145 (3): 725-761.

Greene, Claire, and Joanna Stavins. 2020. 2019 Diary of Consumer Payment Choice. Technical report. Federal Reserve Bank of Atlanta.

Greig, Fiona, Erica Deadman, and Pascal Noel. 2021. Family Cash Balances, Income, and Expenditures Trends through 2021. Technical report. JPMorgan Chase Institute. https://www . jpmorganchase . com / content / dam / jpmc / jpmorgan - chase-and - co / institute / pdf / Liquid-Asset-Report_ADA_Remediated.pdf. 
Grigsby, John, Erik Hurst, Ahu Yildirmaz, and Yulia Zhestkova. 2021. "Nominal Wage Adjustments during the Pandemic Recession." AEA Papers and Proceedings 111:258-262. doi:https://doi. org/10.1257/pandp. 20211056. https : / www . aeaweb. org/articles? id=10.1257/pandp. 20211056.

Guerrieri, Veronica, Guido Lorenzoni, Ludwig Straub, and Iván Werning. 2022. "Macroeconomic implications of COVID-19: Can negative supply shocks cause demand shortages?" American Economic Review 112 (5): 1437-74.

Hershbein, Brad, and Lisa B. Kahn. 2018. "Do Recessions Accelerate Routine-Biased Technological Change? Evidence from Vacancy Postings." American Economic Review 108, no. 7 (July): 1737-72. doi:10 . 1257/aer . 20161570. https : / /www . aeaweb .org/articles? id=10 . 1257/ aer. 20161570.

House Committee on Small Business. 2020. Oversight of the Small Business Administration and Department of Treasury Pandemic Programs: Hearing Before The House Committee on Small Business, 116th Cong. (Testimony of Steven Mnuchin).

Hubbard, Glenn, and Michael R Strain. 2020. "Has the Paycheck Protection Program Succeeded?" Brookings Institution.

Internal Revenue Service. 2022. Internal Revenue Service Data Book 2021. May. https : //www . irs.gov/pub/irs-pdf/p55b.pdf.

Jack, Rebecca, Clare Halloran, James Okun, and Emily Oster. 2023. "Pandemic schooling mode and student test scores: Evidence from US school districts." American Economic Review: Insights.

Jaimovich, Nir, and Henry E Siu. 2020. "Job polarization and jobless recoveries." Review of Economics and Statistics 102 (1): 129-147.

Jappelli, Tullio, and Luigi Pistaferri. 2014. "Fiscal Policy and MPC Heterogeneity." American Economic Journal: Macroeconomics 6, no. 4 (October): 107-36.

Johnson, David S., Jonathan A. Parker, and Nicholas S. Souleles. 2006. "Household Expenditure and the Income Tax Rebates of 2001." American Economic Review 96, no. 5 (December): 1589-1610. doi:10.1257/aer.96.5.1589. https://www . aeaweb.org/articles?id=10.1257/ aer.96.5.1589.

Kaplan, Greg, and Giovanni L Violante. 2014. "A model of the consumption response to fiscal stimulus payments." Econometrica 82 (4): 1199-1239.

Kuznets, Simon. 1941. National Income and Its Composition, 1919-1938. New York: National Bureau of Economic Research. 
Lambert, Lance, and Anne Sraders. 2021. "\$1,400 stimulus checks look likely-but the recipients might change this time." Fortune (January 26). Accessed August 15, 2022. https://fortune. com/2021/01/26/stimulus - check-3-update-3rd-checks-payments-irs-1400-whogets-qualifies/.

Lazear, Edward P., Kathryn L. Shaw, and Christopher Stanton. 2016. "Making Do with Less: Working Harder during Recessions." Journal of Labor Economics 34 (S1): S333-S360. doi:10. 1086 /682406. eprint: https : / / doi .org/10 . 1086/682406. https : //doi .org/10 . 1086/ 682406.

Leamer, Edward E. 2011. Workday, Holiday and Calendar Adjustment with 21st Century Data: Monthly Aggregates from Daily Diesel Fuel Purchases. Working Paper, Working Paper Series 16897. National Bureau of Economic Research, March. doi:10.3386/w16897. http: // www .nber.org/papers/w16897.

Lin, Zhixian, and Christopher M Meissner. 2020. "Health vs. wealth? public health policies and the economy during covid-19." National Bureau of Economic Research.

Makridis, Christos, and Jonathan Hartley. 2020. The Cost of Covid-19: A Rough Estimate of the 2020 US GDP Impact. Technical report.

McElroy, Tucker, Brian Monsell, and Rebecca Hutchinson. 2018. "Modeling of Holiday Effects and Seasonality in Daily Time Series." Center for Statistical Research and Methodology Report Series, RRS2018-01.

Meyer, Bruce D., and Nikolas Mittag. 2021. "An empirical total survey error decomposition using data combination." Journal of Econometrics 224 (2): 286-305. ISSN: 0304-4076. doi:10.1016/ j . jeconom. 2020 .03 . 026. https : / / www. sciencedirect.com/science/article/pii / S0304407620303687.

Miguel, E., C. Camerer, J. Cohen, K.M. Esterling, A. Gerber, D.P Green, R. Glennerster, et al. 2014. "Promoting Transparency in Social Science Research." Science 343 (January): 30-31. doi:10 . 1126 / science . 1245317. https : / / www . science . org/doi / 10 . 1126 / science . 1245317.

Organization for Economic Co-operation and Development. 2023. Working Age Population: Aged 15-64: All Persons for the United States [LFWA64TTUSM647S]. Data retrieved from FRED, Federal Reserve Bank of St. Louis. https://fred.stlouisfed.org/series/LFWA64TTUSM64 $7 \mathrm{~S}$.

Parker, Jonathan A., and Nicholas S. Souleles. 2019. "Reported effects versus revealed-preference estimates: Evidence from the propensity to spend tax rebates." American Economic Review: Insights 1 (3): 273-90. 
Paychex. 2020. Small Business Employment Watch, April. https://www.paychex.com/employme nt-watch.

Petev, Ivaylo, Luigi Pistaferri, and Itay Saporta Eksten. 2011. Consumption and the Great Recession: An analysis of trends, perceptions, and distributional effects.

PwC. 2020. PwC US CFO Pulse Survey. Technical report. June. https://www.pwc.com/us/en/ library/covid-19/pwc-covid-19-cfo-pulse-survey.html.

Sahm, Claudia. 2019. "Direct Stimulus Payments to Individuals." Chap. 3 in Recession Ready: Fiscal Policies to Stabilize the American Economy, edited by Heather Boushey, Ryan Nunn, and Jay Shambaugh, 67-92. Brookings.

Sahm, Claudia R., Matthew D. Shapiro, and Joel Slemrod. 2010. "Household response to the 2008 tax rebate: Survey evidence and aggregate implications." Tax Policy and the Economy 24 (1): 69-110.

- 2012. "Check in the Mail or More in the Paycheck: Does the Effectiveness of Fiscal Stimulus Depend on How It Is Delivered?" American Economic Journal: Economic Policy 4, no. 3 (April): 216-250. doi:10.1257/pol.4.3.216.

Small Business Administration. 2020. Joint Statement by SBA Administrator Jovita Carranza and U.S. Treasury Secretary Steven T. Mnuchin Regarding Enactment of the Paycheck Protection Program Flexibility Act.

Summers, Robert, and Alan Heston. 1984. "Improved International Comparisons of Real Product and its Composition: 1950-1980." Review of Income and Wealth 30 (2): 207-219.

1991. "The Penn World Table (Mark 5): An expanded set of international comparisons, 1950-1988." The Quarterly Journal of Economics 106 (2): 327-368.

U.S. Bureau of Economic Analysis. 2020. National Income and Product Accounts. Data retrieved from U.S. Bureau of Economic Analysis, National Income and Product Accounts.

U.S. Bureau of Labor Statistics. 2023a. Employment Level - All Industries Self-Employed, Unincorporated [LNU02027714]. Data retrieved from FRED, Federal Reserve Bank of St. Louis. https://fred.stlouisfed.org/series/LNU02027714.

- 2023b. Employment Level - Total Wage and Salary, Incorporated Self Employed [LNU02048984]. Data retrieved from FRED, Federal Reserve Bank of St. Louis. https://fred.stlouisfed. org/series/LNU02048984.

- 2023c. Population Level [CNP16OV]. Data retrieved from FRED, Federal Reserve Bank of St. Louis. https://fred.stlouisfed.org/series/CNP160V.

U.S. Census Bureau. 2017. 2017 Statistics of U.S. Businesses (SUSB) Annual Data Tables by Establishment Industry. 
U.S. S.B.A Office of Advocacy. 2020. 2020 Small Business Profile.

Vavra, Joseph. 2021. "Tracking the Pandemic in Real Time: Administrative Micro Data in Business Cycles Enters the Spotlight." Journal of Economic Perspectives 35, no. 3 (August): 47-66. doi:10.1257/jep.35.3.47. https://www . aeaweb.org/articles?id=10.1257/jep.35.3.47.

Villas-Boas, Sofia B, James Sears, Miguel Villas-Boas, and Vasco Villas-Boas. 2020. "Are We \#StayingHome to Flatten the Curve?" UC Berkeley: Department of Agricultural and Resource Economics CUDARE Working Papers (April). https://escholarship.org/uc/item/5h97n884.

Watson, Garrett. 2021. Senate Direct Payment Design Would Create High Implicit Marginal Tax Rates. Technical report. Tax Foundation.

Yagan, Danny. 2019. "Employment Hysteresis from the Great Recession." Journal of Political Economy 127 (5): 2505-2558. 


\section{Online Appendix}

\section{A Automated Data Processing Pipeline}

This appendix describes the automated pipeline we built to ingest raw data, process it to construct aggregate statistics, and release those statistics publicly. This automated pipeline typically allows us to post updated statistics within one business day of receiving the raw data. By automating the data processing to the extent possible, we aim to post data as close to real-time as possible, while maintaining the quality of the data and minimizing the manual upkeep required. The primary source of lags in the posted data is therefore driven by lags in the underlying data generating processes: for example, card transactions can take up to a week to settle and employment income is typically paid in bi-weekly or monthly payrolls. We summarize our data engineering methods here for those who may be interested in setting up similar infrastructure in other contexts.

Step 1: Data Ingestion. To flexibly accommodate diverse data sources with varying secure file transfer methods and update frequencies, we operate a cloud server that pulls updated data from each source on a regular interval. We receive data updates from private companies on a daily, weekly, or monthly cadence. Many companies have unique policies and requirements for securing data transfers, so we write scripts to intake this data using a variety of secure file transfer services (e.g. Amazon S3 buckets and SFTP servers). We also download or scrape a variety of publicly available statistics from the web, such as unemployment insurance claims and COVID-19 case counts.

Three main challenges arise when handling this large volume of frequently updated data: storing, syncing, and version controlling the data we receive. We store all the raw data we receive as flat files in a data lake (an Amazon S3 bucket). We use object storage rather than a database or a more customized storage service (such as Git LFS) to minimize storage costs while maximizing our flexibility to ingest incoming data which arrives in numerous formats that may change over time. We version control each snapshot of the data we download within the same Git repository that stores our code using a tool called DVC ("Data Version Control"). DVC creates a pointer to a hash of the raw data for each data file or folder (in other words, a shortcut to the files in the data lake), which we version control in Git and update every time new data is downloaded. This associates each snapshot of data with the code that existed at the time it was processed, and allows us to easily roll back our code and data simultaneously to any prior state. DVC also facilitates syncing the raw data from the data lake by efficiently downloading the data that is associated with each 
pointer in the Git repository.

Step 2: Data Processing. For each dataset, we have an automated pipeline of programs that process and transform the raw data into the public datasets that we post online. We use an automated build tool to organize and execute this collection of programs. We mostly process the data using Stata and execute our automated builds within Stata using the -project- command developed by Robert Picard.

This data processing step generates two outputs: (1) a set of CSV files that contain all the data to be posted publicly and (2) a quality control report. The quality control report is a document that allows analysts to quickly assess any notable deviations in the data and determine whether the updated data require further review before being publicly released. Each report flags three types of changes that would require manual review: revisions made to previously posted data, large deviations in newly reported data, or newly missing data. The report also contains a series of tables and figures that preview the data and highlight any changes in the newly processed data.

Each time new data is ingested, the data processing step is run automatically. If it runs to completion, a Git pull request is generated with DVC pointers to the newly updated raw data alongside a link to the quality control report. If the data processing fails (for example, because the structure of the raw data has changed), an error report is generated. At this point, we pause and perform a manual review before posting the new data online. If the data processing failed or if any changes were detected in the quality control report that require further review, we manually investigate and write new code as needed, then re-process the data and inspect the updated quality control report before proceeding.

After reviewing and approving the quality control report, we merge the Git pull request containing the new data, which automatically triggers the final Data Release step. This manual review and approval is therefore the only manual step in the data processing pipeline.

Step 3: Data Release. Once the processed data is ready for release, our scripts automatically post the updated data to two public destinations. First, we sync the updated data into the database powering our online data visualization website built by DarkHorse Analytics (www.tracktherecovery.org). While doing so, we also update the "last updated" and "next expected update" dates on the website. Second, we upload the CSV files containing all the updated data to our "data downloads" page. The updated visualizations and data downloads are then both immediately available for public use. 


\section{B Consumer Spending Series Construction}

\section{B.1 Structure of Initial Data}

We receive data from Affinity Solutions in cells corresponding to the intersection of (i) county, (ii) income quartile, (iii) industry, (iv) day and week. Cells where fewer than five unique cards transacted are masked. Income quartile is assigned based on ZIP code of residence using 2014-2018 ACS estimates of median household income. We use population weights when defining quartile thresholds so that each income quartile includes the same number of individuals nationally. County and ZIP code income quartile are both determined by the cardholder's residence.

\section{B.2 Internal Data Processing}

\section{Adjusting for sharp changes in the client base}

The raw Affinity data have discontinuous breaks caused by entry or exit of card providers from the sample. We identify these sudden changes systematically by regressing the number of transacting cards at a weekly level on the date, separately for each year-by-county, and then implementing a Supremum Wald test for a structural break at an unknown break point. We apply a correction to structural breaks where the p-value of the test is less than $5 \times 10^{-10}$.

For counties with only one break below this threshold, we correct our estimates as follows. We first compute the state-level week-to-week percent change in spending excluding all counties with a structural break (using the national series for DC and states for which all counties have a structural break). If we identify a structural break in week $t$, we impute spending levels in weeks $t-1, t$, and $t+1$, as we cannot ascertain the precise date when the structural break occurred (e.g., it may have occurred on the 2 nd day of week $t-1$ or the 6 th day of week $t$ ). When there is a change in coverage we adjust the series to be in line with the lower level of coverage. For example, suppose a county has $n$ active cards up until week $t$, when the number of cards in the county increases to $3 n$. In week $t-2$, the county would have a level of $n$ cards, its reported value. In week $t-1$, if counties in the rest of the state had a $5 \%$ increase in the number of cards, we would impute the county with a break to have a level of $1.05 n$ cards. In week $t$, if counties in the rest of the state had a $10 \%$ increase in the number of cards, we would impute $t$ to have a level of $(1.10) \times(1.05 n)=1.155 n$. Likewise, if counties in the rest of the state had an $8 \%$ decrease in the number of cards in week $t+1$, we would impute $t+1$ to have a level of $(0.92) \times(1.155 n)=1.0626 n$.

We omit counties with multiple structural breaks from our series. We also add manually identified structural breaks which are not identified by the Supremum Wald test, for example because 
the break phases in over more than one week. We do not remove any counties where the structural break occurred between March 10th and March 31st of 2020 because the consumer spending response to the COVID-19 was so strong that in many places it could be classified as a structural break. Additionally, since holiday spending spikes are also sometimes classified as a structural break, we do not adjust breaks detected in the week of Thanksgiving or the weeks immediately before, during or after Christmas.

\section{Adjusting for gradual changes in the client base}

In our processing, we aim to isolate and remove variation in spending driven by the number of debit/credit cards in our sample changing due to steady growth or shrinkage in a payment provider's customer base. However, we also aim to incorporate extensive margin variation in spending driven by the number of debit/credit cards in our sample changing due to changes in the utilization of cards, which can reflect underlying economic conditions. To account for both, we first estimate a two-state switching model of the relationship between Personal Consumption Expenditure as measured by the U.S. Bureau of Economic Analysis and the level of credit and debit spending and number of cards in usage we received from Affinity Solutions. Our estimates imply a state change between February 2020 and August 2020: the number of cards in use is predictive of Personal Consumption Expenditures during this period, but statistically insignificant outside this period. This is consistent with a pattern where people exhibited extensive margin changes in card spending during the initial waves of COVID-19, but outside of that period changes in the number of cards being used reflect changes in the number of people in-sample as opposed to changes in the propensity to consume of a given set of people.

We therefore construct an estimate of spending that reflects total spending during Feb-Aug 2020 and spending per card outside this period. For each location $(l)$, industry $(i)$ and time $(t)$ we compute: 


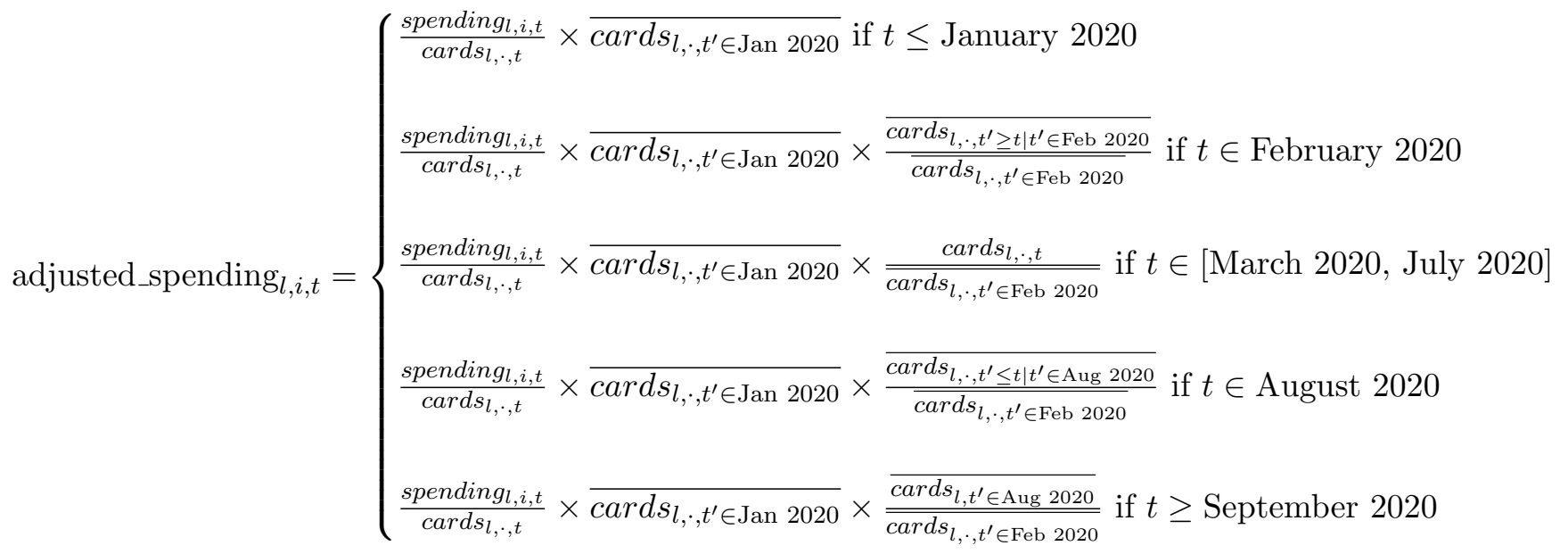

We use this adjusted spending series throughout our analysis, except in Section IV.A, where we always use total spending (thereby including both intensive and extensive margin changes) in order to ensure consistency in comparisons of our estimates across different stimulus rounds.

\section{Addressing spurious changes}

There is an large spike in consumer spending between January 15th, 2019 and January 17th, 2019 that is not found in other data series. This spike in national consumer spending is likely driven by the early release of February 2019 SNAP benefits due to an impending government shutdown. ${ }^{38}$ In order to avoid contaminating our seasonal adjustment with this one-time shock, we replace each impacted day with the average spending on $t-7, t+7$, and $t+14$, where $t$ is the impacted day.

\section{Control for seasonal fluctuations in spending}

We seasonally adjust the data by calculating, for each week and day, the year-on-year change relative to the 2019 value. We norm February 29, 2020 (a Saturday) relative to the average of February 23 and March 2, 2019 (both Saturdays). Labor Day in 2019 fell one week earlier than in 2020, so we adjust the week of Labor Day, as well as the two weeks before, based on the same week in 2019 relative to Labor Day rather than the week number in the year. We then calculate the change relative to the January index period: 2019 data is indexed relative to January 7 th to February 3rd, 2019, data in 2020 onward is indexed relative to January 6th to February 2nd, 2020. We then seasonally adjust by dividing by the indexed 2019 value, which represents the difference between the change since January 2020 compared to the change since January 2019.

\footnotetext{
${ }^{38}$ Described in "Billions in food stamp payments to come early because of shutdown", Politico article on January 11th, 2019: https://www.politico.com/story/2019/01/11/shutdown-food-stamp-scramble-benifits-1081210
} 


\section{B.3 Masking and Publication}

Cells with fewer than 5 card transactions are masked. Additionally, because the supremum wald test cannot identify breaks in the most recent few weeks of data, we mask particularly large changes. If a week-on-week change is $>4 \mathrm{x}$ the median change of that series, and $<1 / 3$ of all series have a large change defined in this way, the value of the change is replaced with the preceding week multiplied by the national average change. We place this $1 / 3$ restriction to avoid overmasking holiday spending, when almost all series experience large changes.

\section{Definition of Categories of Goods}

In parts of our analysis, we distinguish between four categories of goods and services: durable goods; non-durable goods; remote services; and in-person services.

- We define durable goods as the following MCC groups: Building materials, garden equipment, and supplies; electronics and appliances; furniture and home furnishings; motor vehicles and parts; sporting goods, hobbies, musical instruments, and book stores; and telecommunications

- We define nondurable goods as the following MCC groups: General merchandise; wholesale trade; clothing and clothing accessories; health and personal care stores; food and beverage stores; misc store retailers; and gas stations

- We define remote services as the following MCC groups: Utilities, construction, and manufacturing; professional, scientific, and technical services; public administration; administrative and support and waste management and remediation services; information; education; finance; and nonstore retailers

- We define in-person services as the following MCC groups: Rental and leasing; repair and maintenance; and personal and laundry services

\section{Substitution from Card to Cash Spending}

A potential concern with our card-based estimates of spending changes is bias from substitution out of cash purchases, which account for $6.3 \%$ of consumer spending in the United States (Greene and Stavins 2020). For instance, if individuals sought to use more contactless methods to pay or began placing more orders online, trends in card spending might exhibit excess volatility relative to overall spending. To assess the importance of such substitution, we examine cash purchases using 
receipts data from CoinOut, a company that allows individuals to receive rewards by uploading photos of their receipts to a mobile app. We focus on grocery spending in the card data because cash spending in CoinOut is concentrated in certain sectors such as groceries; unfortunately, we are unable to disaggregate the CoinOut data by sector or align sectoral definitions more precisely across the datasets.

Appendix Figure 6B plots week on week changes in aggregate cash purchases in the CoinOut data vs. aggregate card spending at grocery stores over time. The time trends are very similar between the two series (with a correlation of 0.67 at the weekly level), showing a sharp spike in spending in late March (as households stocked up on groceries), followed by a more sustained increase in spending from the latter half of April. These results suggest that households shifted spending similarly across both modes of payment.

\section{B.4 Benchmarking}

Comparison to QSS and MARTS. Total debit and credit card spending in the U.S. was $\$ 7.08$ trillion in 2018 (Board of Governors of the Federal Reserve System 2019), approximately 50\% of total personal consumption expenditures recorded in national accounts. Appendix Figure 2 compares the spending distributions across sectors in the Affinity data to spending captured in the nationally representative Quarterly Services Survey (QSS) and Advance Monthly Retail Trade Survey (MARTS), which together cover $92 \%$ of the expenditure-weighted categories in the Affinity data. The Affinity series has broad coverage across industries, but over-represents categories in which credit and debit cards are used for purchases. In particular, accommodation and food services and clothing constitute a greater share of the card spending data than financial services and motor vehicles. We therefore view the Affinity series as providing statistics that are representative of total card spending, but not total consumer spending. We assess whether the Affinity series accurately captures changes in total card spending in the COVID recession in Section III.A.

\section{Small Business Revenue and Openings Series Construction}

\section{C.1 Structure of Initial Data}

We receive total small business debit and credit revenue data from Womply, where the total revenue data is aggregated from settled credit card transactions that Womply receives from payment processing partners. Additionally, we receive the number of businesses open data from Womply where the number of businesses open is defined as the number of businesses making at least one 
transaction within a three day window. The primary raw data we receive and process is a 52 -week "no-entry" panel of firms at the County by Sector by Week level, which is a repeated panel following the set of firms operating in each week $t$ over the subsequent 52 weeks (with attrition but no entry during the panel). To construct ZIP-level estimates, we additionally use a cross-sectional sample of firms at the ZIP Code by ZIP Income Quartile by Sector by Day level. We measure small business revenue as the sum of all credits (generally purchases) minus debits (generally returns). All transactions and derived data we receive are tied to the ZIP code or County containing the business. The sample is limited to small businesses as defined by the Small Business Administration.

\section{C.2 Internal Data Processing}

\section{Adjusting for the evolving client base}

In each calendar year, we follow the sample of businesses operating during the first week of the year (i.e. we start following a new panel each calendar year). No new businesses enter our panel during the calendar year. Businesses may exit because they stop operating or because the underlying payment processors ceased providing data.

We detect cases where a payment processor disappears by detecting sharp drops in businesses operating, at the national and the state level. We then adjust the series to identify and correct breaks in the data introduced by these merchant exits from the sample. To do so, we identify breaks in series in the period from July 2020 to present as downward discontinuities of at least 2.5 percentage points between weeks $t-1$ and $t$ that persist as a drop of at least 2.5 percentage points between weeks $t-1$ and $t+1$. For weeks prior to July 2020 we manually identify breaks in weeks 21, 22, 27, 31 nationally and at week 25 for a subset of states (where week numbers refer to weeks of 2020).

For breaks identified prior to July 2020, business revenue was in a period of strong recovery so we assume "momentum" during the weeks with missing data. We calculate the average rate of change for the 4 preceding weeks to the discontinuity and use that value to impute the rate of change for the identified week of the discontinuity. For breaks identified from July 2020 to present we adjust a given merchant or sales series as follows. For a merchant series, for the week of a discontinuity we impute the value of the number of merchants as the value from week $t-1$ and adjust the following weeks accordingly resetting the number of merchant to the level prior to the identified exit from the sample. For a sales series, if week $t-1$ has a discontinuity we compute the change in sales between week $t-1$ and week $t-2$ to be zero and adjust the following weeks accordingly. If additionally 
week $t$ has a discontinuity we correct week $t$ following the same procedure and adjust the following weeks accordingly.

\section{Produce the ZIP code series}

As described in Appendix C.1, we do not receive any panel data disaggregated to the ZIP code level: we only observe cross-sectional ZIP level data. We therefore perform an additive adjustment on the cross-sectional ZIP level series so that the weighted sum of the processed ZIP series aligns with the county-level "same store" panel data. The resulting data obtains the levels from the County no-entry panel, and the within-county across-ZIP variation from the ZIP level cross-section.

\section{Reducing the influence of outliers}

To reduce the influence of outliers, firms outside twice the interquartile range of firm annual revenue within this sample are excluded and the sample is further limited to firms with 30 or more transactions in a quarter and more than one transaction in 2 out of the 3 months.

We also manually exclude some State $\mathrm{x}$ Industry breakdowns that present extreme variation from our state and national level calculations, as well as a small number of counties that demonstrate extreme variation.

\section{Controlling for seasonality}

We seasonally adjust reported revenue by calculating the year on year change relative to the corresponding value in 2019. We calculate the change relative to the January index period: 2019 data is indexed relative to January 2019, data in 2020 onward is indexed relative to January 2020. We then seasonally adjust by dividing by the indexed 2019 value, which represents the difference between the change since January 2020 compared to the change since January observed since 2019. Weeks that span the end of the year are treated as the first week of the later year.

\section{C.3 Masking and Publication}

To preserve the privacy of firms in the data and to avoid displaying noisy estimates for small cells, we mask Womply series that report less than $\$ 250,000$ in total revenue during the base period of January 4-31. The ZIP-level data we receive from Womply adds merchants and an imputed revenue quantity such that every cell with 1 or 2 merchants has no fewer than 3 merchants. This imputation has the result of dampening the effect of any declines that would otherwise place the number of merchants in a cell at 1 or 2 , lowering the effect of any increase from 1 or 2 merchants 
to 3 merchants, and enhancing the effect of any increase from 0 merchants to 1 or 2 merchants. We address the effects of this imputation by dropping any ZIP code that has imputed values for more than $25 \%$ of the weeks in our period of study.

\section{C.4 Benchmarking}

Comparison to QSS and MARTS. Appendix Figure 2 shows the distribution of revenues observed in Womply across industries in comparison to national benchmarks. Womply revenues are again broadly distributed across sectors, particularly those where card use is common. A larger share of the Womply revenue data come from industries that have a larger share of small businesses, such as food services, professional services, and other services, as one would expect given that the Womply data only cover small businesses.

\section{Job Postings Series Construction \\ D.1 Structure of Initial Data}

We receive a dataset containing the weekly number of new job postings, defined as those that have not already been posted within a 60 day window. This data is disaggregated by geography (county, state, national), by 2-digit NAICS code, and by ONET code. Jobs postings are sourced by Lightcast (formerly known as Burning Glass Technologies) from over 40,000 jobs boards worldwide.

\section{D.2 Internal Data Processing}

\section{Reducing the influence of outliers}

In order to avoid extreme outliers, we calculate a cutoff of one standard deviation above the 97th percentile of the state-level data for each variable and mask values that exceed this threshold.

\section{D.3 Masking and Publication}

We perform some imputations of the county-level by subgroup data to ensure the privacy of the underlying job postings dataset, as required by our data use agreement. In the 200 most-populated counties, total job posts by subgroup are reported directly without imputation. For total job posts by subgroup in smaller counties, we impute the number of job postings: we report the total county level postings by subgroup multiplied by the share of total state level postings of the corresponding subgroup. All state-level and national data is reported without imputations. 


\section{D.4 Benchmarking}

Comparison to JOLTS. Lightcast data have been used extensively in prior research in economics; for instance, see Hershbein and Kahn (2018) and Deming and Kahn (2018). Carnevale, Jayasundera, and Repnikov (2014) show that the Lightcast data are reasonably well-aligned with government survey-based statistics on job openings and characterize the sample in detail. In Appendix Figure 3, we compare the distribution of industries in the Lightcast data to nationally representative statistics from the Bureau of Labor Statistics' Job Openings and Labor Market Turnover Survey (JOLTS) in January 2020. In general, Lightcast is well aligned across industries with JOLTS, with the one exception that it under-covers government jobs. We therefore view Lightcast as a sample representative of private sector jobs in the U.S.

\section{E Employment Series Construction}

\section{E.1 Structure of Initial Data}

The employment series is constructed with data from three data providers: Paychex, Intuit, and Earnin.

\section{Paychex}

We obtain aggregated weekly data on total employment for each county by industry (two-digit NAICS), time-varying hourly wage quartile (defined below), firm size bin and pay frequency. Salaried employees' wages are translated to hourly wages by dividing weekly pay by 40 hours. To measure private sector employment, we exclude workers employed in public administration and those with an unclassified industry (which each represent $0.8 \%$ of workers as of January 2020). We restrict the sample to workers with weekly, bi-weekly, semi-monthly or monthly pay frequencies; these workers represent over $99.8 \%$ of employees in the Paychex data.

To classify workers by wage quartile while adjusting for wage growth, we construct moving wage quartile thresholds based on $100 \%, 150 \%$ and $250 \%$ of the federal poverty line (FPL). The FPL is defined as an annual income, which we convert into a full-time-equivalent hourly wage by diving by 2000 hours (50 weeks of work at 40 hours per week). In our benchmark period of January 2020 , the thresholds are $\$ 13.10, \$ 19.65$ and $\$ 32.75$. These thresholds group workers approximately into quartiles: in January 2020, the four bins in ascending order by wage contain $23.4 \%, 27.4 \%$, $25.7 \%$, and $23.5 \%$ of CPS respondents. Since the FPL is set annually at the beginning of each year, 
we estimate monthly thresholds within each year by multiplying the FPL by the growth in the monthly Consumer Price Index (CPI) since January. When the official FPL estimate is published at the beginning of the subsequent year, its growth does not exactly match the growth in CPI. To maintain consistency with the levels of the FPL, we revise the thresholds from the prior year when the FPL is released. We compute the difference between our CPI-based thresholds and the official FPL thresholds during the relevant year, divide this residual by 12 , and add the rescaled residual to the projected FPL in each month.

We estimate and provide these moving wage quartile thresholds to Paychex, which are then used internally by Paychex to assign workers to an hourly wage quartile in the aggregated weekly dataset we receive. In January of each year, we provide revised quartile thresholds to Paychex and revise our estimates for the prior year - the revised estimates hold aggregate employment constant but reallocate some workers across quartiles.

Using moving thresholds to assign workers to wage quartiles generates occasional discontinuities in each quartile due to bunching in the wage distribution at integers, as discussed in Section II.B.4 and detailed in Appendix E.2. To correct these discontinuities, we receive weekly counts of the number of employees earning an integer hourly wage for each integer value between $\$ 13$ and $\$ 25$. These counts are received at the same level of disaggregation as the weekly data on employment: county by industry (two-digit NAICS), firm size bin and pay frequency.

\section{Intuit}

We obtain anonymized, aggregated data on month-on-month and year-on-year changes in total employment (the number of workers paid in the prior month) and average earnings at the state and county level by month, based on repeated cross-sections. To develop a national series, we take population-weighted averages of state changes in each month.

\section{Earnin}

We obtain anonymized data from Earnin at the paycheck level with information on industry (2-digit NAICS), firm size, ZIP code, unemployment status, wages, and earnings. The median worker in the Earnin sample in January 2020 has an hourly wage rate of $\$ 10.80$, which falls at the 16 th percentile of the national distribution of private sector non-farm workers in January 2020 CPS data. The interquartile range of wages in the Earnin sample is $\$ 8.03-\$ 14.33$ (corresponding to the 3rd and 40th percentiles of the national distribution). 
Industry and firm size are not directly measured in Earnin's administrative databases, so these variables were attached to the anonymized paycheck-level data by linking a list of employers with more than ten Earnin users to external databases. To obtain information on industry, we use a custom-built crosswalk created by Digital Divide Data which contains NAICS codes for each employer in the Earnin data with more than ten Earnin users. To obtain information on firm size, we crosswalk Earnin employers to ReferenceUSA data at the firm location level by spatially matching Earnin employers to ReferenceUSA firms. We begin by geocoding Earnin addresses to obtain latitudes and longitudes for each Earnin employer. We then remove common prefixes and suffixes of firm names, such as "inc" and "associated". Next, we compute the trigram similarities between firm names for all Earnin and ReferenceUSA firms within twenty-five miles of another. We then select one "match" for each Earnin firm within the ReferenceUSA data, among the subset of firms within one mile. We first match Earnin employers to ReferenceUSA firms if the firms are within one mile of one another, and share the same firm name. Second, where no such match is available, we choose the geographically closest firm (up to a distance of one mile) among all firms with string similarities of over 0.6. Third, where no such match is available, we match an Earnin employer to the ReferenceUSA employer within twenty-five miles with the highest trigram string similarity, provided that the match has a trigram string similarity of 0.9 . We then compute the modal parent-firm match in the ReferenceUSA data for each parent-firm grouping in Earnin. Where at least $80 \%$ of locations within a parent-firm grouping in Earnin are matched to a single parentfirm grouping in the ReferenceUSA data, we impute that parent-firm to every Earnin location. In total, we match around $70 \%$ of Earnin employers to ReferenceUSA firms.

\section{E.2 Internal Data Processing}

Data is processed in the following ways for data received from the three data providers: Paychex, Intuit, and Earnin.

\section{Paychex}

Addressing anomalous spikes. We manually identify large anomalous spikes in the data and smooth these by interpolating values from adjacent weeks at the county x 2-digit NAICS code $\mathrm{x}$ hourly wage quartile x 2019 firm size bin x pay frequency level.

Adjusting for discontinuities when quartile thresholds cross integer wages. We adjust for occasional discontinuities in employment in each wage quartile due to bunching in the wage distribution. 
Our adjustment is mathematically equivalent to adding a uniform random variable distributed between $[-0.5,0.5]$ to whole number wages, transforming the point mass of employees at the integer wage into a uniform distribution between [wage -0.5 , wage +0.5$]$. Rather than adding the random variable ex ante using employee microdata before aggregating, which we did not access, we applied an equivalent procedure that is feasible ex post after receiving the aggregated data described above containing employee counts. As an example, suppose the threshold separating the first wage quartile (Q1) and the second wage quartile (Q2) is $\$ 13.75$ in a given month. Then adding the uniform random variable to the wages of employees earning $\$ 14$ will move $25 \%$ of the point mass below the threshold. Since we observe the counts on each side of the $\$ 13.75$ threshold and the count at the $\$ 14$ point mass, we add $0.25 \times($ Number of Employees at $\$ 14$ ) to the Q1 count and subtract the same number from the Q2 count. We perform the analogous process for each threshold in each month, calculating the share of the point mass at the integer value within $\$ 0.50$ of the threshold that should be moved across the threshold, and adding and subtracting that value from the quartiles below and above the threshold accordingly.

Mapping paychecks to employment periods. To construct a series of employment as of each date, we construct a series of pay periods ending as of each date. We take a separate approach for paychecks following regular weekly cycles (i.e. weekly and bi-weekly paychecks) and for paychecks following a cycle based on fixed calendar dates (i.e. semi-monthly and monthly paychecks). For weekly and bi-weekly pay frequencies, we use data provided by Paychex on the distribution of the number of days between a worker's pay date and the last date in the worker's pay period (i.e., date at which payroll is processed - last date in pay period), for weekly and bi-weekly pay frequencies, to distribute paychecks to the last date of the corresponding pay period. We treat the distribution of (date at which payroll is processed - last date in pay period) as constant across geographies and NAICS codes. For monthly and semi-monthly pay frequencies, where cycles regularly occur on fixed calendar dates (e.g. the 15th and 30th of each month for semi-monthly paycycles), we assume that the last date within each pay period is the closest preceding calendar date that is the 15th or the 30th day of the month (semi-monthly paycycles) or the 30th day of the month (monthly paycycles). We then record a worker as being employed for the full duration of the pay cycle up until the last date in their pay period, under the assumption that workers are employed for each day during their pay period.

Adjusting for an evolving client base. We take steps to adjust for the entry and exit of Paychex clients from the sample. In each county $\mathrm{x}$ industry (two-digit NAICS code) $\mathrm{x}$ firm size $\mathrm{x}$ wage 
quartile cell, we compute the change in employment relative to January 4-31 2020, and the change in employment relative to July 1-31 2020. Let Min Normed $J_{u l y}{ }_{c, i, s, q}$ be the smallest value of indexed employment we observe at each date relative to its mean level over the period July 1-31 2020 and Max Normed January ${ }_{c, i, s, q}$ be the largest value of indexed employment we observe at each date relative to its mean level over the period January 4-31 2020.

For county $\mathrm{x}$ industry $\mathrm{x}$ firm size $\mathrm{x}$ wage quartile cells with at most 50 employees at all points between January 2020 and the end of the series, we reduce the weight we place on the series if we observe large changes in employment that indicate firm entry or exit. In particular, we compute the weight on the cell for county $c$, industry $i$, firm size $s$, and wage quartile $q$ as:

$$
\begin{aligned}
\text { Weight }_{c, i, s, q}= & \max \left\{1-\mathbf{1}\left\{\text { Min Normed } \mathrm{July}_{c, i, s, q} \leq 50\right\} \times\left(50-\text { Min Normed } \mathrm{July}_{c, i, s, q}\right) \times 0.02\right. \\
& -\mathbf{1}\left\{\text { Max Normed January }_{c, i, s, q} \geq 4000\right\} \times(\text { Max Normed January } \\
c, i, s, q & -4000) \times 0.001 \\
& 0\}
\end{aligned}
$$

That is, we reduce the weight we place on the cell by two percentage points for each percentage point of decline we observe below 50 percentage points relative to July 2020. We further reduce the weight by 0.1 percentage points for each percentage point of growth we observe above 4000 percentage points relative to January 2020.

For county $\mathrm{x}$ industry $\mathrm{x}$ firm size $\mathrm{x}$ wage quartile cells with over 50 employees at any point between January 2020 and the end of the series, we reduce the weight we place on the series using more stringent restrictions, reflecting the fact that extreme growth rates are more anomalous in larger cells. In particular, we compute the weight on the cell for county $c$, industry $i$, firm size $s$, and wage quartile $q$ as:

$$
\begin{aligned}
& \text { Weight }_{c, i, s, q}=\max \left\{1-\mathbf{1}\left\{\text { Min Normed } \mathrm{July}_{c, i, s, q} \leq 50\right\} \times\left(50-\text { Min Normed } \mathrm{July}_{c, i, s, q}\right) \times 0.02\right. \\
& -\mathbf{1}\{\text { Max Normed January } \text { N }, i, s, q \geq 600\} \times\left(\text { Max Normed January }{ }_{c, i, s, q}-600\right) \times 0.005, \\
& 0\}
\end{aligned}
$$

That is, we reduce the weight we place on the cell by two percentage points for each percentage point of decline we observe below 50 percentage points relative to July 2020. We further reduce the weight by 0.5 percentage points for each percentage point of growth we observe above 600 percentage points relative to January 2020. 
In addition, we address the especially concentrated entry and exit of firms from the sample at the end of each calendar year, where there is significant churn as firms renew their payroll processing contracts. Due to this seasonal pattern, the raw Paychex data display a downwards trend in employment at the end of each calendar year as some clients leave Paychex, followed by an upward trend in employment at the very beginning of each calendar year as new clients join. To avoid this source of error, we adjust for the end-of-year pattern in the Paychex data using data from the end of 2019. For each date between November 152020 and January 10 2021, using Paychex data on employment at the national level, we compute the change in employment relative to November 152020 at the two-digit NAICS code $\mathrm{x}$ wage quartile level. We also compute the change in employment between the corresponding day in the previous year and November 152019 . We divide the change in employment relative to November 152020 by the corresponding change in employment the previous year relative to November 15 2019. To avoid a break in the series at January 10, we adjust the series from January 10 onwards using the adjusted level on January 10 and the unadjusted trend from January 10. We repeat this end-of-year adjustment during each subsequent year. We then apply the same adjustment to each two-digit NAICS code $\mathrm{x}$ wage quartile cell at the state, county and city levels.

Adjusting for minimum wage changes. Finally, we address mismeasurement of the change in employment in the first and second wage quartiles due to minimum wage increases in California, Massachusetts, and New York during our period of study. By increasing the minimum wage above the threshold between the first and second wage quartiles at the end of 2020 or start of 2021, these states mechanically shift workers out of the first wage quartile into the second wage quartile, leading to spurious changes in the quartile-specific series. ${ }^{39}$ To address this issue, we make the following adjustments. We begin by calculating the percentage change in the number of employees in each state $\mathrm{x}$ industry (2-digit NAICS) cell from December 42020 onwards for the first two wage quartiles combined. From December 42020 onwards, for the first two wage quartiles in minimum wage change states, we impute the trend in each county $\mathrm{x}$ industry $\mathrm{x}$ wage quartile cell using the below-median income employment trend in their own state $\mathrm{x}$ industry cell. Since employment in the first wage quartile recovered less than employment in the second wage quartile in 2021, an imputation that aggregates the trends in the first and second wage quartiles tends to overstate the recovery in the first quartile and understate the recovery in the second quartile. As such, we further

\footnotetext{
${ }^{39}$ Arizona also increased its minimum wage during this period, but its minimum wage $(\$ 12.15$ in $2021 ; \$ 12.80$ in 2022 ) remained well below the threshold between the first and second wage quartiles $(\$ 13.25$ in January $2021 ; \$ 13.88$ in January 2022), so we do not adjust the employment series for this state.
} 
rescale the state $\mathrm{x}$ industry below-median income trend separately for each wage quartile, using the coefficient from the regression of that quartile's employment change on the below-median income employment change in non-minimum wage-change states without a constant between December 4 2020 and December 3 2021. We then aggregate the adjusted employment counts to the relevant geographies (e.g. state; national) before calculating the change in employment since January 2020.

\section{Paychex and Intuit: Combined Employment Series}

We combine Paychex and Intuit data to construct our primary employment series. Our data sharing agreements requires us to produce combined estimates in our public releases of employment data.

Imputing local composition of Intuit data. Because Paychex is disaggregated by sector and covers all sectors and wage levels fairly comprehensively, we use it as the base for the combined employment series. We then use Intuit to refine the series in cells represented by those datasets. Intuit provides us with overall national industry shares as of 2019, but does not disaggregate the monthly employment data we receive by wage level or industry. We therefore impute the Intuit data to wage-industry cells before combining it with the Paychex data. To do so, we assume that any differences in employment between Intuit and Paychex are constant (in percentage terms, relative to the January baseline) by industry and wage quartiles within a given geography and month. For each date, we impute the number of Intuit employees in a given geography $\mathrm{x}$ industry $\mathrm{x}$ wage quartile cell as the number of Paychex employees in that cell reweighted by the national Intuit industry distribution. We then weight the geography-level changes in employment in the Intuit data by the imputed number of employees in its geography $\mathrm{x}$ industry $\mathrm{x}$ wage quartile cell.

Combining Paychex and Intuit data. We take a weighted average of the Paychex data and the imputed Intuit data to compute the final combined series. We place the majority of the weight on Paychex, with greater weight on Intuit in sectors where it has greater coverage; the exact weights are undisclosed to protect privacy. We report seven-day moving averages of these series, expressed as a percentage change relative to January 4-31.

\section{Earnin}

Sample Restrictions. We restrict the sample to workers who are active Earnin users, with nonmissing earnings and hours worked over the last 28 days. Next, we exclude workers whose reported income over the prior 28 days is greater than $\$ 50,000 / 13$ (corresponding to an income of greater than $\$ 50,000$ annually). We then restrict the sample to workers who are in paid employment. 
Users may continue to use Earnin after they have been laid off; we exclude payments which Earnin classifies as unemployment payments, either based on the user's registration with Earnin as being unemployed, or based on the string description of the transaction.

Finally, we omit the first and last 32 weeks of data for each user from our analysis to mitigate non-random entry and exit from the customer base. We observe that a person's probability of finding or losing a job is elevated near the time they entered or exited the sample - changes in employment likely induce people to sign up for the service or reconsider their need for the service. However, after omitting the first and last 32 weeks, the probability of a user finding or losing a job is no longer correlated with the number of weeks that elapse after entry into the sample or before exiting the sample.

Mapping paychecks to chained employment. We construct an employment series in the Earnin data from our analysis sample as follows. In the paycheck-level data, we observe the worker's paycycle frequency. As in the Paychex data, we use paycycle frequency to construct an employment series by assuming that workers are employed throughout the full duration of their paycycle. That is, we assume that a worker paid every two weeks has been fully employed for the two weeks prior to receiving their paycheck. We exclude workers with pay periods greater than 3 weeks, omitting approximately $1 \%$ of the sample. To account for the delay in receipt of paychecks, we shift the Earnin series back by one week. We then take the count of employed individuals across the Earnin sample as our measure of employment. We use that to calculate an indexed measure of weekover-week employment percentage change, for each geographic unit, indexed to their first week in the sample. Then, the average percentage change in the four weeks from January 4th, 2020 to January 31st, 2020 is set as the reference value and indexed to zero. The employment series is then expressed as a change relative to January 4-31. We suppress estimates for ZIP codes with fewer than 10 paychecks observed over this period.

\section{E.3 Masking and Publication}

In a few cases, Earnin and Intuit data do not provide coverage for a given geographical region or industry; we suppress such cells. We also suppress cells in which Paychex records fewer than 150 monthly employees in January 4-31 2020 at the geography x wage quartile or geography x industry (2-digit NAICS) x wage quartile level, depending on the series. When aggregating employment series to the geographical level without breakdowns by industry or wage quartile, however, we use data from all cells, without masking. 


\section{Comparison of Construction of Paychex and Earnin Employment Series to Cajner et al. (2020) ADP Series}

In both the Paychex and Earnin datasets, we construct daily employment series using data on paychecks. Our treatment of paycheck data is similar to the treatment of paycheck data in Cajner et al. (2020), who estimate employment based on paycheck deposits using firm-level data from ADP. Cajner et al. (2020) define employment within a week as the count of paychecks that are processed during that week. For businesses which do not process payroll every week (e.g. businesses whose workers are paid every two weeks), Cajner et al. (2020) impute the count of paychecks in the "missing" week using the number of paychecks in the next period in which the businesses processes payroll. Because the Earnin data are available at the worker level, we do not observe whether a business as a whole does not process payroll every week. However, under the assumption that all workers within a business are paid on the same paycycle, our worker-level approach of distributing paychecks uniformly over the paycycle matches the approach in Cajner et al. (2020) of imputing employment based on the next week in which paychecks are observed. The two primary differences between our treatment of paycycles and the treatment in Cajner et al. (2020) are that we use a 7-day moving average, whereas Cajner et al. (2020) use a 14-day moving average, and that we treat that the last date of the employment period as seven days prior to the receipt of the paycheck, whereas Cajner et al. (2020) observe the pay period directly. The seven-day lag accounts for delays between the end of a worker's pay period, which is the event observed in Cajner et al. (2020), and the date on which paychecks are received by workers, which is the event observed in the Earnin data.

Because the Paychex data are not available at the firm level, we are not able to directly implement the approach in Cajner et al. (2020) of imputing employment using the count of paychecks in the "missing" week for firms that do not process payroll on a weekly basis. Instead, we make the conceptually similar assumption that workers are employed throughout the full duration of their paycycle, such that we can infer the full set of dates on which an individual worked by observing the last date of each of their pay periods and their pay frequency. Under the assumptions that all workers within a given firm are paid according to the same paycycle, our approach of inferring employment based on last date of pay period matches the approach in Cajner et al. (2020) of imputing employment based on the next week in which paychecks are observed. A further difference is that pay period is observed in Cajner et al. (2020); by contrast, in the Paychex data, pay periods are imputed using payroll processing date and the distribution of (payroll processing date - last date 
in pay period). Finally, Cajner et al. (2020) use a 14-day moving average, whereas we use a 7-day moving average.

\section{E.4 Accounting for Low-Wage Employment Changes due to Wage Growth}

To calculate the share of low-wage employment changes due to wage growth, we decompose the level of the bottom-quartile-wage series from Figure 5A at the end of December 2021 into the part explained by real wage growth and not. We perform this decomposition by estimating ventile-specific wage growth rates in the CPS, calculated as the month-to-month change in ventiles, reweighting each monthly CPS sample to hold constant the distribution of industry, occupation, race, gender, age, education, region, and citizenship. This follows the procedure in Gould and Kandra (2022). Under the assumption that all remaining wage changes within these buckets reflect wage growth rather than changes in the nature of the jobs themselves, this procedure will estimate wage growth at each ventile of the wage distribution. There were extreme movements into and out of the labor force between January and July 2020, for which the reweighting may not adjust correctly. We thus employ our estimation procedure to estimate wage growth only over the period July 2020 - December 2021. We impute wage growth rates between January and July 2020 using a 2.9\% annualized wage growth rate (which prevailed between January 2019 and December 2019). Grigsby et al. (2021) suggest that this is likely an upper bound on the wage growth actually experienced during the early months of the pandemic, so that our overall wage growth adjustment will also be an upper bound on the changes in bottom-wage-quartile employment explained by wage growth.

With ventile-specific wage growth rates in hand, we then adjust the distribution of wages in the January 2020 CPS and recalculate total employment below the bottom-quartile-wage threshold for December 2021 (\$13.79). We additionally add uniform noise between [-\$0.50,\$0.50] to whole number wages to smooth out spikes in the wage distribution at whole numbers, to mirror our treatment of these integer-wage spikes in the Paychex data (see Section II.B.4 for more details on this issue). Bottom-quartile-wage employment falls in this counterfactual by $13.5 \mathrm{pp}$, reflecting the decline not explained by real wage growth; the remaining $7.7 \mathrm{pp}$ deficit in December 2021 is the share explained by real wage growth.

\section{E.5 Benchmarking}

Comparisons to QCEW and OES. Appendix Table 3 compares industry shares in each of the data sources above to nationally representative statistics from the Quarterly Census of Employment 
and Wages (QCEW). The Paychex-Intuit combined sample and the Earnin sample are broadly representative of the U.S. industry mix. Appendix Table 4 shows that wage rates in our data sources are similar to nationally representative statistics from the BLS's Occupational Employment Statistics. Overall, our combined datasets appear to provide a representative portrait of private non-farm employment in the United States.

\section{F Unemployment Claims Series Construction}

\section{F.1 Structure of Initial Data}

We collect state-level unemployment initial claims data from the Department of Labor, Employment and Training Administration public data. We additionally collect data on state-level PUA, PUEC and continued claims from the Bureau of Labor Statistics public data. Finally, we gather countylevel unemployment claims data from 22 state agencies who publish their state's data in various online formats, which we scrape and transform into a standard format.

\section{F.2 Internal Data Processing \\ Harmonizing weekly and monthly estimates}

In some cases, states only publish county-level data at the monthly frequency. In order to align with the weekly series of most UI data we collect, we impute the weekly values by assigning the county-level monthly total to each week within the month the monthly values using the state-level distribution of the weekly claims within the month, as published by the Department of Labor. This imputation implicitly assumes that each county within the state had the same relative distribution of UI claims within the month.

\section{F.3 Masking and Publication}

We apply no further masking beyond any masking applied by state and national agencies.

\section{G COVID-19 Infections and Vaccinations Series Construction}

\section{G.1 Structure of Initial Data}

We collect publicly available data on cases and deaths reported by the New York Times, publicly available data on hospitalizations from COVID-19 from the U.S. Department of Health and Human Services, publicly available data on the number of vaccine doses administered from the Centers for 
Disease Control and Prevention, and publicly available data on the number of COVID-19 tests from Johns Hopkins University.

\section{G.2 Internal Data Processing}

\section{Reducing the influence of outliers}

We manually review any spikes in cases, tests, or deaths that are larger than $25 \%$. If news reports suggest that the spike is a reporting artifact, we smooth the data by imputing a value for the day of the spike using the growth rate in the outcome on the prior day.

\section{G.3 Masking and Publication}

We apply no further masking beyond any masking applied by state and national agencies.

\section{H Time Outside Home Series Construction}

\section{H.1 Structure of Initial Data}

We collect publicly available data on changes in time spent at various locations from Google's COVID-19 Community Mobility Reports to construct measures of daily time spent at parks, retail and recreation, grocery, transit locations, and workplaces. Additionally we collect publicly available time use data from the American Time Use Survey.

\section{H.2 Internal Data Processing}

Generating measures of time at home and away from home We use the American Time Use Survey to measure the mean time spent inside the home (excluding time asleep) and outside the home in January 2018 for each day of the week. We combine the data on time spent in and outside the home with Google's data on changes in time spent at and away from home. To do so we multiply the time spent inside home in January with Google's percent change in time spent at residential locations to get an estimate of time spent inside the home for each date. The remainder of waking hours in the day provides an estimate for time spent outside the home.

\section{H.3 Masking and Publication}

Google does not release data for geographies where their internal quality and privacy thresholds are not met. 


\section{Educational Progress Data}

Zearn is a non-profit math curriculum publisher that combines in-person instruction with digital lessons. Zearn was used by approximately 925,000 students in the U.S. in Spring 2020. Many schools continued to use Zearn as part of their math curriculum after COVID-19 induced schools to shift to remote learning. We use data from Zearn to measure educational progress during the pandemic.

\section{I.1 Structure of Initial Data}

We receive data from Zearn on the number of students using Zearn Math and student progress in Zearn Math as measured by the number of lessons completed by students in a given week for a given school.

\section{I.2 Internal Data Processing}

\section{Reducing the effects of transitory outliers on the series}

To reduce the effects of transitory outliers, we replace the value of any week for a given school that reflects a $50 \%$ decrease (increase) greater than the week before or after it with the mean value for the three relevant weeks.

\section{Accounting for missing values}

If a school is actively using Zearn at any point in a given semester, then for any week where we observe no reported values for both the number of students using Zearn Math and for student progress in Zearn Math, we impute these missing values as zeros.

\section{I.3 Masking and Publication}

The data we obtain are masked such that any county with fewer than two districts, fewer than three schools, or fewer than 50 students on average using Zearn Math during the preperiod of January 6 2020 to February 72020 is excluded. We fill in these masked county statistics with the commuting zone mean whenever possible. We winsorize values reflecting an increase of greater than $300 \%$ at the school level. We exclude schools which did not have at least 5 students using Zearn Math for at least one week during January 62020 to February 7 2020. After taking these steps, we aggregate to the county, state, and national level, in each case weighting by the average number of students using the platform at each school during the base period of January 6-February 7 2020, and we normalize relative to this base period to construct the indices we report. 


\section{I.4 Representativeness of Zearn Data}

We assess the representativeness of the Zearn data in Appendix Table 8 by comparing the demographic characteristics of the schools for which we obtain Zearn data (based on the ZIP codes in which they are located) to the demographic characteristics of K-12 students in the U.S. as a whole, as measured in the American Community Survey. The distribution of income, education, and race and ethnicity of the schools in the Zearn sample is similar to that in the U.S. as a whole, suggesting that Zearn provides a representative picture of online learning for students in the U.S.

\section{J Dates and Geographic Definitions}

In this appendix, we provide additional details about how we define key dates and geographic units used in our analysis.

Key Dates for COVID-19 Crisis. The Economic Tracker includes information about key dates relevant for understanding the impacts of the COVID-19 crisis. At the national level, we focus on three key dates:

- First U.S. COVID-19 Case: 1/20/2020

- National Emergency Declared: 3/13/2020

- CARES Act Signed in to Law: 3/27/2020

At the state level we collect information on the following events:

- Schools closed statewide: Sourced from COVID-19 Impact: School Status Updates by MCH Strategic Data, available here. Compiled from public federal, state and local school information and media updates.

- Nonessential businesses closed: Sourced from the Institute for Health Metrics and Evaluation state-level data (available here), who define a non-essential business closure order as: "Only locally defined 'essential services' are in operation. Typically, this results in closure of public spaces such as stadiums, cinemas, shopping malls, museums, and playgrounds. It also includes restrictions on bars and restaurants (they may provide take-away and delivery services only), closure of general retail stores, and services (like nail salons, hair salons, and barber shops) where appropriate social distancing measures are not practical. There is an enforceable consequence for non-compliance such as fines or prosecution." 
- Stay-at-home order goes into effect: Sourced and verified from the New York Times reopening data, available here, and hand-collection from local news and government sources where needed.

- Stay-at-home order ends: Sourced and verified from the New York Times reopening data, available here, and hand-collection from local news and government sources where needed. Defined as the date at which the state government lifted or eased executive action or other policies instructing residents to stay home. We code "regional" and "statewide" expiry of stay-at-home orders separately. A "regional" expiration of a stay-at-home orders occurs when a stay-at-home order expires in one region within a state, but not everywhere within the state. A "statewide" expiration of a stay-at-home order occurs when a stay-at-home order first expired throughout a whole state, either due to a statewide change in policy, or due to the stay-at-home order in each county having expired.

- Partial business reopening: Sourced and verified from the New York Times reopening data, available here, and hand-collection from local news and government sources where needed. Defined as the date at which the state government allowed the first set of major industries to reopen (non-essential retail or manufacturing in nearly every case). Deviations from the New York Times reopening data are deliberate and usually involve our regional classification or our inclusion of manufacturing. A "regional" reopening occurs when businesses are allowed to reopen in one region within a state, but not everywhere within the state. A "statewide" reopening occurs when businesses are allowed to reopen throughout a whole state, either due to a statewide change in policy, or due to restrictions being eased in each individual county.

Geographic Definitions. For many of the series we convert from counties to metros and ZIP codes to counties. We use the HUD-USPS ZIP code Crosswalk Files to convert from ZIP code to county. When a ZIP code corresponds to multiple counties, we assign the entity to the county with the highest business ratio, as defined by HUD-USPS ZIP Crosswalk. We generate metro values for a selection of large cities using a custom metro-county crosswalk, available in Appendix Table 9. We assigned metros to counties and ensured that a significant portion of the county population was in the metro of interest. Some large metros share a county, in this case the smaller metro was subsumed into the larger metro. We use the Uniform Data Systems (UDS) Mapper to crosswalk from ZIP codes to ZCTAs. 


\section{K Analysis of Economic Impact Payments}

This appendix presents technical details for our analysis of the effects of the three rounds of economic impact (i.e., "stimulus") payments on consumer spending.

\section{K.1 Construction of the Data}

In order to prepare the spending data for analysis of the stimulus, we first aggregate the raw data to calculate total card spending on each date, in each ZIP code income quartile. See Section II.B.1 and Appendix B for more details on the source of the consumer spending series. Note that unlike in our baseline spending series, we use total spending (thereby including both intensive margin changes

in spending per card and extensive margin changes in the number of cards) to ensure consistency in comparisons of our estimates across different stimulus rounds.

We then index spending in each ZIP Code income quartile relative to spending between January 4-31 2019. We include data from January 2020 in the "control" series, normed to January 2019, for the purpose of estimating the effects of the 2nd stimulus in January 2021.

We residualize indexed spending in each ZIP Code income quartile with respect to day-of-week fixed effects calculated using 2019 data. For the April 2020 and March 2021 stimulus payments, we further residualize spending with respect to a linear pre-trend estimated in the pre-period data pooled across income quartiles; this procedure adjusts for economic trends related to the pandemic that differ from the prior year (and thus remain in the indexed data). We do not adjust for a linear pre-trend for the January 2021 stimulus payment due to the omission of the holiday period immediately before the stimulus payments.

Figure 7 plots these data, differenced treatment minus control for each day relative to the stimulus events. Appendix Figure 21 depicts analogous plots without adjusting for pre-trends in any of the three stimulus payment periods. As discussed in Section IV.A, our analysis yields similar conclusions regardless of the linear adjustment for pre-trends.

\section{K.2 Calculation of Effects of Stimulus Payments on Consumer Spending}

We estimate the effects of each stimulus payment on indexed consumer spending using a differencein-difference approach (Appendix Table 6). To capture the non-linear dynamics evident in the non-parametric figure, we estimate separate treatment effects for the first five days (Column 1) and from the 6th day onwards (Column 2). This window runs through the 25 th day for the stimulus payments in April 2020 and March 2021, and through the 16th day for the stimulus payment in 
January 2021 (reflecting the data available at the time of our "real-time estimate"). Finally, we sum these effects to estimate the causal effect of the stimulus on spending the month after checks were sent out, under the identification assumption that daily trends in spending in 2020 would have matched those in 2019 (up to a linear difference in pre-trends for the first and third stimulus). We convert these estimates into a projected "first month" effect, measured in percentage points of baseline spending levels, by assuming the daily estimate from the second treatment coefficient within each stimulus continues through the 31st day (Column 3).

\section{K.3 Calculating Spending Changes per Check Recipient}

We map percentage point increases in spending into dollars per $\$ 1,200$ check in three steps.

First, we translate the percentage point impact estimated from our difference-in-difference model $(\beta)$ into the total additional dollars of spending by scaling using the baseline spending levels from January 2019 (to calculate total extra spending in the Affinity data) and then scaling that value up to match total national spending using information for PCE from the NIPA tables, following the method described in Appendix Figure 5. We report these effects in dollar terms in Appendix Table 6, Column 4. Denote this rescaled total dollar effect for each ZIP income quartile as $\tilde{\beta}$.

Second, we calculate the total amount of stimulus dollars for which residents of each ZIP-income quartile were eligible $(S)$, which is the number of households in each set of ZIP Codes times the eligibility rate. We calculate the number of households by household-type $\mathrm{x}$ income bin $\mathrm{x}$ ZIP Code income quartile from the ACS 2014-2018, where household-type is the combination of single vs. married and number of children. We use total reported income in the ACS as a proxy for adjusted gross income (AGI), which determines eligibility for stimulus payments. We assume that mean household size is constant across income bins within each ZIP Code for each household type (i.e. we assume the mean household size of married and unmarried households does not vary by income). This assumption permits us to combine these datasets to calculate the number of people in each income bin $\mathrm{x}$ household-type $\mathrm{x}$ ZIP Code income quartile.

We then calculate the eligibility rate at the ZIP Code level in three steps: (A) computing the share of people in single households who are eligible for stimulus payments; (B) computing the share of people in joint-filing households who are eligible for stimulus payments; and (C) combining these estimates using data on marriage rates to create overall ZIP Code-level eligibility rates. We assign fractional eligiblity rates to reflect partial payments; for instance, a single household with no children eligible for a $\$ 600$ check during the first stimulus (which paid $\$ 1,200$ checks) would be 
assigned an eligibility rate of $50 \%$.

(A) Eligibility among single households. Single households with incomes below $\$ 75,000$ were eligible to receive the full stimulus amount. The precise structure of payments depends on the number of children within the household; for simplicity, we use the structure of payments for families without children for all families. In practice, since high-income households with children faced more lenient eligibility requirements than we assume, our estimates represent an upper bound for consumption per stimulus recipient. The most granular income bins available in the ACS 20142018 data at a ZIP Code level do not disaggregate between households earning $\$ 75,000-\$ 99,999$. Under the assumption that incomes are uniformly distributed within each ZIP Code $\mathrm{x}$ income bin, we assign an eligibility rate of $25 \%$ for these households.

(B) Eligibility among married households. We treat married households as joint-filers. Married households with incomes below $\$ 150,000$ were eligible to receive the full stimulus amount. As above, we do not account for the effects of number of children within the household on phase-out; instead, we assume that stimulus payments were phased out for households earning over $\$ 150,000$ at a rate of $\$ 5$ per person per $\$ 100$ increment over $\$ 150,000$, with payments fully phased out at household incomes over $\$ 174,000(\$ 198,000)$ for the January 2021 (April 2020) round of stimulus payments. The most granular income bins available in the ACS 2014-2018 data at a ZIP Code level do not disaggregate between households earning $\$ 150,000-\$ 199,999$ together. Under the assumption that incomes are uniformly distributed within each ZIP Code x income bin, we assign an eligibility rate of $25 \%$ for these households.

(C) ZIP Code-level eligibility rates. Steps (1) and (2) allow us to assign eligibility rates to each income bin $\mathrm{x}$ ZIP Code $\mathrm{x}$ household type (i.e. single vs. married). We then turn to calculating the composition of household types within each income bin. To do so, we first regress marriage rates on median household income at the ZIP Code level, weighting by population; we assume the ZIP Code-level relationship between marriage rates and household income approximates the individuallevel relationship between marriage rates and household income. We then assign a marriage rate equal to the fitted value of marriage rates at the midpoint of each household income bin. This allows us to estimate eligibility rates within each ZIP Code x income bin. Finally, we calculate a population-weighted mean eligibility rate within each ZIP Code income quartile. After that, we multiply this rate by $\$ 1,200$ and by the population within each ZIP Code income quartile to calculate total expected stimulus spending in each ZIP Code income quartile.

Third, we adjust for the actual fraction of stimulus checks paid during the treatment period 
$(f)$. To do so, we calculate the share of the stimulus payments distributed by the first week of the treatment period using Daily Treasury Statements. For instance, the total amount disbursed for stimulus payments under the CARES Act of April 2020 is $\$ 271.4$ billion (Internal Revenue Service 2022). We use Daily Treasury Statements to calculate that total spending on stimulus payments prior to April 21 was roughly $\$ 174$ billion. We therefore find that roughly $64 \%$ of payments had been distributed by April 21. A similar calculation for payments made under the COVID-related Tax Relief Act of 2020 yields estimates that roughly $91 \%$ of payments were distributed by January 10, and that $59 \%$ of payments made under the American Rescue Plan had occurred by March 23, 2021. We assume that these rates are constant across ZIP Code income quartiles; it is possible that this fraction is higher for higher income households, due to the larger number of low-income households without bank information on file at the IRS, in which case we would overestimate the total stimulus payments in the lowest ZIP Code income quartile, leading to an underestimate of the amount spent per recipient for these households.

Combining these three steps, our final estimate of the dollars spent per $\$ 1,200$ received is $\frac{\$ 1,200 \cdot \tilde{\beta}}{S \cdot f}$. These estimates are reported in Figure 8 and Appendix Table 6, Column 5.

\section{Supplemental Policy Analyses}

\section{L.1 State-Ordered Reopenings}

Many states enacted stay-at-home orders and shutdowns of businesses in an effort to limit the spread of COVID infection and later reopened their economies by removing these restrictions. We examine how these executive orders affected economic activity by exploiting variation across states in the timing of shutdowns and reopenings.

Throughout this section, we define the reopening date to be the day that a state began the reopening process (see Appendix $\mathrm{J}$ for details). In most states, reopening was a gradual process in which certain industries and types of businesses opened before others, but there was a lot of heterogeneity across states in the precise form that the reopening took. Our estimates should therefore be viewed as an assessment of the average impact of typical reopening efforts on aggregate economic activity; we defer a more detailed analysis of how different types of reopenings affected different sectors (which can be undertaken with the data we have made publicly available) to future work.

We begin with a case study comparing Colorado and New Mexico that is representative of our broader findings. These two states both issued stay-at-home orders during the final week of 
March (New Mexico on March 24, Colorado on March 26). Colorado then partially reopened its economy, permitting retail and personal service businesses to open to the public, on May 1, while New Mexico did not reopen until two weeks later, on May 16. Appendix Figure 26A plots consumer spending (using the Affinity Solutions data) in Colorado and New Mexico. Spending evolved nearly identically in these two states: in particular, there is no evidence that the earlier reopening in Colorado boosted spending during the two intervening weeks before New Mexico reopened.

Appendix Figure 26B generalizes the case study in Appendix Figure 26A by studying partial reopenings in the five states that issued such orders on or before April 27. For each reopening date (of which there are three: April 20, 24, and 27), we compare the trajectory of spending in treated states to a group of control states that had not reopened at the time that the treated state reopened. We select at least three control states (listed in Appendix Table 10) for each of the reopening dates by matching on pre-period levels of spending (relative to January) during the three weeks prior to reopening. We then calculate unweighted means of the outcome variables in the control and treatment states to construct the two series for each reopening date. Finally, we pool these three event studies together (redefining calendar time as time relative to the reopening date) to create Appendix Figure 26B.

As in the case study of Colorado vs. New Mexico, the trajectories of spending in the treated states almost exactly mirror those in the control states. We formalize the estimate from this design using a difference-in-differences (DD) design that compares the two weeks before the reopening in the treated states and two weeks after. We estimate that reopenings led to a 1.22 percentage point increase in spending. This DD estimate also appears in Appendix Table 11, Column 1. Column 2 replicates that specification, but focuses on reopenings where we can go out three weeks after the event before control states begin to reopen; the DD estimate is unchanged with this wider window, at 1.71 percentage points. Appendix Figure 26B shows that we also find little impact of reopenings on employment (using the Paychex-Intuit data). Finally, Appendix Figure 26B also shows (using data from Womply) that there was a 3.45 percentage point increase in the fraction of small businesses open after states allowed businesses to reopen - confirming that state orders did have some mechanical impact on the fraction of businesses that were open. However, this mechanical effect does not appear to translate to noticeable impacts on total employment or spending.

In line with these small treatment effect estimates, reopenings accounted for a relatively small share of the overall variation in economic conditions across states. To demonstrate this, we first 
calculate the actual variance in spending levels and other outcomes across states. We then counterfactually add our estimated effect of reopening to all states that were not yet open as of May 18, and recalculate the variance. Appendix Figure 26C then plots 1 minus the ratio of the counterfactual variance to the actual variance, which is a measure of the importance of early reopenings in explaining the variation in economic activity observed on May 18. These ratios are very low, showing that early reopenings did not play an important role in explaining why some states had stronger employment trajectories than others. ${ }^{40}$ These results are consistent with the findings of other contemporaneous studies showing that little of the state-level variation in employment, job vacancies, or time spent outside home is related to state-level stay-at-home orders or business closures (Bartik et al. 2020, Forsythe et al. 2020, Goolsbee and Syverson 2021, Lin and Meissner 2020, Villas-Boas et al. 2020).

Why did these reopenings have so little immediate impact on economic activity? The evidence in Section III suggests that health concerns among consumers were the primary driver of the sharp decline in economic activity in March and April. Consistent with that evidence, spending fell sharply in most states before formal state closures (Appendix Figure 27). If individuals' own health concerns are the core driver of reductions in spending during pandemics, governments may have limited capacity to mechanically restore economic activity through reopenings if those reopenings are not interpreted by consumers as a signal of reduced health risks. ${ }^{41}$

\section{L.2 Paycheck Protection Program: Loans to Small Businesses}

The Paycheck Protection Program (PPP) sought to reduce employment losses by providing financial support to small businesses. Congress appropriated nearly $\$ 350$ billion for loans to small businesses in an initial tranche paid beginning on April 3, followed by another $\$ 175$ billion in a second round beginning on April 27. The program offered loan forgiveness for businesses that maintained sufficiently high employment (relative to pre-crisis levels).

According to the House Committee on Small Business (2020), the stated primary purpose of the PPP was to encourage businesses to maintain employment even as they lost revenue. The Small Business Administration (2020) emphasized the employment impacts of the PPP as a key

\footnotetext{
${ }^{40}$ We emphasize that these results apply to average employment rates and are thus not inconsistent with evidence of modest impacts in specific subsectors, particularly at higher wage levels, as identified e.g., by Cajner et al. (2020).

${ }^{41}$ In this vein, we stress that our research design only identifies the impacts of individual states opening earlier vs. later; if one state's actions impact behavior in other states (e.g., by shaping perceptions about health risks), the total impacts of shutdowns or reopenings at a national level could be larger. Moreover, these conclusions only apply to the initial stages of the pandemic that we study here. If health concerns diminish over time (e.g., due to quarantine fatigue), government restrictions could have larger effects on economic activity.
} 
measure of the program's success, noting that the PPP "ensure[d] that over approximately 50 million hardworking Americans stay[ed] connected to their jobs" based on self-reports of the number of jobs retained by firms that received PPP assistance.

Here, we study the marginal impacts of the PPP on employment directly using payroll data from Paychex and Earnin, exploiting the fact that eligibility for the PPP depended on business size. Firms with fewer than 500 employees before the COVID crisis qualified for PPP loans, while those with more than 500 employees generally did not. One important exception to this rule was the food services industry, which was treated differently because of the prevalence of franchises. We therefore omit the food services sector from the analysis that follows. ${ }^{42}$

We estimate the causal effect of the PPP on employment rates at small businesses using a difference-in-differences research design, comparing trends in employment for firms below the 500 employee cutoff (the treated group) vs. those above the 500 employee cutoff (the control group) before vs. after April 3, when the PPP program began. ${ }^{43}$ We do not condition on firm survival and simply count the total number of employees still working in each week at firms that initially had more than 500 vs. less than 500 employees. Our estimates thus take both the intensive (reductions in employees for surviving firms) and extensive (firm closure) margins into account.

Appendix Figure 28A plots the average change in employment rates (inferred from payroll deposits) relative to January for firms employing 100-500 employees, which were eligible for PPP loans, vs. firms employing 501-800 employees, which were generally ineligible for PPP loans combining data from Paychex and Earnin. ${ }^{44}$ To adjust for the fact that industry composition varies across firms of different sizes, we reweight by two-digit NAICS code so that the distribution of industries in the below-500 and above-500 employee groups match the overall distribution of industries in January 2020 when computing mean employment rates by firm size. We also residualize employment rates by county $\mathrm{x}$ wage quartile $\mathrm{x}$ week fixed effects, to account for the differential time patterns of employment rates by county and wage quartile shown in Section III.C.

Before April 3, trends in employment were similar among eligible vs. ineligible firms, showing

\footnotetext{
${ }^{42}$ According to SBA data on PPP receipt throughout the life of the program, $10.5 \%$ of total PPP loan volume ( $7.1 \%$ of the total number of loans) was disbursed to firms in the food services sector (NAICS 72). The remaining exceptions to this rule affect relatively few workers: omitting food services, more than $90 \%$ of employees work at firms that face the 500 employee threshold for eligibility.

${ }^{43}$ Firms with more than 500 employees were still eligible for the Employee Retention Credit (ERC), which gave all firms that lost more than $50 \%$ of their revenue a tax credit worth up to $\$ 5,000$ per employee if they did not take up the PPP. While data on ERC takeup are unavailable, fewer than $10 \%$ of CFOs of large firms report revenue losses larger than 25\% (PwC 2020), suggesting that the vast majority of firms with more than 500 employees were not eligible for the ERC and hence serve as a valid counterfactual for employment in the absence of government assistance.

${ }^{44}$ We report estimates pooling Paychex and Earnin because our data use agreements do not permit us to report results based solely on Paychex data, and Intuit does not have coverage around the 500 employee cutoff.
} 
that larger businesses provide a good counterfactual for employment trends one would have observed in smaller firms absent the PPP program (conditional on the reweighting and controls described above). After April 3, employment continued to follow a similar trajectory in the treated $(<500$ employees) and control (>500 employees) groups, with at most a relative increase of $2 \mathrm{pp}$ in the treated group until August, after which employment rates in the two groups are essentially identical again. These findings imply that the PPP program had little marginal impact on employment at small businesses under the identification assumption that employment trends in the two groups would have remained similar absent the PPP.

Appendix Figure 28B plots the change in employment from January 4-January 31 to June 1June 23 by firm size bin. The decline in employment is quite similar across firm sizes, and is not markedly smaller for firms below the 500 employee eligibility threshold. ${ }^{45}$

In Appendix Table 12, we quantify the impacts of the PPP using OLS regressions of the form:

$$
\text { Emp }_{s c q i t}=\alpha_{c q t}+\delta \text { Eligible }_{s}+\gamma \text { Post-PPP }_{t}+\beta_{D D} \text { Eligible }_{s} \cdot \text { Post-PPP }_{t}+\varepsilon_{s c q i t},
$$

where $\mathrm{Emp}_{\text {scqit }}$ is the change in employment within each firm size category $s \times$ county $c \times$ wage quartile $q \times 2$-digit NAICS industry $i$ on week $t$ cell, relative to January 4-January 31, Eligible $s_{s}$ is an indicator variable for whether firm size is 500 or fewer employees in the pre-COVID period, Post-PPP ${ }_{t}$ is an indicator variable for the date being on or after 3 April 2020, and $\alpha_{c q t}$ represents a county-week-wage quartile fixed effect. We estimate this regression on the sample of firms with 100-800 employees using data from March 11 to August 15. We focus on employment impacts up to August 15 because Appendix Figure 28A suggests that employment rates in the two groups converged after early August (extending the estimation window would only further reduce the estimated impacts of the PPP). We reweight by two-digit NAICS code so that the distributions of industries in the below-500 and above-500 employee groups both match the overall distribution of industries in January 2020. We cluster standard errors at the county-by-industry-by-firm-size level to permit correlation in errors across firms and over time within counties and estimate the regression using OLS, weighting by the total number of employees in the cell from January 4-31, 2020.

Column 1 presents the baseline estimate obtained from regression equation (1) of $\beta_{D D}=1.78$ $($ s.e. $=1.99)$, an estimate that matches Appendix Figure $28 \mathrm{~A}$ and is similar to that obtained in

\footnotetext{
${ }^{45}$ Because of differences in the measurement of firm sizes in our data and the SBA data used to determine PPP eligibility (see below), there is no sharp discontinuity in eligibility at the 500 cutoff. Hence, we do not interpret this plot using an RD design, but rather view it as showing that our estimates are insensitive to the bandwidth used to define the treatment and control groups in the DD analysis.
} 
confidential ADP data in contemporaneous work by Autor et al. (2022a). The mean decline in employment among firms in the control group to August 15 was $18.7 \%$, implying that the PPP saved $9.1 \%$ of the jobs that would otherwise have been lost between April and August 2020. In Column 2, we reduce the bandwidth to focus more narrowly around the 500-employee size threshold; the estimates remains statistically indistinguishable from that in Column 1. Column 3 replicates the specification in Column 1 using data from Earnin only. Estimates using the Earnin data (which apply to workers in the bottom wage quartile) are similar to our baseline estimate.

Our difference-in-differences research design identifies the causal effect of the PPP on eligible firms under the assumption that the PPP did not have a causal effect on employment at PPPineligible firms. It is possible that the PPP reduced employment at ineligible firms (relative to the no-PPP counterfactual) through an employment substitution channel: ineligible firms might have hired workers laid off from eligible firms in the absence of the PPP. In the presence of such substitution, our DD estimate would overstate the causal effect of the PPP on employment at small businesses, providing an upper bound for its partial equilibrium impact (ignoring general equilibrium effects that may have influenced consumer demand and employment at all firms).

Measurement Error in Firm Sizes. Our measures of firm size - which are based on employment levels in 2019 from Dun \& Bradstreet data for the Paychex sample and ReferenceUSA in the Earnin sample - do not correspond perfectly to the measures used by the Small Business Administration to determine PPP eligibility. Such measurement error in firm size attenuates the estimates of $\beta_{D D}$ obtained from (1) relative to the true causal effect of PPP eligibility because some of the firms classified as having more than 500 employees may have actually received PPP (and vice versa).

We estimate the degree of this attenuation bias by matching our data on firm sizes to data publicly released by the Small Business Administration (SBA) on a selected set of PPP recipients and assessing the extent to which firms are misclassified around the threshold. We restrict attention to firms receiving loans of at least $\$ 150,000$, as the names and addresses of these firms are publicly available from the SBA. We first geocode addresses recorded in SBA and ReferenceUSA-Dun \& Bradstreet data to obtain a latitude and longitude for each firm. We then compute the trigram similarities between firm names for all SBA and Dun \& Bradstreet firms within twenty-five miles of another. We then select one "match" for each PPP recipient from the Dun \& Bradstreet data for Paychex sample and ReferenceUSA for the Earnin sample, among the subset of firms within twenty-five miles. For firms with loans of above $\$ 150,000$, exact loan size is not observed; we impute loan size as the midpoint of loan range. The SBA released firm names and ZIP codes of 
PPP recipients receiving over $\$ 150,000$ in loans, which represent $72.8 \%$ of total PPP expenditure. Of the roughly 660,000 PPP recipients of these loans, we merge around $60 \%$ of firms and $62 \%$ of total expenditure to firm size data. In this matched subset, we find that mean PPP expenditure per worker is $\$ 2,303$ for firms we classify as having $100-500$ employees and $\$ 586$ per worker for firms with 500-800 employees (excluding firms in the food services industry). Given that we match only $62 \%$ of the publicly available PPP expenditure to our data and the publicly available data covers only $73 \%$ of total PPP expenditure, this implies that firms measured as having 100-500 employees in our sample received $\frac{\$ 2,303}{0.62 \times 0.73}=\$ 5,090$ of PPP assistance per worker, while firms with 500-800 employees received $\frac{\$ 586}{0.62 \times 0.73}=\$ 1,290$ in PPP assistance per worker. ${ }^{46}$ We calculate that PPP assistance to eligible firms with between 100 and 800 employees (excluding NAICS 72) is $\$ 5,092$ per worker on average. ${ }^{47}$ Hence, firms with $501-800$ workers in the ReferenceUSA-Dun $\&$ Bradstreet data (the control group) were effectively treated at an intensity of $\frac{\$ 1,290}{\$ 5,092}=25.3 \%$, whereas firms with 100-500 workers in the ReferenceUSA-Dun \& Bradstreet data (the treatment group) were treated at an intensity of $\frac{\$ 5,090}{\$ 5,092}=100 \%$. Inflating our baseline reduced-form estimates by $\frac{1}{(1-0.253)}=1.35$ yields estimates of the treatment effect of PPP eligibility adjusted for attenuation bias due to mismeasurement of firm size.

Under standard assumptions required to obtain a local average treatment effect in the presence of non-compliance - no direct effect of being classified as having more than 500 workers independent of the PPP and a monotonic treatment effect - we can estimate the LATE of the PPP on employment rates by multiplying the raw estimates reported in Appendix Table 12, Column 1 by 1.35 (Angrist, Imbens, and Rubin 1996). This gives us a final preferred point estimate for the effect of PPP eligibility on employment of 2.41 percentage points.

Costs Per Job Saved. Using Statistics of U.S. Businesses (SUSB) data, we calculate that approximately 62.4 million workers work at firms eligible for PPP assistance (53.7 million workers excluding those in the food services industry, NAICS 72). Thus $92.1 \%$ of total PPP expenditure was received by non-NAICS 72 firms. We then multiply this share by total PPP expenditure as of

\footnotetext{
${ }^{46}$ This calculation assumes that the degree of misclassification of eligibility among identifiable PPP recipients matches the degree of misclassification of eligibility in the broader ReferenceUSA sample.

${ }^{47}$ To compute this statistic, we first calculate the share of total loan amounts received by non-NAICS 72 firms in the publicly released SBA data. We begin by imputing precise loan amount as the midpoint of minimum and maximum of loan range, where precise loan amount is not released. We then calculate the share of loans in firms with firm size between 100 and 500, in NAICS codes other than NAICS 72, under the assumption that our merge rate is constant by firm size. Using this approach, we calculate that $13.1 \%$ of PPP loan spending was allocated to non-NAICS 72 firms with between 100 and 500 employees. We then rescale the total PPP expenditure to the end of June, $\$ 521$ billion, by 0.131 to arrive at an estimate of $\$ 69.22$ billion in PPP loan spending to non-NAICS 72 firms with 100-500 employees. Finally, we divide $\$ 69.22$ billion by the number of workers at non-NAICS 72 firms with 100-500 employees to arrive at an estimate of loan spending per worker.
} 
August 8 to reach an estimate of $\$ 486$ billion in non-NAICS 72 firms. Under the assumption that the PPP's effects on firms with between 100 and 500 employees were the same in percentage terms as the PPP's effects on all eligible firms, our baseline estimates in the combined Paychex-Earnin data (Appendix Table 12, Column 1), adjusted for attenuation bias, imply that the PPP saved $0.02 \times 53.6 M=1.29$ million jobs from April through August $15 .{ }^{48}$ Given a total expenditure on the PPP program of $\$ 486$ billion through August 8 (excluding firms in food services), this translates to an average cost per job saved (over the five months between April and August) of $\$ 377,000$. Even at the upper bound of the $95 \%$ confidence interval for employment impact, we estimate a cost per job saved of $\$ 119,000$.

In order to compute net costs to government per job saved, we account for the fact that a reduction in job losses decreases UI spending. We evaluate replacement rates at the mean level of earnings for workers employed at PPP-eligible firms using the statutory rates in Ganong, Noel, and Vavra (2020, Figure 3(a)), which estimates that displaced workers received roughly $120 \%$ of weekly earnings for the seventeen weeks between the beginning of our treatment period (April 3 2020) and the end of July 2020, and received roughly 40\% of weekly earnings for the following two weeks until the end of our analysis window (August 15). Computing expenditure on UI given these replacement rates and mean earnings, we find that the effect of each job saved by the PPP on UI payments was $\$ 18,350$ over our analysis period. Netting these savings our of the gross cost, we estimate a net cost to the government of $\$ 359,000$ per job saved (and $\$ 101,000$ at the upper bound of the $95 \%$ confidence interval for employment impact). For comparison, mean annual earnings for workers at PPP-eligible firms are only $\$ 45,000$.

\footnotetext{
${ }^{48}$ If the treatment effect of the PPP program on food services were the same in percentage terms as in other sectors, we estimate the PPP saved a total of 1.51 million jobs.
} 


\section{TABle 1: Association Between Rent and Changes in Business Revenue and Employment}

Panel A: Business Revenue

\begin{tabular}{ccc} 
Dep. Var.: & \multicolumn{3}{c}{$\begin{array}{c}\text { Change in Small Business Revenue (percentage points) } \\
\text { from January to April 2020 }\end{array}$} \\
\hline$(1)$ & $(2)$ & $(3)$ \\
\hline & & -13.52 \\
$(0.90)$ & $(2.21)$ & $(2.23)$ \\
& & -1.77 \\
& $\mathrm{X}$ & $(0.28)$ \\
& & $\mathrm{X}$ \\
9,917 & 9,917 & 9,848 \\
ZIP Code & ZIP Code & ZIP Code \\
\hline
\end{tabular}

Median Two-Bedroom Rent (per thousand dollars)

Log Density of

High Wage Workers

County FEs

Observations

Geographic Unit
ZIP Code
Dep. Var.: Change in Low-Wage Employment (percentage points) from January to July 2020

Median Two-Bedroom Rent (per thousand dollars)

$-4.08$

Log Density of
High Wage Workers

\section{County FEs}

937

932

County

County

Paychex \& Intuit

Paychex \& Intuit

$\mathrm{X}$

11,055

Geographic Unit

Data Source

Notes: This table presents estimates from population-weighted OLS regressions at the county and ZIP-level. We regress percentage changes in small business revenue (using Womply data) and low-wage employment (using Paychex-Intuit and Earnin data) on median two-bedroom rent (as measured in the 2014-2018 ACS). Standard errors are reported in parentheses; county-level regressions use robust standard errors and ZIP-level regressions use standard errors clustered by county. The dependent variable is in percentage point units. The dependent variable in Panel A is the average change in small business revenue measured from March 23rd to April 12th 2020, relative to January 4th to January 31st 2020. All regressions in Panel A are at the ZIP-code level. The dependent variable in Panel B is the change in low-wage employment measured from June 27th to July 31st 2020, relative to January 4th to January 31st 2020. In Panel B, Column (1) and (2) are at the county level using combined Paychex and Intuit data, while Column (3) is at the ZIP code level using Earnin data. In both panels, Column (1) shows the baseline regression without any controls: this specification corresponds to the estimated slope coefficient and standard error reported in Figure 3 (small business revenue) and Figure 4C (low-wage employment). In Panel A, Column (2) adds county fixed effects and Column (3) further adds the log of the density of high wage workers as a control (which is observed using the Census LODES for $92 \%$ of ZIP codes representing $99 \%$ of the U.S. population). In Panel B, Column (2) adds the log of the density of high wage workers as a control to the baseline county level regression, while Column (3) switches to ZIP code level data for a specification analogous to the one in Column (3) of Panel A. Data sources: Womply, Paychex, Intuit, Earnin, ACS, Census LODES. 


\section{TABle 2: Mechanisms Underlying the Persistent Reduction in Low-Wage Employment:}

Hysteresis vs. Current Conditions

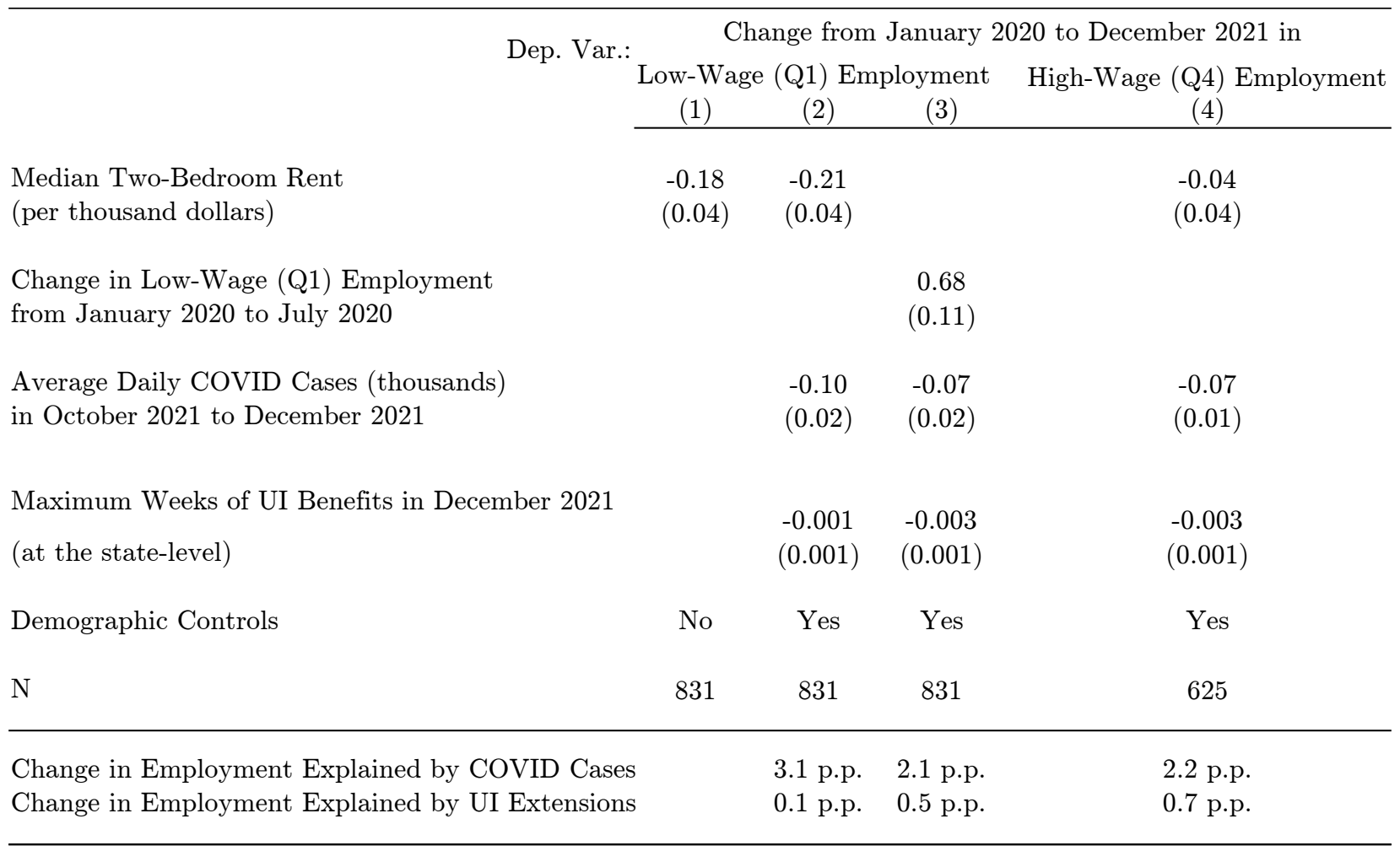

Notes: This table presents estimates for a set of population-weighted regressions examining the determinants of employment patterns in December 2021 at the county level. Robust standard errors are reported in parentheses. The sample omits California, Massachusetts, and New York due to mismeasurement of low-wage employment changes as a result of minimum wage increases; see Appendix E.2 for more information. Column (1) reports the results of regressing the change in low-wage (i.e. bottom quartile) employment from January 2020 to December 2021 against the average median two-bedroom rent (as measured in the 2014-2018 ACS) at the county level. Column (2) adds the average COVID-19 case rate in October 2021 to December 2021 (a measure of the risk of COVID exposure), the maximum number of weeks of unemployment insurance eligibility in each state, and a set of demographic controls: foreign-born population share, non-white population share, share of the population who are working age (25-54), and female population share. Column (3) repeats the specification in Column (2), replacing median two-bedroom rent with the size of the initial low-wage employment shock to each county, measured as the change in low-wage employment from January 2020 to July 2020. Column (4) repeats the specification in Column (2) using the change in high-wage (i.e. top quartile) employment from January 2020 to December 2021 as the dependent variable. The bottom two rows of the table report the change in the dependent variable explained by COVID risk exposure and UI extensions, calculated by multiplying the coefficient by the population-weighted mean of the respective variable. Data sources: Paychex, Intuit. 
Appendix Table 1: Data Sources and Processing Steps

\begin{tabular}{|c|c|c|c|}
\hline Data Series & Sources & $\begin{array}{l}\text { Description of } \\
\text { Processing }\end{array}$ & Overview of Processing Steps \\
\hline Consumer Spending & Affinity Solutions & Appendix B & $\begin{array}{l}\text { Adjust for sharp changes in the client base. } \\
\text { Adjust for gradual changes in the client } \\
\text { base. } \\
\text { Address spurious changes. } \\
\text { Control for seasonal fluctuations in } \\
\text { spending. }\end{array}$ \\
\hline $\begin{array}{l}\text { Small Business } \\
\text { Revenue and Openings }\end{array}$ & Womply & Appendix $\mathrm{C}$ & $\begin{array}{l}\text { Adjust for the evolving client base. } \\
\text { Produce the ZIP code series. } \\
\text { Reduce the influence of outliers. } \\
\text { Control for seasonality. }\end{array}$ \\
\hline Job Postings & Lightcast & Appendix D & Reduce the influence of outliers. \\
\hline Employment & $\begin{array}{l}\text { Paychex } \\
\text { Intuit } \\
\text { Earnin }\end{array}$ & Appendix E & $\begin{array}{l}\text { Paychex } \\
\text { Address anomalous spikes. } \\
\text { Adjust when quartile thresholds cross } \\
\text { integer wages. } \\
\text { Map paychecks to employment periods. } \\
\text { Adjust for an evolving client base. } \\
\text { Adjust for minimum wage changes. } \\
\text { Paychex and Intuit Combined } \\
\text { Impute local composition of Intuit data. } \\
\text { Combine Paychex and Intuit data. } \\
\text { Earnin } \\
\text { Sample Restrictions. } \\
\text { Map paychecks to chained employment. }\end{array}$ \\
\hline Unemployment Claims & $\begin{array}{c}\text { Department of Labor, } \\
\text { Employment and Training } \\
\text { Administration } \\
\text { Bureau of Labor Statistics } \\
\text { State Departments of Labor }\end{array}$ & Appendix F & Harmonize weekly and monthly estimates. \\
\hline $\begin{array}{l}\text { COVID-19 Infections } \\
\text { and Vaccinations }\end{array}$ & $\begin{array}{c}\text { Centers for Disease Control } \\
\text { and Prevention } \\
\text { New York Times } \\
\text { Johns Hopkins Coronavirus } \\
\text { Resource Center } \\
\text { U.S. Department of Health } \\
\text { and Human Services } \\
\end{array}$ & Appendix G & Reduce the influence of outliers. \\
\hline Time Outside Home & $\begin{array}{c}\text { Google COVID-19 } \\
\text { Community Mobility Reports } \\
\text { American Time Use Survey }\end{array}$ & Appendix $\mathrm{H}$ & $\begin{array}{l}\text { Generate measures of time at home and } \\
\text { away from home. }\end{array}$ \\
\hline Educational Progress & Zearn & Appendix I & $\begin{array}{l}\text { Reduce the effects of transitory outliers. } \\
\text { Account for missing values. }\end{array}$ \\
\hline
\end{tabular}

Notes: This table provides an overview of the data series constructed in this paper and published at www. tracktherecovery.org. Further details are provided in Section II and in the appendices referenced in the table. 


\section{Appendix Table 2: Distributions of Sample Sizes}

Panel A: Spending, Small Business Revenue, Job Posts, Employment

Distribution of Sample Across Local Areas

$10^{\text {th }}$ Percentile $25^{\text {th }}$ Percentile $50^{\text {th }}$ Percentile $75^{\text {th }}$ Percentile $90^{\text {th }}$ Percentile

Consumer Spending: Affinity

$\$ 19,657 \quad \$ 111,788 \quad \$ 454,612 \quad \$ 1,409,311 \quad \$ 3,750,812$

Small Business Revenue: Womply

January 2020 Revenue

County level

$\$ 774,550$

$\$ 1,994,485$

$\$ 5,543,055$

$\$ 12,800,000$

$\$ 36,000,000$

ZCTA level

$\$ 10,703$

$\$ 18,577$

$\$ 35,511$

$\$ 65,762$

$\$ 113,147$

Job Postings: Lightcast January 2020 Job Posts (County level)

34

171

1,076

4,066

11,895

Employment: Paychex-Intuit

January 2020 Jobs (County level)

549

3,146

28,390

111,533

219,660

Employment: Earnin

January 2020 Jobs

County level

ZCTA level

92

615

3,373

12,154

35,570

18

61

171

371

667

Panel B: Education

Distribution of Sample Across the Most Populous Counties

Education: Zearn (County level)

Average number of Zearn students

Share of Zearn students

Top 5

Top 10

Top 20

Top 50

Top 100

\begin{tabular}{ccccc}
14,820 & 10,190 & 7,410 & 6,790 & 3,240 \\
$8 \%$ & $11 \%$ & $16 \%$ & $22 \%$ & $35 \%$ \\
$8 \%$ & $13 \%$ & $19 \%$ & $30 \%$ & $42 \%$ \\
\hline
\end{tabular}

Notes: This table presents the distribution of cell sizes for data series we construct from private sector sources. For Affinity Solutions, we report the population-weighted percentiles of the county-level distribution of the average daily total spending during January 4-31 2019. For Womply, we report population-weighted percentiles of the countylevel and ZIP-level distributions of weekly revenue in January 4-31 2020. So, for example, the $\$ 774,550$ under the column "10th Percentile" means that the top $90 \%$ of the population lives in counties with at least $\$ 774,550$ in average weekly small business revenue in the base period. For Lightcast, we report population-weighted percentiles of the county-level distribution of average weekly job posts in January 4-31 2020. For Paychex-Intuit, we report populationweighted percentiles of the county-level distribution of employment in January 4-31 2020. For Earnin, we report population-weighted percentiles of the county-level and ZIP-level distributions of employment in January 4-31 2020. For Zearn, we report the average number of Zearn students and the share of Zearn students in the top 5; top 10; top 20; top 50; and top 100 counties by county population. We also report the share of the U.S. population in these counties for reference. Data sources: Affinity Solutions, Womply, Lightcast, Paychex, Intuit, Earnin, Zearn. 
Appendix Table 3: Industry Employment Shares Across Datasets

\begin{tabular}{|c|c|c|c|c|c|}
\hline \multirow[b]{2}{*}{$\begin{array}{l}\text { NAICS } \\
\text { Code }\end{array}$} & \multirow[b]{2}{*}{ NAICS Description } & \multicolumn{4}{|c|}{ Industry Shares (\%) } \\
\hline & & $\begin{array}{c}\text { QCEW All } \\
\text { Establishments } \\
(1)\end{array}$ & $\begin{array}{c}\text { QCEW Small } \\
\text { Establishments } \\
(2)\end{array}$ & $\begin{array}{c}\text { Paychex + Intuit } \\
(3) \\
\end{array}$ & $\begin{array}{l}\text { Earnin } \\
(4) \\
\end{array}$ \\
\hline 11 & Agriculture, Forestry, Fishing and Hunting & 0.84 & 1.04 & 0.53 & 0.18 \\
\hline 21 & Mining, Quarrying, and Oil and Gas Extraction & 0.55 & 0.43 & 0.15 & 0.21 \\
\hline 22 & Utilities & 0.44 & 0.29 & 0.13 & 0.48 \\
\hline 23 & Construction & 5.72 & 7.62 & 7.39 & 1.32 \\
\hline $31-33$ & Manufacturing & 10.27 & 5.16 & 8.05 & 6.33 \\
\hline 42 & Wholesale Trade & 4.72 & 5.99 & 5.73 & 4.45 \\
\hline $44-45$ & Retail Trade & 12.48 & 14.06 & 7.81 & 23.98 \\
\hline $48-49$ & Transportation and Warehousing & 4.3 & 2.82 & 2.04 & 5.57 \\
\hline 51 & Information & 2.29 & 1.64 & 1.45 & 4.13 \\
\hline 52 & Finance and Insurance & 4.83 & 4.6 & 3.42 & 7.53 \\
\hline 53 & Real Estate and Rental and Leasing & 1.71 & 2.9 & 3.2 & 1.94 \\
\hline 54 & Professional, Scientific, and Technical Services & 7.63 & 8.97 & 14.16 & 4.91 \\
\hline 55 & Management of Companies and Enterprises & 1.93 & 0.79 & 0.25 & 0.37 \\
\hline 56 & Administrative Support & 7.25 & 5.3 & 7.07 & 4.91 \\
\hline 61 & Educational Services & 2.39 & 1.53 & 2.36 & 3.85 \\
\hline 62 & Health Care and Social Assistance & 16.16 & 13.16 & 15.41 & 16.72 \\
\hline 71 & Arts, Entertainment, and Recreation & 1.78 & 1.64 & 1.87 & 1.57 \\
\hline 72 & Accommodation and Food Services & 11.04 & 15.6 & 9.89 & 9.2 \\
\hline 81 & Other Services (except Public Administration) & 3.57 & 6.21 & 9.09 & 2.34 \\
\hline 99 & Unclassified & 0.11 & 0.24 & & \\
\hline
\end{tabular}

Notes: This table compares the industry composition (2-digit NAICS) of two payroll-based employment datasets to the Quarterly Census of Employment and Wages (QCEW), an administrative dataset covering the near-universe of firms in the United States. Each column displays the share of employees (in percentage terms) in the given dataset who work in the specified sector. Column (1) displays the industry composition of the QCEW in the first quarter of 2020. Column (2) replicates column (1) restricting to small establishments, defined as establishments with fewer than 50 employees. Column (3) shows the industry composition of Paychex-Intuit data in January 2020. To construct Column (3), we first separately calculate the number of employees in each 2-digit NAICS code in Paychex and Intuit as the number of worker-days in each 2-digit NAICS code. We then calculate combined Paychex-Intuit employment in each 2-digit NAICS code as a weighted sum of Paychex and Intuit, where the weights are undisclosed to meet privacy protection requirements. Column (4) displays the industry composition in the Earnin data in January 2020. Data sources: Paychex, Intuit, Earnin, QCEW. 
Appendix Table 4: Hourly Wage Rates By Industry Across Datasets

\begin{tabular}{|c|c|c|c|}
\hline NAICS Code & $\begin{array}{c}\text { NAICS Description } \\
\end{array}$ & $\begin{array}{c}\text { Occupational Employment } \\
\text { Statistics (OES) } \\
(1) \\
\end{array}$ & $\begin{array}{c}\text { Paychex + Earnin } \\
(2) \\
\end{array}$ \\
\hline 11 & Agriculture, Forestry, Fishing and Hunting & $\$ 16.35$ & $\$ 20.63$ \\
\hline 21 & Mining, Quarrying, and Oil and Gas Extraction & $\$ 32.15$ & $\$ 32.89$ \\
\hline 22 & Utilities & $\$ 39.80$ & $\$ 33.18$ \\
\hline 23 & Construction & $\$ 27.87$ & $\$ 28.74$ \\
\hline $31-33$ & Manufacturing & $\$ 26.48$ & $\$ 25.44$ \\
\hline 42 & Wholesale Trade & $\$ 28.85$ & $\$ 27.34$ \\
\hline $44-45$ & Retail Trade & $\$ 17.02$ & $\$ 21.07$ \\
\hline $48-49$ & Transportation and Warehousing & $\$ 24.33$ & $\$ 24.62$ \\
\hline 51 & Information & $\$ 39.07$ & $\$ 32.78$ \\
\hline 52 & Finance and Insurance & $\$ 36.73$ & $\$ 32.82$ \\
\hline 53 & Real Estate and Rental and Leasing & $\$ 24.98$ & $\$ 25.66$ \\
\hline 54 & Professional, Scientific, and Technical Services & $\$ 41.83$ & $\$ 34.37$ \\
\hline 55 & Management of Companies and Enterprises & $\$ 42.59$ & $\$ 24.06$ \\
\hline 56 & Administrative Support & $\$ 20.50$ & $\$ 23.51$ \\
\hline 61 & Educational Services & $\$ 28.34$ & $\$ 24.78$ \\
\hline 62 & Health Care and Social Assistance & $\$ 26.98$ & $\$ 25.47$ \\
\hline 71 & Arts, Entertainment, and Recreation & $\$ 19.18$ & $\$ 22.47$ \\
\hline 72 & Accommodation and Food Services & $\$ 13.65$ & $\$ 16.62$ \\
\hline \multirow[t]{3}{*}{81} & Other Services (except Public Administration) & $\$ 21.58$ & $\$ 22.50$ \\
\hline & All & $\$ 25.72$ & $\$ 25.34$ \\
\hline & Industry-Weighted Average of BLS Mean Wages & & $\$ 26.00$ \\
\hline
\end{tabular}

Notes: This table compares mean wages in private sector datasets to mean wages in Occupational Employment Statistics (OES) data, within each two-digit NAICS code. Column (1) reports mean wages in each NAICS code in May 2019 OES data. We inflate these wages to 2020 dollars using the BLS Consumer Price Index. Column (2) reports mean wages in combined Paychex-Earnin data in January 2020. We first compute mean wages separately in Paychex and Earnin data as mean wages in January 2020, weighting by number of worker-days. In Paychex, wages are measured as pre-tax wages recorded by the employer. In Earnin, wages are post-tax wages recorded in payroll deposits. We then take a weighted mean of Paychex and Earnin wages within each industry, where the weights are not disclosed to meet business privacy requirements. The last row of Column (2) displays BLS mean wages, reweighted to match the 2-digit NAICS composition within the combined private sector dataset. Data sources: Paychex, Earnin, OES. 
Appendix Table 5: Consumer Spending on Debit and Credit Cards, by Income Quartile and Sector

\begin{tabular}{|c|c|c|c|c|}
\hline \multirow[b]{3}{*}{ Pooled Card Spending: All Income Quartiles, All Sectors } & \multirow{2}{*}{$\begin{array}{c}\text { Mean Level of Card } \\
\text { Spending Per Day } \\
(\$ \text { Billions }) \\
\text { Level as of } \\
\text { Dec } 30 \text { 2019-Jan } 262020 \\
(1) \\
\end{array}$} & \multicolumn{3}{|c|}{$\begin{array}{c}\text { Change Relative to Dec } 30 \text { 2019-Jan } 262020 \\
\text { (\$ Billions) }\end{array}$} \\
\hline & & $\begin{array}{c}\text { Change as of } \\
\text { April } 142020 \\
(2) \\
\end{array}$ & $\begin{array}{c}\text { Change as of } \\
\text { August } 142020 \\
(3) \\
\end{array}$ & $\begin{array}{c}\text { Change as of } \\
\text { December } 312021 \\
(4)\end{array}$ \\
\hline & $\$ 23.6$ & $-\$ 7.3$ & $-\$ 0.9$ & $+\$ 3.4$ \\
\hline \multicolumn{5}{|l|}{ Panel A: Card Spending, by ZIP Income Quartile } \\
\hline Bottom Quartile & $\begin{array}{c}\$ 3.5 \\
(14.9 \%)\end{array}$ & $\begin{array}{c}-\$ 0.9 \\
(11.8 \%)\end{array}$ & $\begin{array}{c}+\$ 0.1 \\
(-8.7 \%)\end{array}$ & $\begin{array}{c}+\$ 0.7 \\
(22.0 \%)\end{array}$ \\
\hline Second Quartile & $\begin{array}{c}\$ 5.3 \\
(22.3 \%)\end{array}$ & $\begin{array}{c}-\$ 1.5 \\
(20.1 \%)\end{array}$ & $\begin{array}{c}-\$ 0.1 \\
(12.0 \%)\end{array}$ & $\begin{array}{c}+\$ 0.9 \\
(26.3 \%)\end{array}$ \\
\hline Third Quartile & $\begin{array}{c}\$ 6.5 \\
(27.4 \%)\end{array}$ & $\begin{array}{l}-\$ 2.0 \\
(27.3 \%)\end{array}$ & $\begin{array}{c}-\$ 0.3 \\
(27.9 \%)\end{array}$ & $\begin{array}{c}+\$ 0.9 \\
(28.0 \%)\end{array}$ \\
\hline Top Quartile & $\begin{array}{c}\$ 8.3 \\
(35.4 \%)\end{array}$ & $\begin{array}{c}-\$ 3.0 \\
(40.8 \%)\end{array}$ & $\begin{array}{c}-\$ 0.6 \\
(68.7 \%)\end{array}$ & $\begin{array}{c}+\$ 0.8 \\
(23.7 \%)\end{array}$ \\
\hline \multicolumn{5}{|l|}{ Panel B: Card Spending, by Sector } \\
\hline Durable Goods & $\begin{array}{c}\$ 3.7 \\
(15.6 \%)\end{array}$ & $\begin{array}{l}-\$ 0.5 \\
(7.0 \%)\end{array}$ & $\begin{array}{c}+\$ 0.5 \\
(-50.1 \%)\end{array}$ & $\begin{array}{c}+\$ 0.7 \\
(21.6 \%)\end{array}$ \\
\hline Non-Durable Goods & $\begin{array}{c}\$ 7.9 \\
(33.5 \%)\end{array}$ & $\begin{array}{c}-\$ 1.5 \\
(20.4 \%)\end{array}$ & $\begin{array}{l}-\$ 0.0 \\
(4.5 \%)\end{array}$ & $\begin{array}{c}+\$ 1.9 \\
(62.2 \%)\end{array}$ \\
\hline Remote Services & $\begin{array}{c}\$ 5.4 \\
(23.1 \%)\end{array}$ & $\begin{array}{c}-\$ 1.2 \\
(15.9 \%)\end{array}$ & $\begin{array}{c}+\$ 0.3 \\
(-25.6 \%)\end{array}$ & $\begin{array}{c}+\$ 1.1 \\
(35.1 \%)\end{array}$ \\
\hline In-Person Services & $\begin{array}{c}\$ 6.5 \\
(27.7 \%)\end{array}$ & $\begin{array}{c}-\$ 4.2 \\
(56.8 \%)\end{array}$ & $\begin{array}{c}-\$ 1.8 \\
(171.2 \%)\end{array}$ & $\begin{array}{c}-\$ 0.6 \\
(-18.9 \%)\end{array}$ \\
\hline \multicolumn{5}{|l|}{ Panel C: In-Person Services Spending, by Sub-Sector } \\
\hline Hotels \& Food & $\begin{array}{c}\$ 2.9 \\
(43.7 \%)\end{array}$ & $\begin{array}{c}-\$ 1.8 \\
(42.8 \%)\end{array}$ & $\begin{array}{c}-\$ 0.7 \\
(38.5 \%)\end{array}$ & $\begin{array}{c}-\$ 0.1 \\
(11.7 \%)\end{array}$ \\
\hline Transportation & $\begin{array}{c}\$ 1.0 \\
(16.0 \%)\end{array}$ & $\begin{array}{c}-\$ 0.8 \\
(19.4 \%)\end{array}$ & $\begin{array}{c}-\$ 0.6 \\
(34.5 \%)\end{array}$ & $\begin{array}{c}-\$ 0.5 \\
(86.7 \%)\end{array}$ \\
\hline Health Care & $\begin{array}{c}\$ 1.0 \\
(15.4 \%)\end{array}$ & $\begin{array}{c}-\$ 0.6 \\
(13.8 \%)\end{array}$ & $\begin{array}{l}-\$ 0.1 \\
(6.3 \%)\end{array}$ & $\begin{array}{c}+\$ 0.1 \\
(-18.6 \%)\end{array}$ \\
\hline Recreation & $\begin{array}{c}\$ 0.6 \\
(8.9 \%)\end{array}$ & $\begin{array}{l}-\$ 0.4 \\
(9.8 \%)\end{array}$ & $\begin{array}{c}-\$ 0.2 \\
(12.5 \%)\end{array}$ & $\begin{array}{c}-\$ 0.1 \\
(11.5 \%)\end{array}$ \\
\hline Other In-Person Services & $\begin{array}{c}\$ 1.0 \\
(16.1 \%)\end{array}$ & $\begin{array}{c}-\$ 0.6 \\
(14.1 \%)\end{array}$ & $\begin{array}{c}-\$ 0.2 \\
(8.2 \%)\end{array}$ & $\begin{array}{c}-\$ 0.1 \\
(8.7 \%)\end{array}$ \\
\hline
\end{tabular}

Notes: This table presents estimates of the changes in daily national consumer spending from the pre-pandemic baseline (measured as a daily average between January 6 - February 2, 2020) to April 142020 (in Column 2), August 14 2020 (in Column 3) and December 312021 (in Column 4). We construct these estimates by combining statistics on the total daily card spending in January 2020 (categories "Furnishings and durable household equipment", "Recreational goods and vehicles", "Other durable goods", "Food and beverages purchased for off-premises consumption", "Clothing and footwear", "Gasoline and other energy goods", "Other nondurable goods", "Transportation services", "Recreation services", "Food services and accommodations", "Financial services and insurance", and "Other services" from NIPA Table 2.3.5) with our consumer spending series from Affinity Solutions. See Section II.A and Appendix B for more details on the construction of the consumer spending series. We estimate total daily spending (top row in Column 1) by dividing the NIPA monthly estimate by 31 . We estimate the levels in the remaining rows of Column 1 by multiplying the spending share estimated in the Affinity data in January 2020, by total daily spending. We estimate the changes in Columns 2-4 in each row by multiplying the level in Column 1 by the change in the relevant Affinity consumer spending series. The parentheses in each row report the share of the national spending decline (in Columns 2-4) or of the national spending total (in Column 1) accounted for by each subset. Panel A disaggregates spending by income quartile, measured at the ZIP code level using median household income from the 2014-2018 ACS. Panel $\mathrm{B}$ disaggregates spending by sector; Panel C disaggregates in-person service spending by sub-sector (see Appendix B.3 for sector and sub-sector definitions). Data sources: Affinity Solutions, NIPA. 
Appendix Table 6: Effects of Stimulus Payments on Consumer Spending

\begin{tabular}{|c|c|c|c|c|c|}
\hline & \multicolumn{5}{|c|}{ Dependent Variable: Change in Consumer Spending } \\
\hline & $\begin{array}{l}\text { First } 5 \text { Days } \\
\text { Post-Stimulus } \\
\text { (p.p. change) } \\
(1)\end{array}$ & $\begin{array}{l}\text { Days } 6 \text { to } 25 \\
\text { Post-Stimulus } \\
\text { (p.p. change) } \\
(2) \\
\end{array}$ & $\begin{array}{l}\text { Combined: } 31 \text { Days } \\
\text { Post-Stimulus } \\
\text { (p.p. change) } \\
(3) \\
\end{array}$ & $\begin{array}{c}\text { Combined: } 31 \text { Days } \\
\text { Post-Stimulus } \\
\text { (\$ change) } \\
(4) \\
\end{array}$ & $\begin{array}{c}\text { Combined: 31 Days } \\
\text { Post-Stimulus } \\
\text { (\$ change per } \$ 1200 \text { stimulus) } \\
(5) \\
\end{array}$ \\
\hline \multicolumn{6}{|c|}{ Panel A: April 2020 Stimulus Payments (Stimulus 1) } \\
\hline Income Q1: & $\begin{array}{l}19.21 \\
(6.68)\end{array}$ & $\begin{array}{l}21.75 \\
(3.32)\end{array}$ & $\begin{array}{l}21.34 \\
(3.14)\end{array}$ & $\begin{array}{l}438.17 \\
(64.39)\end{array}$ & $\begin{array}{l}438.17 \\
(64.39)\end{array}$ \\
\hline Income Q2: & $\begin{array}{l}12.73 \\
(5.11)\end{array}$ & $\begin{array}{l}18.49 \\
(2.89)\end{array}$ & $\begin{array}{l}17.56 \\
(2.70)\end{array}$ & $\begin{array}{l}562.90 \\
(86.69)\end{array}$ & $\begin{array}{l}562.90 \\
(86.69)\end{array}$ \\
\hline Income Q3: & $\begin{array}{c}7.48 \\
(4.78)\end{array}$ & $\begin{array}{l}16.57 \\
(2.87)\end{array}$ & $\begin{array}{l}15.11 \\
(2.67)\end{array}$ & $\begin{array}{c}637.18 \\
(112.78)\end{array}$ & $\begin{array}{c}637.18 \\
(112.78)\end{array}$ \\
\hline Income Q4: & $\begin{array}{c}1.98 \\
(4.14)\end{array}$ & $\begin{array}{l}12.74 \\
(2.98)\end{array}$ & $\begin{array}{l}11.00 \\
(2.75)\end{array}$ & $\begin{array}{c}726.94 \\
(181.61)\end{array}$ & $\begin{array}{c}726.94 \\
(181.61)\end{array}$ \\
\hline \multicolumn{6}{|c|}{ Panel B: January 2021 Stimulus Payments (Stimulus 2) } \\
\hline Income Q1: & $\begin{array}{l}14.54 \\
(5.55)\end{array}$ & $\begin{array}{c}4.84 \\
(2.43)\end{array}$ & $\begin{array}{c}6.41 \\
(2.40)\end{array}$ & $\begin{array}{l}92.98 \\
(34.85)\end{array}$ & $\begin{array}{l}185.96 \\
(69.69)\end{array}$ \\
\hline Income Q2: & $\begin{array}{c}9.69 \\
(4.29)\end{array}$ & $\begin{array}{c}3.79 \\
(2.19)\end{array}$ & $\begin{array}{c}4.75 \\
(2.12)\end{array}$ & $\begin{array}{l}108.18 \\
(48.33)\end{array}$ & $\begin{array}{l}216.36 \\
(96.65)\end{array}$ \\
\hline Income Q3: & $\begin{array}{c}6.53 \\
(3.85)\end{array}$ & $\begin{array}{c}2.29 \\
(1.94)\end{array}$ & $\begin{array}{c}2.97 \\
(1.91)\end{array}$ & $\begin{array}{c}90.03 \\
(57.76)\end{array}$ & $\begin{array}{c}180.06 \\
(115.53)\end{array}$ \\
\hline Income Q4: & $\begin{array}{c}3.45 \\
(3.40)\end{array}$ & $\begin{array}{c}-.17 \\
(1.89)\end{array}$ & $\begin{array}{c}0.41 \\
(1.82)\end{array}$ & $\begin{array}{c}19.88 \\
(88.04)\end{array}$ & $\begin{array}{c}39.76 \\
(176.09)\end{array}$ \\
\hline \multicolumn{6}{|c|}{ Panel C: March 2021 Stimulus Payments (Stimulus 3) } \\
\hline Income Q1: & $\begin{array}{l}26.11 \\
(6.67)\end{array}$ & $\begin{array}{c}9.95 \\
(3.90)\end{array}$ & $\begin{array}{l}12.56 \\
(3.81)\end{array}$ & $\begin{array}{l}282.01 \\
(85.48)\end{array}$ & $\begin{array}{l}241.72 \\
(73.27)\end{array}$ \\
\hline Income Q2: & $\begin{array}{l}15.23 \\
(4.39)\end{array}$ & $\begin{array}{l}40.00 \\
(3.21)\end{array}$ & $\begin{array}{c}5.82 \\
(3.06)\end{array}$ & $\begin{array}{c}205.91 \\
(108.18)\end{array}$ & $\begin{array}{l}176.49 \\
(92.73)\end{array}$ \\
\hline Income Q3: & $\begin{array}{c}7.82 \\
(3.45)\end{array}$ & $\begin{array}{c}1.09 \\
(3.13)\end{array}$ & $\begin{array}{c}2.18 \\
(2.94)\end{array}$ & $\begin{array}{c}102.96 \\
(138.96)\end{array}$ & $\begin{array}{c}88.25 \\
(119.11)\end{array}$ \\
\hline Income Q4: & $\begin{array}{c}2.05 \\
(2.68)\end{array}$ & $\begin{array}{l}-1.20 \\
(3.33)\end{array}$ & $\begin{array}{l}-0.67 \\
(3.08)\end{array}$ & $\begin{array}{c}-51.53 \\
(235.45) \\
\end{array}$ & $\begin{array}{c}-44.17 \\
(201.82) \\
\end{array}$ \\
\hline
\end{tabular}

Notes: This table reports difference-in-differences estimates of the impacts of the three rounds of economic impact payments on consumer spending by ZIP income quartile. Panels A, B, and C respectively show estimates for the payments primarily made on April 15 2020, January 4 2021, and March 17 2021. In Panels A and C, we use a window of 25 days before and after the stimulus payment date as the estimation sample. In Panel A, we exclude the partially treated date of April 14 and in Panel C, we exclude the partially treated dates of March 13-16. In Panel B, we use December 4-14, 2020 and January 4-19, 2021 as the estimation window; we exclude the intervening holiday period because of the high degree of volatility of spending during that period (Appendix Figure 23). We then regress daily consumer spending within the relevant window and the corresponding period starting in 2019 (after residualizing it on day-of-week fixed effects) on separate "after" variables for the first five days of the post-period and the rest of the post-period along with these two variables interacted with an indicator for being in the treated group. In Panels $\mathrm{A}$ and C, we also adjust for a linear pre-trend in both the treatment and control series; we do not adjust for a linear pre-trend in Panel B due to the omission of the holiday period. The coefficients reported in columns 1 and 2 are those on the interaction of the two post-period indicators with the indicator for the treated year. Column 3 combines these two spending estimates to project the total percentage effect on spending for the first 31 days after the reform. Column 4 converts this combined percentage estimate into a total dollar estimate using base period daily average spending (see Appendix K for details) and column 5 rescales the dollar estimates to be per $\$ 1,200$ of stimulus. In each panel, we estimate separate models for each quartile of the ZIP median household income distribution (see Figure 7 for details). Robust standard errors are reported in parentheses. Data source: Affinity Solutions. 


\section{Appendix Table 7: Association Between Changes in Consumer Spending and Workplace Rent by ZIP Code}

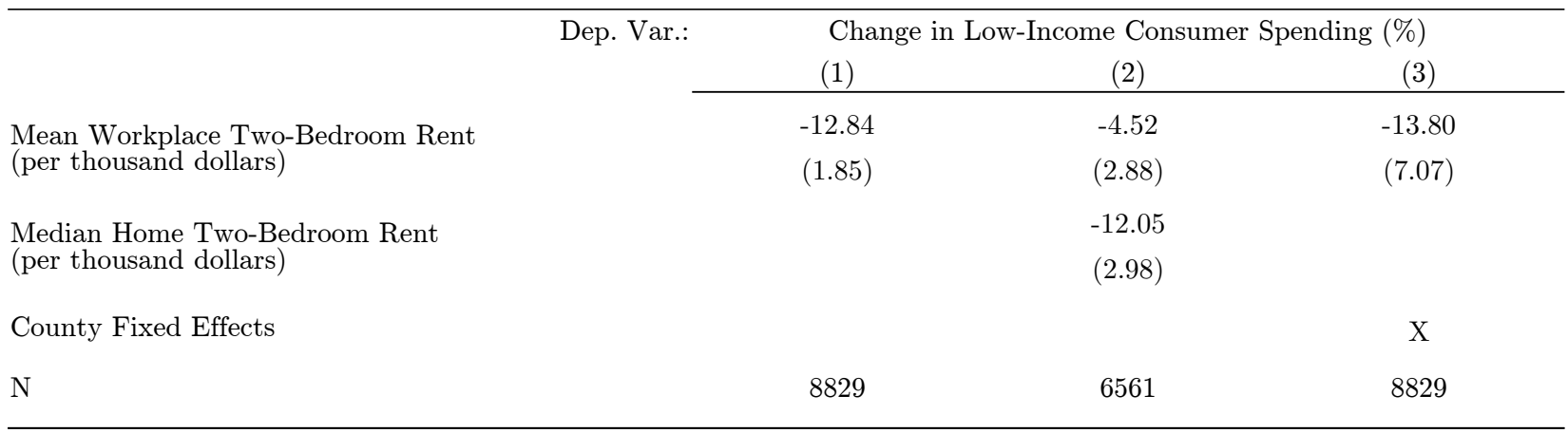

Notes: This table presents results from regressions of changes in low-income consumer spending in the first month of the pandemic on the median rent of the workplaces of those low wage workers. We measure the dependent variable as the average value of our consumer spending index during the period March 25-April 14, 2020 (see Section II.A and Appendix B for details on the construction of this series). Unlike our baseline spending series, we compute these data for this table at the ZIP code level. We then construct the average workplace rent using the Census' LODES data (to measure the workplace ZIP codes for low-wage workers residing in each ZIP code) and the median rent data for each ZIP code from the 2014-2018 ACS. Our independent variable is the average of median workplace ZIP rents using the LODES workplace distribution as the weights for each residential ZIP code. We then restrict the sample for the regression to the residential ZIP codes in the (population-weighted) bottom quartile of median income. We scale the dependent and independent variables such the coefficients represent the predicted change in percentage points for each $\$ 1000$ increase in rent; for instance, the coefficient of -12.84 in Column (1) means that a $\$ 1000$ increase in average workplace median rent for low-wage workers residing a given low-income ZIP code is associated with a 12.84 percentage point reduction in consumer spending in that ZIP code. Column (2) replicates the specification in Column (1) including median rent in the residential ZIP code as an additional control. Column (3) replicates the specification in Column (1) including county fixed effects. Standard errors are clustered at the county level and reported in parentheses. Data sources: Affinity Solutions, Census LODES, ACS. 
Appendix Table 8: Demographic Characteristics of Zearn Users

\begin{tabular}{|c|c|c|}
\hline & $\begin{array}{c}\text { Zearn Users } \\
(1)\end{array}$ & $\begin{array}{c}\text { U.S. Population } \\
(2)\end{array}$ \\
\hline \multicolumn{3}{|c|}{ Panel A: Income } \\
\hline \multicolumn{3}{|c|}{ ZIP Median Household Income } \\
\hline 25th Percentile & 43,355 & 45,655 \\
\hline Median & 54,941 & 57,869 \\
\hline 75th Percentile & 71,485 & 77,014 \\
\hline Number of ZIP codes & 6,529 & 33,253 \\
\hline Number of People & 925,978 & $322,586,624$ \\
\hline \multicolumn{3}{|c|}{ Panel B: School Demographics } \\
\hline \multicolumn{3}{|c|}{ Share of Black Students } \\
\hline 25th Percentile & $1.2 \%$ & $1.5 \%$ \\
\hline Median & $5.2 \%$ & $5.8 \%$ \\
\hline 75th Percentile & $21.3 \%$ & $19.1 \%$ \\
\hline \multicolumn{3}{|c|}{ Share of Hispanic Students } \\
\hline 25th Percentile & $4.3 \%$ & $5.6 \%$ \\
\hline Median & $11.4 \%$ & $15.0 \%$ \\
\hline 75th Percentile & $33.5 \%$ & $40.6 \%$ \\
\hline \multicolumn{3}{|c|}{ Share of Students Receiving FRPL } \\
\hline 25th Percentile & $35.7 \%$ & $28.2 \%$ \\
\hline Median & $56.9 \%$ & $50.1 \%$ \\
\hline 75th Percentile & $80.4 \%$ & $74.8 \%$ \\
\hline Number of Schools & 11,400 & 88,459 \\
\hline Number of Students & 887,592 & $49,038,524$ \\
\hline \multicolumn{3}{|l|}{ Panel C: Region } \\
\hline \multicolumn{3}{|l|}{ Share of Students } \\
\hline Midwest & $24.0 \%$ & $21.0 \%$ \\
\hline Northeast & $14.1 \%$ & $15.7 \%$ \\
\hline South & $33.0 \%$ & $38.9 \%$ \\
\hline West & $28.8 \%$ & $24.3 \%$ \\
\hline
\end{tabular}

Notes: This table reports demographic characteristics for Zearn schools vs. the U.S. population. Panel A compares income characteristics of ZIP codes with Zearn coverage vs. all ZIP codes. We define Zearn to have coverage in a ZIP code if at least five students at schools in that ZIP code used Zearn between January 62020 and February 7 2020. Column 1 shows income characteristics of Zearn-covered ZIP codes. The first three rows in Panel A display the 25th, 50th, and 75th percentiles of ZIP-level median household income in Zearn-covered ZIP codes, as measured in the 2014-2018 ACS. The fourth and fifth rows of Panel A display the number of Zearn-covered ZIP codes, and the number of students using Zearn in those ZIP codes. Column 2 replicates Column 1 using all ZIP codes in the U.S. The fourth and fifth rows of Column 2 replicates Column 1 using all ZIP codes in the U.S. and counting the total population, respectively. Panel B presents the demographic composition of schools in the Zearn data (Column 1) and of all U.S. K-12 schools (Column 2), calculated using school-level data from the Common Core dataset as constructed by MDR Education, a private education data firm. The first three rows of Panel B show the 25th, 50th, and 75th percentiles of share of Black students in Zearn schools (Column 1) and in all US K-12 schools (Column 2). Rows 4-6 and 7-9 of Panel B replicate Rows 1-3 using the share of Hispanic students and the share of students receiving free or reduced-price lunch meals. Rows 10 and 11 of Panel B display the number of Zearn schools matched to the Common Core data and the number of students in those schools. Panel C compares the share of students by region in Zearn vs. the US population. Data sources: Zearn, ACS, Common Core. 
Appendix Table 9: City to County Crosswalk

\begin{tabular}{|c|c|c|c|}
\hline City & State & County & County FIPS Code \\
\hline Albuquerque & New Mexico & Bernalillo & 35001 \\
\hline Atlanta & Georgia & Fulton & 13121 \\
\hline Austin & Texas & Travis & 48453 \\
\hline Bakersfield & California & Kern & 6029 \\
\hline Baltimore & Maryland & Baltimore & 24005 \\
\hline Boise & Idaho & Ada & 16001 \\
\hline Boston & Massachusetts & Suffolk & 25025 \\
\hline Charlotte & North Carolina & Mecklenburg & 37119 \\
\hline Chicago & Illinois & Cook & 17031 \\
\hline Cleveland & Ohio & Cuyahoga & 39035 \\
\hline Colorado Springs & Colorado & El Paso & 8041 \\
\hline Columbus & Ohio & Franklin & 39049 \\
\hline Dallas & Texas & Dallas & 48113 \\
\hline Denver & Colorado & Denver & 8031 \\
\hline Detroit & Michigan & Wayne & 26163 \\
\hline El Paso & Texas & El Paso & 48141 \\
\hline Fort Worth & Texas & Tarrant & 48439 \\
\hline Fresno & California & Fresno & 6019 \\
\hline Honolulu & Hawaii & Honolulu & 15003 \\
\hline Houston & Texas & Harris & 48201 \\
\hline Indianapolis & Indiana & Marion & 18097 \\
\hline Jacksonville & Florida & Duval & 12031 \\
\hline Kansas City & Missouri & Jackson & 29095 \\
\hline Las Vegas & Nevada & Clark & 32003 \\
\hline Los Angeles & California & Los Angeles & 6037 \\
\hline Louisville & Kentucky & Jefferson & 21111 \\
\hline Memphis & Tennessee & Shelby & 47157 \\
\hline Miami & Florida & Dade & 12086 \\
\hline Milwaukee & Wisconsin & Milwaukee & 55079 \\
\hline Minneapolis & Minnesota & Hennepin & 27053 \\
\hline Nashville & Tennessee & Davidson & 47037 \\
\hline New Orleans & Louisiana & Orleans & 22071 \\
\hline New York City & New York & Bronx & 36005 \\
\hline New York City & New York & Kings & 36047 \\
\hline New York City & New York & New York & 36061 \\
\hline New York City & New York & Queens & 36081 \\
\hline New York City & New York & Richmond & 36085 \\
\hline Oakland & California & Alameda & 6001 \\
\hline Oklahoma City & Oklahoma & Oklahoma & 40109 \\
\hline Omaha & Nebraska & Douglas & 31055 \\
\hline Philadelphia & Pennsylvania & Philadelphia & 42101 \\
\hline Phoenix & Arizona & Maricopa & 4013 \\
\hline Portland & Oregon & Multnomah & 41051 \\
\hline Raleigh & North Carolina & Wake & 37183 \\
\hline Sacramento & California & Sacramento & 6067 \\
\hline Salt Lake City & Utah & Salt Lake & 49035 \\
\hline San Antonio & Texas & Bexar & 48029 \\
\hline San Diego & California & San Diego & 6073 \\
\hline San Francisco & California & San Francisco & 6075 \\
\hline San Jose & California & Santa Clara & 6085 \\
\hline Seattle & Washington & King & 53033 \\
\hline Tampa & Florida & Hillsborough & 12057 \\
\hline Tucson & Arizona & Pima & 4019 \\
\hline Tulsa & Oklahoma & Tulsa & 40143 \\
\hline Virginia Beach & Virginia & Virginia Beach City & 51810 \\
\hline Washington & District of Columbia & District Of Columbia & 11001 \\
\hline Wichita & Kansas & Sedgwick & 20173 \\
\hline
\end{tabular}

Notes: This table shows our metro area (city) to county crosswalk. We assigned metros to counties and verified that a significant portion of the county population was in the metro of interest. Some large metros share a county; in this case the smaller metro was subsumed into the larger metro. 


\section{Appendix Table 10: List of Re-Opening States and Control States for Event Studies}

\begin{tabular}{|c|c|c|c|c|}
\hline Date & States that Re-Opened & Consumer Spending Controls & $\underset{(2)}{\operatorname{Employment} \text { Controls }}$ & $\begin{array}{c}\text { Small Businesses Open Controls } \\
(3)\end{array}$ \\
\hline $\begin{array}{c}\text { April } 20^{\text {th }} \\
2020\end{array}$ & South Carolina & $\begin{array}{l}\text { California, Connecticut, } \\
\text { Delaware, Florida, Hawaii, } \\
\text { Illinois, Indiana, Louisiana, } \\
\text { Maryland, Massachusetts, } \\
\text { Missouri, Nebraska, New } \\
\text { Jersey, New Mexico, New } \\
\text { York, Oregon, Pennsylvania, } \\
\text { South Dakota, Virginia, } \\
\text { Washington, Wisconsin }\end{array}$ & $\begin{array}{c}\text { California, Connecticut, } \\
\text { Delaware, District Of } \\
\text { Columbia, Florida, Illinois, } \\
\text { Indiana, Louisiana, } \\
\text { Maryland, Missouri, } \\
\text { Nebraska, New Mexico, } \\
\text { Oregon, Pennsylvania, } \\
\text { South Dakota, Virginia, } \\
\text { Washington, Wisconsin }\end{array}$ & $\begin{array}{c}\text { California, Connecticut, } \\
\text { Delaware, District Of Columbia, } \\
\text { Florida, Hawaii, Illinois, } \\
\text { Indiana, Louisiana, Maryland, } \\
\text { Massachusetts, Missouri, } \\
\text { Nebraska, New Jersey, New } \\
\text { Mexico, New York, Oregon, } \\
\text { Pennsylvania, South Dakota, } \\
\text { Virginia, Washington, } \\
\text { Wisconsin }\end{array}$ \\
\hline $\begin{array}{l}\text { April } 24^{\text {th }} \\
2020\end{array}$ & Alaska, Georgia & $\begin{array}{l}\text { California, Connecticut, } \\
\text { Delaware, Florida, Illinois, } \\
\text { Indiana, Louisiana, } \\
\text { Maryland, Massachusetts, } \\
\text { Missouri, Nebraska, New } \\
\text { Jersey, New Mexico, New } \\
\text { York, Pennsylvania, South } \\
\text { Dakota, Virginia, } \\
\text { Washington, Wisconsin }\end{array}$ & $\begin{array}{l}\text { California, Connecticut, } \\
\text { Delaware, District Of } \\
\text { Columbia, Florida, Illinois, } \\
\text { Indiana, Louisiana, } \\
\text { Maryland, Massachusetts, } \\
\text { Missouri, Nebraska, New } \\
\text { Jersey, New Mexico, } \\
\text { Pennsylvania, South } \\
\text { Dakota, Virginia, } \\
\text { Washington, Wisconsin }\end{array}$ & $\begin{array}{c}\text { California, Connecticut, } \\
\text { Delaware, District Of Columbia, } \\
\text { Florida, Illinois, Indiana, } \\
\text { Louisiana, Maryland, } \\
\text { Massachusetts, Missouri, } \\
\text { Nebraska, New Jersey, New } \\
\text { Mexico, New York, } \\
\text { Pennsylvania, South Dakota, } \\
\text { Virginia, Washington, } \\
\text { Wisconsin }\end{array}$ \\
\hline $\begin{array}{l}\text { April } 27^{\text {th }} \\
2020\end{array}$ & Minnesota, Mississippi & $\begin{array}{c}\text { Illinois, Nebraska, New } \\
\text { Jersey, New York, } \\
\text { Pennsylvania, South } \\
\text { Dakota, Virginia, Wisconsin }\end{array}$ & $\begin{array}{l}\text { California, Delaware, } \\
\text { District Of Columbia, } \\
\text { Illinois, Maryland, } \\
\text { Nebraska, New Mexico, } \\
\text { South Dakota, Virginia, } \\
\text { Wisconsin }\end{array}$ & $\begin{array}{l}\text { California, Connecticut, } \\
\text { Delaware, District Of Columbia, } \\
\text { Illinois, Maryland, Nebraska, } \\
\text { New Jersey, New Mexico, New } \\
\text { York, Pennsylvania, South } \\
\text { Dakota, Virginia, Washington, } \\
\text { Wisconsin }\end{array}$ \\
\hline
\end{tabular}

Notes: This table lists the treatment and control states for the analysis of state reopenings in Appendix Figure 26 and Appendix Table 11. Column (1) displays the control states that are compared to the treatment states in the two-week event horizon in the event study of consumer spending (as measured in the Affinity data) described in Appendix Figure 26 and Appendix Table 11. Column (2) replicates Column (1) for employment (as measured in the Paychex-Intuit data). Column (3) replicates Column (1) for number of small businesses open (as measured in the Womply data). 
Appendix Table 11: Causal Effects of Re-Openings on Economic Activity

\begin{tabular}{|c|c|c|c|c|c|c|}
\hline \multirow{2}{*}{ Dep. Var.: } & \multicolumn{2}{|c|}{ Spending (\%) } & \multicolumn{2}{|c|}{ Employment (\%) } & \multicolumn{2}{|c|}{$\begin{array}{c}\text { Small Businesses } \\
\text { Open (\%) }\end{array}$} \\
\hline & $(1)$ & $(2)$ & $(3)$ & $(4)$ & $(5)^{1}$ & $(6)$ \\
\hline $\begin{array}{l}\text { DD Estimate of } \\
\text { Effect of Reopening: }\end{array}$ & $\begin{array}{l}1.22 \\
(0.36)\end{array}$ & $\begin{array}{c}1.71 \\
(0.66)\end{array}$ & $\begin{array}{l}1.30 \\
(0.41)\end{array}$ & $\begin{array}{c}1.34 \\
(0.66)\end{array}$ & $\begin{array}{c}3.45 \\
(1.24)\end{array}$ & $\begin{array}{l}5.05 \\
(2.04)\end{array}$ \\
\hline State-Week Observations: & 212 & 312 & 208 & 270 & 248 & 324 \\
\hline $\begin{array}{l}\text { Analysis Window (weeks on } \\
\text { either side of reopening): }\end{array}$ & 2 & 3 & 2 & 3 & 2 & 3 \\
\hline $\begin{array}{l}\text { Mean Decline in Outcome } \\
\text { (January to April 2020): }\end{array}$ & \multicolumn{2}{|c|}{$-30 \%$} & \multicolumn{2}{|c|}{$-22 \%$} & \multicolumn{2}{|c|}{$-29 \%$} \\
\hline
\end{tabular}

Notes: This table estimates the effects of state reopenings on various outcomes using an event study design based on states that reopened non-essential businesses between April 20 and April 27. Each state that reopens is matched to multiple control states (listed in Appendix Table 10) that did not reopen within the subsequent 3 weeks but had similar trends of the outcome variable during the weeks preceding the reopening. We construct the control group separately for each re-opening day and then stack the resulting event studies to align the events. All estimates are from OLS regressions at the State $\mathrm{x}$ Week level of the change in the outcome variable relative to January 2020, regressed on an indicator variable for the state being a state that reopened, an indicator variable for the date being after the reopening date, and the interaction between these two variables. We report the coefficient and standard error on the interaction term, which we refer to as the difference-in-difference (DD) estimate of the effect of reopening. Standard errors are clustered at the state level and reported in parentheses. The dependent variable is rescaled to be in percentage terms such that, for example, the first row of Column (1) indicates that the difference-in-difference estimate for the effect of reopening on consumer spending over a two-week horizon is a 1.15 percentage point increase in consumer spending. The third row indicates the "Analysis Window" used in the regression: for example, the sample in column (1) is restricted to the two weeks before and after the date of reopening, whereas the sample in column (2) is restricted to the three weeks before and after the date of reopening. The last row shows the mean decline in the outcome variable across states from the period January 4-31 2020 to the period March 25-April 142020 - except in Columns (1) and (2) where the reference period is January 6 - February 2, 2020. Column (1) shows the estimated effect of reopening on consumer spending using data from Affinity Solutions. Consumer spending is expressed as a percentage change relative to its level over the period January 6 - February 2, 2020, and seasonally adjusted using 2019 data. Columns (3) and (4) replicate columns (1) and (2) using changes in employment as the dependent variable. Employment is calculated using Paychex-Intuit data and expressed as a percentage change relative to its level over the period January 4-31 2020. Columns (5) and (6) replicate columns (1) and (2) respectively using the number of small businesses open as the dependent variable, calculated using Womply data and expressed as a percentage change relative to its level over the period January 4-31 2020. Columns (1), (3), and (5) correspond to the specifications displayed in Appendix Figure 26B. Data sources: Affinity Solutions, Paychex, Intuit, Womply. 
Appendix Table 12: Causal Effect of the Paycheck Protection Program on Employment

Dep. Var.: $\quad$ Change in Employment (\%)

\begin{tabular}{|c|c|c|}
\hline \multicolumn{2}{|c|}{ Combined Paychex and Earnin Data } & \multirow{2}{*}{$\begin{array}{c}\text { Earnin Data } \\
(3)\end{array}$} \\
\hline (1) & $(2)$ & \\
\hline $\begin{array}{c}\text { Baseline Estimate } \\
\text { (100-800 Employees) }\end{array}$ & $\begin{array}{c}\text { Smaller Bandwidth } \\
\text { (300-700 Employees) }\end{array}$ & $\begin{array}{c}\text { Baseline Estimate } \\
\text { (100-800 Employees) }\end{array}$ \\
\hline $\begin{array}{l}1.78 \\
(1.99)\end{array}$ & $\begin{array}{l}1.62 \\
(2.68)\end{array}$ & $\begin{array}{l}1.01 \\
(0.94)\end{array}$ \\
\hline
\end{tabular}

Notes: This table reports difference-in-difference (DD) estimates of the effect of PPP eligibility (defined as the parent firm having 500 or fewer employees) on employment. The outcome variable is employment at the county $\mathrm{x}$ 2-digit NAICS x income quartile x PPP eligibility x week level, excluding the Accommodations and Food Services Sector (NAICS 72), expressed as a percentage change relative to a pre-period of January 4-31 2020. Columns (1) and (2) present regressions in combined Paychex-Earnin data. In the baseline estimate in column (1), we begin by restricting the sample to firms with 100-800 employees. We then reweight firms on 2-digit NAICS codes such that the (worker-weighted) distribution of 2-digit NAICS codes within Paychex firms in each size bin matches the national distribution of 2-digit NAICS codes among Paychex firms in the period January 4-31 2020. We do the same for Earnin firms. Next, to combine the datasets, we reweight such that the (worker-weighted) share of each dataset is constant in each firm size bin. We then sum employment across datasets at the county $\mathrm{x} 2$-digit NAICS $\mathrm{x}$ income quartile $\mathrm{x}$ eligibility $\mathrm{x}$ week level. Finally, we report estimates from an OLS regression of changes in employment on county $\mathrm{x}$ worker income quartile $\mathrm{x}$ week fixed effects, an indicator for PPP eligibility (firm size i 500 employees), an indicator for dates after April 3, and an interaction term between PPP eligibility and the date being after April 3 (the DD estimate). The sample for this regression is limited to weeks ending between March 11 and August 15 . The DD estimate is the coefficient on the interaction term for PPP eligibility and the date being after April 3. We cluster standard errors (reported in parentheses) at the county $\mathrm{x}$ industry level, and winsorize the dependent variable at the 99th percentile (weighted by reweighted employment over the period January 4-31). Column (2) replicates Column (1), restricting to firms with between 300 and 700 employees. Column (3) replicates Column (1) in the Earnin data alone. As we treat all Earnin workers as belonging to the first quartile, Column (3) uses county x week fixed effects, rather than county $\mathrm{x}$ worker income quartile $\mathrm{x}$ week fixed effects. Data sources: Paychex, Earnin. 


\section{Figure 1: Changes in Consumer Spending During the COVID Pandemic}

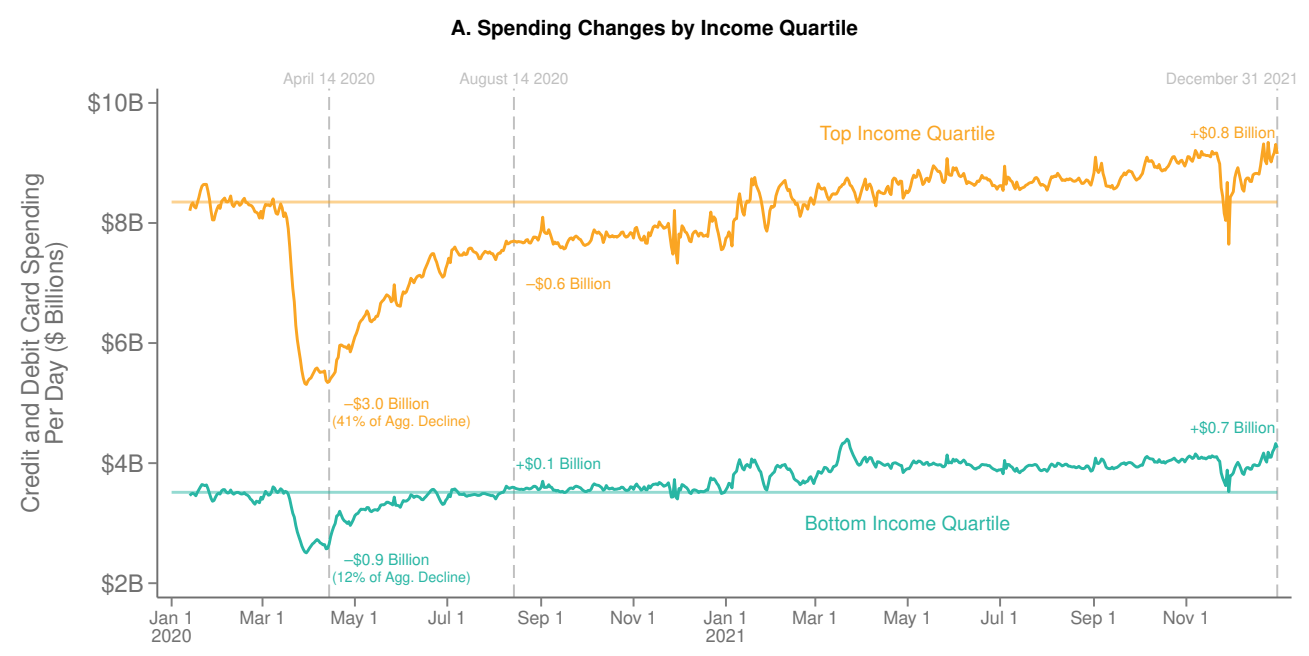

B. Spending Changes by Sector

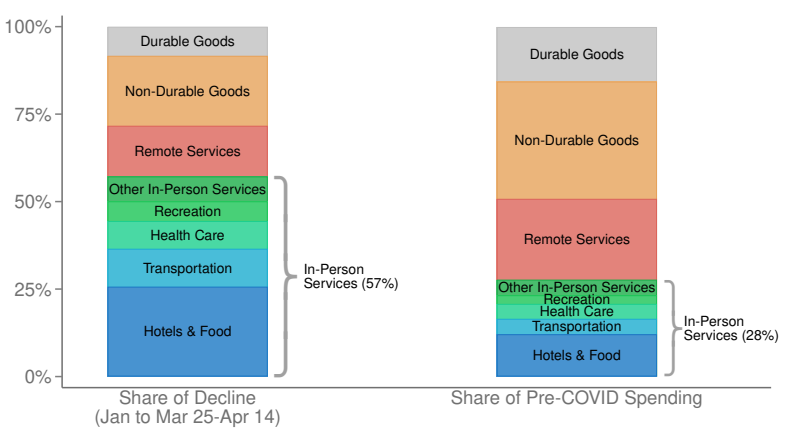

C. Spending Changes by Sector: COVID vs Great Recession

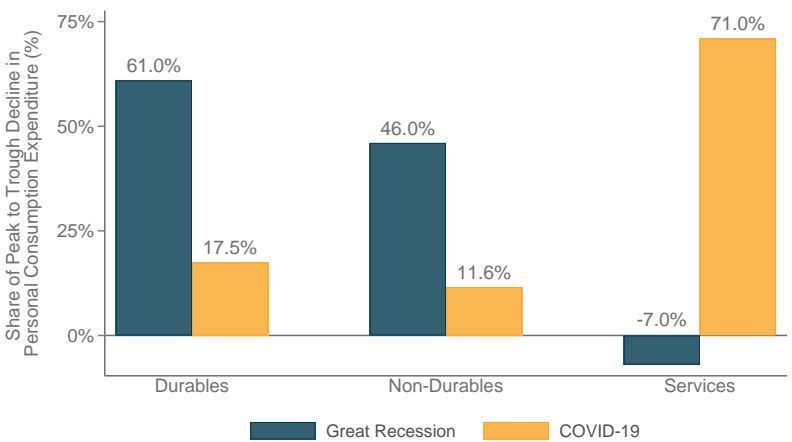

Notes: This figure disaggregates spending changes by income and sector using debit and credit card data from Affinity Solutions and national accounts (NIPA) data. Panel A plots daily spending levels for consumers in the highest and lowest quartiles of household income by combining total card spending in January 2020 (from NIPA Table 2.3.5) with our Affinity Solutions spending series. See the notes to Appendix Table 5 for details on this method. Panel B disaggregates the sectoral shares of seasonally-adjusted spending changes (left bar) and pre-COVID spending levels (right bar). See Appendix B.3 for the definitions of the sectors plotted in Panel B. Panel C decomposes the change in personal consumption expenditures (PCE) in the Great Recession and the COVID-19 Recession using NIPA Table 2.3.6. PCE is defined here as the sum of durable goods, non-durable goods and services in seasonally adjusted, chained (2012) dollars. The peak to trough declines are calculated from December 2007 to June 2009 for the Great Recession and from January 2020 to April 2020 for the COVID-19 Recession. Data sources: Affinity Solutions, NIPA. 
Figure 2: Association Between COVID-19 Incidence and Changes in Consumer Spending

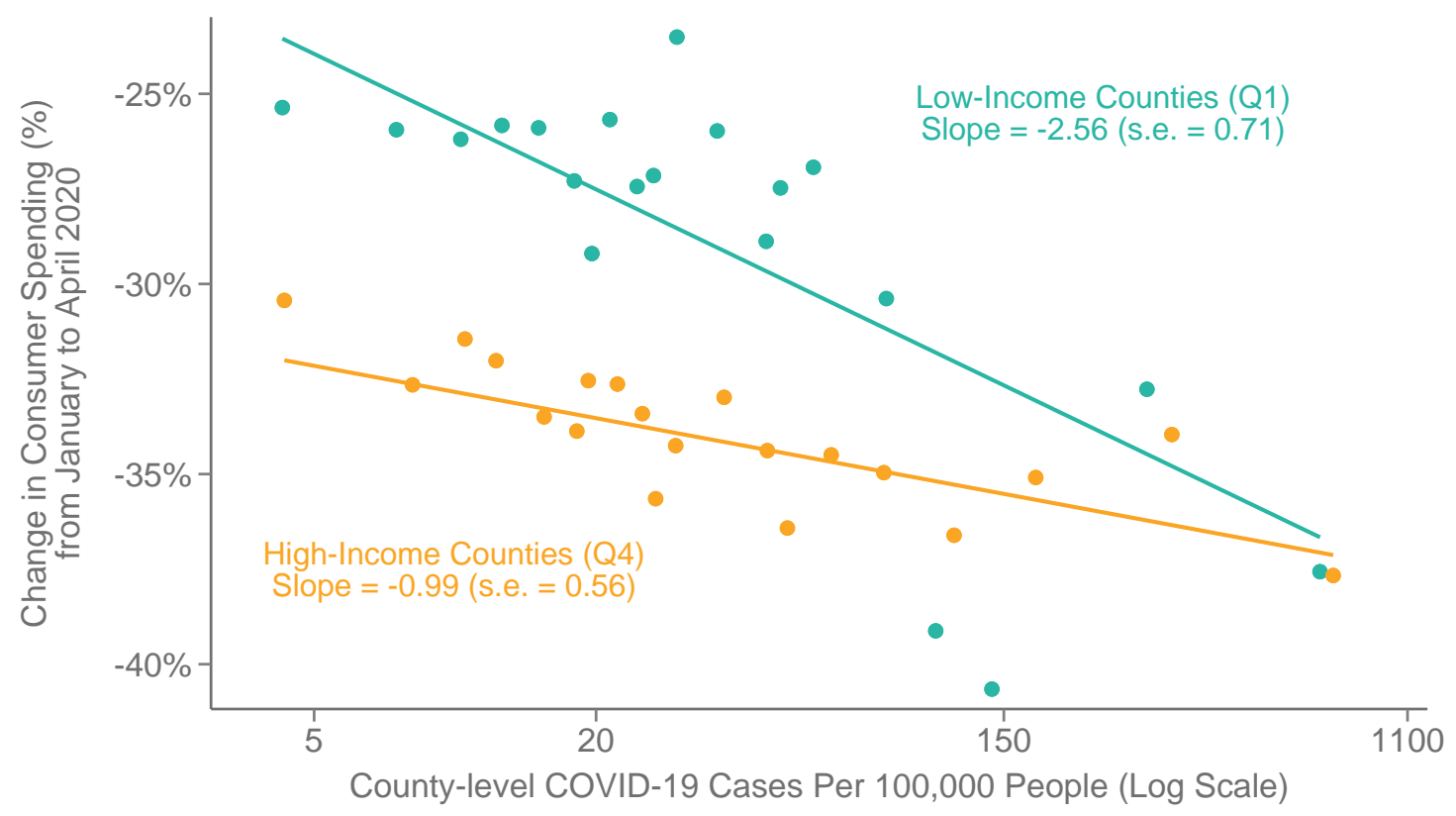

Notes: This figure presents a county-level binned scatter plot. To construct it, we divide the data into twenty equal-sized bins, ranking by the x-axis variable and weighting by the county's population, and plot the (populationweighted) means of the $\mathrm{y}$-axis and $\mathrm{x}$-axis variables within each bin. The $\mathrm{y}$-axis presents the change in seasonally adjusted consumer spending from the base period (January 6 - February 2, 2020) to the three-week period of March 25-April 142020 (see Section II.A and Appendix B for details on the construction of our consumer spending series). The x-axis variable is the logarithm of the county's cumulative COVID case rate per capita as of April 14, 2020; with axis labels showing the levels on a logarithmic scale. We plot values separately for counties in the top and bottom quartiles of median household income (measured using population-weighted 2014-2018 ACS data). Data sources: Affinity Solutions, New York Times. 
Figure 3: Changes in Small Business Revenues vs. Median Two Bedroom Rent, by ZIP

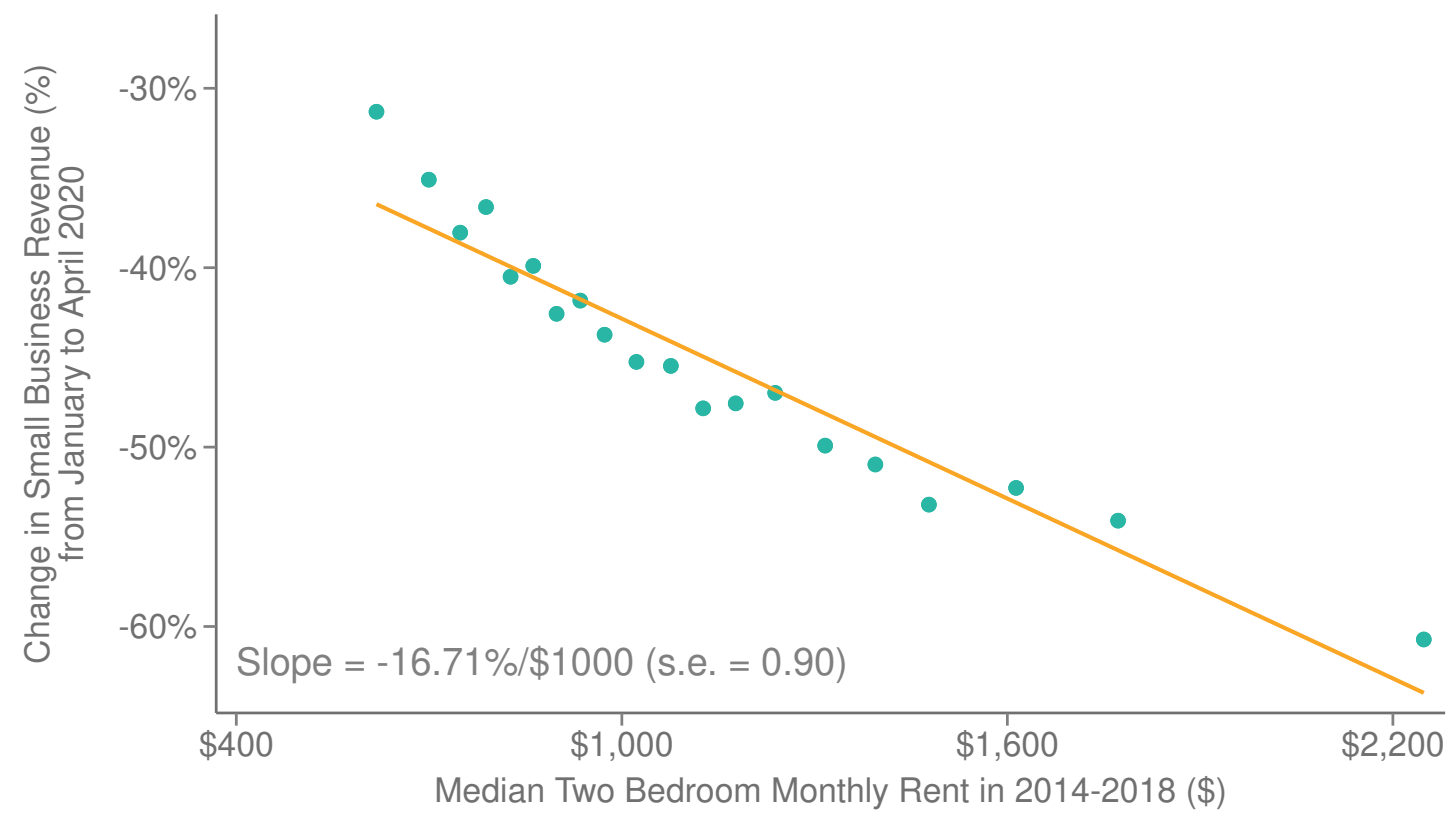

Notes: This figure presents a binned scatter plot showing the relationship between changes in seasonally-adjusted small business revenue in Womply data vs. rent at the ZIP code level. We measure changes in small busines revenue as the average value of our index at the ZIP code level during the period of March 23 to April 12, 2020 (see Section II.B and Appendix $\mathrm{C}$ for details on the construction of our small business revenue series). The $\mathrm{x}$-axis variable is the ZIP code median rent for a two-bedroom apartment in the 2014-2018 ACS. Data sources: Womply, ACS. 


\section{Figure 4: Changes in Job Postings and Employment Rates vs. Rent}

A. Job Postings for Low-Education Workers vs. Median Rent, by County

April 2020

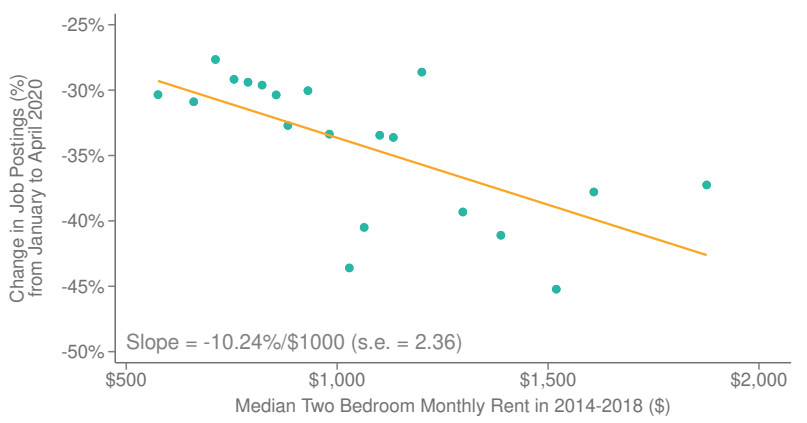

B. Job Postings for High-Education Workers vs. Median Rent, by County

April 2020

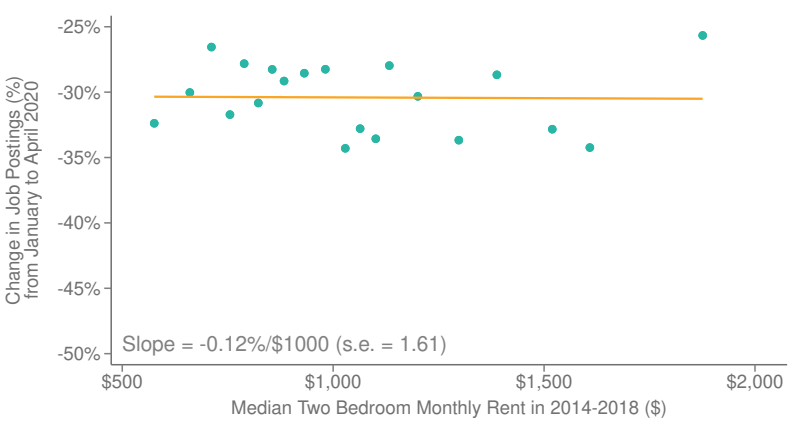

C. Low-Wage Employment vs. Median Rent, by County

July 2020

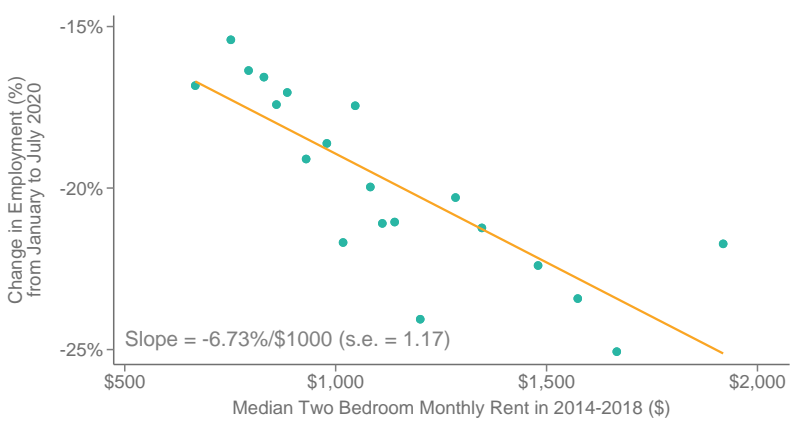

Notes: This figure shows binned scatter plots of the relationship between median rents and changes in job postings (Panels A and B) or changes in employment rates (Panel C). The binned scatter plots are constructed as described in Figure 2. Solid lines are best-fit lines estimated using OLS. Each panel also displays the slope coefficient and standard error of the corresponding linear OLS regression. In each panel, the x-axis variable is the median rent within a county for a two-bedroom apartment in the 2014-2018 ACS. In Panel A, the y-axis variable is the value of our job postings series for jobs requiring minimal or some education averaged over the period of March 25 to April 14, 2020 (see Section II.C and Appendix D for more detail on our job postings series). Panel B replicates Panel A with job postings for workers with moderate, considerable, or extensive education. In both Panels A and B, we winsorize our job postings series at the 99th percentile of the (population-weighted) county level distribution within each level of required education. In Panel $\mathrm{C}$, the $\mathrm{y}$-axis variable is the average value of our bottom wage quartile employment series during the month of July 2020 (see Section II.D and Appendix E for more detail on the construction of our employment series). Data sources: Paychex, Intuit, Lightcast, ACS. 


\section{Figure 5: Changes in Employment by Wage Quartile}

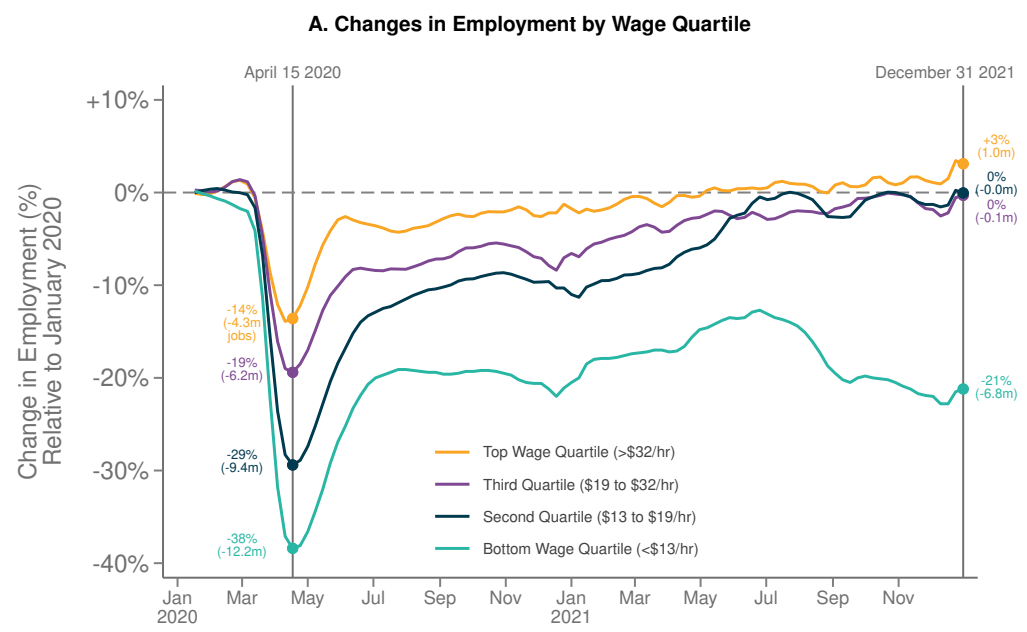

B. Changes in Employment by Wage Quartile, Reweighting Across Industries and Areas

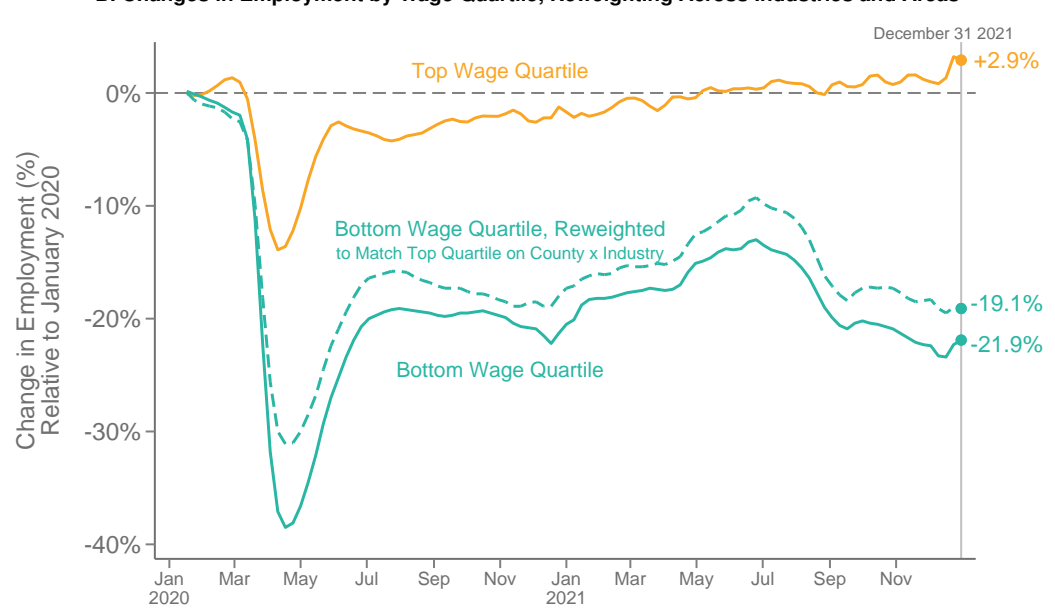

Notes: Panel A plots our combined Paychex-Intuit employment series from January 2020 through December 2021 for each wage quartile. We define moving wage quartiles thresholds in each month based on $100 \%, 150 \%$ and $250 \%$ of the federal poverty line (FPL) for a family of four, adjusted for inflation, then converted into a full-time-equivalent hourly wage by diving by 2000 hours ( 50 weeks of work at 40 hours per week). These thresholds group workers approximately into quartiles in January 2020; see Section II.D and Appendix E for details on the construction of this series. In Panel B, we reweight the county-by-industry (2-digit NAICS) distribution of bottom wage quartile employment to match the distribution for top wage quartile employment in January 2020. For each series in Panel $\mathrm{B}$, we restrict the sample to county-by-industry cells with non-zero employment in all four wage quartiles in January 2020; this sample restriction excludes $2.5 \%$ of worker-days from the sample. Data sources: Paychex, Intuit. 


\section{Figure 6: Evolution of the Association between Low-Education Job Postings and Low-Wage Employment with Rent}

A. Job Postings for Low-Education Workers vs. Median Rent, by County

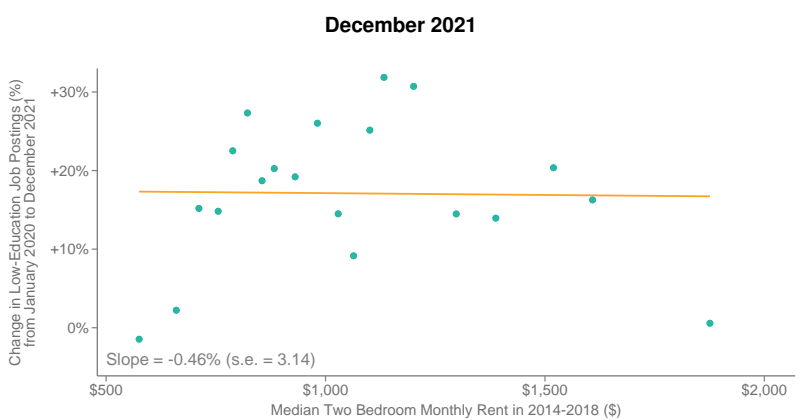

C. Relationship Between Low-Education Job Postings and Rent, by County

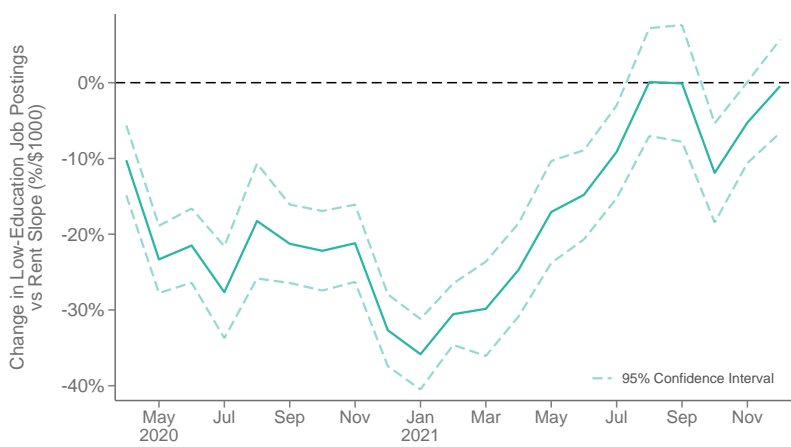

B. Low-Wage Employment vs. Median Rent, by County

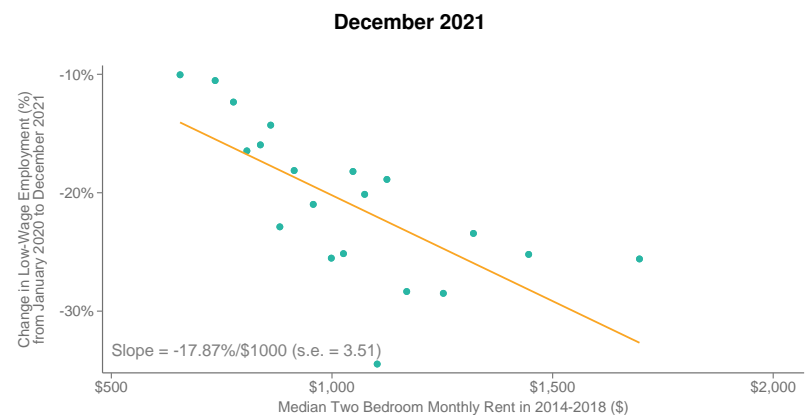

D. Relationship Between Low-Wage Employment and Rent, by County

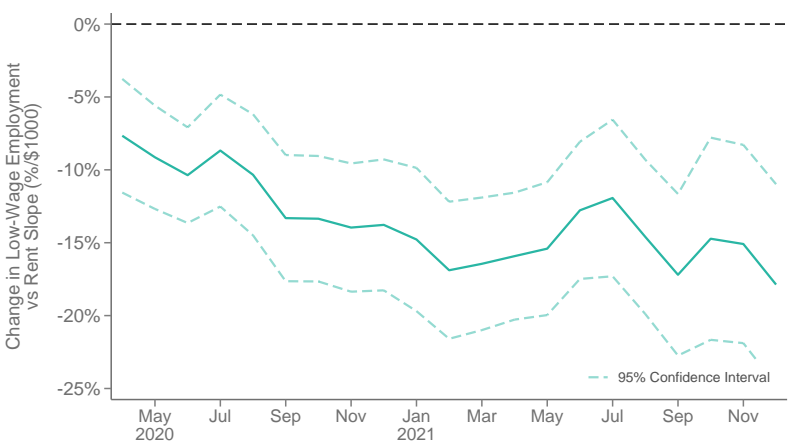

Notes: This figure presents a summary of the results of a set of regressions documenting the relationship between job postings and employment with rent over time. Panel A replicates Figure 4A, but using the average value of the low-education job postings series in December 2021 instead of April 2020. Panel B replicates Figure 4C, but using the average value of the Paychex-Intuit employment series in December 2021 instead of July 2020. Panel C plots the slope of the best-fit line from a population-weighted regression of low-education job postings on median county rent (as in Panel A) for each month from April 2020 through December 2021. The slopes estimated in Figures 4A and $6 \mathrm{~A}$ are the first and last estimates in this series, respectively. Panel D replicates Panel C for the slope of the bottom wage quartile employment vs. median rent (as in Panel B). In both Panels $\mathrm{C}$ and D, the dashed lines above and below the solid series represent the upper and lower boundaries of the $95 \%$ confidence interval for the slope estimated in each month. Panels B and D omit counties from CA, MA, and NY, since these three states raised the minimum wage at some point after July 2020 above our upper threshold for the bottom wage quartile of employment. Data sources: Lightcast, Paychex, Intuit, ACS. 


\section{Figure 7: Effects of Stimulus Payments on Spending: Event Studies}
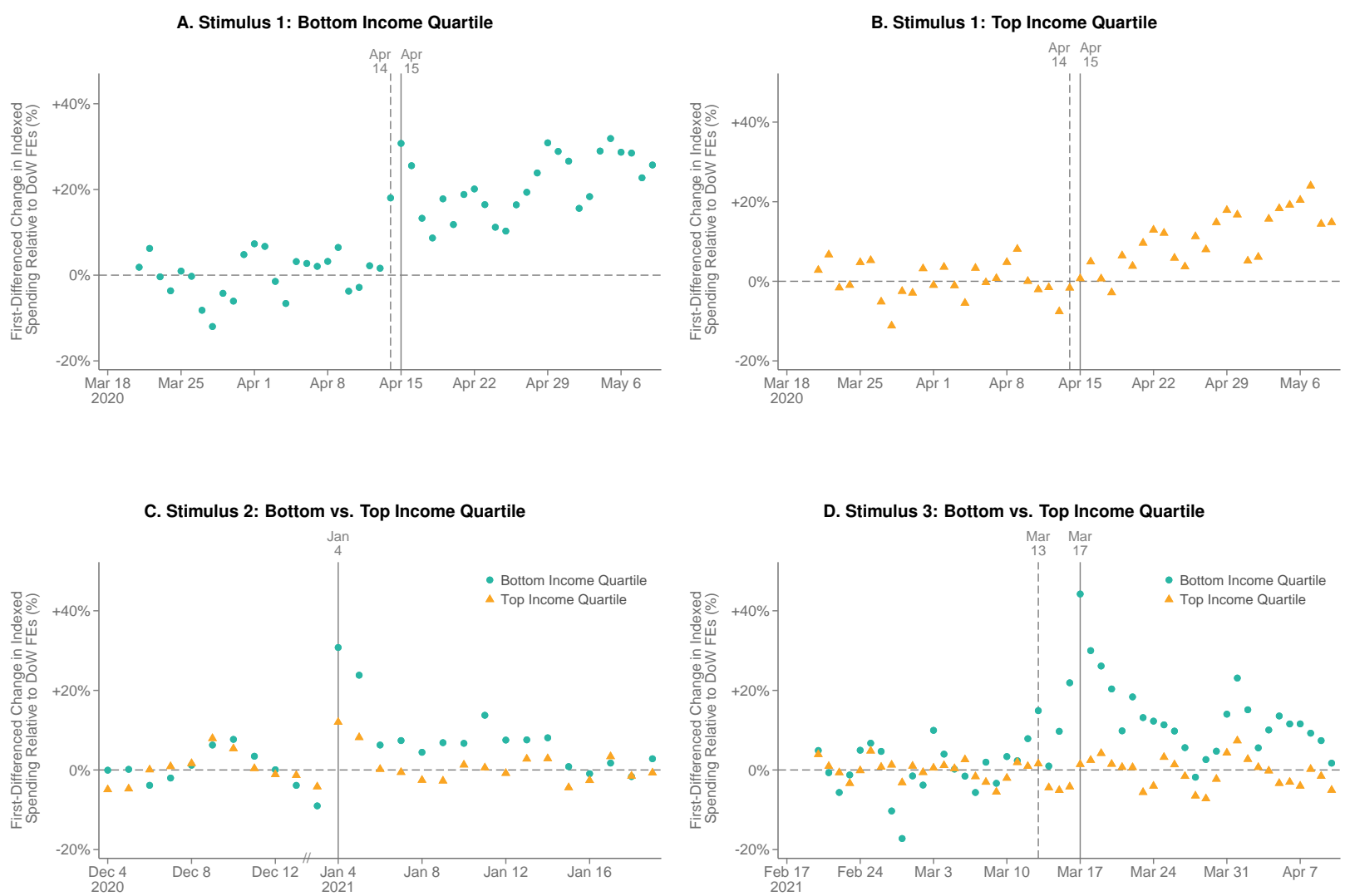

Notes: This figure shows event studies of the effect of stimulus payments on consumer spending. We measure consumer spending using data from Affinity Solutions. To construct each consumer spending time series, we express consumer spending on each day as a percentage change relative to mean daily consumer spending over January 2019, residualize these daily percentage changes with respect to day-of-week fixed effects (estimated out-of-sample using data in 2019), calculate the first difference with respect to values from the corresponding period starting in 2019, and adjust the estimates for a linear pre-trend in first differences. Panel A depicts this spending time series for 25 days before and after April 15, 2020 (the modal date for deposits of the CARES Act economic impact payments) for cardholders with residential addresses in the bottom income quartile of ZIP codes. We exclude April 14 from the pre-period as some households received stimulus payments on this date. Panel B repeats this figure for the top income quartile of ZIP codes. Panel C repeats Panels A and B for the days around January 4, 2021 (the modal date for deposits of the COVID-Related Tax Relief Act economic impact payments), plotting outcomes for both the bottom and top income quartiles. The pre-period in Panel C runs from December 4-14, 2020, with the holiday period (December 15, 2020 - January 3, 2021) removed due to high daily volatility in spending levels (see Section IV.A and Appendix Figure 23 for more details). The post-period runs from January 4-19, 2021, reflecting the data available when this analysis was originally published on January 26, 2021. Due to the omission of the holiday period, we do not remove a linear pre-trend as in Panels A and B. Panel D repeats Panel C for the days around March 17, 2021 (the modal date for deposits of the American Rescue Plan Act economic impact payments). We exclude March 13-16 from the pre-period as payments were made starting March 13. In Panels A, B, and D, we interpolate the value for Easter Sunday using the average of adjacent daily values. Data sources: Affinity Solutions, ACS. 
Figure 8: Impacts of Stimulus Payments on Spending, by Income Quartile

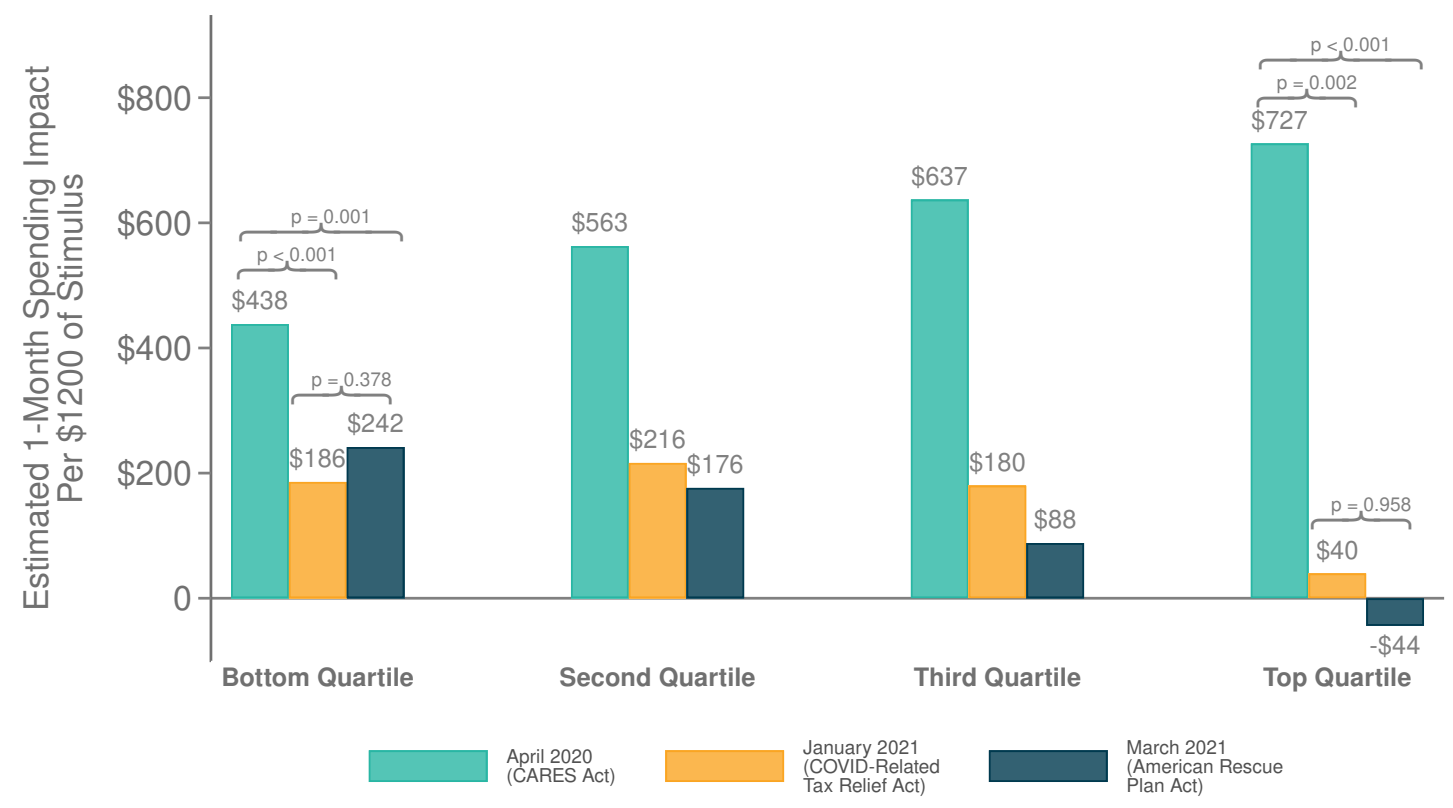

Notes: This figure plots estimates of the marginal propensity to spend out of stimulus payments in the first month after receipt for each of the three rounds of stimulus payments, separately by income quartile (based on median ZIP code income). The estimates are scaled per $\$ 1,200$ of stimulus payment and correspond to the "Combined Dollar" estimates reported in Column 5 of Appendix Table 6. See Section IV.A and Appendix Section K.3 for details on how these estimates were calculated. We also report p-values testing the null hypothesis of equal effect sizes between each pair of stimulus rounds, for the highest- and lowest-quartile of ZIP-level incomes. These p-values are based on permutation tests reported in Appendix Figures 24 and 25. Data source: Affinity Solutions. 
Figure 9: Changes in Employment and Consumer Spending for Low-Income Households vs. Workplace Rent

A. Low-Wage Employment vs. Workplace Rent, by ZIP

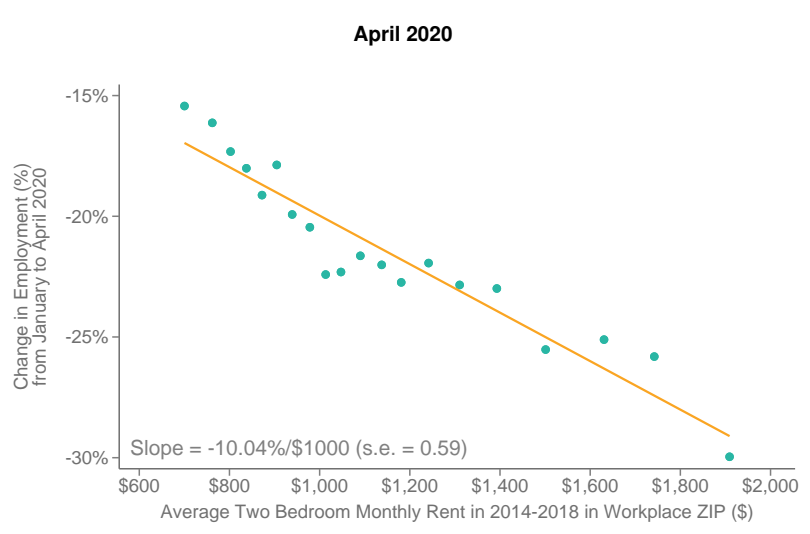

C. Spending Among Low-Income Households vs. Workplace Rent, by ZIP

October 2020

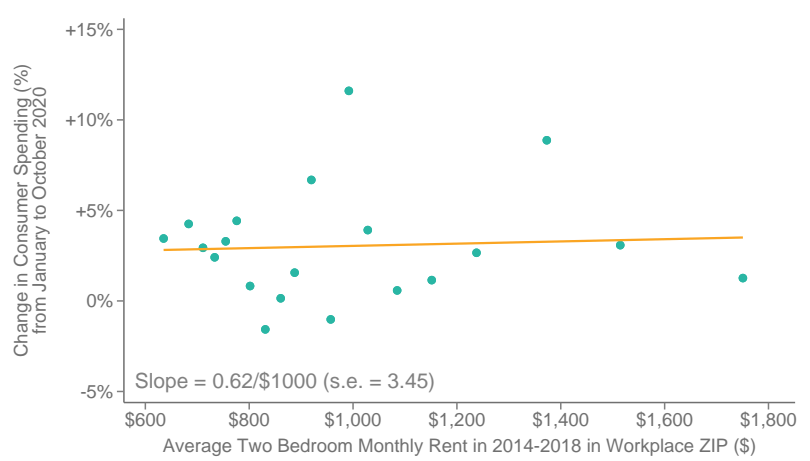

B. Spending Among Low-Income Households vs. Workplace Rent, by ZIP

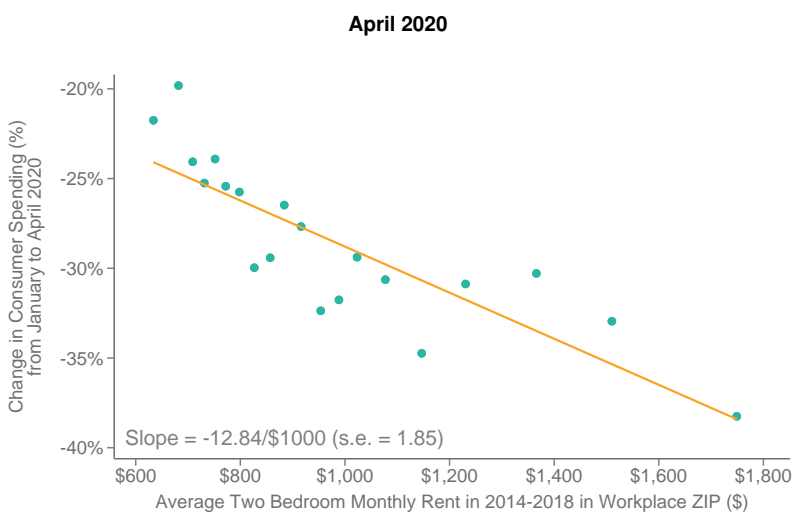

D. Spending by Low-Income Households Living in ZIP Codes with High Workplace Rent

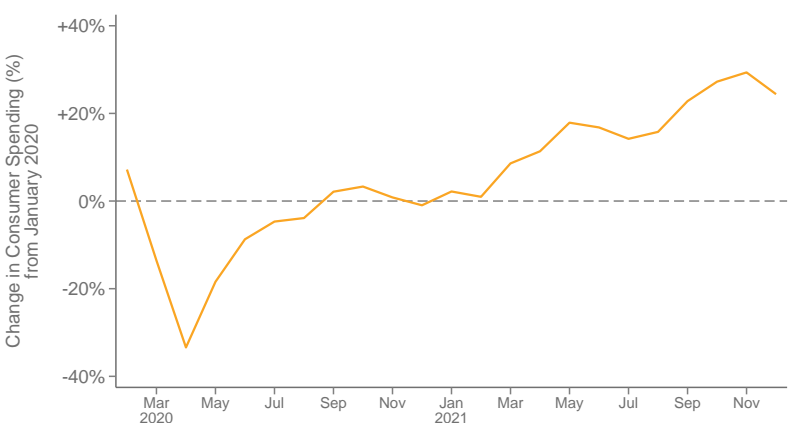

Notes: This figure examines the relationship between low-wage employment and consumer spending for individuals living in a home ZIP code $z$ with the average rent in the ZIP codes of the workplaces for low-wage workers who live in home ZIP code $z$. Panel A presents a binned scatterplot showing the relationship between low-wage employment for workers living in a home ZIP code and the average median rent in the workplace ZIP codes for low-wage workers from that home ZIP code. We measure low-wage employment in each home ZIP code using the Earnin employment series in April 2020. We then match each home ZIP code to the distribution of workplace ZIP codes using the Census' LODES data for low-wage workers. We calculate the x-axis variable as the average median rent for a two-bedroom apartment (measured in the 2014-2018 ACS), averaged across workplace ZIP codes using the distribution from the LODES data for each home ZIP code. See Section IV.C for a detailed discussion. Panel B replicates Panel A for a different outcome: average consumer spending between March 252020 and April 14 2020, restricting to ZIP codes in the bottom quartile of median income, as measured in the 2014-2018 ACS. Panel C replicates Panel B with consumer spending instead measured during the month of October 2020. Panel D plots the average level of consumer spending for the top quartile of households appearing in Panels B and C ranked on average median workplace rent (i.e., the five right-most dots) in each month from February 2020 through December 2021. Data sources: Earnin, Affinity Solutions, Census LODES, ACS. 
Figure 10: Effects of COVID-19 on Educational Progress by Income Group

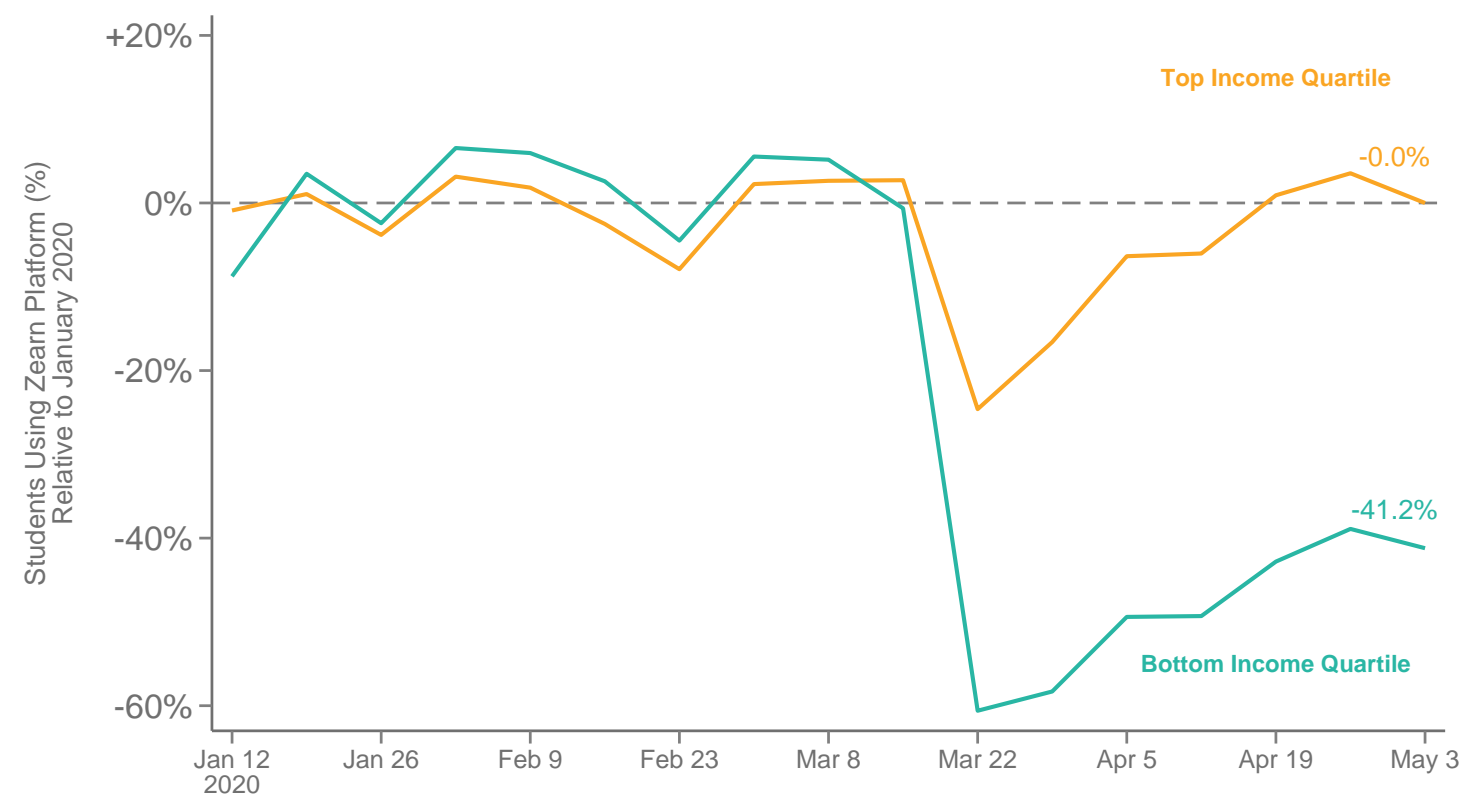

Notes: This figure plots a time series of student engagement on the Zearn Math online platform, splitting schools into quartiles based on the share of students in the school eligible for Free or Reduced Price Lunch (FRPL). We measure student engagement as the average number of students using the Zearn Math application in each week, relative to the mean value of students using the platform in the same classroom during the reference period of January 6 to February 7 2020. We restrict the sample to classrooms with at least 10 students using Zearn on average and at least 5 students doing so in each week during the reference period. We measure the share of students eligible for Free and Reduced Price Lunch in each school using demographic data from the Common Core dataset from MDR Education, a private education data firm. Data sources: Zearn, Common Core. 


\section{Appendix Figure 1: Correction of Structural Breaks in Spending, Small Business Revenue, and Employment}

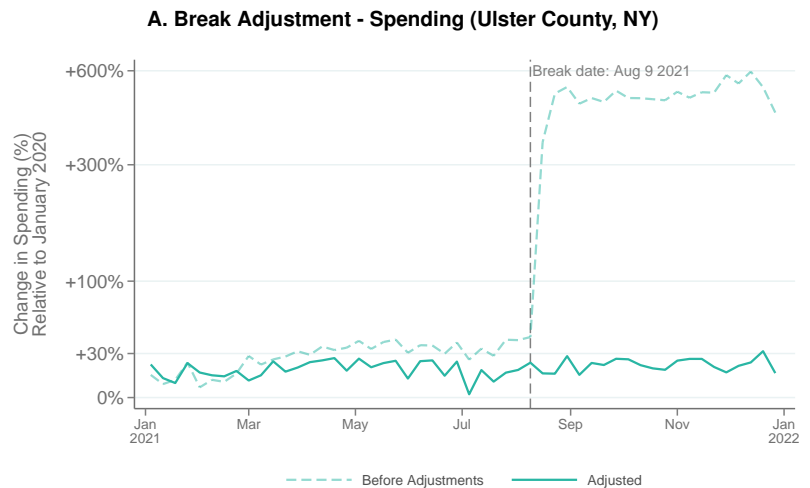

B. Break Adjustment - Small Business Revenue (Connecticut)

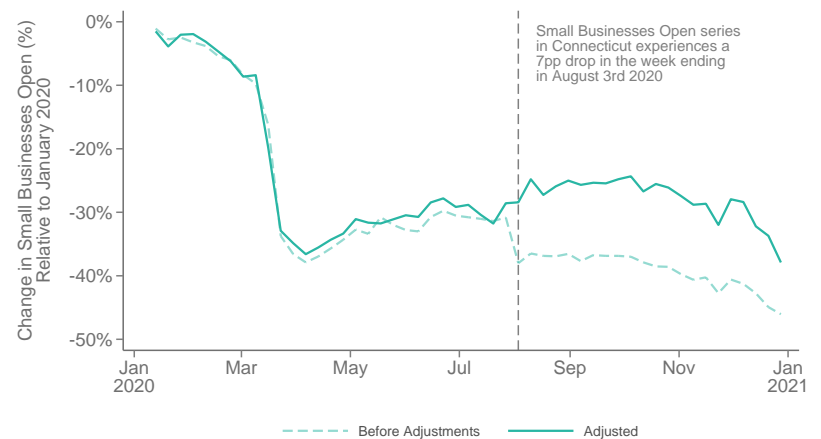

C. Break Adjustment - Employment (National, Q2 and Q3)

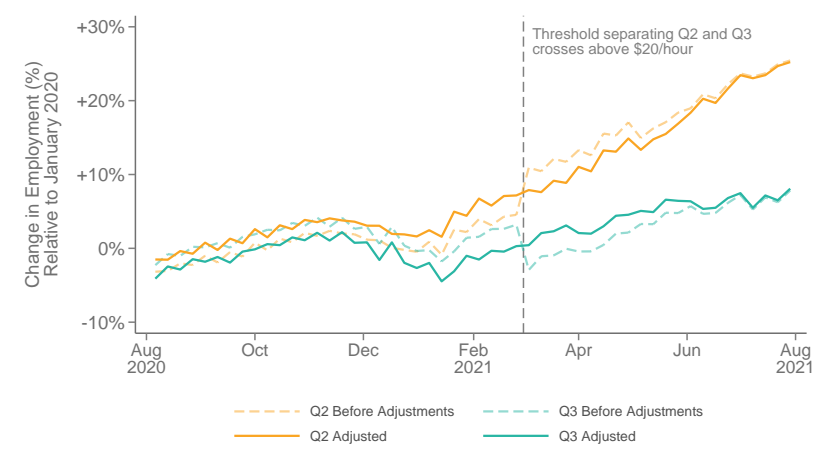

Notes: This figure presents examples of the data adjustment procedures described in Section II for the consumer spending series (Panel A), the small business revenue series (Panel B) and the combined Paychex-Intuit employment series (Panel C). Data sources: Affinity Solutions, Womply, Paychex, Intuit. 


\section{Appendix Figure 2: Industry Shares of Consumer Spending and Business Revenues Across Datasets}

A. Compared to QSS

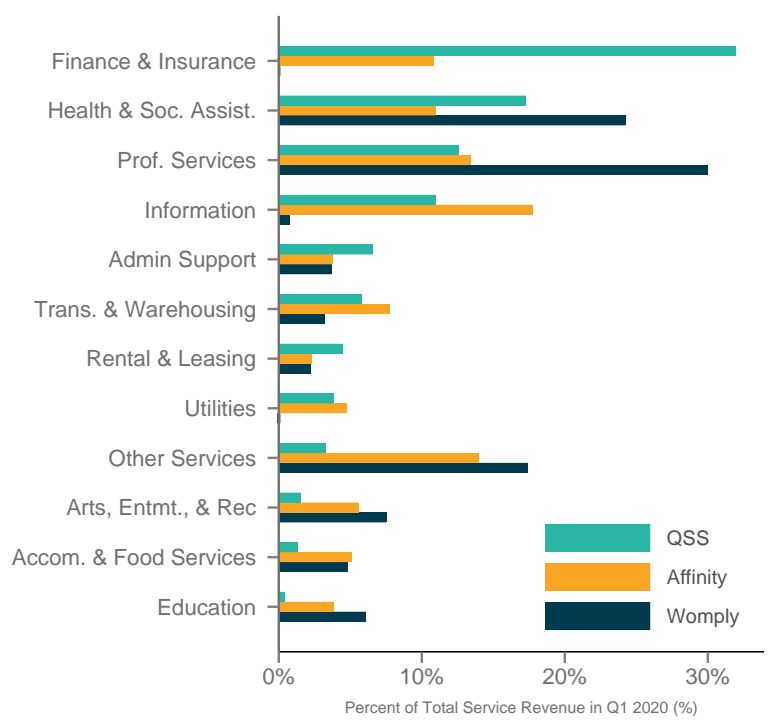

B. Compared to MARTS

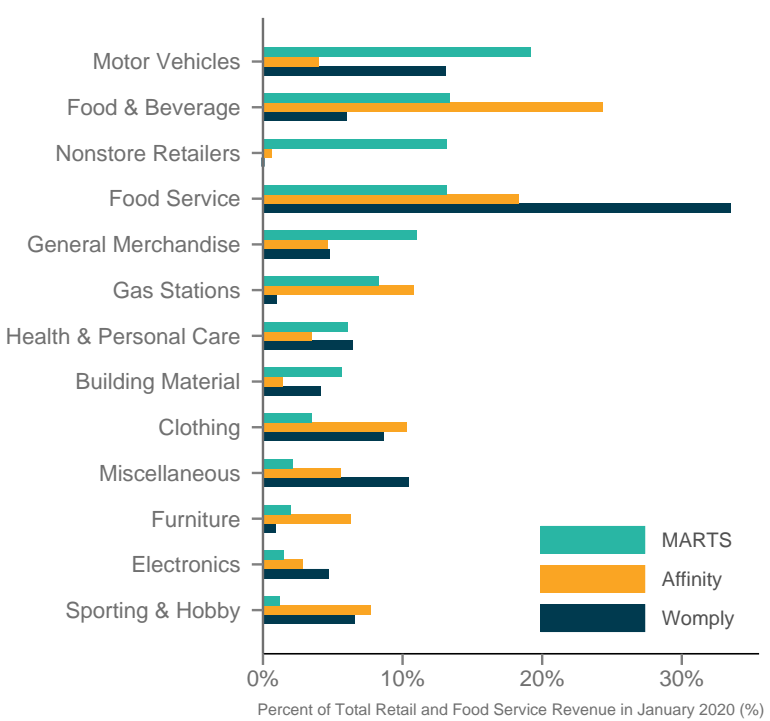

Notes: This figure compares the industry composition of spending in private sector datasets to the industry composition of spending in representative survey datasets. Panel A shows the NAICS 2-digit industry mix for transactions in the Affinity Solutions and Womply datasets compared with the Quarterly Services Survey (QSS), a survey dataset providing timely estimates of revenue and expenses for selected service industries. Subsetting to the industries in the QSS, each bar represents the share of revenue in the specified sector during Q1 2020 . We construct spending and revenue shares for the Affinity Solutions and Womply datasets (respectively) by aggregating card transactions in Q1 2020, using the merchant to classify the purchase by sector. Panel B shows the NAICS 3-digit industry mix for the same two sector private datasets compared with the Advance Monthly Retail Trade Survey (MARTS), another survey dataset which provides current estimates of sales at retail and food services stores across the United States. Subsetting to the industries in the MARTS, each bar represents the share of revenue in the specified sector during January 2020. We construct revenue shares for the private datasets, Affinity and Womply, by aggregating firm revenue from card transactions in January 2020. Data sources: Affinity Solutions, Womply, QSS, MARTS. 


\section{ApPendix Figure 3: Industry Shares of Job Postings in Lightcast and JOLTS}

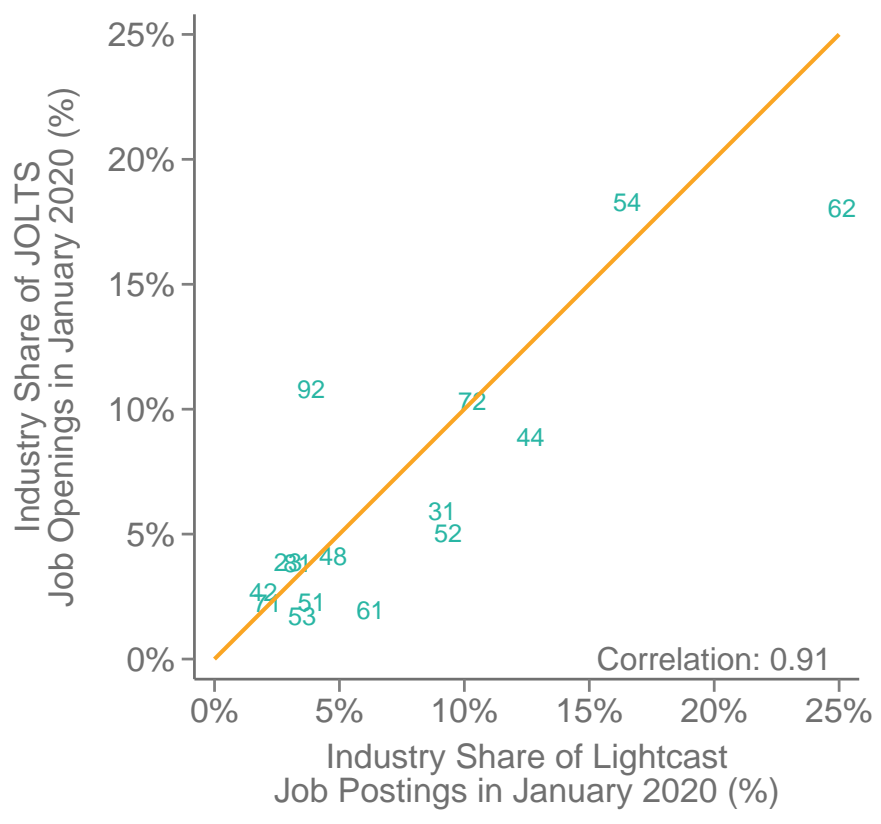

Notes: This figure presents a scatter plot showing the industry share of each 2-digit NAICS code of job postings in the Job Openings and Labor Turnover Survey (JOLTS) data in January 2020 vs. the corresponding industry share in job postings in Lightcast data in January 2020. The solid line is a 45 degree line. The annotation in the bottom right corner of the panel displays the correlation between 2-digit NAICS industry shares in the JOLTS vs. Lightcast data in January 2020, excluding NAICS 92 (Public Administration), and weighting according to total job openings in each NAICS code in JOLTS in January 2020. Data sources: Lightcast, JOLTS. 


\section{Appendix Figure 4: Seasonal Fluctuations in Consumer Spending vs. Employment}

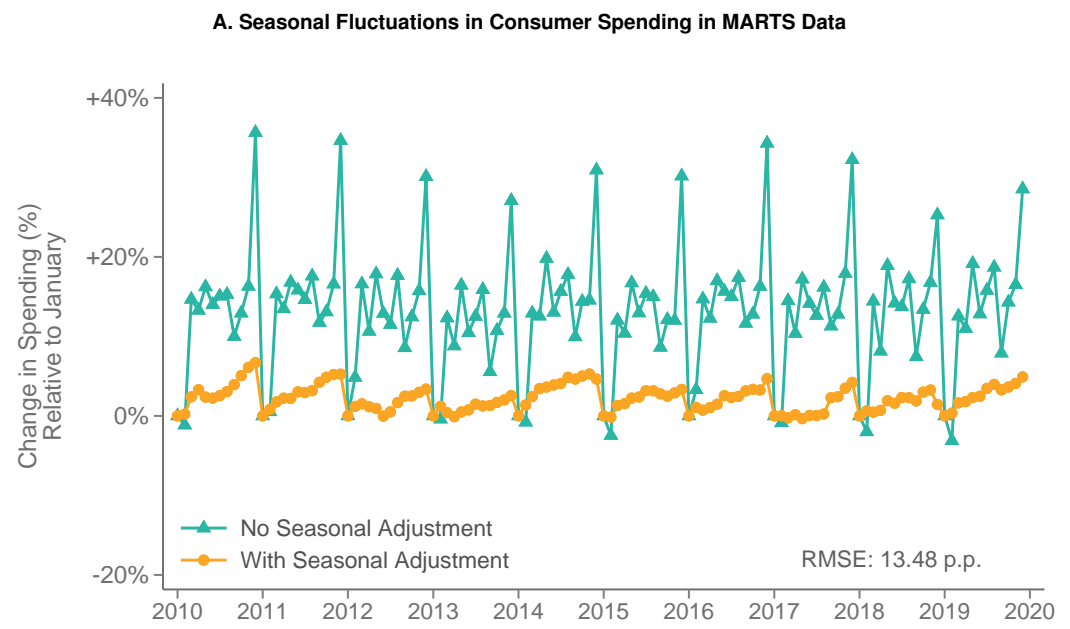

B. Seasonal Fluctuations in Employment in CES Data

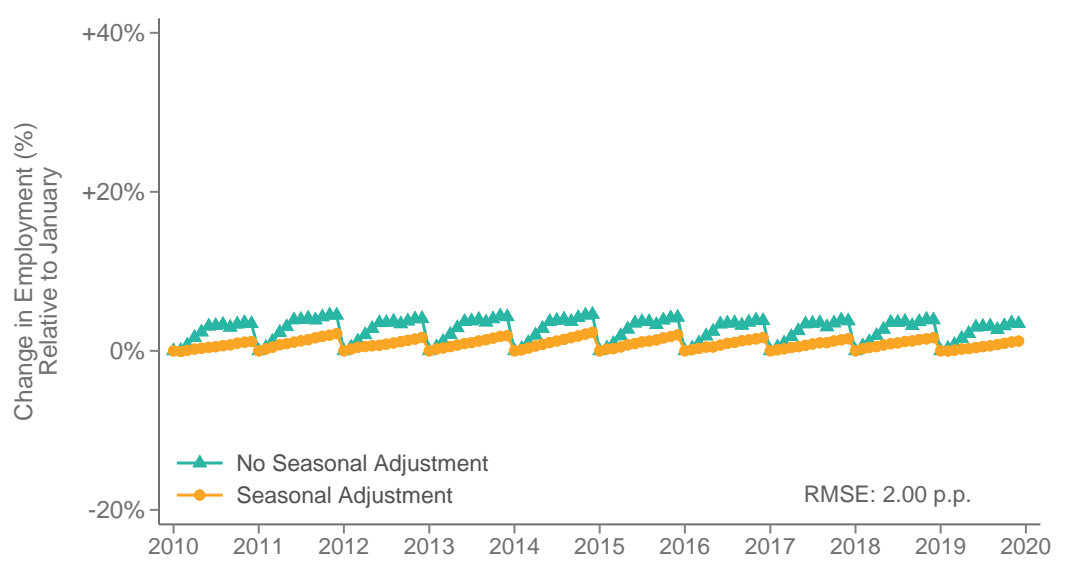

Notes: This figure compares seasonal fluctuations in Advance Monthly Retail Trade Survey (MARTS) data on consumer spending on retail sales and food services (excluding motor vehicle and gas) vs. Current Employment Statistics (CES) data on private sector non-farm employment. Panel A shows seasonal fluctuations in consumer spending in MARTS data. The series marked in triangles shows trends in consumer spending without seasonal adjustment, expressed as percentage changes in consumer spending in each month relative to January of the same year. The series marked in circles shows trends in consumer spending, as seasonally adjusted by the U.S. Census Bureau, expressed as percentage changes in consumer spending in each month relative to January of the same year. The annotation in the lower right hand corner displays the RMSE for the difference between the two series. Panel B replicates Panel A using CES data on private sector, non-farm employment. Data sources: MARTS, CES. 


\section{Appendix Figure 5: Consumer Spending in National Accounts vs. Credit and Debit Card Data}

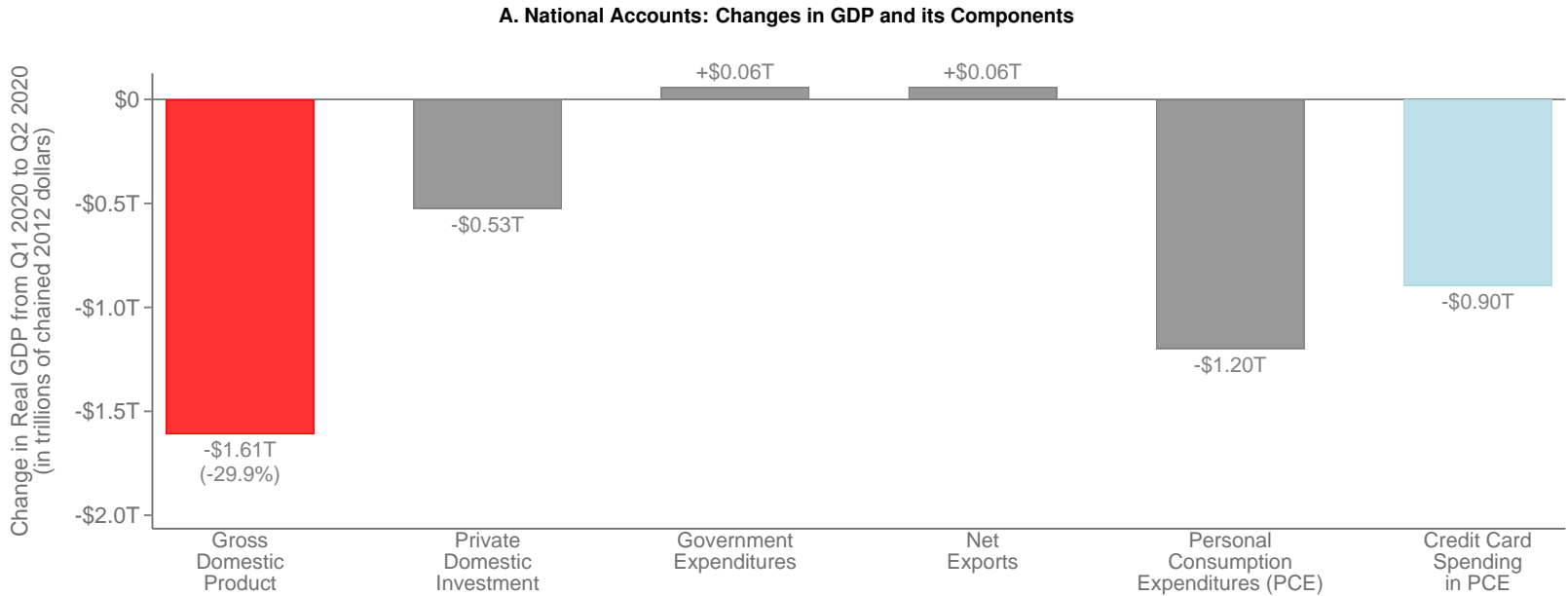

B. Affinity Solutions Data vs. Advance Monthly Retail Trade Survey

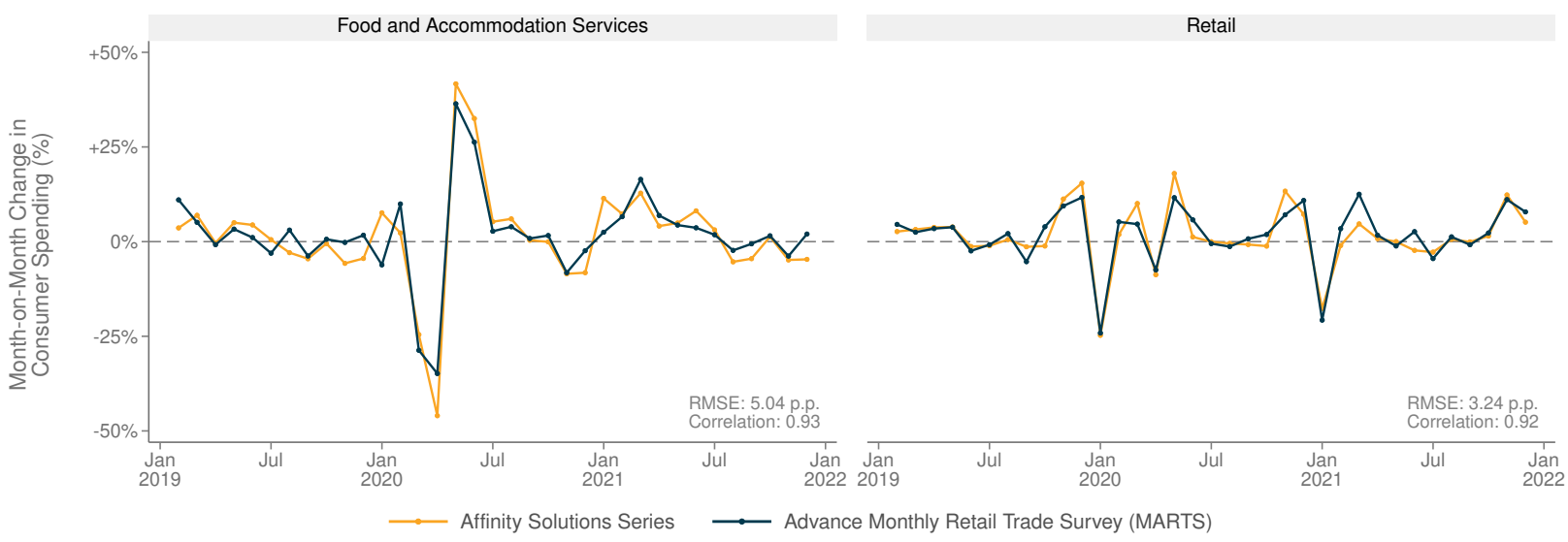

Notes: This figure examines changes in consumer spending measured in Affinity Solutions credit and debit card data, National Income and Product Accounts (NIPA) data, and Advance Monthly Retail Trade Survey (MARTS) data. Panel A shows the change in GDP from Q1 to Q2 2020 using NIPA data (Tables 1.1.1, 1.1.6 and 2.3.2). The first bar shows the seasonally-adjusted decline in real GDP $(\$ 1.61 \mathrm{~T})$. In parentheses under the first bar we report the compound annual growth rate corresponding to this change in real GDP (29.9\%). Bars two through five decompose the change in real GDP, estimated using NIPA Table 1.1.1. The final bar shows the contribution of components of Personal Consumption Expenditures (PCE) that are likely to be captured in credit card spending ( $\$ 0.90 \mathrm{~T})$, estimated using NIPA Table 2.3.2. This includes all components of PCE except for motor vehicles and parts, housing and utilities, health care, and the final consumption expenditures of nonprofit institutions serving households. This bar indicates total spending (including spending in other modes of payment such as cash) in categories of goods and services which are likely to be well represented in card spending data, rather than total card spending itself. Panel B reports month-on-month changes in average daily spending for each month in the Affinity Solutions credit and debit card data and the Advance Monthly Retail Trade Survey (MARTS). The Food and Accommodation Services series in Panel B restricts to NAICS 72; the Retail series restricts to NAICS 44-45. The MARTS series in Panel B are constructed by dividing the total spending in each category by the number of days in that month, and then indexing to the average daily spending of January 2019. The Affinity series are constructed by taking the monthly average of the seven-day moving average series, indexed to January 2019. We also report the root mean squared error (RMSE) corresponding to the difference between these two series. Data sources: Affinity Solutions, NIPA. 


\section{Appendix Figure 6: Consumer Spending Benchmarks, Affinity vs. MARTS and}

CoinOut
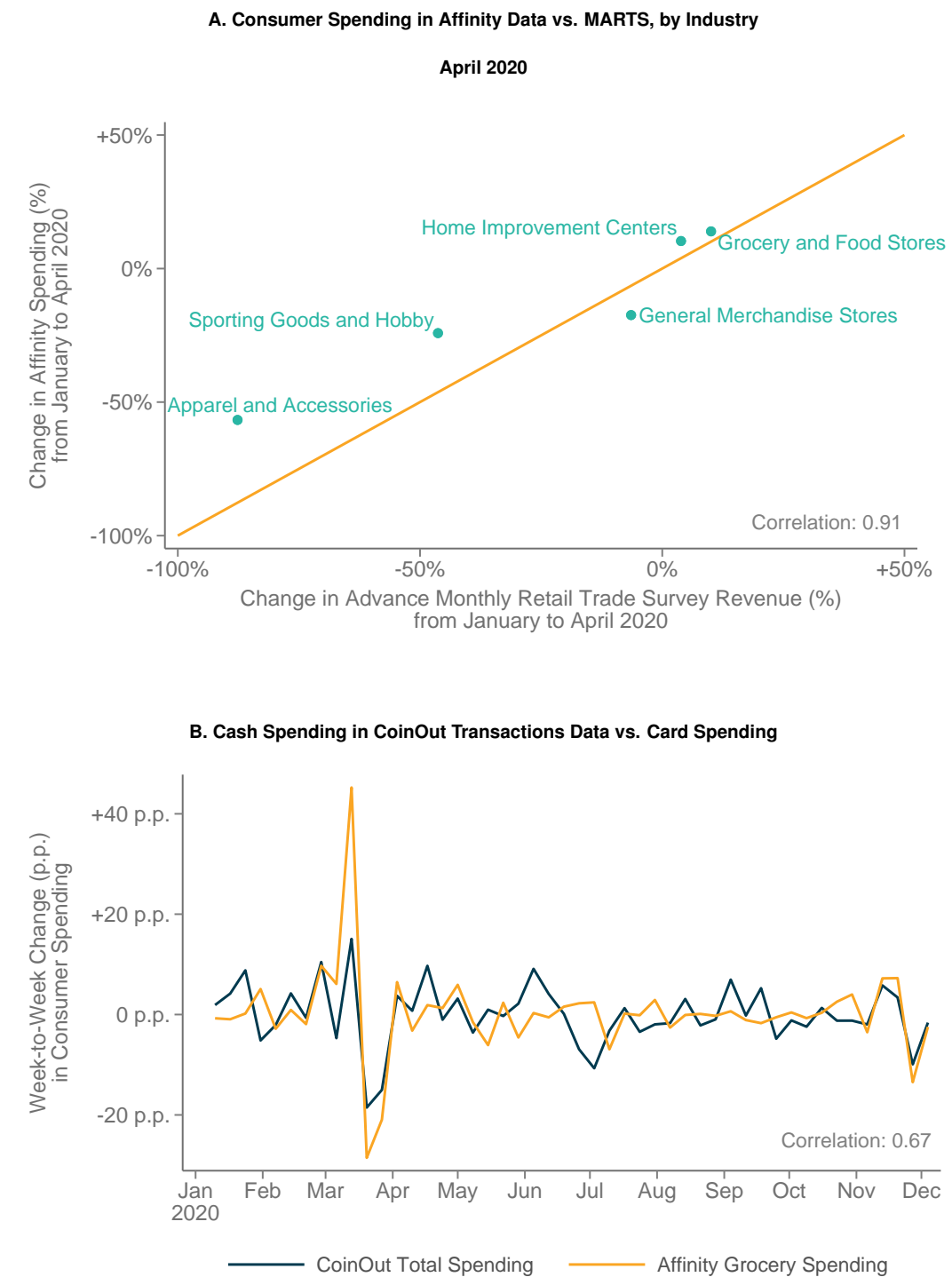

Notes: This figure benchmarks Affinity Solutions data against MARTS and CoinOut data. Panel A displays a scatter plot of changes in spending at the three-digit NAICS code level between January and April 2020 in the Affinity data vs. the MARTS data, restricting to industries where the industry definitions in the Affinity Solutions data align closely with a three-digit NAICS code surveyed in the MARTS. We report the correlation between changes in the Affinity and MARTS data, weighted by total MARTS spending in January 2020. Panel B compares week-to-week changes of national trends in cash transactions in CoinOut data vs. card spending on groceries in Affinity Solutions data between January 12020 and December 31 2020. See Appendix B.3 for a description of the CoinOut data. Data sources: CoinOut, Affinity Solutions, MARTS. 


\section{Appendix Figure 7: Association Between COVID-19 Incidence and Mobility}

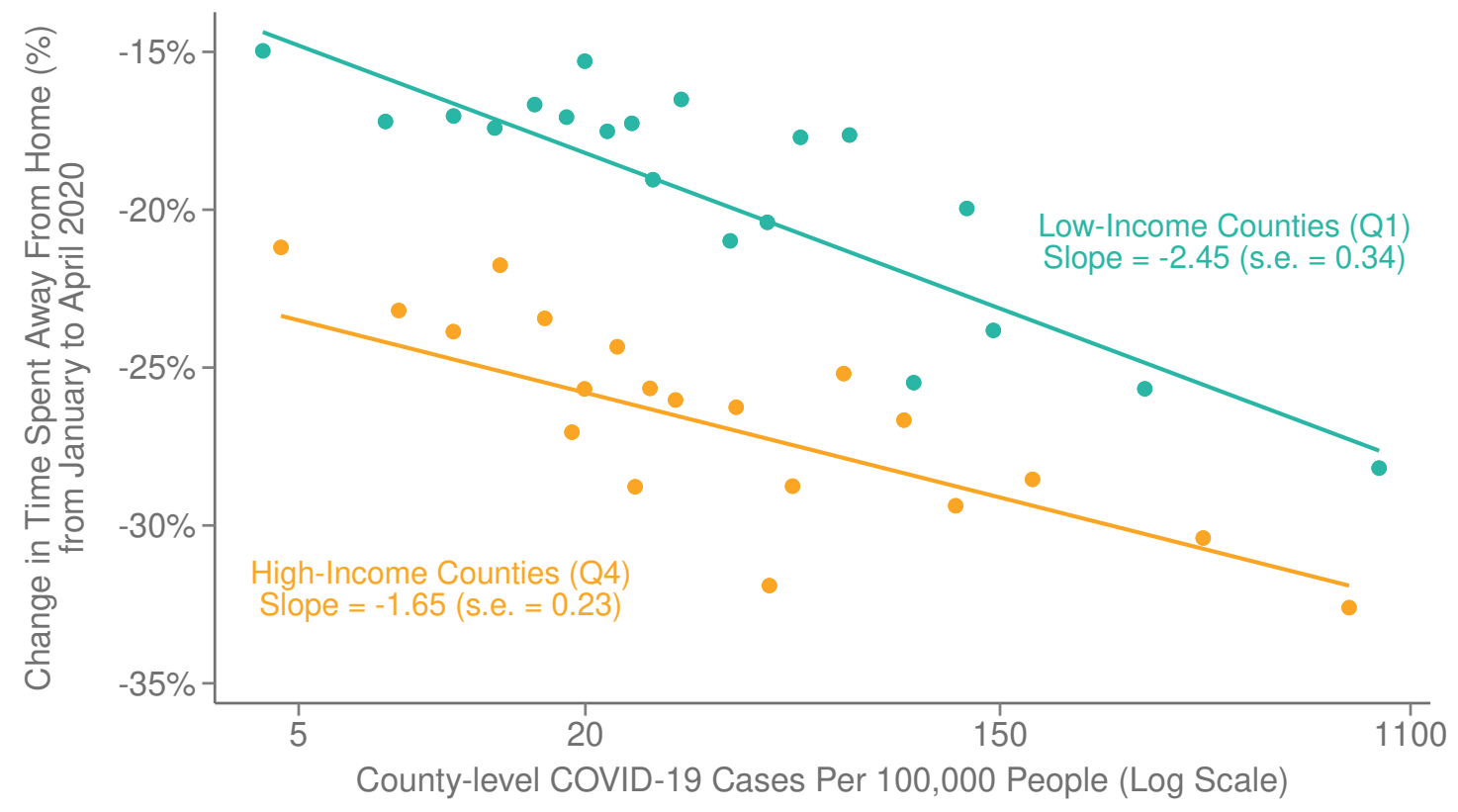

Notes: This figure presents a county-level binned scatter plot, constructed as described in Figure 2. The y-axis presents the change in time spent away from home from the base period (Jan 3-Feb 6 2020) to the three-week period of March 25-April 142020 (see Appendix H for details on the time-away-from-home series from Google Community Mobility Reports). The x-axis variable is the logarithm of the county's cumulative COVID case rate per capita as of April 14, 2020; with axis labels showing the levels on a logarithmic scale. We plot values separately for counties in the top and bottom quartiles of median household income (measured using population-weighted 2014-2018 ACS data). Data sources: Google Community Mobility Reports, New York Times. 


\section{Appendix Figure 8: Small Business Revenue Changes vs. Consumer Spending Changes}

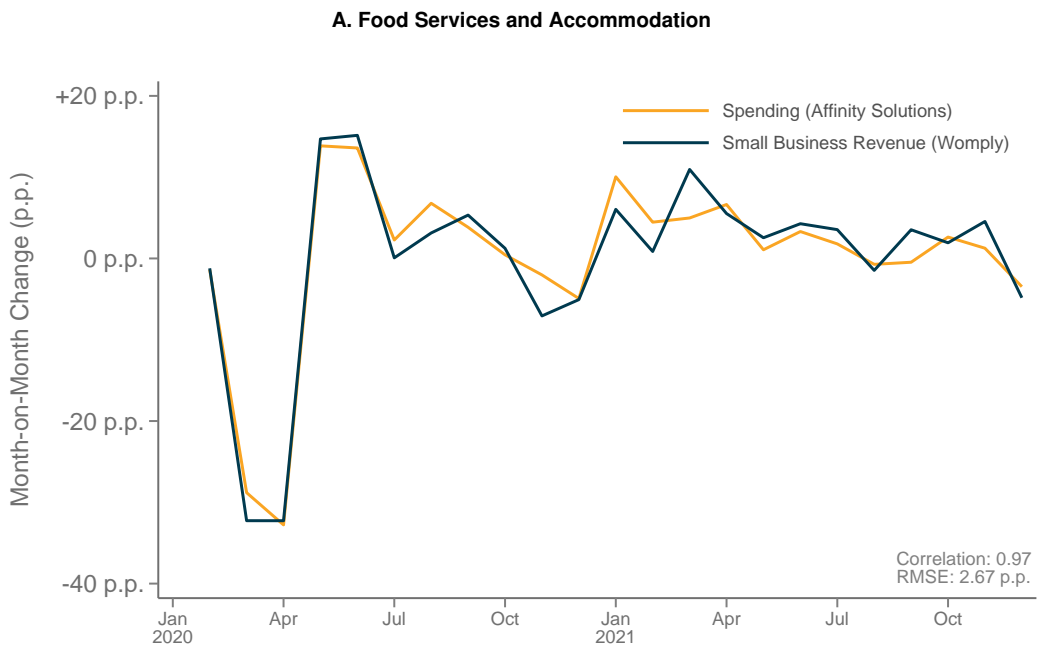

B. Retail Services

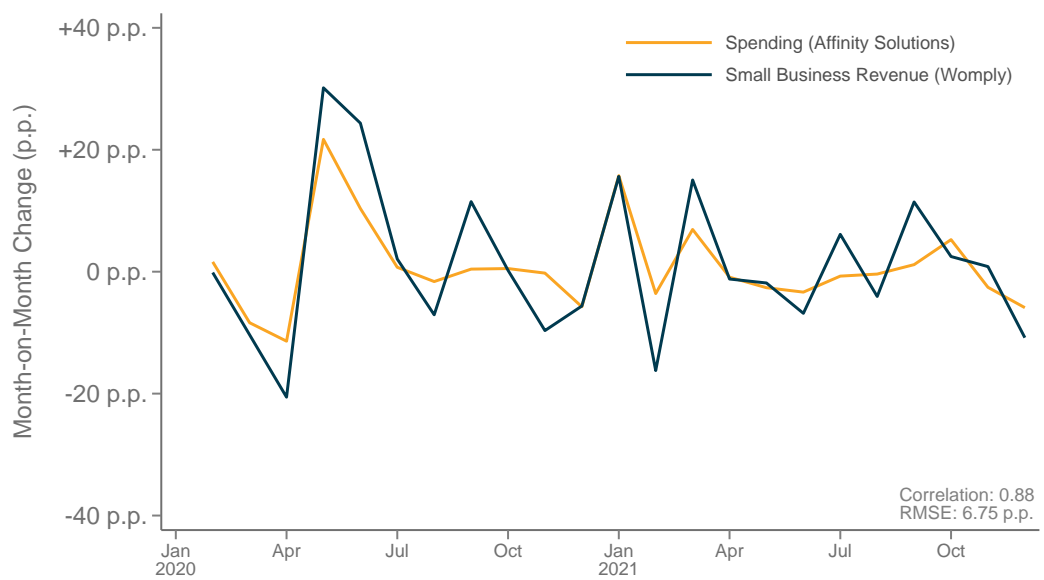

Notes: This figure compares the month-on-month changes in total consumer spending (from Affinity Solutions data) and small business revenue (from Womply data) for the period from January 2020 to December 2021 . The spending series is expressed as a percentage change relative to January 6 - February 2, 2020 and the small business revenue series is expressed as a percentage change relative to January 4-31 2020. We do not seasonally adjust spending or small business revenue in this figure because seasonal fluctuations provide useful variation to assess whether the consumer spending series tracks the small business revenue series. Panel A restricts to food services and accommodation (NAICS code 72), and Panel B restricts to retail trade sectors (NAICS code 44-45). The bottom right corner of each panel reports the root mean squared error (RMSE) corresponding to the difference between the two lines and the correlation between the month-on-month changes series. Data sources: Affinity Solutions, Womply. 


\section{Appendix Figure 9: National Trends in Small Business Revenue and Job Postings for}

Low-Education Workers

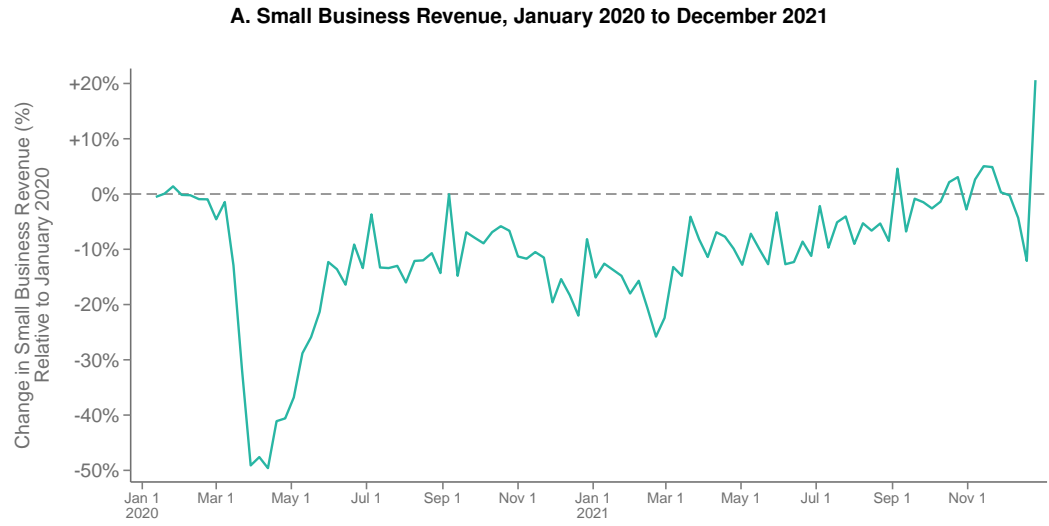

B. Job Postings for Low-Education Workers, January 2020 to December 2021

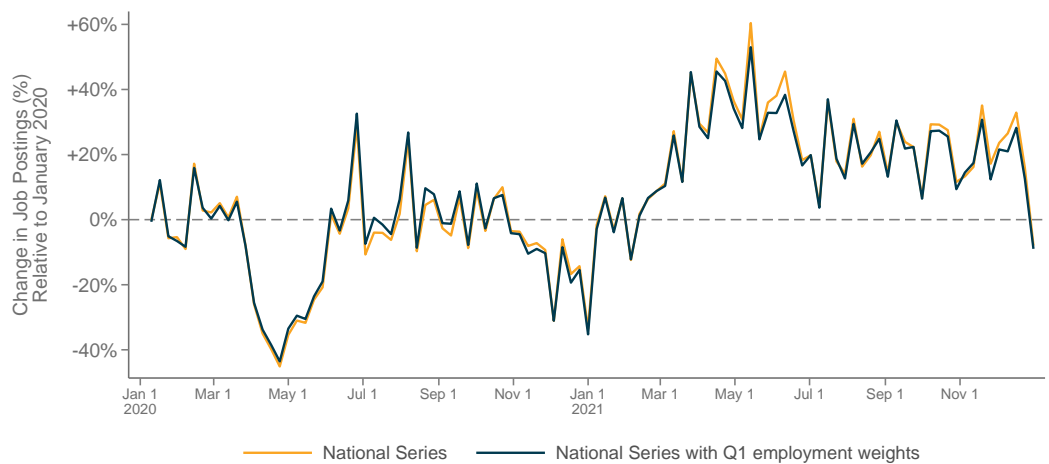

Notes: Panel A shows the changes in small business revenue between January 2020 and December 2021, relative to January 4-31 2020. Panel B shows the changes in job postings for low-education workers between January 2020 and December 2021, relative to January 4-31 2020. To address potential spatial mismatch in job postings, in the orange series of panel B, we reweight county-level job postings by the number of bottom-wage-quartile workers in January 2020 (as derived from the Paychex-Intuit data) and aggregate to the national level. Data sources: Womply, Lightcast, Paychex, Intuit. 


\section{Appendix Figure 10: Changes in Small Business Revenues by ZIP Code}
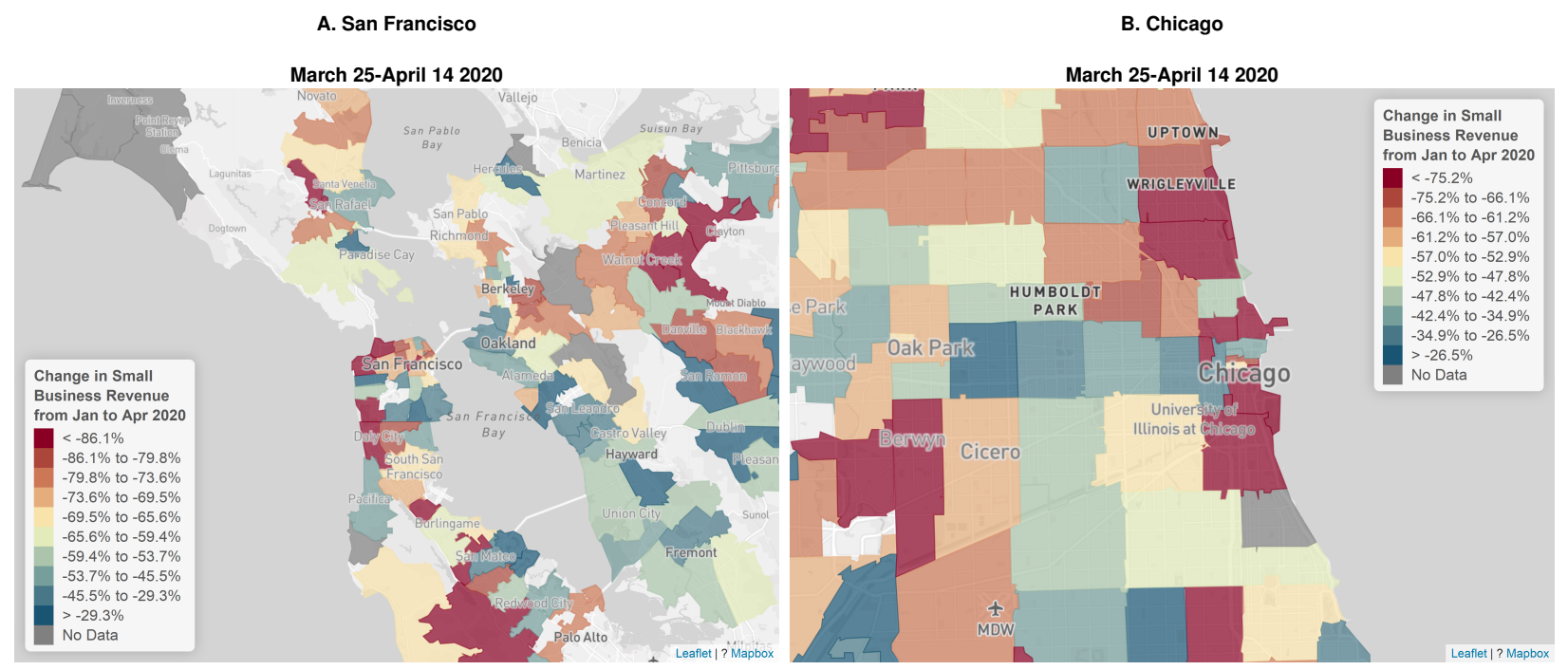

C. New York City

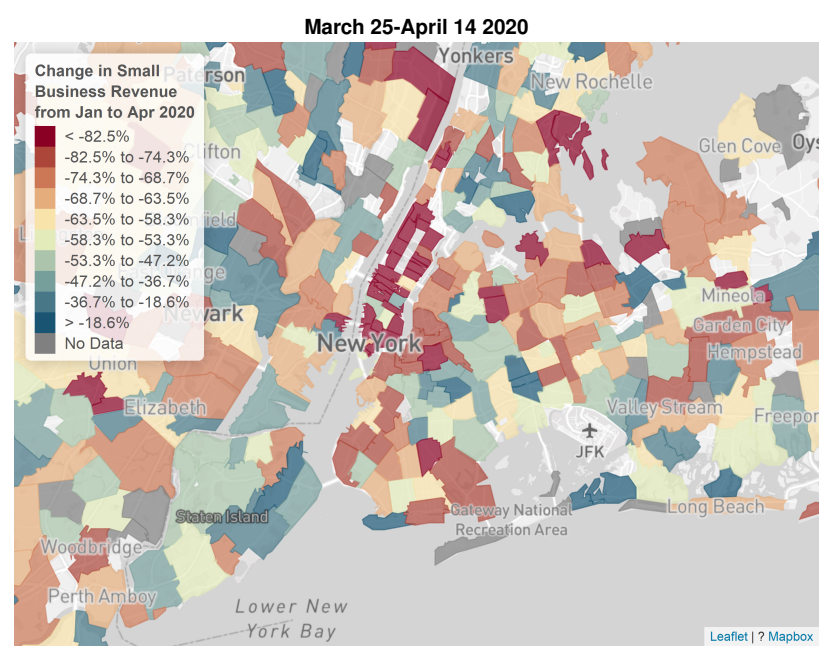

Notes: This figure plots seasonally-adjusted changes in small business revenue by ZIP code in the MSAs corresponding to San Francisco-Oakland-Hayward, CA (Panel A), Chicago-Naperville-Elgin, IL-IN-WI (Panel B), and New York-Newark-Jersey City, NY-NJ-PA (Panel C). The changes are measured during March 23 to April 122020 relative to January 4-31 2020. We seasonally-adjust revenue in each week by dividing the indexed value relative to January for that week in 2020 by the corresponding indexed value from 2019 . These maps must be viewed in color to be interpretable; dark red colors represent areas with larger revenue declines, while dark blue colors represent areas with smaller declines. Data source: Womply. 


\section{Appendix Figure 11: Changes in Small Business Revenues vs. ZIP Code Characteristics}

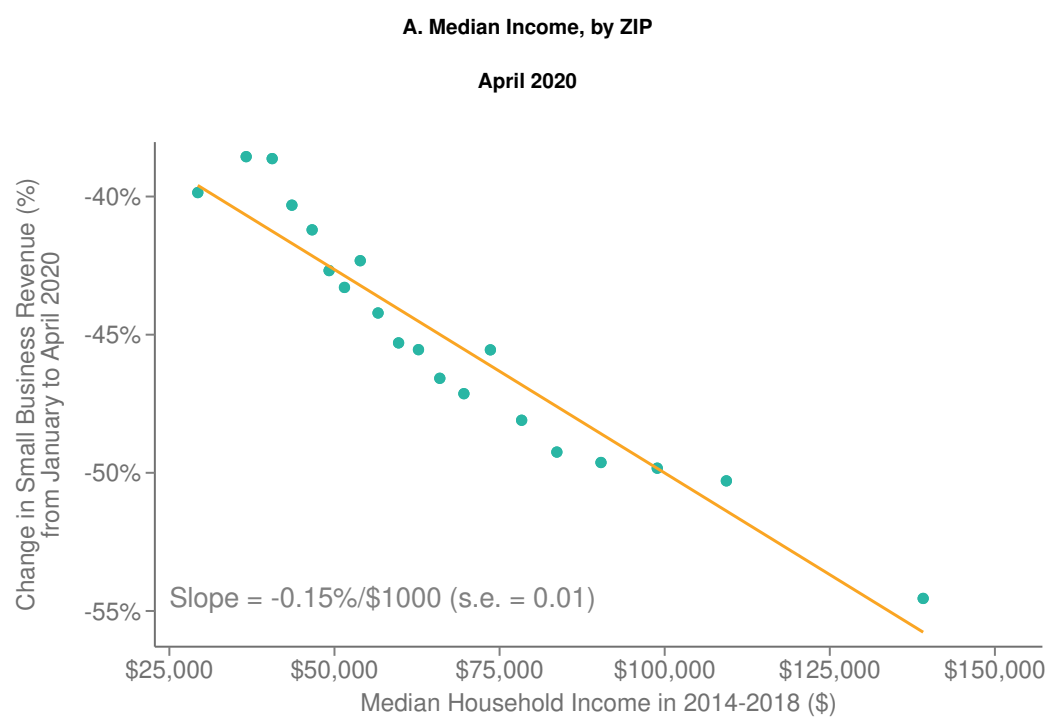

B. Population Density, by ZIP

April 2020

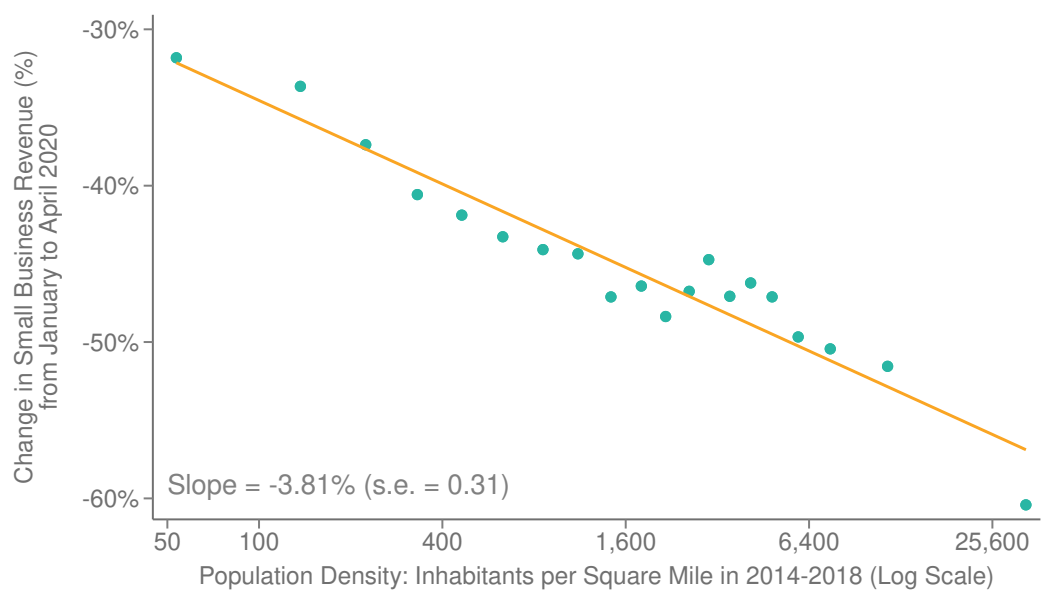

Notes: This figure presents binned scatter plots showing the relationship between changes in seasonally-adjusted small business revenue in Womply data vs. various local area characteristics at the ZIP code level. In each panel, we measure changes in small busines revenue as the average value of our index at the ZIP code level during the period of March 23 to April 12, 2020 (see Section II.B and Appendix C for details on the construction of our small business revenue series). In Panel A, the $\mathrm{x}$-axis variable is median household income at the ZIP code level from the 2014-2018 ACS. In Panel B, the $\mathrm{x}$-axis variable is the logarithm of the number of ZIP code inhabitants per square mile in the 2014-18 ACS; with axis labels showing the levels on a logarithmic scale. Data sources: Womply, ACS. 


\section{Appendix Figure 12: Changes in Small Business Revenues vs. Local Characteristics}
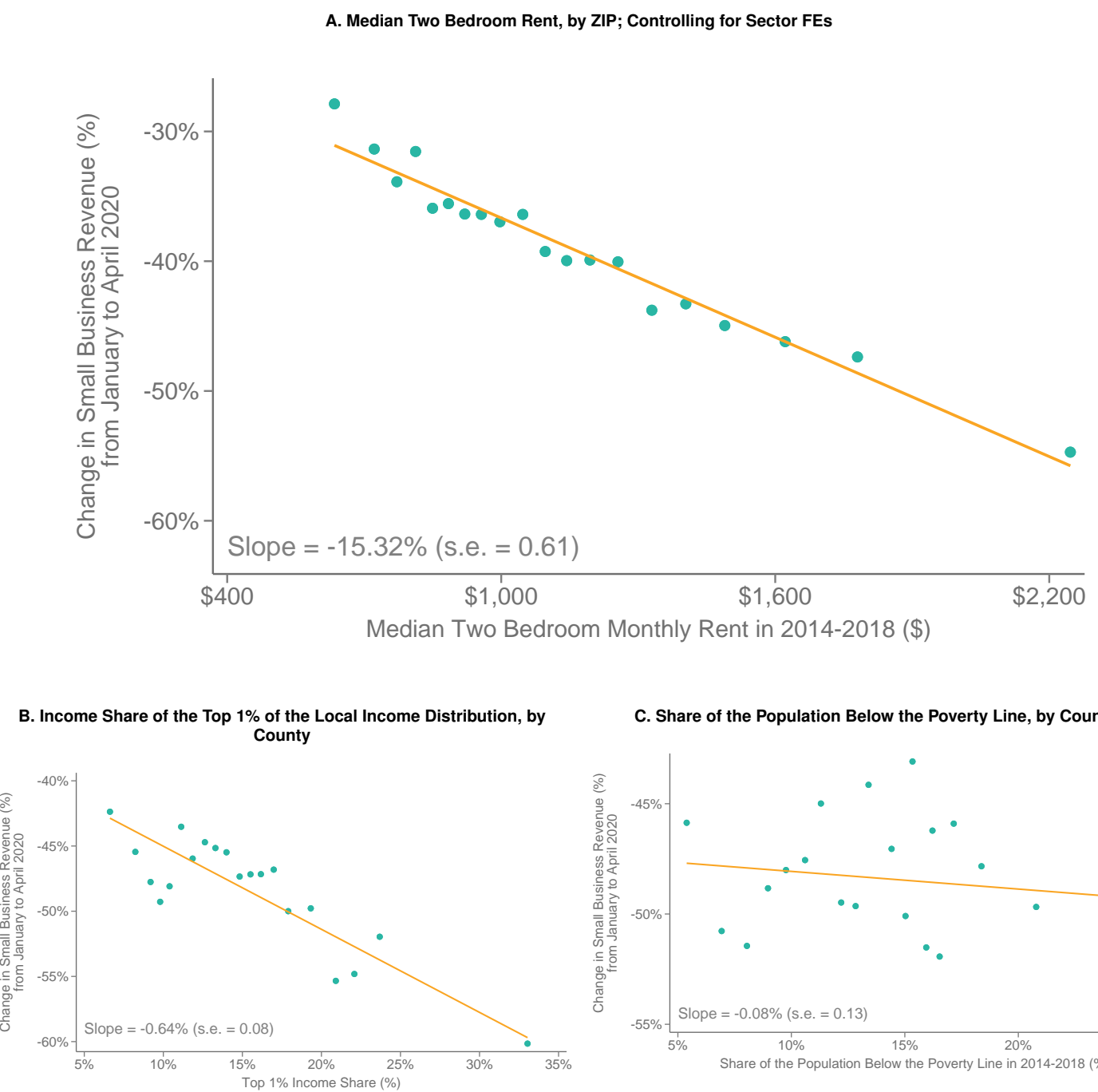

C. Share of the Population Below the Poverty Line, by County

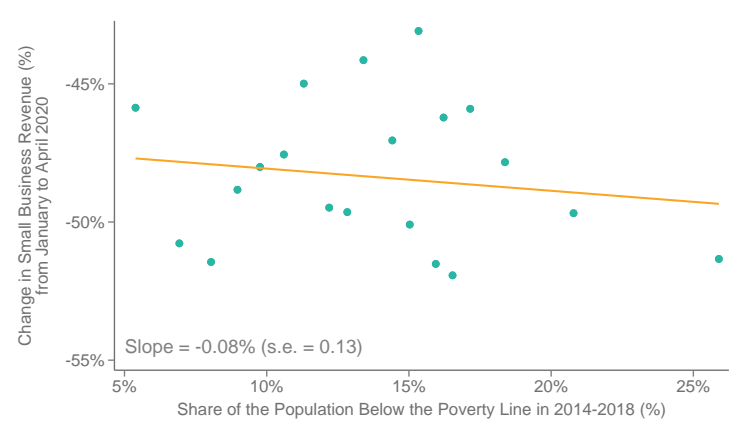

Notes: This figure shows the association between ZIP-level or county-level characteristics and changes in small business revenues between January 4-31 2020 and March 23-April 12 2020, as measured in Womply data. Panel A presents a binned scatter plot of changes in small business revenue at the ZIP $\mathrm{x}$ sector (2-digit NAICS) level vs. median two-bedroom rent at the ZIP level, controlling for sector fixed effects. Panels B and C replicate Figure 3 but compare the declines in small business revenue with various measures of the distribution of income at the county level. Panel B presents a binned scatter plot of changes in small business revenue vs. the income share of the top $1 \%$ of the income distribution within each county, constructed using the distribution of parent incomes in Chetty et al. (2014). The top $1 \%$ of the income distribution is defined using the distribution of incomes within each county, rather than the national income distribution. Panel $\mathrm{C}$ presents a binned scatter plot of changes in small business revenue vs. the share of the county population with incomes below the poverty line in the 2014-2018 ACS. Data source: Womply. 


\section{Appendix Figure 13: Changes in Employment Rates Over Time}

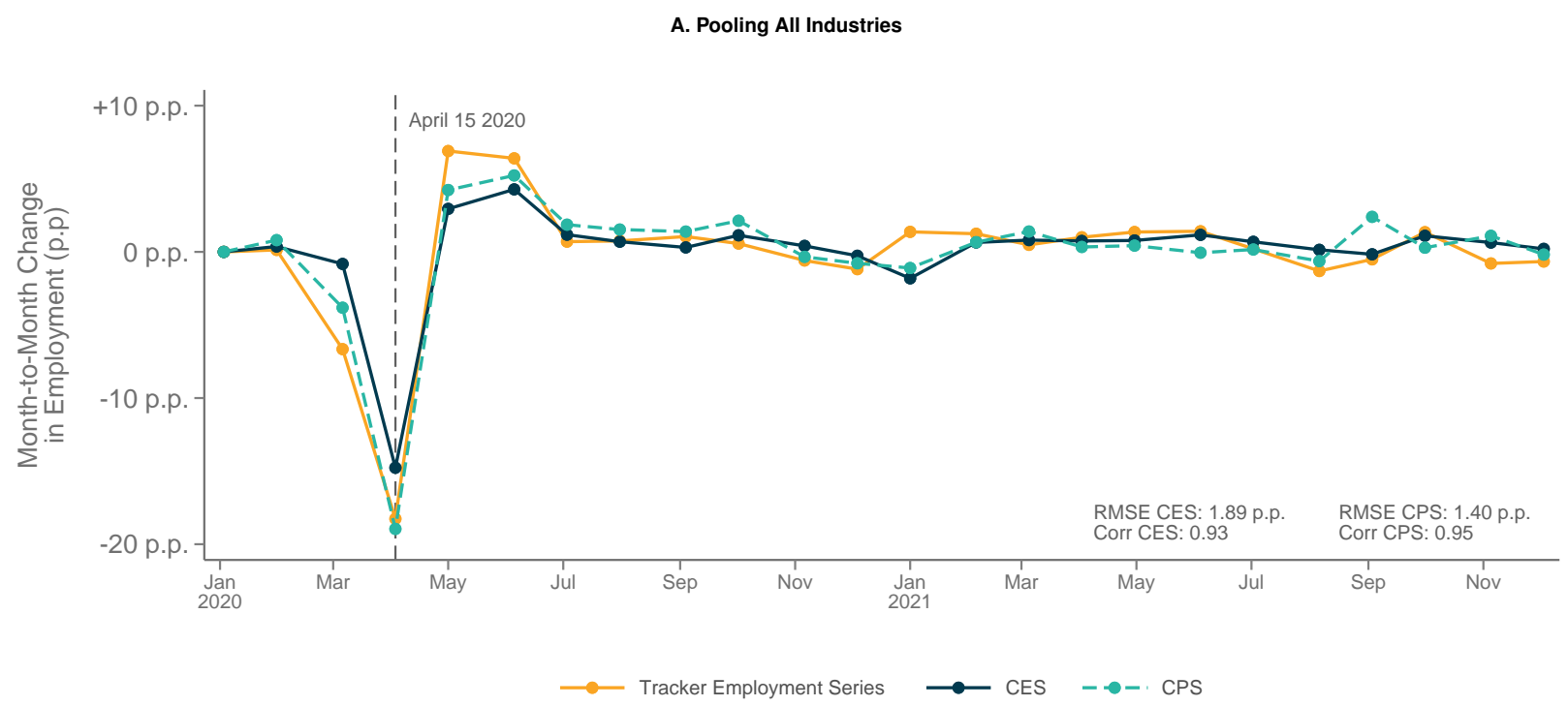

B. Accommodation and Food Services vs. Professional Services

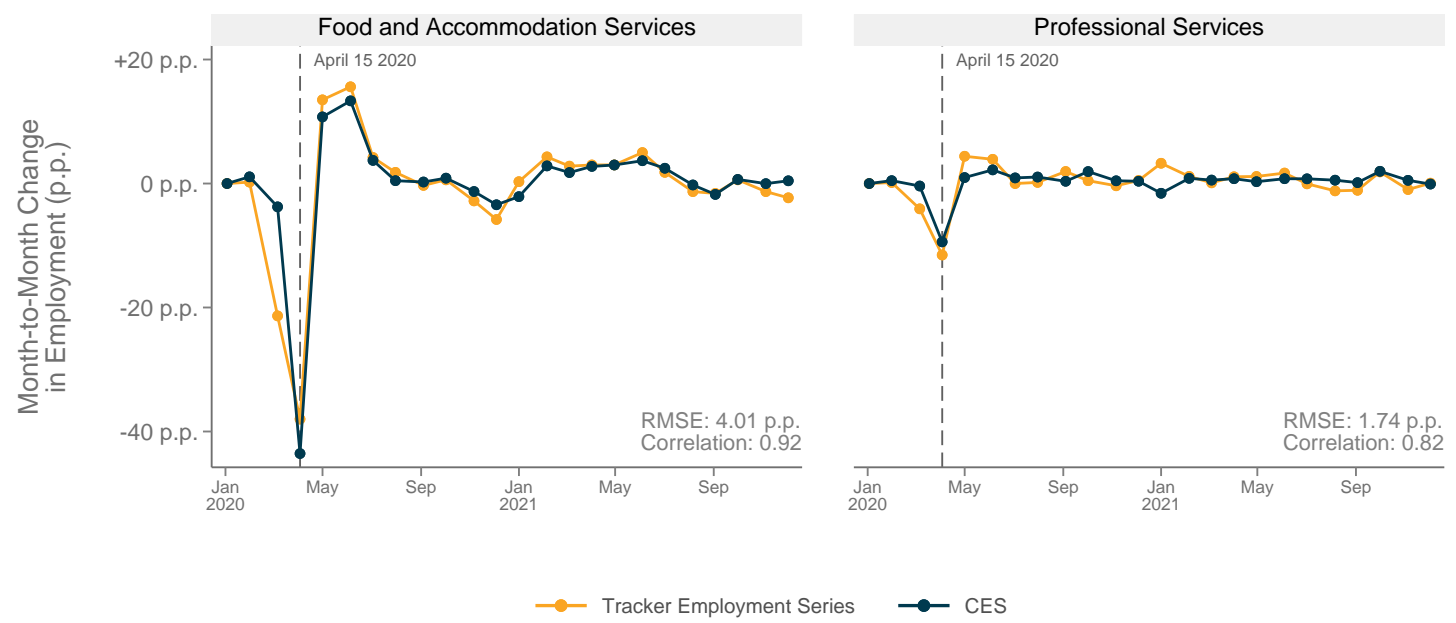

Notes: This figure compares month-to-month changes in employment, as measured in three different datasets. The series for the combined Paychex-Intuit dataset plots values of the changes measured as of the week of the 15th of a given month relative to the same value on the week of the 15 th of the prior month. The series for the Current Employment Statistics (CES) and Current Population Survey (CPS) plot the change to the current monthly value relative to the prior monthly value. Panel A presents data from these three series pooling employment in all private non-farm sectors. Panel B repeats Panel A restricting to employment in the Food and Accommodation sector (NAICS 72) and the Professional and Business Services sector (NAICS 61-62). Data sources: Paychex, Intuit, CES, CPS. 
Appendix Figure 14: Changes in Employment as of July 2020 in Paychex-Intuit Data vs. CES and QCEW

A. Change in Employment Rates by Industry (2-Digit NAICS): Paychex-Intuit vs.

CES

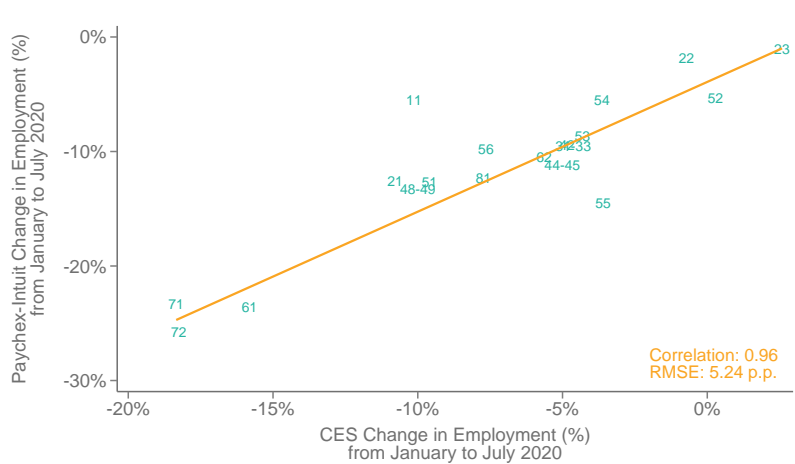

B. Change in Employment Rates by State: Paychex-Intuit vs. CES

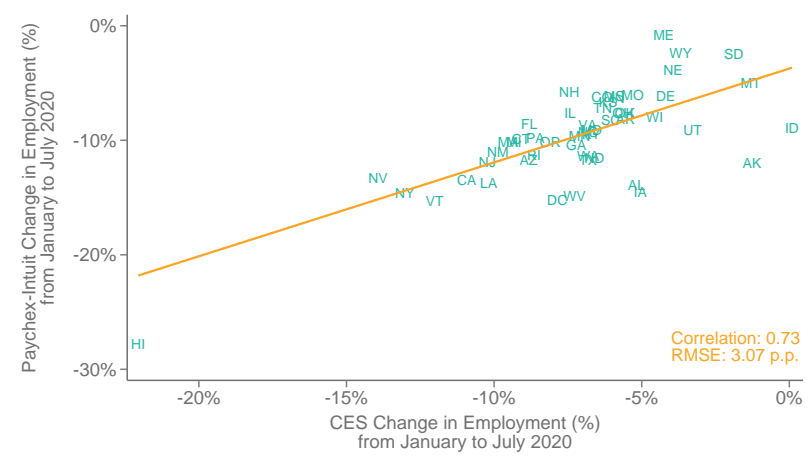

C. Change in Employment Rates by Commuting Zone: Paychex-Intuit vs. QCEW

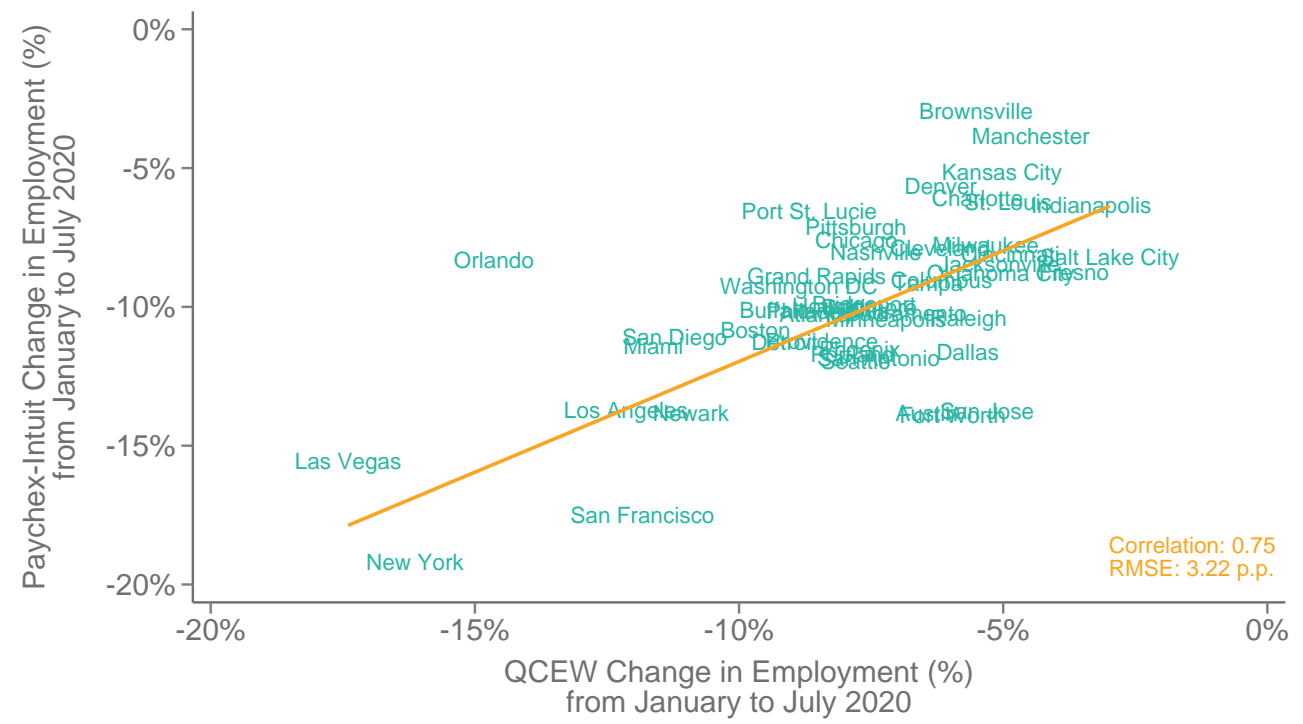

Notes: This figure benchmarks the Paychex-Intuit combined employment series to the Current Employment Statistics (CES) and the Quarterly Census of Employment and Wages (QCEW). Panel A shows a scatter plot of changes in employment in Paychex-Intuit combined data between January 4-31 2020 and July 172020 vs. changes in CES employment between January and July by industry (2-digit NAICS code). Panel B shows a scatter plot of changes in employment in Paychex-Intuit combined data between January 4-31 2020 and July 172020 vs. changes in CES employment between January and July, by state. Panel C shows a scatter plot of changes in employment in Paychex-Intuit combined data between January 4-31 2020 and July 172020 vs. changes in QCEW employment between January and July, by commuting zone for the 50 largest commuting zones by population. In all panels, the bottom right corner displays the correlation between the data points in each graph, weighted respectively by CES employment in each NAICS code (Panel A), state population (Panel B), and commuting zone population (Panel C). Data sources: Paychex, Intuit, CES, QCEW. 


\section{ApPendix Figure 15: Employment in Paychex-Intuit Data vs. ADP and CPS}

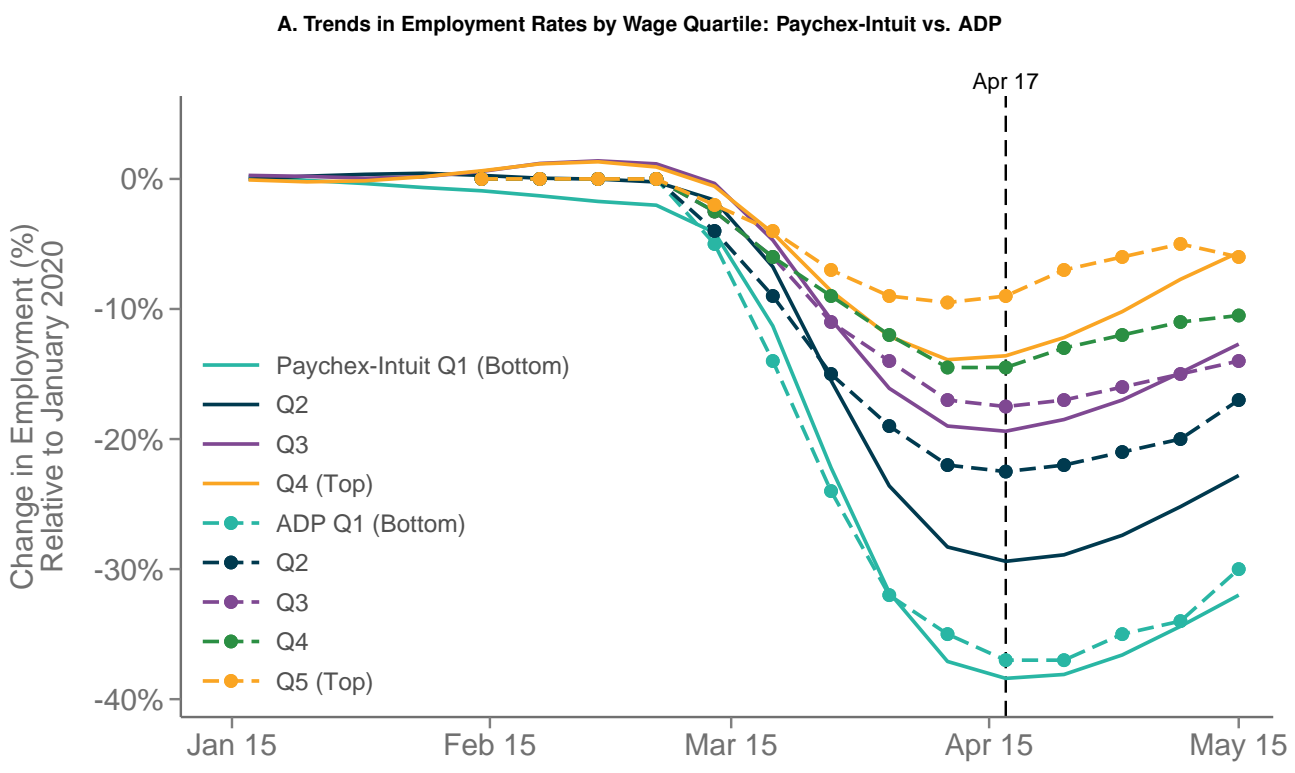

B. Change in Employment Rates by Wage Quartile: Paychex-Intuit vs. ADP vs. CPS

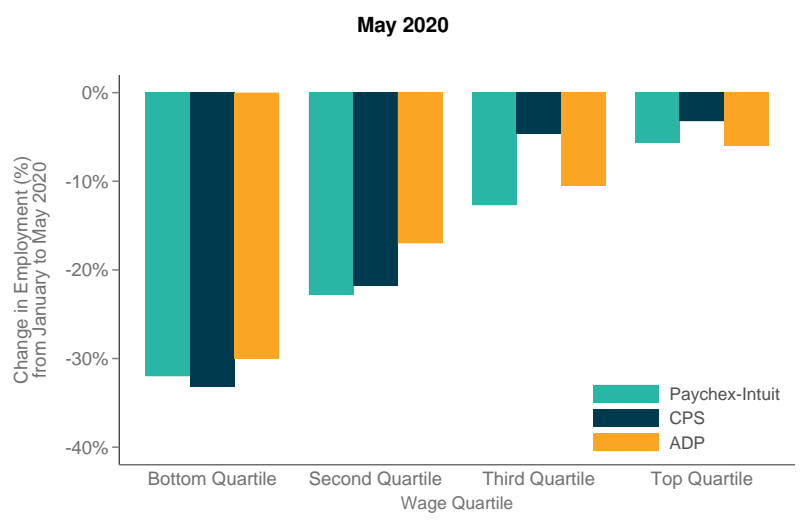

C. Change in Employment Rates by Wage Quartile: Paychex-Intuit vs. CPS December 2021

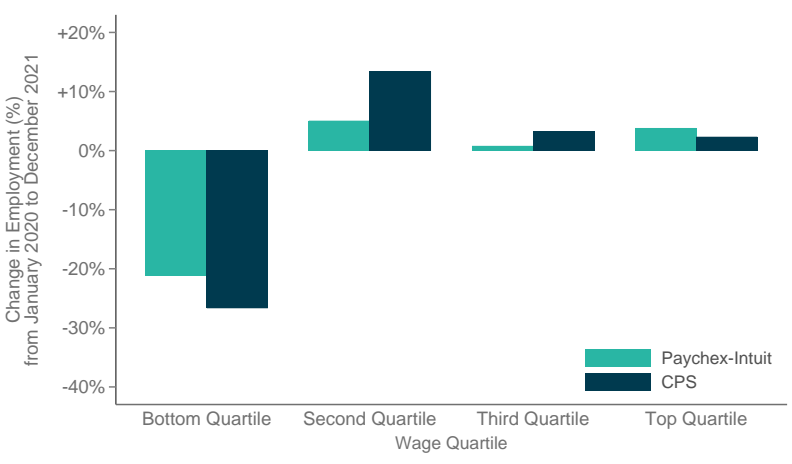

Notes: This figure benchmarks the Paychex-Intuit combined employment series to the Current Population Survey (CPS) and estimates based on ADP data in Cajner et al. (2020). Panel A shows employment trends in the PaychexIntuit combined data (solid series) and ADP data (dashed series), split by wage quartile (combined Paychex-Intuit data) or wage quintile (ADP data). The Paychex-Intuit series is expressed as a percentage change relative to January 4-31 2020. The ADP series (from Cajner et al. 2020) is expressed as a percentage change relative to February 15 2020. Panel B shows changes in employment in the Paychex-Intuit, ADP, and CPS datasets from January to May 2020, split by wage quartile. The CPS series is expressed as a percentage change relative to January 2020. We omit the third wage quintile of the ADP series and compare the fourth and fifth quintiles of the ADP series to the third and fourth quartiles of the Paychex-Intuit series. Panel C replicates Panel B in December 2021 for the combined Paychex-Intuit series and CPS. For Panel C, we drop CA, MA, and NY since these three states raised the minimum wage above our upper wage threshold for bottom wage quartile employment after July 2020. Data sources: Paychex, Intuit, CPS, ADP. 


\section{Appendix Figure 16: Changes in Low-Wage Employment by ZIP Code}

A. Low-Wage Employment vs. Median Rent, by ZIP

July 2020

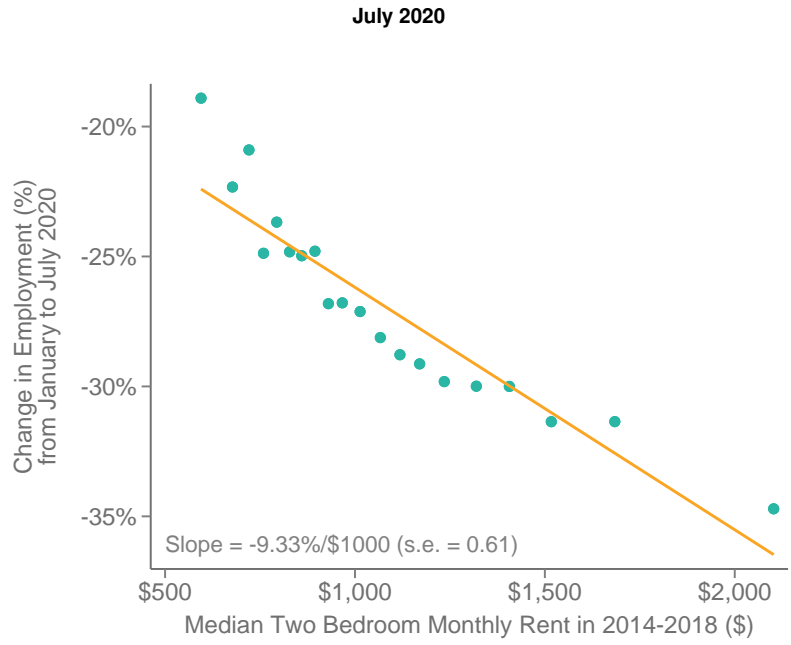

C. Change in Low-Wage Employment in Chicago

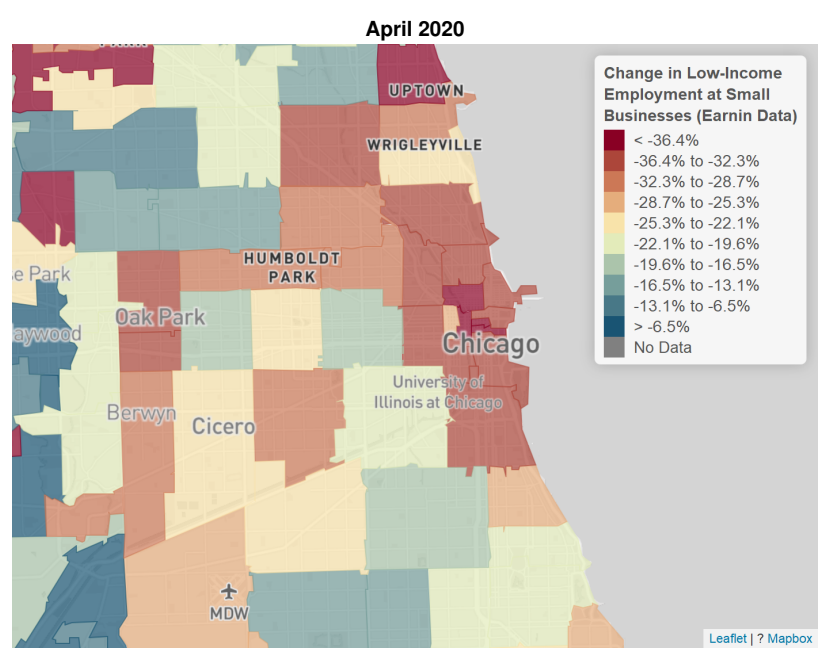

B. Change in Low-Wage Employment in San Francisco

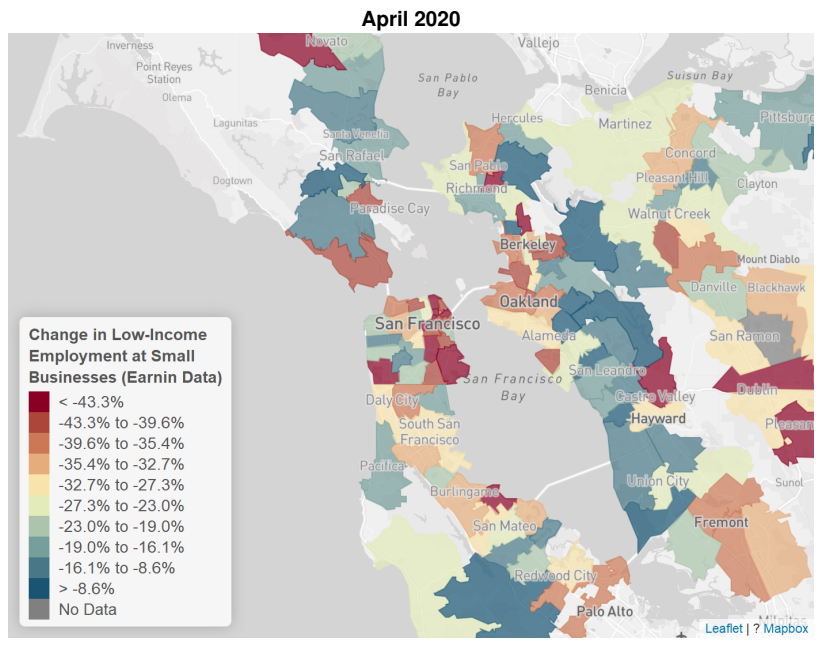

D. Change in Low-Wage Employment in New York City

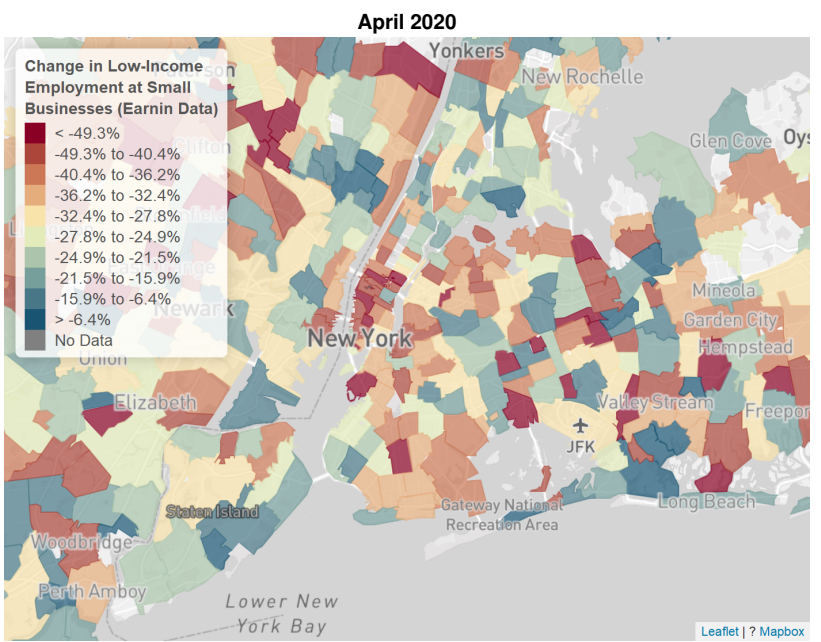

Notes: Panel A shows a binned scatter plot of the relationship between low-wage employment and median rent at the ZIP code level. The x-axis variable is the median rent within a ZIP code for a two-bedroom apartment in the 2014-2018 ACS. The y-axis variable is the average value of low wage employment at the ZIP code level from Earnin during the month of July 2020 (see Section II.D and Appendix E for more detail on the construction of the Earnin employment series). Panels B, C and D replicate Appendix Figure 10 using Earnin data on changes in employment among low-wage workers, plotted by employer ZIP code. We measure the change in employment as total average weekly employment during the period of March 27 - April 24th 2020 divided by total average weekly employment in the period of January 4-31 2020. These maps must be viewed in color to be interpretable; dark red colors represent areas with larger employment declines, while dark blue colors represent areas with smaller declines. Data sources: Earnin, ACS. 


\section{Appendix Figure 17: Geography of Employment Losses in the Great Recession vs. COVID Recession}

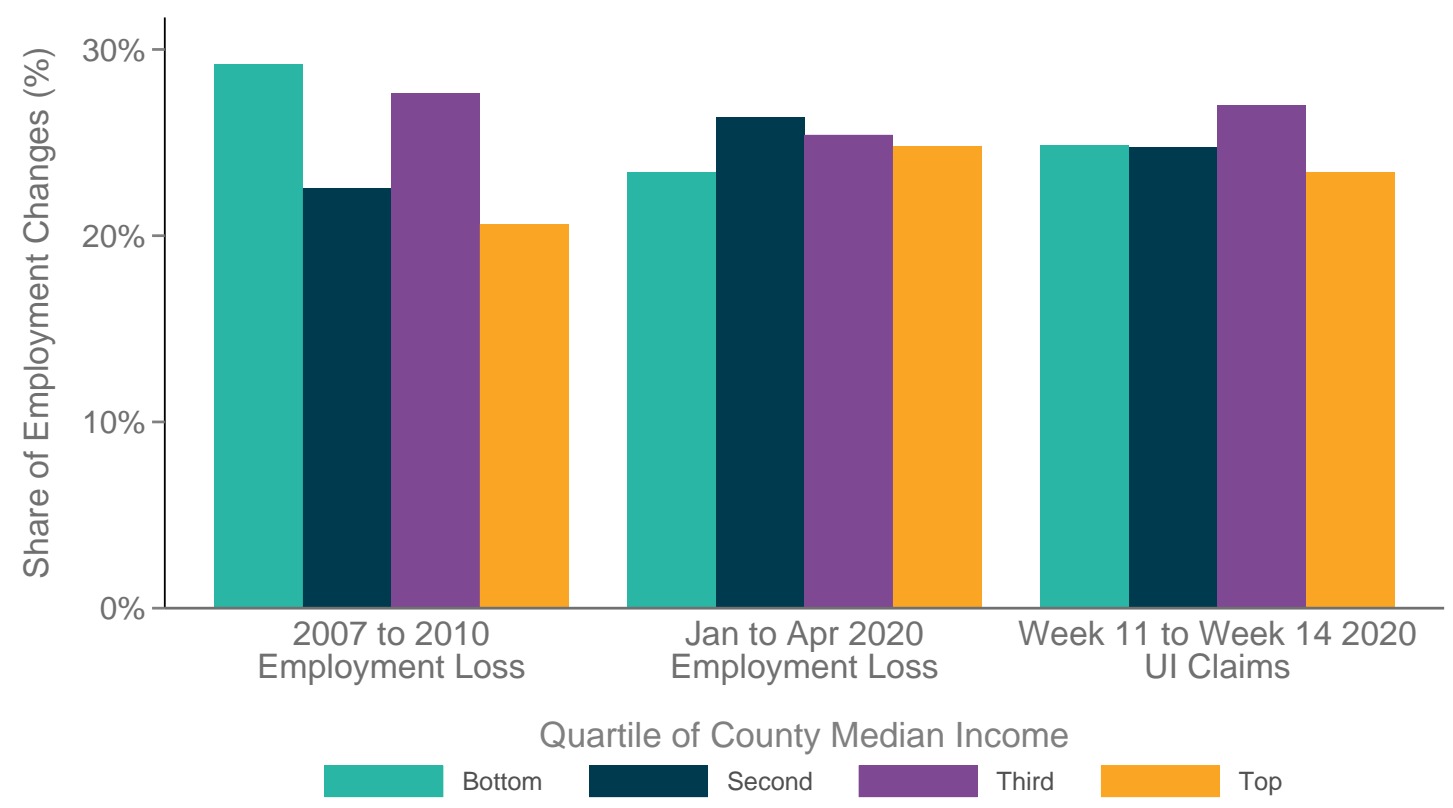

Notes: This figure displays the share of job losses occurring in low vs. high income counties during the Great Recession and the COVID Recession. We split counties into population-weighted quartiles by median household income in the 2006 ACS for the Great Recession (left bars) and the 2014-2018 ACS for the COVID Recession (middle and right bars). To construct the first set of four bars, we use BLS data to measure the share of the national employment losses from 2007 and 2010 occurring within counties in each quartile of median household income. The second set of bars replicates the first set of bars using the employment losses from January 2020 to April 2020 . The third set of bars reports the share of total initial UI claims within each county income quartile between March 15 (the first week of COVID-related UI claims) and April 12 2020. In this third set of bars, we only include counties within states that issue weekly reports of county-level UI claims data; these states include $53 \%$ of the U.S. population. The increase in unemployment rates between February and April 2020 (11\%) was only two-thirds as large as the decrease in employment (16\%). The difference was due to a $5 \%$ decline in the labor force: many people lost their jobs but were not actively searching for a new job in the midst of the pandemic(Coibion, Gorodnichenko, and Weber 2020). In the three prior recessions, the labor force continued to grow by $0.3 \%$ to $0.8 \%$ annually. We therefore focus on the decline in employment rates to obtain comparable statistics on job loss across recessions.Data source: BLS. 


\section{Appendix Figure 18: Changes in Employment by Wage Quartile and Consumer}

Spending, Retail Trade

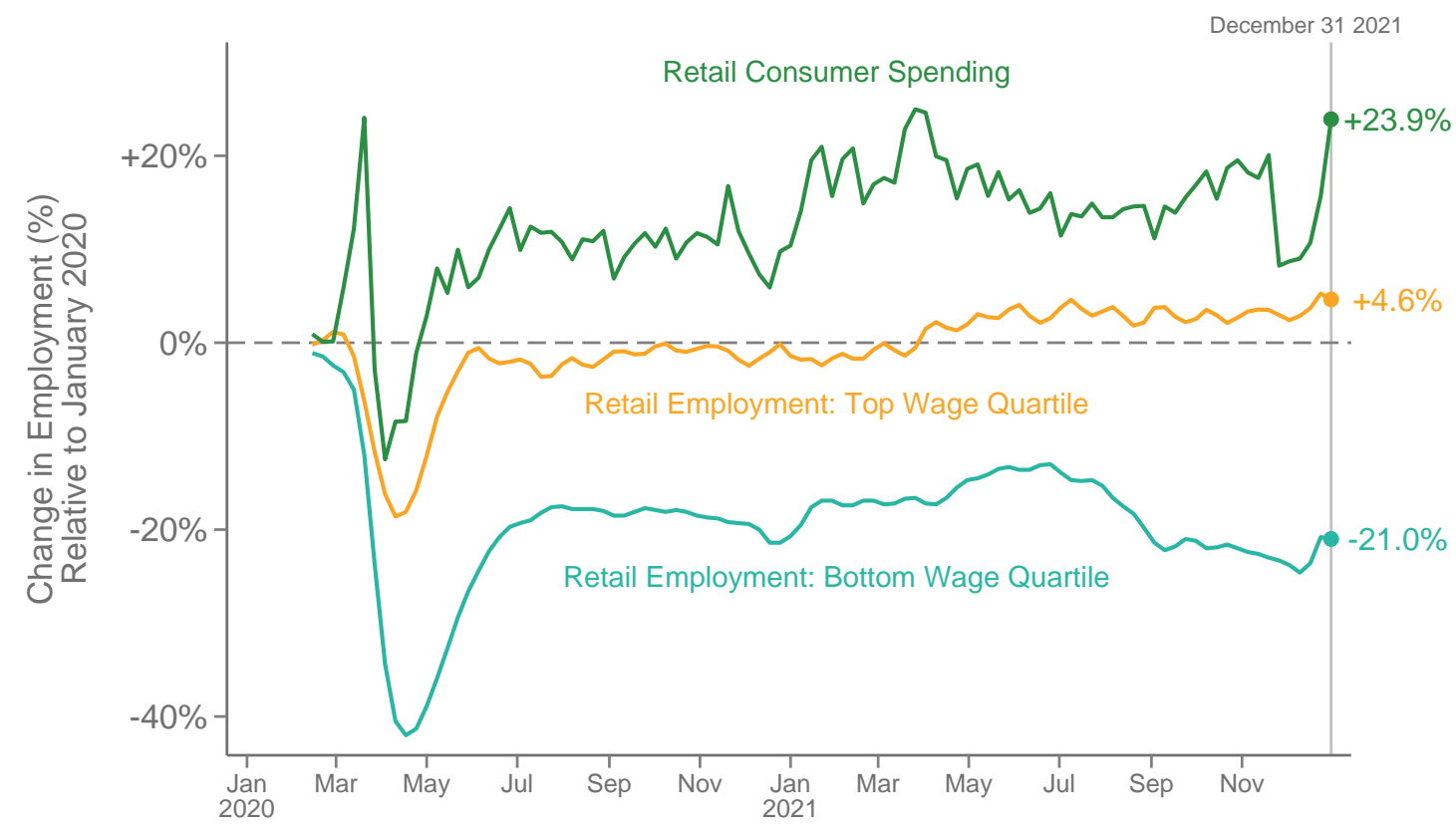

Notes: This figure plots our combined Paychex-Intuit employment series for top and bottom wage quartile jobs in the Retail Trade sector (NAICS 44-45), along with our consumer spending series for this sector (see Section II.A and Appendix B for details on the construction of the consumer spending series). Data sources: Paychex, Intuit, Affinity Solutions. 


\section{Appendix Figure 19: Relationship between Employment and Rent in CPS Panel}

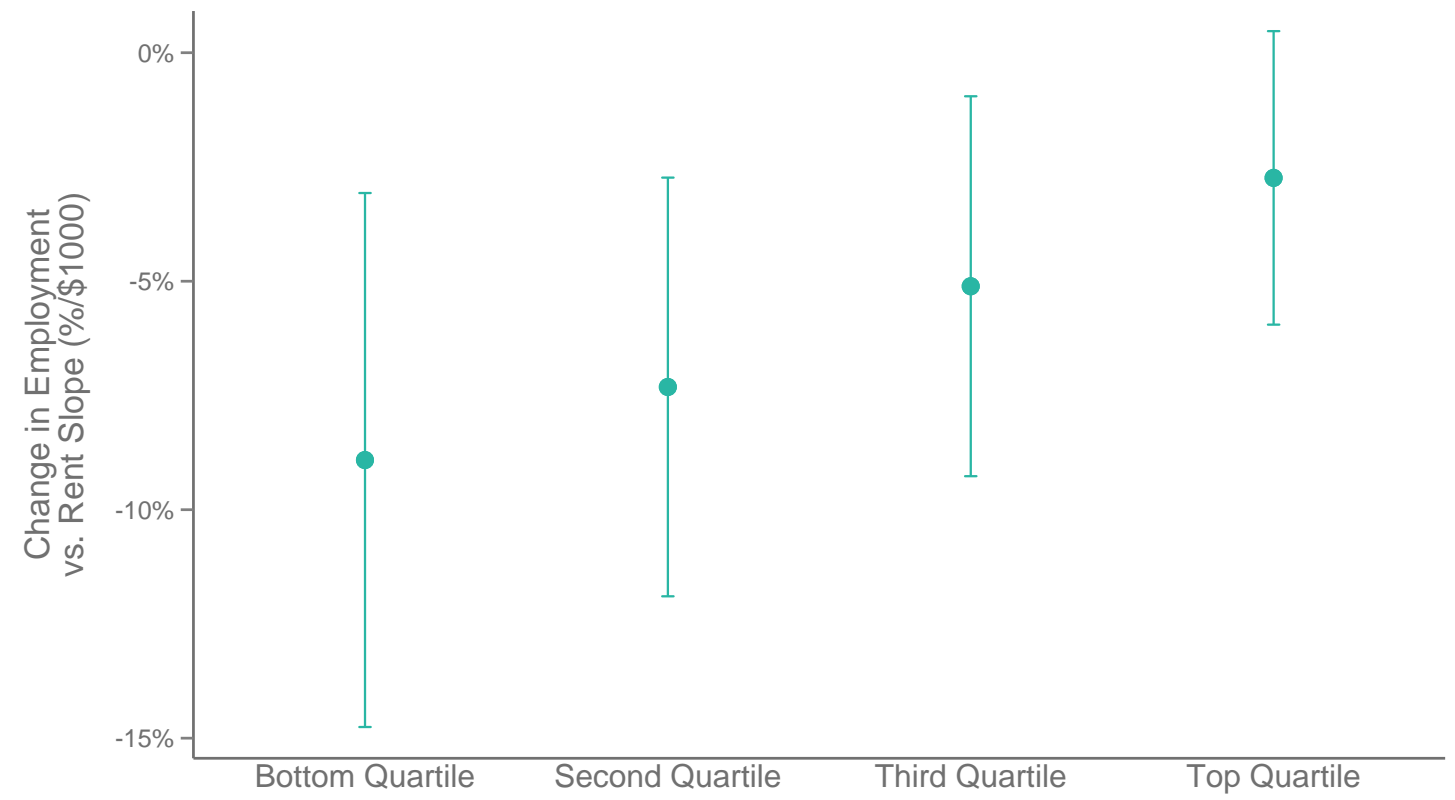

Notes: This figure plots regression estimates of the relationship between state-level changes in employment, measured separately for each wage quartile, and median two-bedroom rent in the CPS panel. We obtain the point estimates and 95\% confidence intervals from population-weighted state-level OLS regressions. We use the change in employment between each respondent's initial survey (conducted 12 months before their follow-up survey) and their follow-up survey in July 2020-February 2021. To construct the CPS panel, we first restrict the sample to the set of individuals who were employed during their initial survey and had their follow-up survey between July 2020 and February 2021. We then classify these individuals by their wage quartile during their initial survey (July 2019 to February 2020) based on inflation-adjusted values of the Federal Poverty Line, adding uniform noise between [-\$0.50, $\$ 0.50]$ to whole number wages to smooth out spikes in the wage distribution at whole numbers. See Section II.D for more details on the wage quartile thresholds and smoothing. The sample omits California, Massachusetts, and New York due to mismeasurement of bottom-quartile employment changes as a result of minimum wage increases; see Appendix E.2 for more details. Data sources: CPS. 


\section{Appendix Figure 20: Changes in Labor Supply due to Population Shifts}

A. Trends in Low-Wage Employment for US-Born vs. Naturalized Citizens vs. Non-Citizens

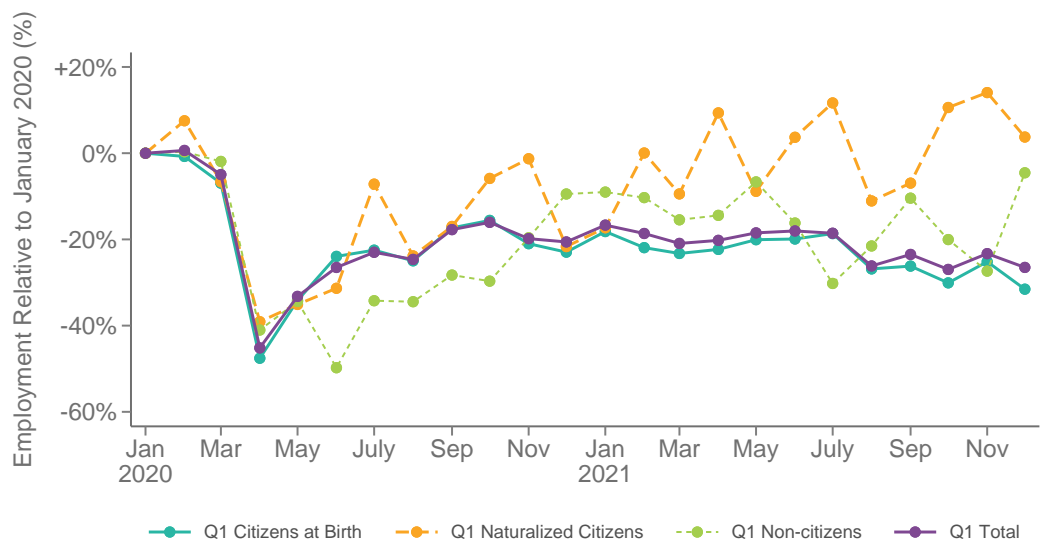

B. Net In-Migration vs. Rent in 2021

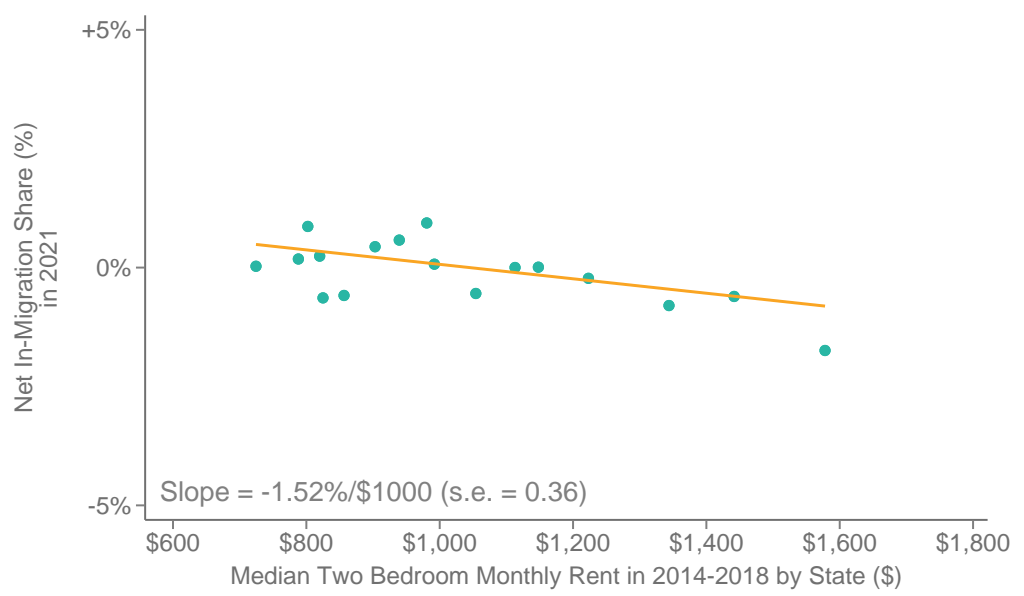

Notes: Panel A uses CPS data to show the employment change relative to January 2020 for workers in the bottom wage quartile, comparing those who are U.S. citizens at birth, naturalized U.S. citizens, or non-U.S. citizens. Panel B presents the association between net in-migration shares in 2021 and median rent at the state level in the ACS 2014-2018. For each state we calculate the net in-migration share as in-migration minus out-migration divided by the state population, using Current Population Survey Annual Social and Economic Supplement (CPS ASEC). Data sources: CPS, ACS. 
Appendix Figure 21: Effects of Stimulus Payments on Spending, without Adjusting for Pre-Trends
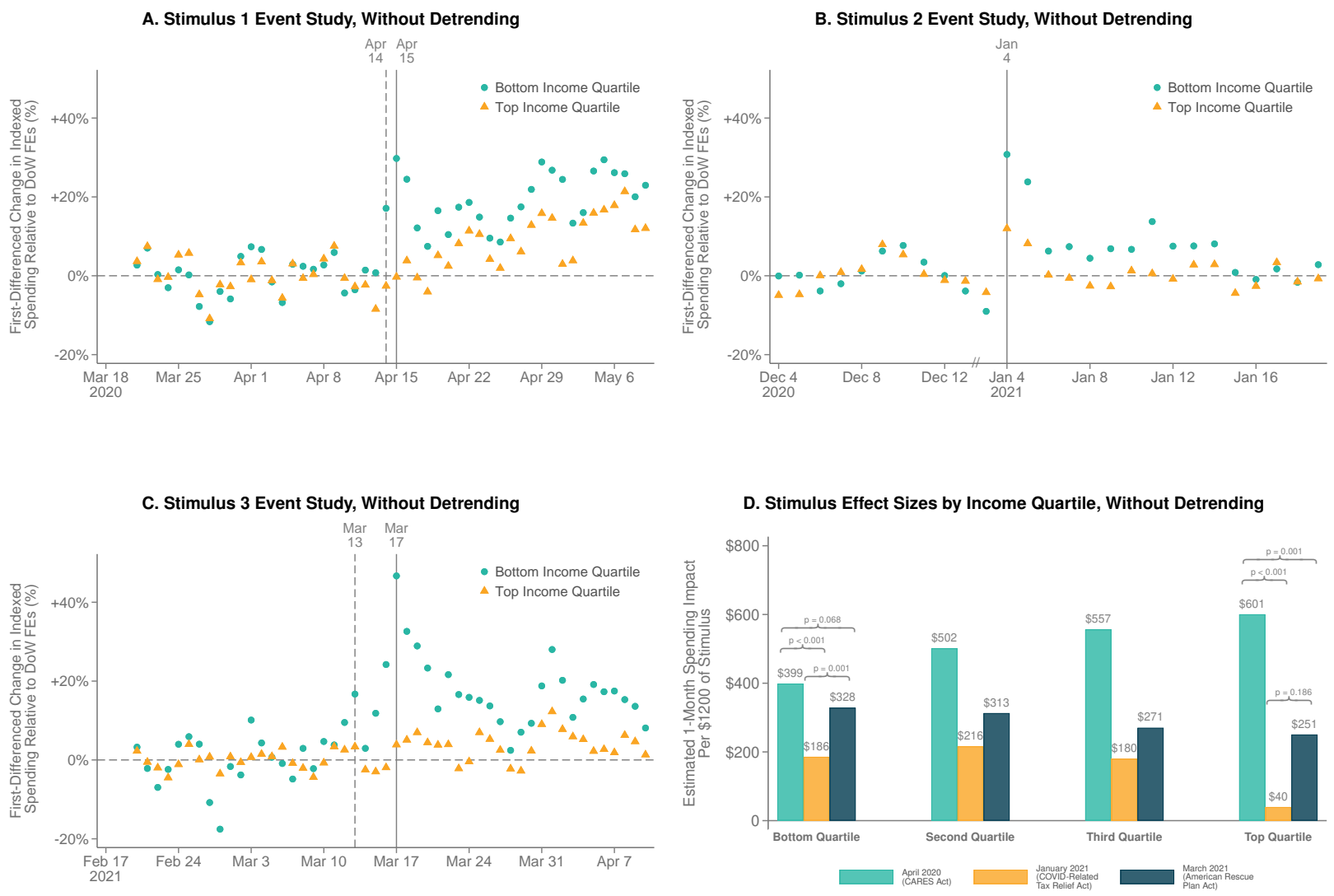

Notes: This figure shows event studies of spending around stimulus payments without adjusting for linear pretrends. Panel A shows the equivalent of Figures 7A and 7B without adjusting for linear pre-trends. Panel B is identical to Figure 7C, since both figures do not adjust for linear pre-trends. Panel $\mathrm{C}$ shows the equivalent of Figure $7 \mathrm{D}$ without adjusting for linear pre-trends. Panel D shows the equivalent of Figure 8 without adjusting for linear pre-trends. Data source: Affinity Solutions. 


\section{Appendix Figure 22: Robustness of Stimulus Effect Size to Post-Stimulus Event Window}
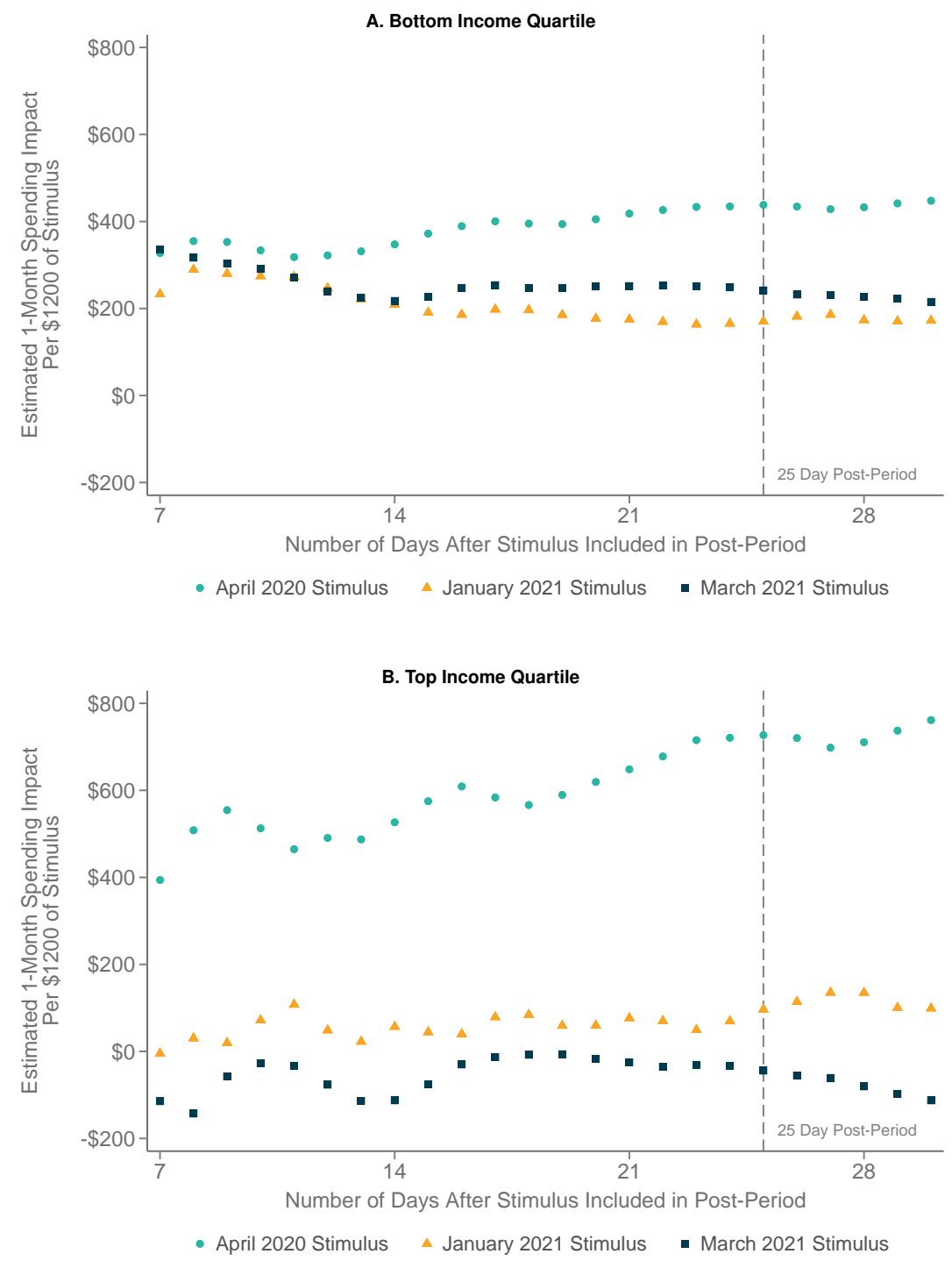

Notes: This figure displays coefficient estimates from varying post-period windows as a robustness check for the analysis displayed in Figure 7, Figure 8, and Appendix Table 6. Each dot corresponds to a different estimate for the "Combined Dollar" effects from Appendix Table 6, Column 5. Panel A plots estimates for cardholders residing in the bottom income quartile of ZIP codes, varying the post-period from 7 to 30 days, for each of the three rounds of stimulus. Panel B repeats this analysis for cardholders residing in the top income quartile of ZIP codes. For the April 2020 and March 2021 stimulus rounds, the estimate at 25 days matches the estimate in Appendix Table 6, Column 5; for the January 2021 stimulus round, the estimate at 16 days matches the estimate in Appendix Table 6, Column 5 . See Section IV.A and the notes to Figure 7 and Appendix Table 6 for details on how these estimates were calculated. Data source: Affinity Solutions. 


\section{Appendix Figure 23: Daily Variance of Consumer Spending, by Week}
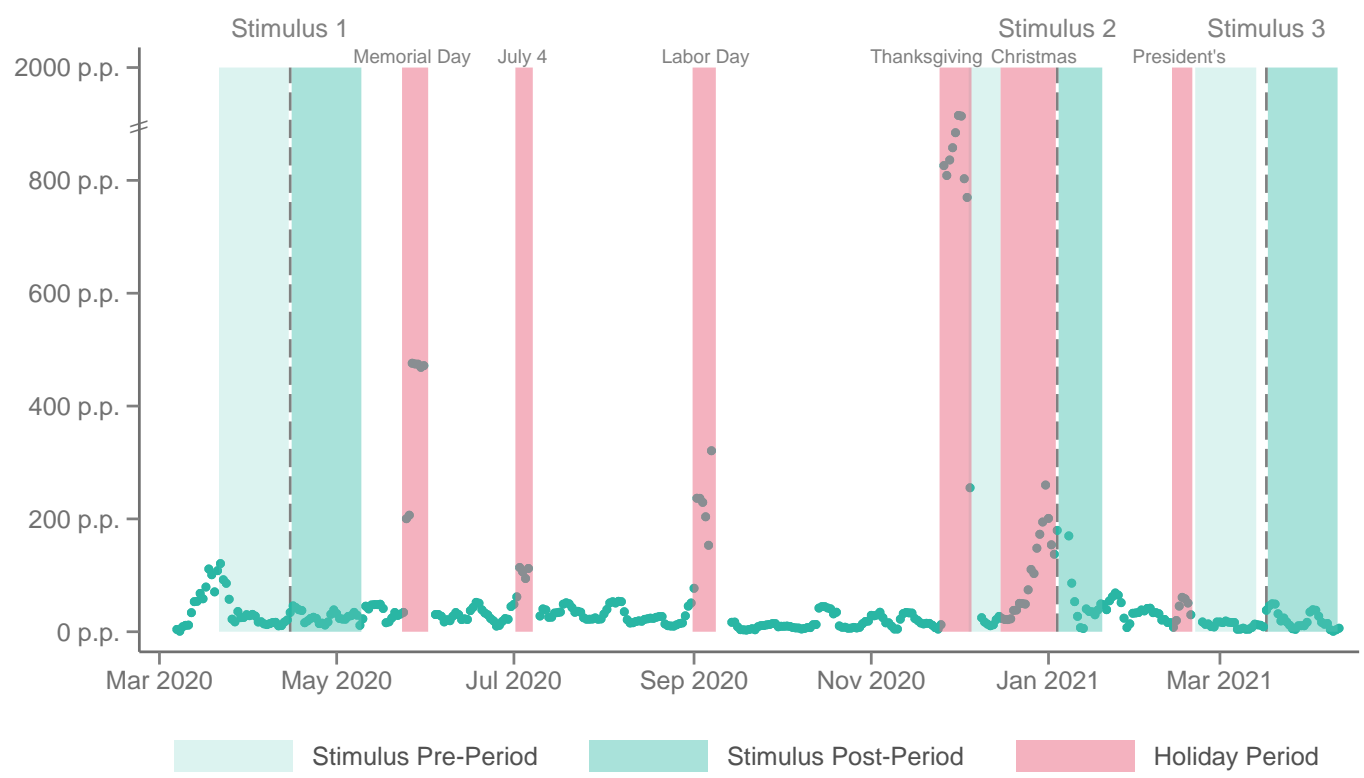

Stimulus 3

Notes: This figure depicts the within-week daily variance in the first-differenced change in indexed spending, which we construct as described in Appendix Section K.1. We then plot a 7-day trailing average of variance, omitting the points in the 6 days after holidays. The values in the Thanksgiving period were rescaled to fit on the graph. Three vertical dashed lines mark the timing of deposits for each of the three rounds of stimulus payments, with light green shading to mark the pre-periods and dark green shading to mark the post-periods in the respective event studies in Figure 7 and Appendix Table 6. The red shaded dates denote holiday periods that we drop from the event study analysis (in Figure 7C) and from the permutation analysis (in Appendix Figures 24 and 25). Data source: Affinity Solutions. 


\section{Appendix Figure 24: Permutation Test for Differences in Stimulus Effects, Bottom Income Quartile}

A. 1st Stimulus Minus 2nd Stimulus, Bottom Income Quartile

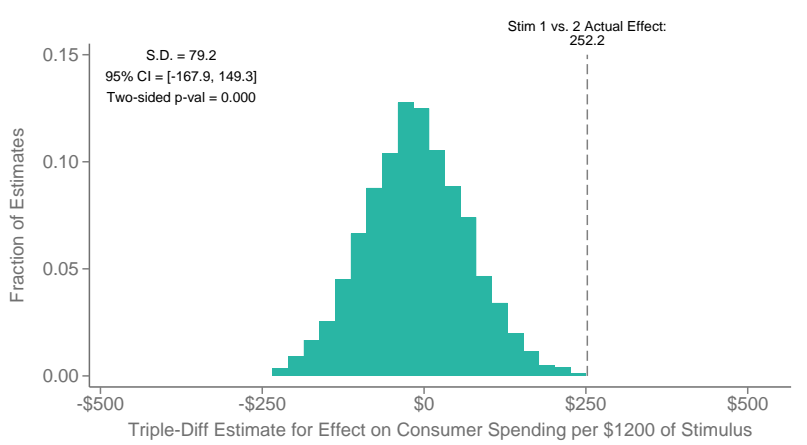

B. 1st Stimulus Minus 3rd Stimulus, Bottom Income Quartile

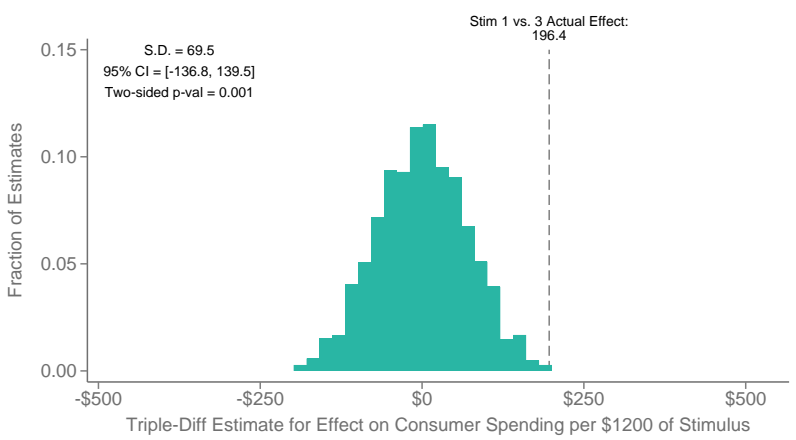

C. 2nd Stimulus Minus 3rd Stimulus, Bottom Income Quartile

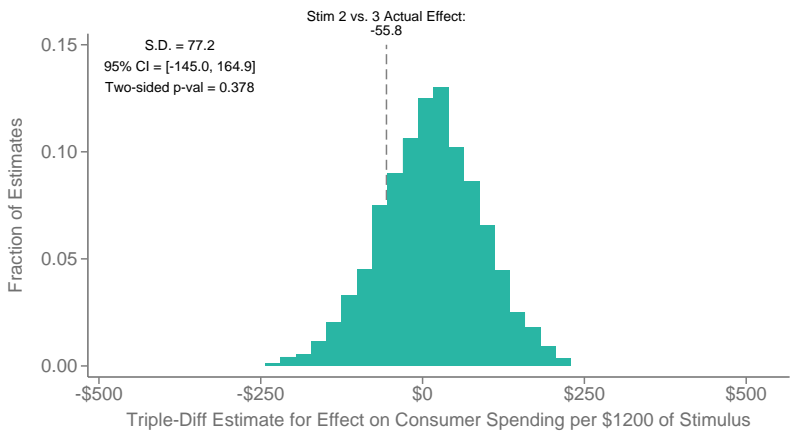

Notes: These figures present a permutation test of the null hypothesis that there is no difference in spending impacts across rounds of stimulus payments for households in the bottom income quartile of ZIP codes. We consider all placebo dates for stimulus payments from August 1, 2020 to May 1, 2021, dropping dates that fall within 25 days of the beginning or end of an actual pre- or post-stimulus window or within a high-variance holiday period (see Appendix Figure 23 for more details). We then calculate the "combined dollar" estimate for each placebo date (as in Appendix Table 6, Column 5) for each income quartile and stimulus round, following the approach described in Appendix Section K.3. We include 25 days pre-event and then either 25 days post-event (1st and 3rd stimulus) or 16 days post-event (2nd stimulus). We drop days in the pre- or post-period that fall within a holiday period, and we omit the estimate entirely if a holiday falls in the post-period. We adjust for linear pre-trends in both the treatment and control series whenever there are more than 20 days in the pre-period. This leads to 89 placebo estimates for the first stimulus and third stimulus, and 59 placebo estimates for the second stimulus. We take the difference between each possible pair of placebo estimates (1st minus the 2nd stimulus; 1st minus the 3rd stimulus; and 2nd minus the 3rd stimulus) and plot the distribution of the calculated difference in "Combined Dollar" effects. Panel A plots the distribution of placebo differences between the 1st minus the 2nd stimulus. Panel B repeats this for the 1st minus the 3rd stimulus, and Panel $\mathrm{C}$ repeats this for the 2nd minus the 3rd stimulus. On each panel, we mark the actual difference in estimates (taken from the appropriate difference between estimates in Appendix Table 6, Column 5) with a dashed vertical line. We also report the standard deviation of the placebo draws, the $95 \%$ confidence interval (the smallest interval that covers $95 \%$ of placebo differences), and the two-sided p-value (twice the minimum of the fraction of placebo differences to the right of the actual estimate and the fraction to the left of the actual estimate). Data source: Affinity Solutions. 


\section{Appendix Figure 25: Permutation Test for Differences in Stimulus Effects, Top Income Quartile}

A. 1st Stimulus Minus 2nd Stimulus, Top Income Quartile

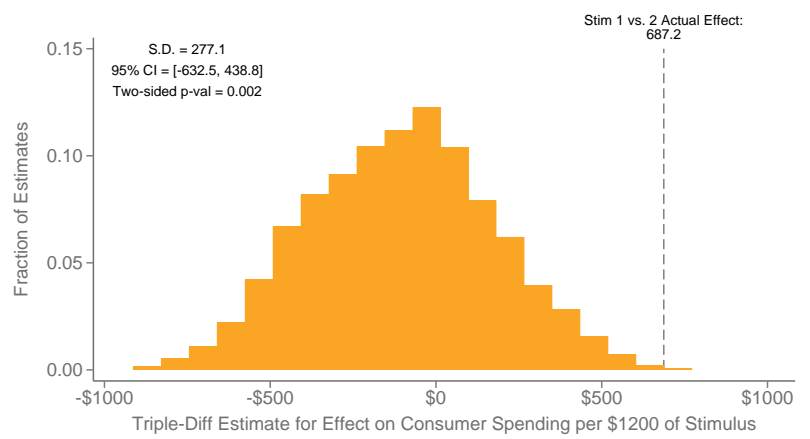

B. 1st Stimulus Minus 3rd Stimulus, Top Income Quartile

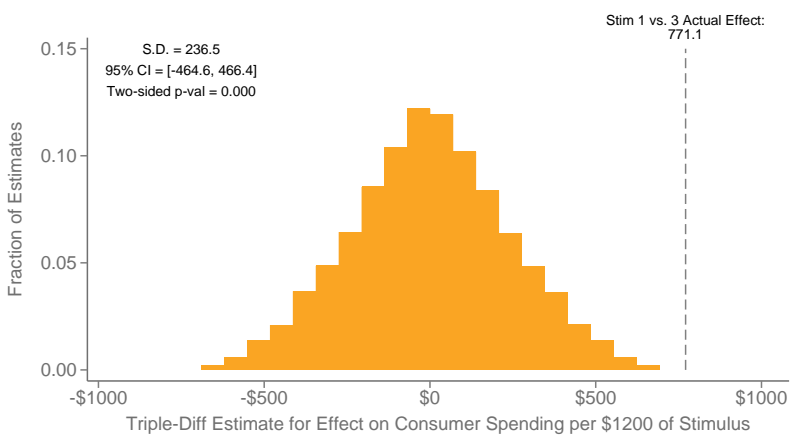

C. 2nd Stimulus Minus 3rd Stimulus, Top Income Quartile

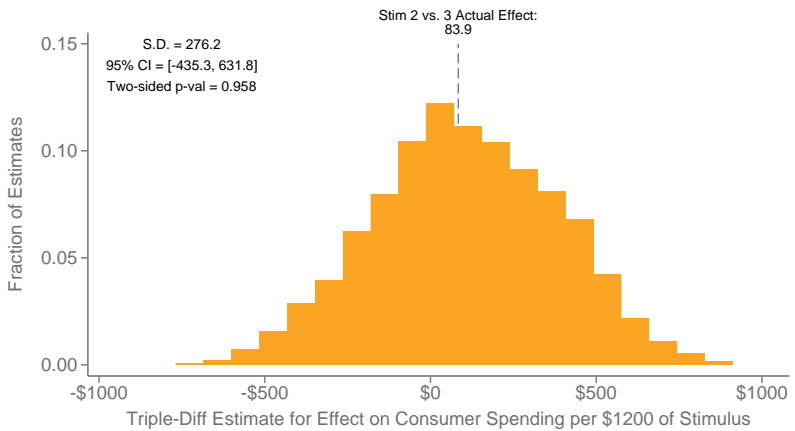

Notes: These figures present a permutation test of the null hypothesis that there is no difference in spending impacts across rounds of stimulus payments for households in the top income quartile of ZIP codes. Each panel is constructed analogously to the corresponding panel in Appendix Figure 24. Data source: Affinity Solutions. 


\section{Appendix Figure 26: Effects of Reopenings on Economic Activity}

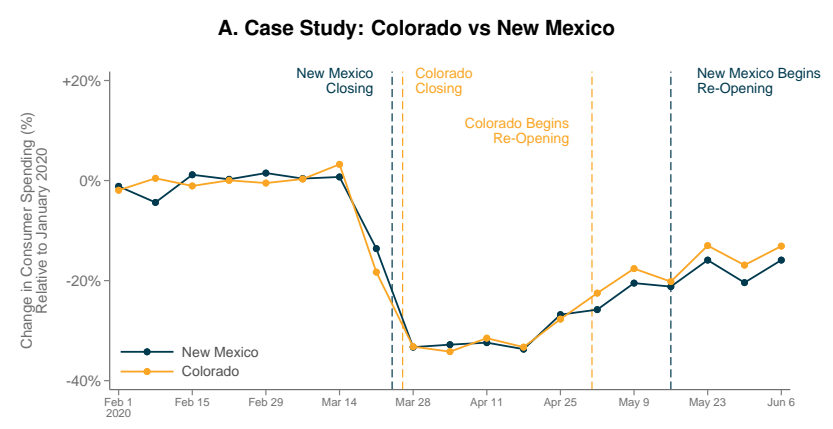

B. Stacked Event Study: Re-Opened States vs. Control States
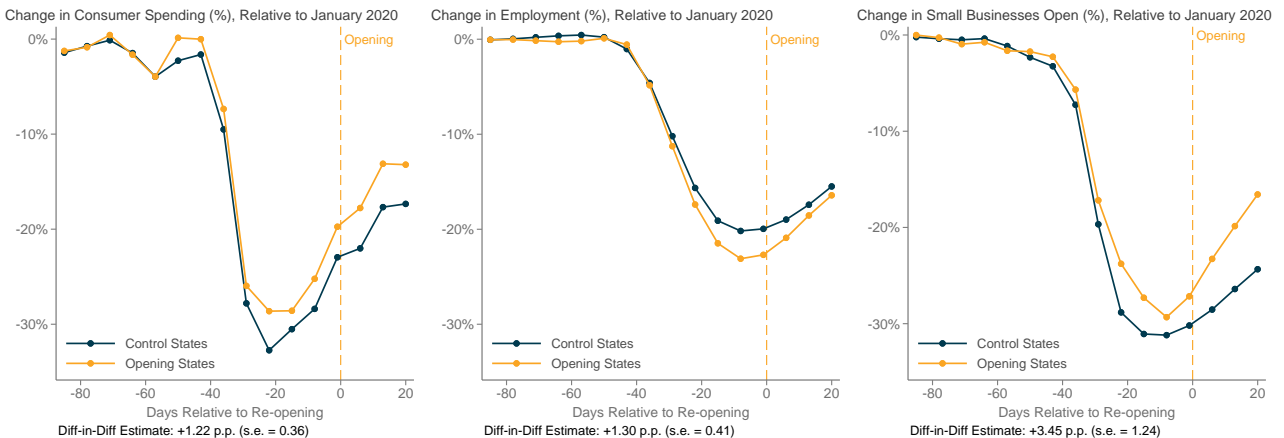

C. Variance Explained by Reopenings

May 2020

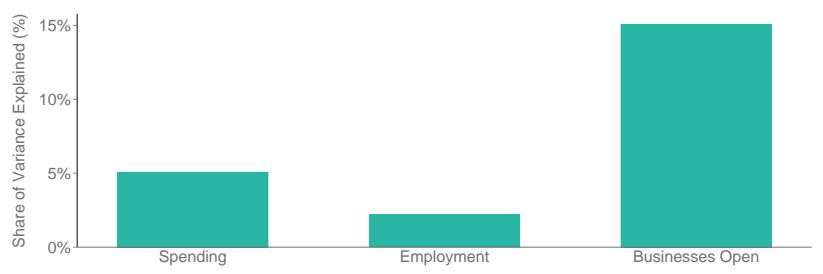

Notes: Panel A presents a time series plot of the change in seasonally-adjusted consumer spending relative to the base period of January 6 - February 2, 2020 for New Mexico and Colorado. Colorado partially reopened non-essential businesses on May 1, while New Mexico did not do so until May 16. Panel B1 presents an event study plot of the same outcome variable, showing average spending changes in five states (SC, AK, GA, MN and MS) that partially reopened non-essential businesses between April 20 and April 27. Each reopening state is matched to multiple control states (listed in Appendix Table 10) that did not reopen within the subsequent 3 weeks but had similar trends of the outcome variable during the weeks preceding the reopening. We construct the control group separately for each reopening day and then stack the resulting event studies to align the events. Panel B2 replicates Panel B1 with the change in employment relative to January 4-31 measured using combined Paychex-Intuit data. Panel B3 replicates Panel B1 with the seasonally-adjusted change in small businesses open measured using Womply data. In Panels B1 to B3, we report the coefficient from a difference-in-differences regression comparing treated vs. untreated states in the two weeks following vs. the two weeks prior to the partial reopening (also reported in Appendix Table 11). Panel $\mathrm{C}$ reports the share of the variance in outcomes explained by reopenings as of May 18. To estimate these variance shares, we first calculate the variance of each outcome across states on May 18, 2020. Then, we add the difference-in-difference estimate for the effect of reopening on a given outcome to all states not open on May 18 (adding only half of the effect if the state opened between May 11 and May 18). We then recalculate the variance in this counterfactual in which all states had reopened. The share of variance explained by reopenings for each outcome is defined as 1-(counterfactual variance/actual variance). Data sources: Affinity Solutions, Paychex, Intuit, Womply. 


\section{Appendix Figure 27: Effects of State-Ordered Business Closures on Consumer Spending}

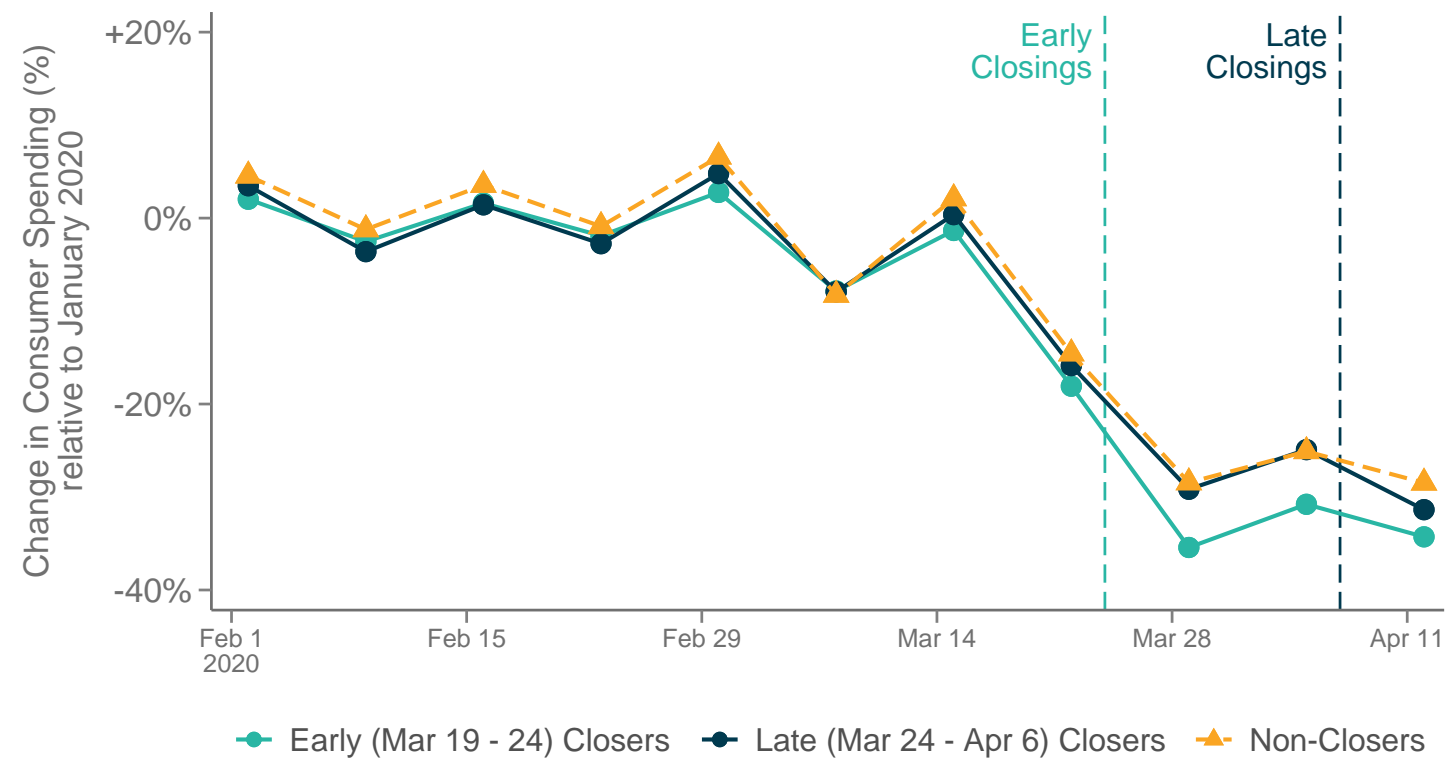

Notes: This figure displays trends in seasonally-adjusted consumer spending in the Affinity Solutions data, pooling states by the date on which a state-wide order closed non-essential businesses. States are aggregated into three groups: "Early" (state-wide closure order issued between March 19 and March 24 2020), "Late" (state-wide closure order issued between March 30 and April 6 2020), and "Non-Closers" (no state-wide closure order issued by April 6 2020). Dashed lines denote the first date on which state-wide orders closing non-essential businesses were issued by "Early Closers" (March 19) and "Late Closers" (March 30). Data source: Affinity Solutions. 


\section{Appendix Figure 28: Effects of the Paycheck Protection Program on Employment}

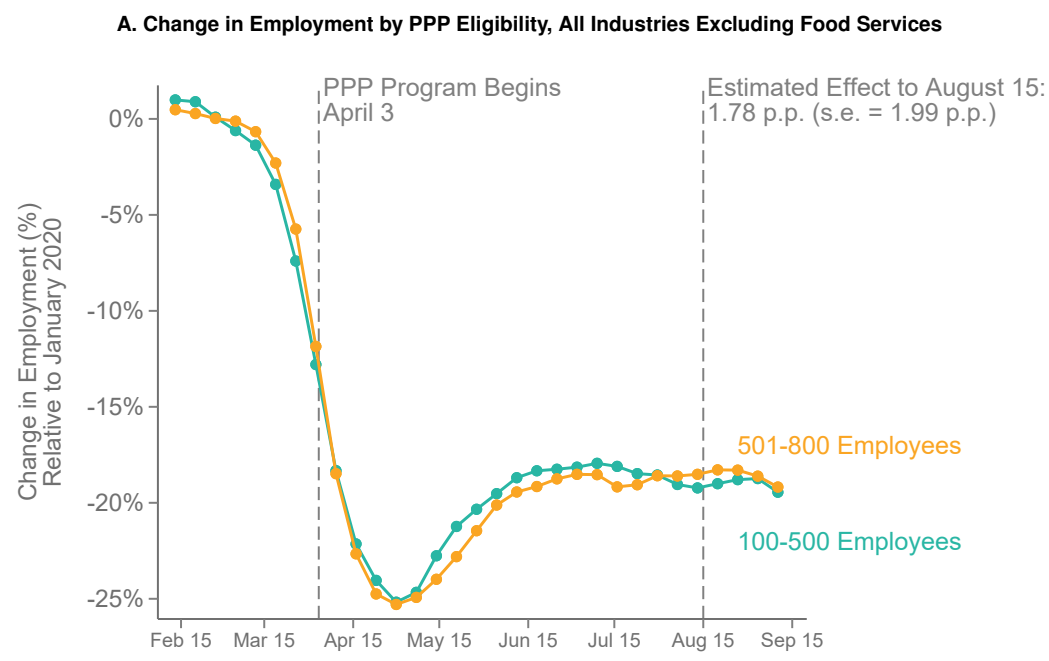

B. Change in Employment by Firm Size, All Industries Excluding Food Services

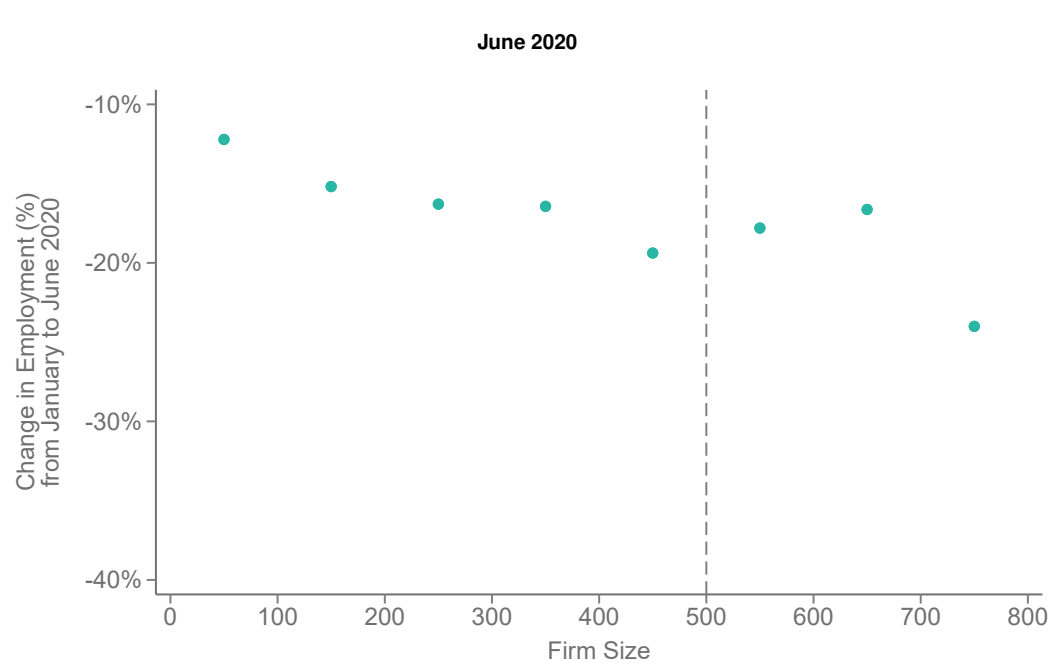

Notes: This figure analyzes the effects of the Paycheck Protection Program on employment using the threshold in eligibility at 500 employees. We pool all industries except Accommodation and Food Services (NAICS 72), which was subject to different eligibility rules (discussed in Appendix L.2). Panel A compares employment trends measured in Paychex and Earnin data among firms with 100-500 employees (generally eligible for PPP loans) to firms with 501-800 employees (generally ineligible for PPP loans). To construct these employment trends, we begin by calculating weekly employment changes relative to January 4-31 2020 disaggregated by data source, county, industry (2-digit NAICS), wage quartile and firm size bin. We reweight these cells so that the composition in each firm size bin matches the pooled distribution of industry and data source over the period January 4-31 2020. We plot the "control" series (firms with 501-800 employees) directly as the mean weekly value of the reweighted employment series. We plot the "treated" series (firms with 100-500 employees) as the sum of the control series and the weekly difference between control and treated firms after residualizing on interacted county and wage quartile fixed effects. For visual clarity, we recenter each series so the mean change in employment is $0 \%$ over the pre-period (February 12 to March 18). The difference between these two series is the regression estimate in Column 1 of Appendix Table 12, which is also reported in the figure. Panel B presents a binned scatter plot of changes in reweighted employment from January 4-31 to June 1-23 vs. firm size. Data sources: Paychex, Earnin. 